\title{
RAYNAUD'S PHENOMENON \\ OF \\ OCCUPATIONAL ORIGIN
}

BY

\author{
WILLIAM TAYLOR, \\ B.Sc., Ph.D., M.D., \\ F.R.C.P. (Edin). \\ for the degree of \\ DOCTOR OF SCIENCE
}

in the

UNIVERSITY OF EDINBURGH

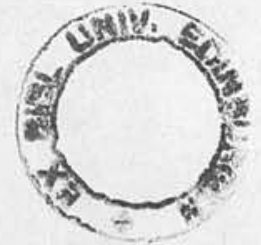


I. PRIMARY RAYNAUD'S DISEASE

II. SECONDARY RAYNAUD'S PHENOMENON 10 CLASSIFICATION 11

III. PHYSIOLOGY AND PATHOLOGY OF RAYNAUD' $S$ DISEASE

IV. PHYSIOLOGY AND PATHOLOGY OF RAYNAUD'S PHENOMENON

A. RAYNAUD'S PHENOMENON OF OCCUPATIONAL ORIGIN

Pneumatic Hammers

Grinding Wheels

Hand Tools

Chain Saws

B. SECONDARY COMPLICATIONS

OF RAYNAUD'S PHENOMENON

OF OCCUPATIONAL ORIGIN

32

1. Acro-osteolysis

42

2. Skin Necrosis or

Gangrene of the Digits 
POPULATION FOR STUDY

1. POPULATION GROUPS

2. STAGES OF RAYNAUD'S PHENOMENON

3. ILLUSTRATIONS OF PROCESSES

OBJECTIVE TESTS FOR DEGREE OF SEVERITY

OF RAYNAUD'S PHENOMENON

RE SULTS

1. Prevalence of VWF in some

Industrial processes in Britain

2. Latent Intervals and Vibration Levels

3. Vibration-induced White Finger in Forestry Chain Saw Operators. A seven-year Prospective Study.

Vibration Threshold Limits and Standards

Draft for Development. BSI (FEb. 1975) DD 43.

Draft Proposal: Guide for the

Measurement and Evaluation of

Human Exposure to Vibration

Transmitted to the Hand

(Sep. 1975) ISO/TC $108 /$ SC.

Prescription

Code of Practice 


\section{PAGE}

REFERENCE S

APPENDICES

1. CASE HISTORIES

2. SURVEY FORMS

3. PROPOSED BSI DRAFT STANDARD

4. PUBLISHED PAPERS 
Name of Candidate …...............................

Address

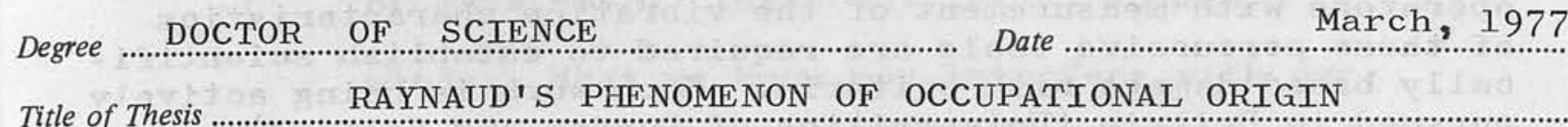

Many industrial processes are using hand-held vibratory tools and grinding operations in which there is increasing vibration energy entering the hands and arms of operators. The vibration stimulus causes digital artery changes giving rise to Raynaud's Phenomenon of Occupational Origin.

The serious nature of this hazard came to the author's attention in chain saw forestry workers around 1965-68 when the saw usage time, and therefore the vibration exposure time, increased from $1-1 \frac{1}{2}$ hours to $5 \frac{1}{2}-6$ hours per day for 5 days per week, resulting in a prevalence of vibration-induced white finger (VWF) of over $90 \%$ in one forest in Norfolk.

From 1968 to 1976, the period covered by this Thesis, an epidemiological study of 18 work situations (1283 vibration exposed subjects and controls) has been carried out to define the extent of VWF in industry and to assess its severity. At the same time a team of physicists and engineers measured the vibration characteristics of these work processes, the object being to relate the prevalence rates of VWF, the latent intervals ( $t$ ime interval between vibration exposure and the appearance of the first white finger tip), and Stage assessments (severity) to the vibration spectra, thus establishing damage risk criteria. With the help of this survey data, as opposed to limits obtained from subjective comfort responses, a British Standard Draft Proposal (1975) for hand-arm vibration has been issued mainly to act as a guide to hand-held vibratory tool manufacturers and to prevent the complications of VWF such as finger tip tissue necrosis from arising following long-term vibration exposure. A suggested Code of Practice is described. The difficult question whether to accept Raynaud's phenomenon of occupational origin as a Prescribed Disease is discussed.

Raynaud's phenomenon arising from chain saw operation has not been reported since anti-vibration treatment of the chain saw introduced by Forestry Commission in 1970. No new case of VWF has been found after six years of $\mathrm{A} / \mathrm{V}$ saw usage. On the other hand pneumatic tool users still constitute a high risk VWF area despite the fairly long latent interval (6-7 years compared with 2-3 years for chain saws). Measurement of vibration/ 
vibration and the energy entering the hands of pneumatic tool operators (grip force) have proved difficult both from the instrumentation (destruction of accelerometers) and standardisation of method. Further medical surveys of pneumatic tool operators with measurement of the vibration characteristics of these percussive tools are required to establish scientifically based damage risk criteria. Such work is being actively pursued in Britain (Universities of Dundee and Salford) and surveys are being planned with the author for chippers and grinders using pneumatic tools in foundries in the United States of America.

Despite considerable efforts to find an objective test which would establish the diagnosis of Raynaud's phenomenon and its degree of severity other than by the subject's own description of VWF attacks, no single reliable field test has been devised on an individual basis. All the established tests quoted in the literature, heating and cooling of the digits, plathysmography, vibro-tactile threshold levels and neurological tests (light touch, pain and temperature) - will differentiate, at a significant level, differences between vibration exposed populations and controls. All fail, however, on an individual basis. The long term solution lies in prospective surveys as opposed to the retrospective surveys described in this Thesis. 


\begin{abstract}
"There is no place in medicine for 'doctrines' or 'systems'. These only exist in men's minds. What we know may interfere with our learning of what we do not know."
\end{abstract}

CLAUDE BERNARD

An Introduction to the Study of Experimental Medicine. 1865.

Claude Bernard (1813-1878), the famous French physiologist and experimenter towards the end of his life conducted experiments on the blood vessels of the submaxillary gland of the rabbit. He discovered that division of the cervical "sympathectomy" nerve raised the temperature on that side of the head and neck thus showing that the sympathetic nerve was the constrictor of the blood vessels. This was the first fundamental description of vasomotor physiology. One hundred years later we are involved in this Thesis in the same basic physiological process. 
EXCERPT FROM "THE WEEPING WOOD" by Vicki Baum.

The following excerpt from the novel "The Weeping Wood" by Vicki Baum is the earliest known reference to circulation difficulties arising in the fingers from vibration exposure, in this case from a tyre manufacturing company in Detroit where workmen built up tyre treads from thin layers rotating on a wooden spindle held in the hands and slid on to the master tyre section. There was a high vibration component entering the spindle from the revolving tyre sections Year 1908-1910 at the beginning of production of the model ' $T$ ' Ford。

"When you passed through a rubber workers' district in the morning, you could hear exactly where a tyre builder lived. You could hear a funny noise, sounded like threshing and it went on for ten minutes at a time. That was when the tyre builders hit their fingers against the edge of their beds to get the soreness and stiffness out of them and the circulation going before they went to work. As if your hands had turned to stone, except they're still sore".

This classic description was given to the author by The India Tyre Company, Abbotsinch, Renfrewshire, where cases of vibration-induced white finger were known to occur from this "rolling-on" method of tyre construction. 
CERTAIN ARTS AND CRAFTS SOMETIMES DERIVE FROM THEM GRAVE INJURIES. WHERE THEY HOPED FOR A SUBSISTENCE TO PROLONG THEIR LIVES AND FEED THEIR FAMILIES, THEY ARE TOO OFTEN REPAID WITH DANGEROUS DISEASES. FINALLY UTTERING CURSES ON THE PROFESSION TO WHICH THEY HAD DEVOTED THEMSELVES, THEY DESERT THEIR POST AMONG THE LIVING.

RAMAZZINI (1713)

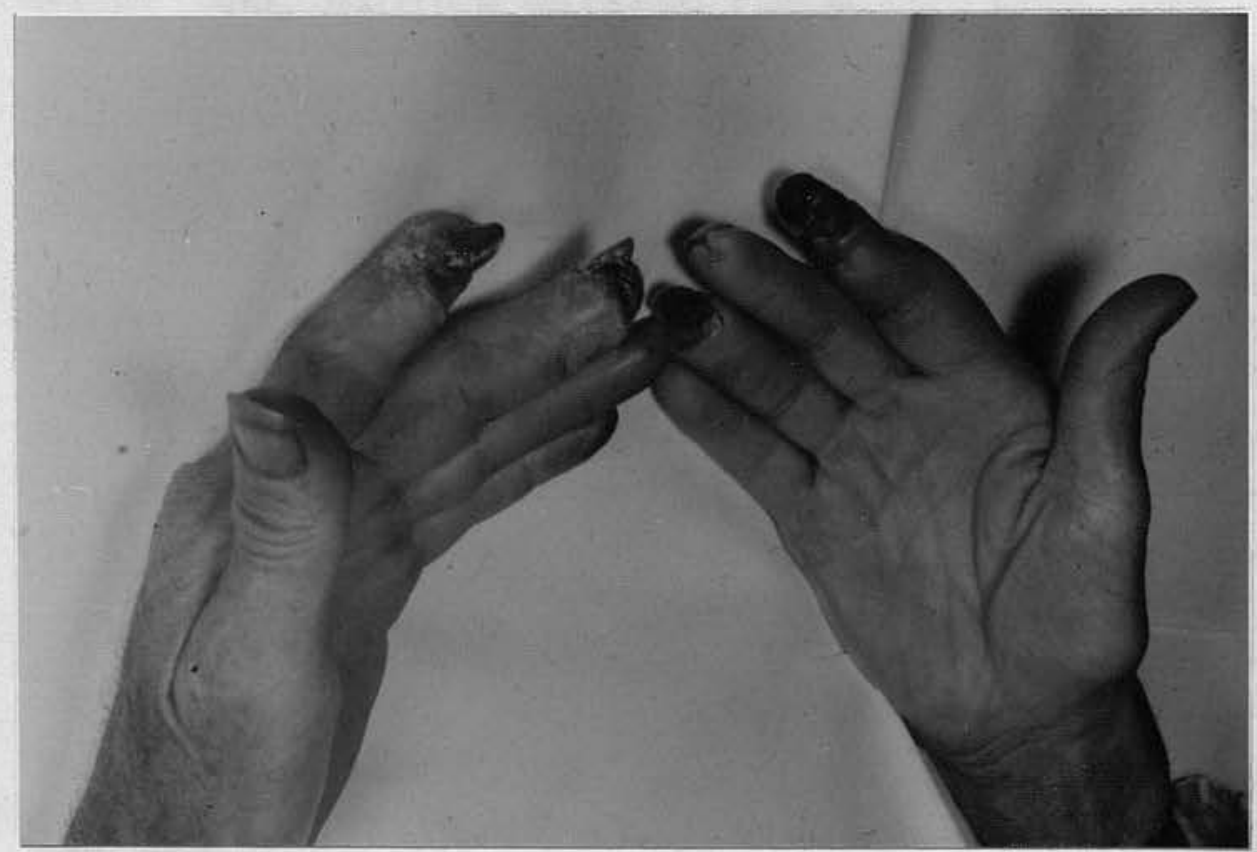

Fig. 1. 


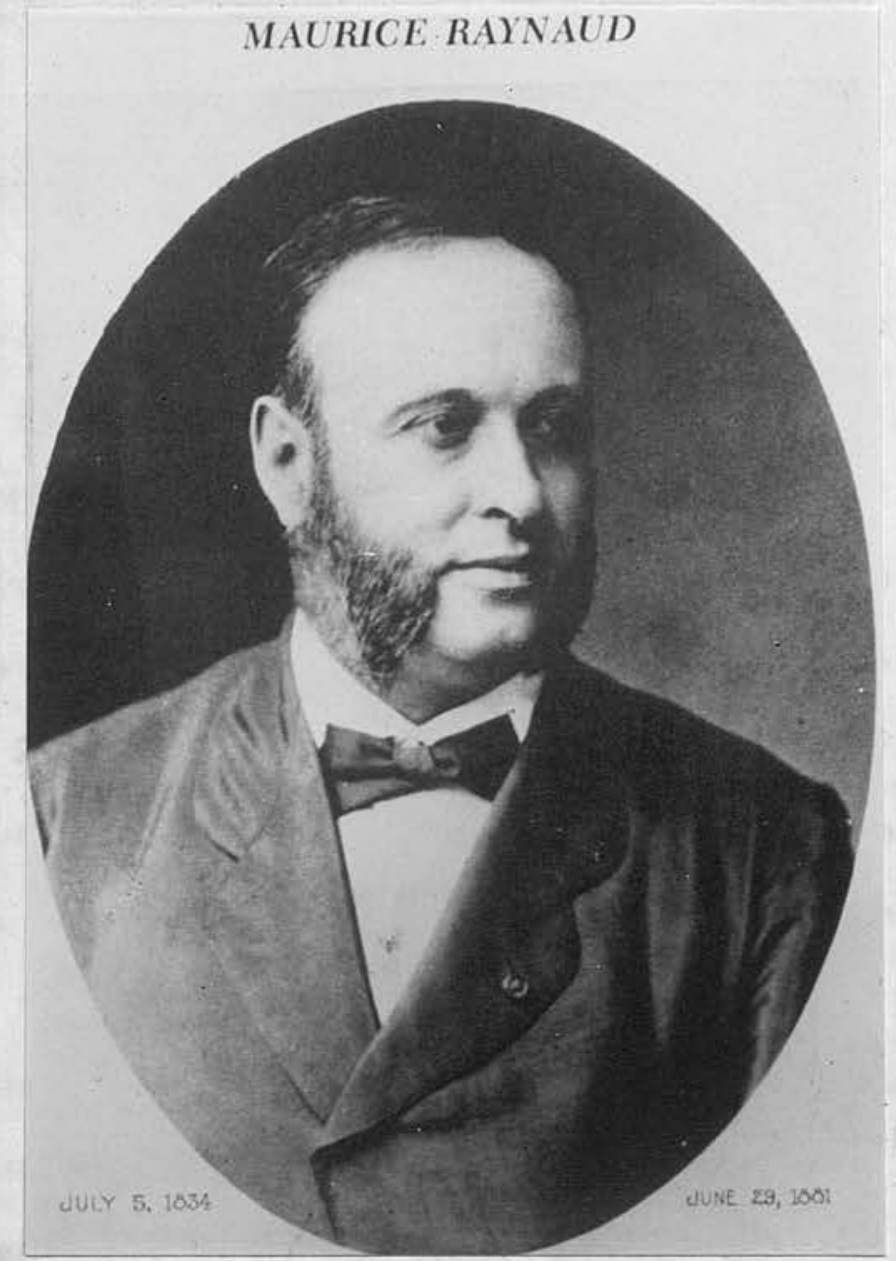

DR. MAURICE RAYNAUD (1834-1881)

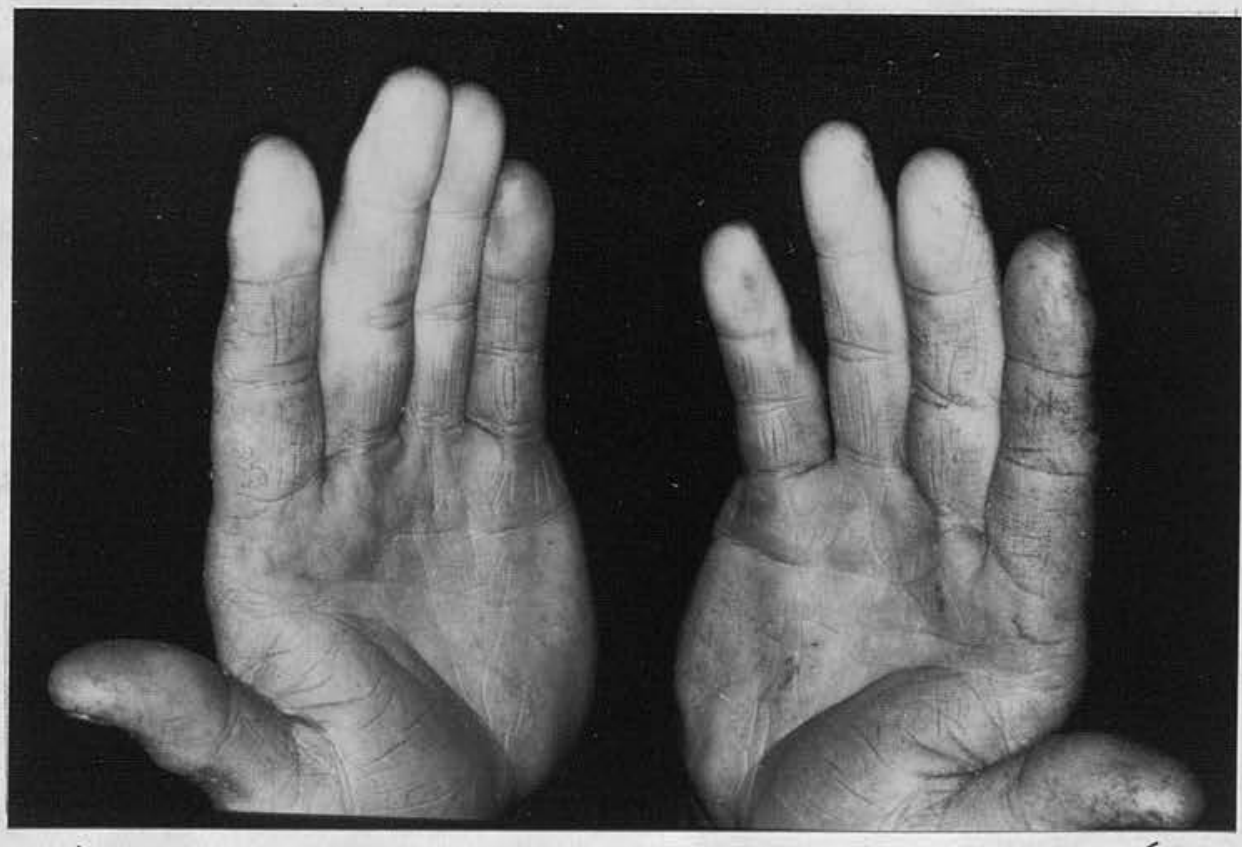

THÉSE POUR LE DOCTORAT EN MEDECINE. PRÉSENTÉE LE FÉVRIER 1862 。 DE L'ASPHYXIE LOCALE ET DE LA GANGRENE SYMÉTRIQUE DES EXTRÉMITIES. 


\section{INTRODUCTION}

\section{Primary Raynaud's Disease}

"In its simplest form a condition, perfectly compatible with health, a local syncopy where persons who are ordinarily females see under the least stimulus, sometimes without cause, one or more fingers becoming pale and cold all at once. It is the phenomenon known under the name of the "dead finger". The duration of the attack varies from a few minutes to many hours. The determining cause is often the impression of cold. The skin of the affected parts assumes a dead white colour. The cutaneous sensibility becomes blunted, then annihilated".

This extract from the M.D. Thesis of Dr. Maurice Raynaud, "De L'Asphyxie locale et de la Gangrene Symetrique des Extremities", submitted in 1862 , describes intermittent blanching attacks of the fingers, symmetrical in distribution, induced by exposure to cold, trivial in its early stages, but leading ultimately in a small proportion of cases to cynotic fingers, finally becoming gangrenous. Raynaud demonstrated a form of dry gangrene which was impossible to explain by a vascular obstruction in the digital arteries of the fingers "sometimes the digits become entirely black and insensible; small phlyctenulae appear on one digit (particularly the little one), then on another, always 
at the extremity. That which strikes one most is the slender form which the ends of the digits take, the hardness of their tissue, and their shrivelled aspect". In 1874 Raynaud published further work on white fingers but his death at the early age of 47 years, in 1881, closed the researches of this French physician. His now famous Thesis and his later work have both been translated into English by Barlow (1888).

The clinical entity off intermittent pallor, cyanosis, sensory loss and pain on return of circulation affecting the fingers and induced by cold, has now passed into the terminology of clinical medicine as Primary Raynaud's Disease. As early as 1893 Hutchinson, although recognising the significance and importance of Raynaud's Thesis, thought that "Raynaud's Phenomenon was not a clinical entity but a syndrome occurring in many conditions". It became evident that in Raynaud's series there were cases of leukaemia, sclerodactyle, arterial disease and small vessel disease associated with diabetes, the latter unknown in Raynaud's day, (Hunt 1936) and for this reason Hunt suggested that the syndrome be renamed "Raynaud's Phenomenon" in line with an earlier definition by Lewis and Pickering (1934) "The active and intermittent closure of small arteries (of the order of digital arteries) supplying the extremities, it shows itself clinically by discoloration of the parts affected. They become waxy white or fully cyanotic, often numb, and their temperature falls to that of the surrounding air". 
Thus early in the twentieth century it was accepted that clinically in the community there existed cases, mainly women, who presented with intermittent pallor or if the attacks continued long enough cyanosis of the extremities, precipitated by exposure to cold and without evidence of blockage of the peripheral vessels. In severe cases nutrional lesions followed such as skin necrosis at the extremities of the distal phalanx.

None of these definitions is satisfactory. Since, as Naide and Sayen (1946) pointed out, not only may Raynaud's disease occur with blockage of the peripheral vessels but the venules must also play a part in that the striking pallor of the digits during an attack must be due to spasm of the venules concurrent with or secondary to the arterial spasm.

By the $1950^{\prime}$ s therefore little progress had been made in differential diagnosis. In Primary Raynaud's disease there is intermittent constriction of the peripheral vessels arterioles and veins, either in the hands or feet, with pallor, numbness and pain on return of circulation to the digits, precipitated by exposure to cold, commonly found in females, usually symetric in distribution, and commencing before the age of 20 years, with a strong constitutional element present. Because of a strong family connection in Primary Raynaud's disease, a further diagnosis has been introduced - Constitutional Cold Finger. There is in Primary Raynaud's disease no association with a number of conditions and diseases known to produce white fingers in which the classical 
signs and symptoms appear as a secondary manifestation.

\section{Secondary Raynaud's Phenomenon.}

Classification of the causes of Raynaud's phenomenon has been confusing and more inadequate than the definition. Edwards (1954) attempted to clarify the field by grouping conditions according to the probable mechanism responsible for the signs and symptoms. Allen et al (1962) proposed a classification according to whether Raynaud's phenomenon occurred with or without contributing diseases. Thulesius (1976) proposed a simple clinical scheme dividing Raynaud's Phenomenon into (A) Primary, and (B) Secondary. Under (A) Thulesius includes Raynaud's disease and Episodic acrocyanosis. Under (B), Raynaud's phenomenon should be suspected whenever the symptoms commence in middle life or later with a unilateral distribution and with increasing severity of symptoms. Under Section (B), Thulesius lists three main conditions of Raynaud's phenomenon which could mislead clinicians - scleroderma, the costoclavicular compression syndrome and vibration-induced white finger. A comprehensive Classification to aid diagnosis based on the responsible mechanisms is shown in Table 1, devised by Taylor and Pelmear. 
TABLE 1.

CAUSES OF RAYNAUD'S PHENOMENON

(A) PRIMARY

1. Raynaud's Disease

2. Constitutional White Finger or episodic acrocyanosis

(B) SECONDARY 1. Trauma Direct to Extremities

(a) Injury, fracture, laceration

(b) Frostbite or immersion syndrome

(c) Vibration-induced

\section{Connective Tissue Disease}

(a) Scleroderma

(b) Rheumatoid Arthritis

(c) Polyarteritis Nodosa

(d) Systemic Lupus Erythematosis

3. Vascular Compression Syndrome

(a) Thoracic outlet syndrome.

Cervical rib

Scalenus Anterior Muscle

(b) Costoclavicular and hyperabduction syndrome

4. Intoxication

(a) Acro-osteolysis (Vinyl Chloride Monomer disease)

(b) Ergot

(c) Nicotine

(d) Beta-blockers 


\section{TABLE 1.- continued}

\section{CAUSES OF RAYNAUD'S PHENOMENON}

(B) SECONDARY (cont.)

5. Occlusive Vascular Disease

(a) Arteriosclerosis

(b) Embolism

(c) Thrombosis

6. Dysglobulinaemia

(a) Cold Haemagglutination

Cryoglobulinaemia

Macroglobulinaemia

\section{Neurogenic}

(a) Poliomylitis

(b) Syringomyelia

(c) Hemiplegia

8. Hypothyroidism 
III. Physiology and Pathology of Primary Raynaud's Disease.

The original description by Raynaud in 1862 of "Local asphyxia and symmetrical gangrene of the extremities" contained a number of clinical case reports all of which showed advanced circulatory disturbances with gangrene of fingers and toes. He concluded that there was no obstacle in the lumen of the capillaries but that the circulation was "slackened" by spasm of the capillary vessels "Exaggerated peristaltic contraction of the capillaries drives the blood before it. The extremities become pale, withered looking, and insensible. This is the 'dead hand'. But this phenomenon does not persist long enough for gangrene to follow. The contraction is succeeded by relaxation and circulation is re-established and everything returns to the normal state after a period of reaction more or less painful. Such is local syncope, in which the venules participate in the contraction of the arterioles".

At this time, around the $1860^{\prime} \mathrm{s}, \mathrm{Claude}$ Bernard's work in basic physiology was making a very large impact on medical science. Bernard had demonstrated the presence of sympathetic nerves supplying blood vessels and that these were responsible for changes in vascular calibre. The only other acceptable theory about peripheral vascular obstruction was embolism and Raynaud ruled this out. 
Raynaud's interpretation remained unchallenged until

Lewis and Pickering (1934) postulated that Raynaud's phenomenon could be either a purely spasmodic affair or alternatively associated with an obstructive disease in the digital vessels.

"In fingers, the arterial supply to which has already been the seat of thrombolic or embolic processes, anastomotic sources of supply may fail to become established fully and subsequently normal increases of tone, such as are induced by cold, will cause transient arrest or conspicuous reduction of blood flow. The original disturbance may be a sudden and non-recurring event, leaving behind it a proneness to attacks of cyanosis, which wrongly come to be regarded as signifying active disease. There is increasing evidence that when gangrene occurs a structural change such as thrombosis has happened and permanently plugs the vessel. Intimal changes including thrombosis are usually always responsible for the obliteration of small arteries leading to necrosis."

In the early stages of Primary Raynaud's disease little is known about the basic physiology because of the difficulty of obtaining digital artery sections. The classical work of Lewis (1938) is of value in comparing 18 subjects who during life showed no Raynaud's phenomenon (16 with habitually warm hands and 2 with habitually cold hands) and 2 mild cases of Raynaud's disease. In the warm handed people the adventitia is thin with the media forming the thickest coat. The elastica interna formed a bold and 
continuously wavy line within which is a scant subendothelial layer of intima. The intimal thickening is not much in evidence until 50 years of age and over when a general thickening of the intima is the rule. At the same age sclerosis of the media of the digital arteries becomes more obvious. The 2 cold-handed people showed no abnormal intima thickening. In the 2 cases with Raynaud's disease there was "hyperplasia of the intima but this change was no more displayed on these subjects than in many of those whose hands have always been warm and who give no history of attacks of ischaemia". Thus, Lewis concluded that changes in the vessel wall were not responsible for the attacks of discoloration. On the other hand he was in no doubt that occlusion of the vessel was generally the result of thrombus formation, a sudden abrupt affair.

"It may be reasonable to suppose that in certain instances thrombi form in vessels the endothelium of which has been damaged by previous prolonged or repeated loss of blood supply. A considerable proportion of cases experiencing necrosis are cases in which the whole train of symptoms form attacks of discoloration to ultimate necrosis is determined by an initial thrombolic event."

In cases of scleroderma with Raynaud's phenomenon conspicuous thickening of the intima of arteries is found and within the lumen of the vessels organising thrombi 
are not uncommon. These changes are seen not only in the digital vessels but occur in most of the vessels in the tissues of the body and in the skin. This is an important differential diagnostic point.

Other workers including Magos and Okos were interested in the action of a cold stimulus - the defensive reaction to cooling on exposure to cold the blood vessels first constrict to diminish heat loss but later dilate to preserve heat and warm the tissues. Magos and Okos studied the thermal behaviour of the vessels of 10 normal subjects, 10 patients with Raynaud's phenomenon of occupational origin. No difference in blood vessel constriction behaviour was observed but in the Primary Raynaud's and the occupational group, dilation was delayed - a weakened reaction of the vessels to cold. From an arteriographic and histological study of digital arteries Laws et al (1967) confirmed Lewis's findings that digital arteries usually show increased intimal thickening with age. Occlusion of the vessels was uncommon before the age of 50 years. Beyond the age of 50 it occurs chiefly in men especially if there is some associated cardiovascular disease such as atheroma of the aorta and coronary vessels or the peripheral vascular lesion associated with rheumatoid arthritis. Arterial tortuosity was found to be associated with destruction of the elastica but not necessarily with narrowing of the lumen. 
IV. Physiology and Pathology of Raynaud's Phenomenon of Occupational Origin.

It is not surprising to find, in view of the relative lack of information on the basic pathology and physiology of Primary Raynaud's Disease, that progress has been slow in elucidating the basic processes when external stimuli such as trauma or toxic agents such as vinyl chloride monomer are added to a condition known to be present in the community. In this research project the episodic attacks of white finger, the paraesthesia and the subsequent hyperaemic phase have been vibrationinduced and subsequently the attacks precipitated by exposure to cold. A case of unilateral Raynaud's phenomenon in a pneumatic road ripper worker described by Mills in 1942 showed the histology of the posterior tibial artery "to have been occluded by yellow thrombus, the media hyalinised, the elestica interna markedly tortuous and flanked by hyaline substance. The lumen was filled by loose fibrous tissue containing numerous vessels of recanalization. Even in those vessels the endothelium was hypertrophied. The vein showed essentially the same changes but much less marked and only mild intimal proliferation was seen, there being no thrombus. The findings were typical of thromboangiitis obliterans in a moderately late, severe and progressive stage. Thus this patient may have been a candidate for the development of Buerger's syndrome in the absence of the trauma of the vibrating pneumatic hammer. However there was a total 
absence of clinical findings in the $\mathrm{R}$ lower extremity. Finger tip biopsies from 5 females with Raynaud's phenomenon of occupational origin were examined by Gurdijian and Walker (1945). No abnormality of the capillaries or larger vessels was seen. The subjects were all mild cases without sensory impairment. In a clinical survey of 37 men with Raynaud's phenomenon of occupational origin, Marshall et al (1954) found that the majority had impaired sensibility to light touch and pinprick, and $20 \%$ showed impairment of passive movement. In addition to the numbness during the ischaemic phase of an attack, many cases had impairment of motor and sensory functions. This work raised the question whether the traumatic stimuli from vibrating tools could produce permanent neurological effects and that the lesions may lie in the nerve fibres as opposed to the sensory end organs. The authors believed that damage to the nerve trunks might be the main cause of the vasomotor instability of the vessels as well as explaining the motor and sensory changes. This work was, however, marred by the absence of controls which would be required to establish normal thresholds.

Further evidence on vessel wall changes induced by vibration has been obtained from the work of Ashe and his colleagues (1962, 1964) from Ohio. In 1962, two miners using Jackleg drills were examined and the digital arteries of the fingers biopsied. Patient 1 with mild Raynaud's phenomena - the vessel walls showed medial muscular hypertrophy with no particular tendency for 


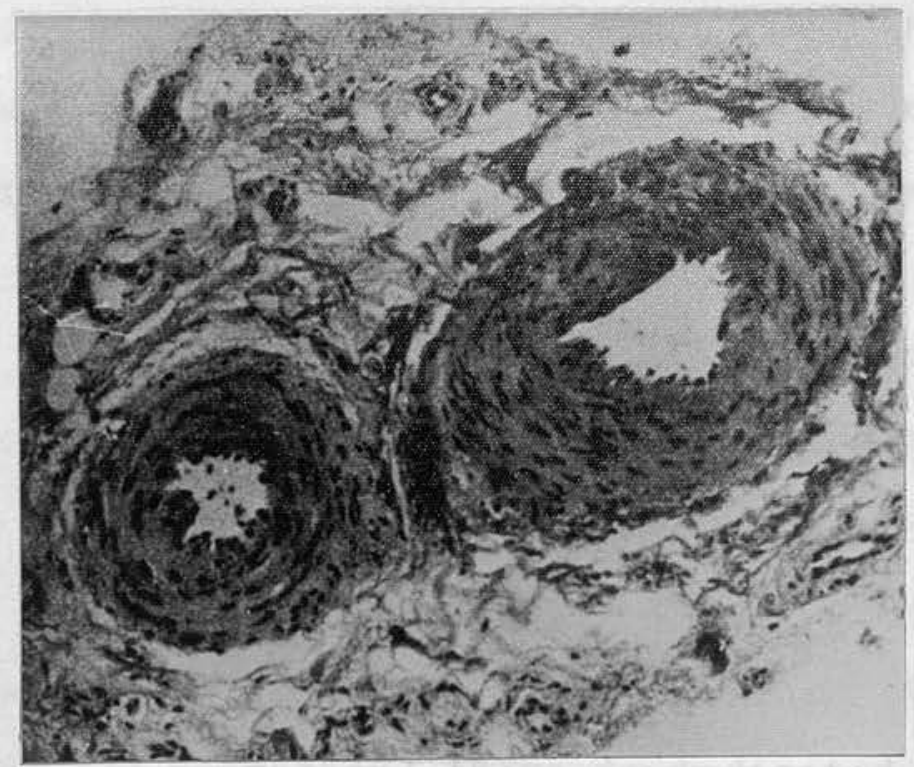

Fig. 2

Raynaud's Phenomenon - case of moderate severity (Stages 1 or 2)

Digital arteries show moderate hypertrophy of medial coat. No significant fibrosis. Between VWF attacks digits of normal colour. (Ash et al, 1962)

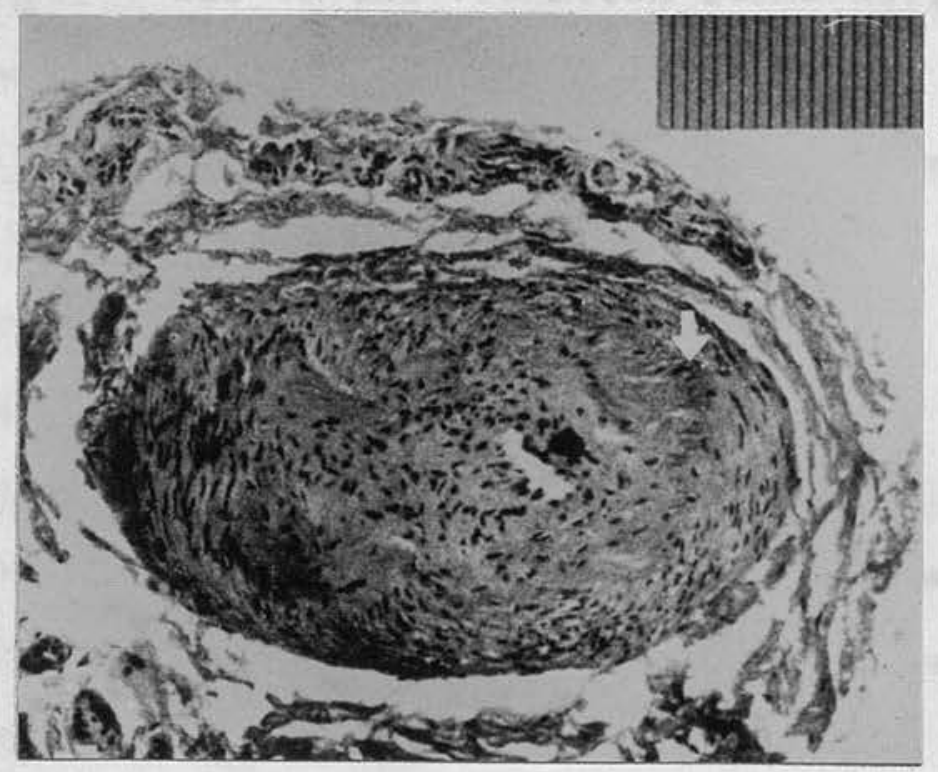

Fig. 3

Raynaud's Phenomenon - advanced stage, (Stage 3 or 4) permanently cyanosed. Artery section (digital) shows sub-intimal reactive fibrosis. Arrow indicates internal elastic lamella. The tissue to the left of the arrow is hypertrophied smooth muscle. (after Ashe et al, 1962) 
hyalinization and no subintimal fibrosis. Patient 2 was a severe case of Raynaud's phenomenon with permanent cyanotic fingers. The vessel walls showed advanced muscular hypertrophy together with moderate to marked subintimal fibrosis. Thickening of the arterial wall with reduction in the lumen of the vessel can only be considered to be pathological in nature. These pathological findings were summarised by Ashe,"Upon the application of external stimulae (cold and vibration) there is indicated a physiological spasm of vessels in the areas subjected to vibration. The repeated spasm leads to functional hypertrophy of vessels (Patient 1). Following the vessel wall changes ( due to the vibration stimulus), they are triggered into spasm by cold. The hypertrophy can progress to a point where the vessels are so thickened that the vibration stimulus no longer causes testriction and there is a permanent restriction to flow due to the narrowed lumen of the vessel, (Patient 2). Where induced restriction can take place, there is blanching of the tissues but where the vessel has become fixed by advanced hypertrophy and fibrosis, only limited blood flow is possible, leading to cyanosis of the stagnation type." (Figs. 2 and 3) 
In a follow up study of 7 miners with Raynaud's phenomenon due to vibration, 4 patients had $30-50 \%$ of the observable thickness of the arterial wall composed of sub-intimal fibrous tissue whilst the remainder of the wall showed hyperplastic changes in the smooth muscle tissue.

There are many difficulties to be overcome before it is possible to obtain enough physiological and pathological data on which to base sound theories on the aetiology of Raynaud's phenomenon,

(a) the ethical problem of digital artery biopsy procedure,

(b) the problem of obtaining biopsy control material from normal subjects.

(c) Biopsy procedures may in themselves produce restriction of the vascular lumen.

(d) The difficulty of obtaining and interpreting post-mortem material.

In summary, it is known that there is a very wide variation of blood flow volume in the fingers and toes and that some individuals have hypersensitive reactions (constriction and dilation) in their arterial systems to any form of stimulus particularly exposure to cold a functional over-reaction on the part of the arteries being found in Raynaud's phenomenon (Primary)。 If an external stimulus, such as repeated trauma (vibration) is then applied to the vessels, fibrotic changes first noted as hypertrophy of the medial muscle coat and 
followed on continued stimulation by intima proliferation and fibrosis and gradual reduction of the lumen of the vessel.

In the advanced cases, the two processes may be additive.

Further evidence on the artery changes following prolonged vibration exposure has been reported by Walton (1974), from a pneumatic road ripper operator of 26 years vibration exposure. (Details in Appendix). The digital arteries showed marked medial hypertrophy and fibrosis with reduction of the lumen by extensive intimal proliferation and elastosis. In other sections the lumen was completely obliterated by a meshwork of fibrous tissue showing the presence of shreds of material giving the histochemical and immunohistological (Fig.4) reactions of fibrin. There were platelet thrombi in veins and venules. The main trunks of the digital nerves and Meissner's corpuscles were normal but the superficial cutaneous plexus and the branches extending into the dermal papillae showed degeneration and perineural infiltration by small round cells. Sections from the aorta, subclavian and coronary arteries showed the presence of characteristic atherosclerotic plaques at various stages of development. No evidence was seen in any of these vessels of granulomatous arteries nor of any thrombotic process.

In this case there was loss of sensation to light touch and to pinprick and a typical clumsiness due to loss of touch sensitivity. 


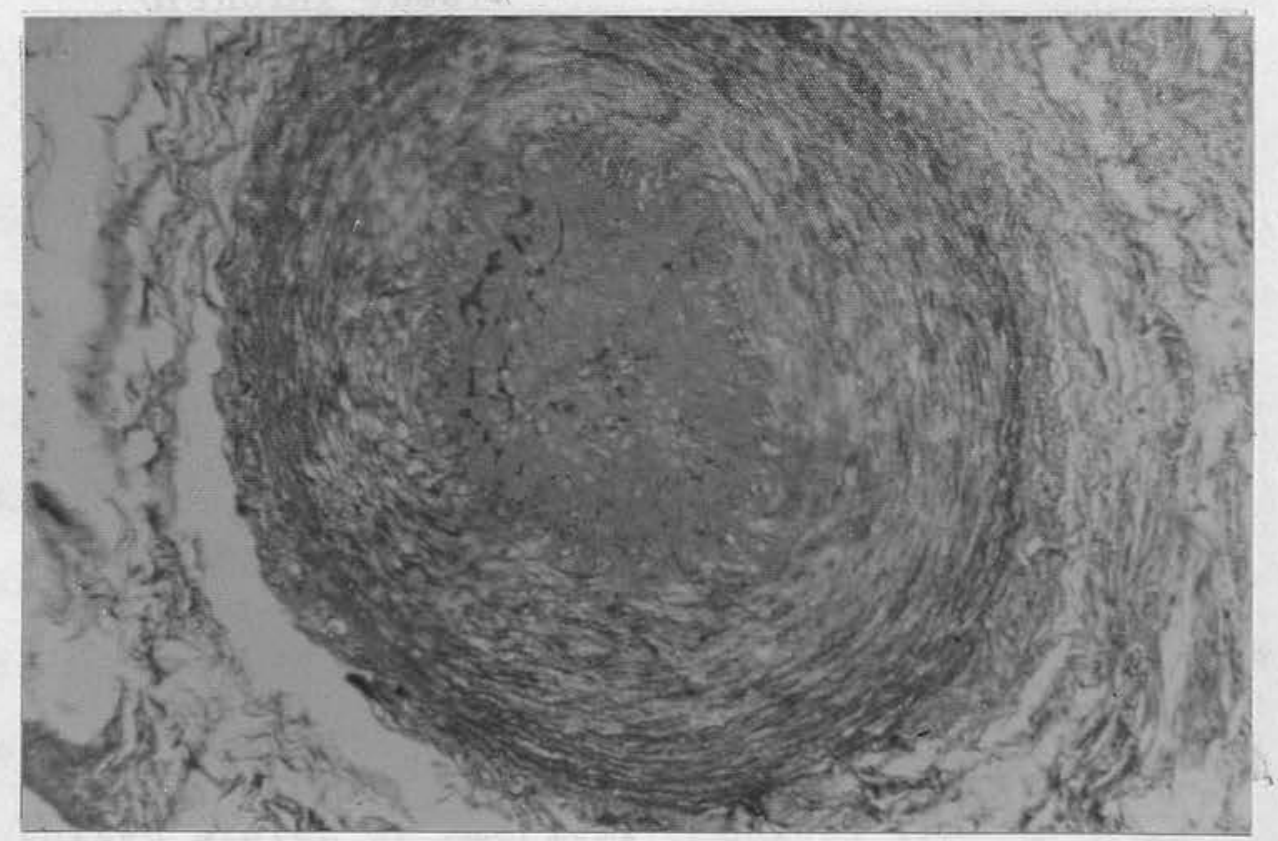

\section{Fig. 4}

CASE HISTORY: MR. W.P.

\section{DIGITAL ARTERY SECTION (Post Mortem)}

This artery shows hypertrophy and fibrosis of the media.

The lumen is filled with structureless material

containing fragments of material giving staining reaction to fibrin. 
HISTORICAL REVIEW

(A) RAYNAUD'S PHENOMENON OF

OCCUPATIONAL ORIGIN

Pneumatic Hammers

Grinding Wheels

Hand Tools

Chain Saws

Attacks of white fingers or "dead hand" arising from the use of hand held pneumatic tools was first reported by Loriga of Italy (1911; 1913). These air driven, mining drills were introduced into French mines as early as 1839. About 1896, pneumatic drills were introduced into the limestone quarries of Bedford and Indiana in the United States of America. Medical examinations of the miners by Leake (1918), Edsall (1918), Cary (1918), Cottingham (1918) and Hamilton (1918; 1930), noted "spastic anaemia" of the hands, ascertaining that the latent interval between vibration exposure and the onset of signs of white finger varied from 6 months to 2 years. For this research project it is of interest to note that this population of miners was examined at the request of the U.S. Bureau of Labor Statistics and the Journeymen Stonecutters Association. The miners in the labour dispute had voted to abolish the tool. Alice Hamilton, of Harvard, surveyed 150 miners in 1918 and reported that men using the air hammer suffer from attacks of blanched, numb fingers usually early in the morning or after work. Between attacks the hands become normal and men do not complain of discomfort. Stonecutters who 
did not use the air hammer did not have this condition. Those who had given up the use of the air hammer for many years still may have their fingers turn white and numb in cold weather.

An important observation made by the stonecutters concerned their inability to take up a skilled trade which exposes the hands to cold whereas this condition does not impair their skill for ordinary stonecutting and carving.

Hamilton concluded that the trouble appeared "to be caused by four factors - long, continuous use of the air hammer, grasping the tool too tightly, using worn, loose air hammers and by cold in the work place.

This classical description of Raynaud's phenomenon of occupational origin by Hamilton (1918) has been unsurpassed in the subsequent literature.

In 1933, Hardgrove and Barker reporting on a limestone cutter aged 25, with 6 years drill usage, thought that the "pneumatic disease was relatively benign, most of the stonecutters paying little attention to the vasospastic phenomenon and the sensory disturbance". Although the vasospasm could easily be demonstrated, trophic skin changes were rare even after years of use of the hammer. Mills (1942) reported a case of unilateral Raynaud's Phenomenon of occupational origin in the left leg and foot in drilling rock where he pressed the drill down with his left foot, resting by this method his body weight on the drill. Williams and Riegert (1960) 
reported a high incidence of Raynaud's phenomenon in Canadian uranium miners using drills (Jackleg). He drew attention to the reluctance on the part of the miners to report the condition to management for fear of dismissal and unemployment. Miura et al (1966) from Japan, reported a prevalence rate of $37 \%$ in Japanese limestone quarriers with a latent period of $3 \frac{1}{2}-4$ years. Metal grinding operations as an occupational cause of Raynaud's phenomenon was first reported in 1931 by Seyring. This investigator correlated the signs and symptoms with vibration exposure time and found $4 \%$ at 2 years, $48 \%$ around 3 years, 55\% within 10 years, and $61 \%$ after 10 years. She also drew attention to the nature of the material - an increasing prevalence with hard resistant material. Agate et al (1946) investigated foundry grinders and found 32 of 37 men with symptoms. Later in 1949, he investigated a population of 233 grinders and polishers of metal casting, and found $70 \%$ of the males and $47 \%$ of the 45 women affected, with an average latent period of approximately 2 years. Examining the same population two and a half years later the prevalence had increased to over $80 \%$ of those who had had signs and symptoms. $50 \%$ had remained stationary, $36 \%$ had deteriorated, and $5 \%$ only had improved. At this time Hunter et al (1945) examined 286 pneumatic tool workers in various trades. The incidence was $71 \%$ in fettlers, $74 \%$ in riveters and $82 \%$ in caulkers; with a latent period in the region of 
2 - 5 years. At the Rehabilitation Centre of the

Workmen's Compensation Board at Vancouver, McKinnon and Kemp found Raynaud's phenomenon in $40 \%$ of riveters, $25 \%$ of holders-on, $22 \%$ caulkers, $9 \%$ reamers, and $4 \%$ bolters-up. Peters (1946) found $11 \%$ of 1,000 employees using small $1 \frac{1}{4} 1 \mathrm{~b}$. hand pneumatic tools in aircraft construction to be suffering from pain, numbness and stiffness but no blanching.

The cold air blast from pneumatic tools has been considered to be an aggravating factor in precipitating attacks of Raynaud's in pneumatic tool workers, especially when the blast is directed towards the hands. Reports of similar tools electrically driven appeared in the literature. Whitewell (1945) reported seeing white finger in three operators using flexible shaft tools for grinding and polishing. 'Dead hand' was noted by Telford et al (1945) in 25\% of employees using electricallydriven tools for cutting and polishing. Brocklehurst (1945) found Raynaud's phenomenon in 17 of 23 fettlers of magnesium castings.

Using portable, electrical, hand-held vibratory tools with a latent period of 14 months, Biden-Steele and King (1947) reported Raynaud's in three factories where fettling of duralumin castings of aero engines was carried. out with a mean latent interval of 2 years.

Raynaud's phenomenon in workers using hand-held vibratory tools was investigated by Jepson (1954) who made several important observations. "The period of 
time before onset did not appear to be related to family history, the degree of exposure to cold at work, age or anatomical type fingers. It was common to find the condition to be more severe in fingers to which most vibration was transmitted (e.g. 4 th finger of Left Hand resting on a loose chisel). The severity and frequency of attacks appears to reach a maximum of years after the onset. Thereafter further vibration exposuré does not appreciably increase either the severity or the number of attacks。 of the 13 patients who had changed their occupation, all but one stated that the attacks persisted unchanged and became more severe and frequent after their change of employment. Although Raynaud's phenomenon rarely interfered with the work situation, all complained of considerable handicap during their leisure hours interference with gardening, swimming and watching or playing outdoor games.

By means of letters of enquiry to 50 American State, County and City Industrial Health Agencies, Pecora et al (1960) attempted to assess the numbers exposed to hand-held vibratory tools and those reporting signs or symptoms from regular use. Eleven large plants were visited and discussions were held with industrial medical officers. Not a single case of Raynaud's phenomenon of occupational origin was found. The authors concluded,

\footnotetext{
"The impression from industry is that Raynaud's
} 
phenomenon of occupational origin from vibrations from hand-held tools is practically non-existent since no cases have been reported in the last 10 years, and no compensation claimed for this disease has been paid".

The above conclusion must be suspect since Agate and Druett (1947) pointed out that it is never safe to assume that there are no cases of Raynaud's phenomenon from the use of a suspected tool until direct (as opposed to the indirect method of Pecora) has been made.

A comprehensive study of pneumatic tool workers by Magos and Okos (1963) in the Hungarian Iron, Steel and Engineering Industry, found that workers with over 2 years exposure to pneumatic tools had the following prevalence rates - steel casting cleaners $79 \%$, chippers and caulkers $55 \%$, iron casting cleaners $31 \%$, riveters $24 \%$ and mixed grinding and fettling $20 \%$.

\section{Power-operated Chain Saws.}

A petrol-driven two-stroke cycle power unit driving a cutting chain was developed for timber fellers in Germany before the Second World War. By the 1950's chain saws were in regular forest use in Scandinavia and in Britain. By the $1960^{\prime}$ 's, debranching or snedding was also carried out with the new mechanical saw. The forest operators of felling, snedding and crosscutting therefore now meant, at the end of the $60^{\prime} \mathrm{s}$, at least $5 \frac{1}{2}-6$ hours of continued saw usage every 8 hours/5 days/week.

That this new hand-held tool could give rise to 
Raynaud's was unsuspected until Grounds (1964) found 20 forestry saw users (from a total force of 22) affected in Tasmania, with a latent period of one year. It is surprising that since attacks are invariably precipitated by cold that the first report incriminating chain saws should come from Australia until it is realised that the climate in Maydena (temperature $33^{\circ}-72^{\circ} \mathrm{F}$ ) is cold by Australian standards (but not by Scandinavian). It was not long before reports from Japan (Miura et all 1966) and Sweden (Axelsson 1968; Kylin et al 1968) confirmed the early findings that chain saws were a new source of vibration-induced Raynaud's phenomenon. The New South Wales State Forestry Commission, through Barnes et al (1969), investigated the prevalence amongst timber workers on the North coast of New South Wales. Of the 80 chain saw operators examined, $50 \%$ were affected with a variable latent period of 1 to 10 years. All workers at the time of the interview considered the condition more of an annoyance than a disability, and none contemplated giving up their present occupation. The authors concluded that vibration disease in timber workers in the warmer parts of Australia presented little disability even although the condition was relatively common.

The Forestry Commission (Scotland) suffered a severe blow-down following a 90-100 m.p.h. gale early in January, 1968, with 2 to 300 acres of flattened forests in the Glen Finnart and Glen Branter area in West Scotland. Tidying up these blown forest areas, several chain sawyers experienced white finger attacks some for the 
first time, all precipitated by the cold JanuaryFebruary weather. The Forestry Commission (G.B.) requested the help of the Department of Occupational Medicine, University of Dundee to investigate the prevalence of vibration-induced white finger in Britain. The survey was reported by Taylor et al in 1971. A questionnaire from 800 random selected forestry workers (response rate 97\%), of which 142 were chain saw operators, showed that $44 \%$ had Raynaud's phenomenon compared with $18 \%$ in the non-users。 The prevalence increased with increasing saw usage time, with a marked increase to $73 \%$ at over 8 years saw usage or vibration exposure time. Similar studies on forestry workers have been carried out in Norway (Hellstrom and Andersen, 1972) and Sweden (1972). 
(B) SECONDARY COMPLICATIONS OF RAYNAUD'S

PHENOMENON OF OCCUPATIONAL ORIGIN.

It was recognised by early workers studying Raynaud's phenomenon that several new features other than the blanching of the digits, the sensory loss, and the hyperaemia of the recovery phase were associated with the occupational tasks being performed. The earliest complication observed was thickening of the skin or formation of callus on the palmar surfaces of the fingers commonly found in heavy pneumatic hammer or drill operators. Edsall (1918) observed "hard pads of thickened skin usually seen on the fingers exerting the most pressure on the vibrating tool. A swelling of one or more fingers is also common". Recently Stewart and Goda (1970), noting the callus on the finger pads and on the palms of vibration exposed workers, postulated that in their view this increased subcutaneous fibrotic layer was the cause of vibration white finger by constricting the capillaries externally and reducing their ability to react to small temperature differences, the hands becoming cold-weather sensitive. There was no pathological or physiological evidence to support this theory. Both McCallum (1971) and Walton (1974) remain unconvinced that callus formation contributed directly to the aetiology of Raynaud's phenomenon.

The Industrial Injuries Advisory Council, however, in its 1970 Report, Section 17, referring to the cause of 
vibration induced white finger (VWF) "we recognise that the callus theory awaits clinical confirmation and that there may be other factors contributing to VWF in which symptoms have been displayed before the onset of finger callus, but it does tend to confirm earlier findings about the limitation of the possible disabling effects of VWF".

The last clause of this statement is untrue and since it is known that severe cases of Raynaud's phenomenon may occur without callus formation, it is not possible to base a conclusion regarding the severity of VWF on a questionable theory of callus formation. The question of changes in sensory perception in the hands following exposure to hand-held vibratory tools and the part played by nerve injury in Raynaud's phenomenon has occupied the attention of research workers since the very early research in the 1918-1920 era in the United States of America. There are reports throughout the literature of disturbances of light touch, pressure, pinprick, temperature (thermal sensation), and appreciation of vibration. Permanent sensory changes in the hands which did not follow peripheral nerve trunk distribution, were described by Hardgrove and Barker (1933) whilst Junghanns (1937) noted a disturbance in the sense of touch and sensitivity to cold. Peters (1946) reported pain, throbbing and burning in those fingers in contact with the vibrating tool, with a positive correlation between the sensory changes and the method by which the tool was held. There was diminished or absent sensation 
to touch, pain and temperature in that portion of the hand in closest contact with the tool. Impaired or diminished sensibility to light touch and pinprick was also noted by Marshall et al (1954).

From the 1960's onwards many attempts were made to determine the threshold of vibration in the finger pads by applying stimuli with known vibration parameters. The greatest damage to vibration sensibility is caused by vibration frequencies in the range $200-500 \mathrm{~Hz}$, Mikulinskii (1966). Using a vibrator at $125 \mathrm{~Hz}$, Miura et al (1966) measured the threshold stimulus for vibration at the finger tip. He found a markedly higher threshold in subjects with affected fingers. An apparatus for delivering vibrational energy to the finger tip has been described by Neilson et al (1969). Self recording equipment for determining the threshold of vibratory sensation with a high level of reproductivity was used by research workers in all countries, particularly Sweden (Lidstrom 1975), in an attempt to measure temporary threshold shifts following stimulation of the hand with intense sinusoidal vibration for a known period ( 4 minutes), the recovery to normal following this test dose being found to vary linearly with log time. This line of research appealed to those workers previously engaged in noise research (comparison Temporary Threshold Shift, TTS and Permanent Threshold Shift, PTS), where the shift in the vibratory sensation resembles the TTS observed on exposure to noise. A further refinement of the vibrator 
delivering known frequency and acceleration parameters was the introduction of a handle to the vibrator to which strain gauges were applied thus registering a known 'grip' or force factor between the stimulus and the hand (Lidstrom 1975 ; Streeter 1970) - a vibrating hand dynamometer equipped with a strain gauge bridge.

It is accepted by neurologists that the human hand and digits do not possess separate vibration sense detector organs. The perception of vibration is brought about through appreciation of the separate, rapidly repetitive, impulses acting on the touch and pressure receptors. In the experiments of Streeter (1970), tactile sensitivy loss was found to be frequency dependent, being greatest at 60, 120 and $240 \mathrm{~Hz}$. Increasing the power or energy input to the hand caused increased loss of sensitivity. Grip strength was not found to be a significant factor. The dynamometer apparatus proved useful in showing that a surprisingly high energy content reached the arm, shoulder and head, indicating that the whole hand-arm system should be studied, particularly at low frequencies, around $30 \mathrm{~Hz}$. A small amount of tactile sensitivity was found reflecting a small amount of energy absorption in the subject's hands. The resonant frequency of the hand is at or near $30-50 \mathrm{~Hz}$. but the exact significance of the part played by resonance, Pacinian corpuscles and Meisner's plexus - the end organs of touch and pressure, has not been evaluated. The temporary loss of sensitivity or tactile sensation must represent fatigue 
fatigue of these end organs due to vibration stimulii.

Nerve conduction velocity experiments in the motor nerves of the median and ulnar have been made, (Seppalainen, 1970) and where numbness is a complaint, there has been neuropathic involvement. These findings were confirmed by Jandova et al (1971). To date no practical test has been developed clinically outside the laboratory or hospital based on nerve conduction tests. It is thought that the vibration stimulus acts on the subcutaneous end organ and leaves unaffected the nerve trunk in cases of Raynaud's phenomenon

$$
\text { Prolonged use of vibrating tools if affecting }
$$

sensory end organs and thus diminishing tactile sensitivity, will then have discernible effects on fine manipulative skills. This aspect of the complications of Raynaud's phenomenon is of importance when rehabilitating severely affected cases. Chain saw operators have been tested with controls using a purdue pegboard. (Bannister and Smith, 1972). The dominant hand of the saw workers completed fewer items and thus was more affected than the controls. It has been found impossible to rehabilitate severely affected sawyers to, for example, electronic circuit construction due to their inability to perform fine tasks. 
Arthritic Conditions, Bone Cysts.

In 1950 the question whether Raynaud's phenomenon should be prescribed under the National Insurance (Industrial Injuries) Act, 1946 was raised. Prescription was rejected (Cmnd. Report 9347, 1954). In 1967 the Minister of Social Security referred to the Industrial Injuries Advisory Council the question whether "diseases of the bones, joints, muscles, blood vessels or nerves of the hand, arm or shoulder (including Raynaud's phenomenon) caused by vibrating machines should be prescribed under the National Insurance (Industrial Injuries) Act, 1965 (Cmnd. Report 4430, 1970)".

The broader issues on which information was sought in the period 1967 - 1970 was deemed necessary following a report from Reynard (1954) who described, as well as white fingers, damage to arteries, nerves, muscles, joints, bones and sub-cutaneous tissue of the upper limbs - a complex which Reynard termed "the Vibration Syndrome". In 1931, Seyring reported joint injuries in pneumatic drill operators (road or rock drillers), mainly involving the right elbow. There was pain in the elbows and shoulders particularly at night with gradual limitation of extension of the elbows with increasing exposure time. In 1936 Brailsford drew attention to what he termed "cancellous injury to the bone", not sufficient to breach the continuity of the surface, but to produce localised absorption of trabeculae with the production of cysts. The common sites reported were 
the heads of the metacarpals and the carpal scaphoid. On X-raying the hands of men with more than 10 years usage of compressed air drills, the cysts appear with translucent absorbed bone in the centre of the cyst with fresh bone laid down on the circumference of the cyst. Cazamian et al (1936) confirmed the presence of bone cysts in the wrist with exostosis of the elbows. It had been assumed by radiologists that bone cyst formation in the hands inevitably followed heavy manual work. An important contribution came from McLaren (1937) who found $65 \%$ of users of pneumatic rivetting tools with definite radiological tone changes. The most frequently affected bones showing cystic changes were the semilunar, or magnum and scaphoid, and the metacarpal heads of the second and third fingers. It was also noted that the cystic areas in the metacarpal heads were of a larger type than those in the wrist bones. Unfortunately there are no details given of the vibration entering the hands due to lack of instrumentation, so that all that McLaren could conclude was "that it is not uncommon to see occasional cystic areas in the carpal bones of manual workers but an incidence of $65 \%$ is very high". The nature of these radiological changes is an index of the trauma received by the hands.

Reviewing the literature concerning the bony complications following the use of vibratory tools, Copeman (1940) listed decalcification of the carpal 
bones, periosteal thickening of the shafts of the phalanges, necrosis of the lunate, arthritis of the elbow joints, and calcified subacromial bursa with early degenerative changes around the shoulder joint.

In handling heavy vibratory tools (jackhammers, pneumatic road rippers and drillers) there is prolonged tension of the musculat/fe with abnormal strains on the muscle attachments resulting in periosteal proliferation. Olecranon spurs have been described in the aluminium electrolytic cell reduction process (Sweeney, 1965). The shoulder joint appears to be less affected but where this occurs the condition is likely to be ordinary, traumatic osteoarthritis.

The whole field of bony change due to vibration was discussed by Hunter et al (1945) who found that there was no convincing evidence that could be attributed solely to the use and handling of vibrating tools. Arthritic changes were rare but they did find small areas of decalcification in the carpal bones of riveters, caulkers, fettlers and holders-up. There was no evidence to show that bone cysts predisposed to arthritis or fractures or impaired working ability. Further evidence that the cysts were innocuous came from Jepson (1954) and Davies et al (1957). Casciu et al (1968) surveyed miners using pickaxe hammers and pneumatic drills and did not reveal any skeletal changes. Building employees who used pneumatic tools spasmodically were examined by Gentaz et al (1972). Of the 103 subjects X-rayed, two cases of Kienboeck's disease were found, and in half 
of the cases, spur formation at the olecrannon was found at the insertion of the triceps tendon.

Throughout these investigations on heavy pneumatic tools, it has been difficult to dissociate the weight factor from the vibration stimulus and their effects on the human hand-arm-shoulder system. Therefore it was of interest to investigate chain saw operators where the weight of the hand-held tool is reduced by approximately 50\%. Barnes et al (1969) found a peculiar notched appearance consistent with traumatic epithelial bone cysts at the ends of the terminal digits in chain saw operators. On the other hand Kumlin et al (1971), by means of densitometric studies on the metacarpal bones of lumberjacks using chain saws, showed no bony changes and this negative result was confirmed by Hellstrom and Andersen (1972), who concluded that osteoporosis of the metacarpals was not influenced by chain saw vibration. Later however Kumlin et al (1973) X-rayed 35 lumberjacks, 31 of whom had Raynaud's phenomenon, i.e. with long term chain saw usage. In 7 cases $(20 \%)$, with a saw usage time of 10 - 18 years, bone vacuoles were present in the carpal region. In this study bone cysts ( $2-3 \mathrm{~mm}$ diameter) found in the central part of the carpal bones and metacarpal heads, were differentiated from vacuoles (4 - 6 mm diameter) situated juxta-articularly. In an age-matched control group no corresponding skeletal bone changes were found. Unfortunately, with the exception of Kumlin's study, little attention has been given to matching the vibration workers with a control population. 
An added difficulty is the question of selecting the control population, whether from a manual group, e.g. forestry workers in the same environment as a chain sawyer, but without vibration exposure, or a sedentary group who have not experienced hand trauma or tool pressure. 


\section{Acro-osteolysis}

Vinyl Chloride Monomer (VCM) readily polymerises to polyvinyl chloride (PVC). In Britain some 2,000 workers are concerned in its manufacture, of whom 500 are exposed to VCM vapour in the early production stage in autoclaves. This chemical process was discovered in Germany in the mid 1930's and has been in use for over 40 years in the U.S. and in Britain since 1940.

In 1963 Suciu et al first described Raynaud's phenomenon in polyvinyl workers. In 1966, Cordier et al described in two VCM autoclave workers in Belgium a condition acro-osteolysis, "a curious condition the nature of which we cannot decide and in which the aetiology is by no means clear." The triad of Raynaud's phenomenon, sclerodermatous skin changes and osteolysis of the distal phalanges was confirmed in several investigations of autoclave workers (Wilson 1967), Dinman (1971). The epidemiological study by Dinman covered 5011 workers in VCM and PVC plants throughout the United States and Canada. The total number of acro-osteolysis cases found was 25 with 16 men manifesting the early stages of AOL namely Raynaud's phenomenon. Dodson et al (1971) confirmed acroosteolysis in four subjects, all reactor vessel cleaners. The literature revealed that this condition is clearly associated with hand cleaning of the autoclaves following polymerisation, using hand-held vibratory tools (Cook et al, 1971). At first therefore the disease 
was assumed to be associated with vibration and the observed Raynaud's phenomenon consisted mainly of blanching of the fingers with tingling and numbness of the finger tips. With continued exposure, however, to the VCM gas, osteolysis of the terminal phalanges of the hands, styloid processes of the ulna and radius and the sacro-iliac joints was seen. The osteolysis as seen in Figs $5,6,7$ was severe at the finger ends with crescentshaped erosions of the shafts of the phalanges and finger clubbing from the increase and thickening of the collagen fibres with simultaneous destruction of the elastic fibre network resulting in clubbing of the fingers with shortening and increasing mobility of the finger ends. In 1974 an association was reported (Creech et al, 1974) between exposure to VCM and a rare liver tumour angiosarcoma - in autoclave cleaners, confirming animal work by Viola (1971) and Maltoni (1973).

The whole problem of VCM, including Raynaud's phenomenon, the tissue and bone changes, is concerned first with arterial degeneration with conspicuous fibrosis in digital arteries throughout the body especially the portal vessels of the liver, leading to the presenting signs of blanched fingers and complaints of cold hands. The angiosarcoma cases now presenting may be the result of previous exposure of very high concentrations of VCM in autoclave workers (Barnes, 1976). In some cases there is a suggestion of addiction.

Acro-osteolysis is an example of a hitherto unsuspected health hazard in a familiar, safe chemical 


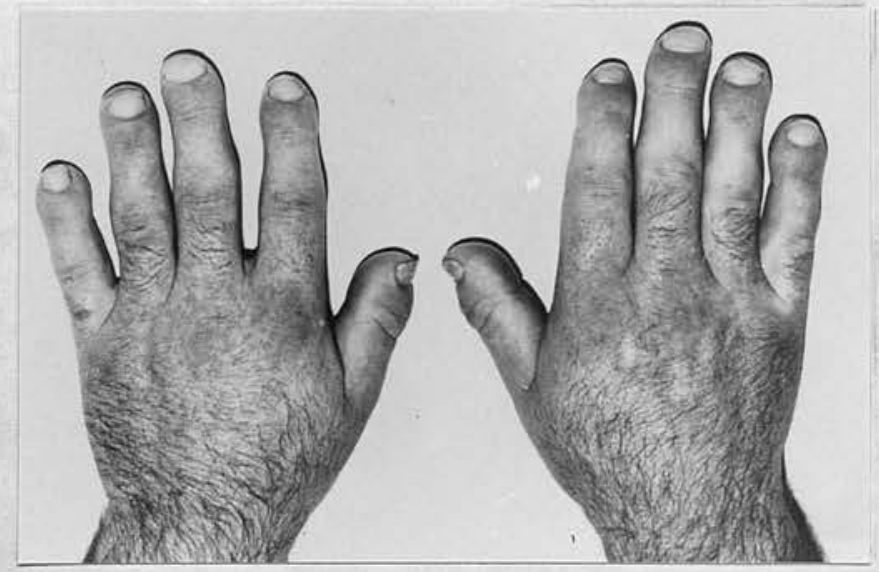

Fig. 5

MR. A.D. VCM Autoclave worker $5 \frac{1}{2}$ years presented with severe Raynaud's phenomenon, thickness and tightening of the skin. Soft tissue thickening of the digits, shortening and increasing flexibility of terminal phalanxes of all digits in both hands.

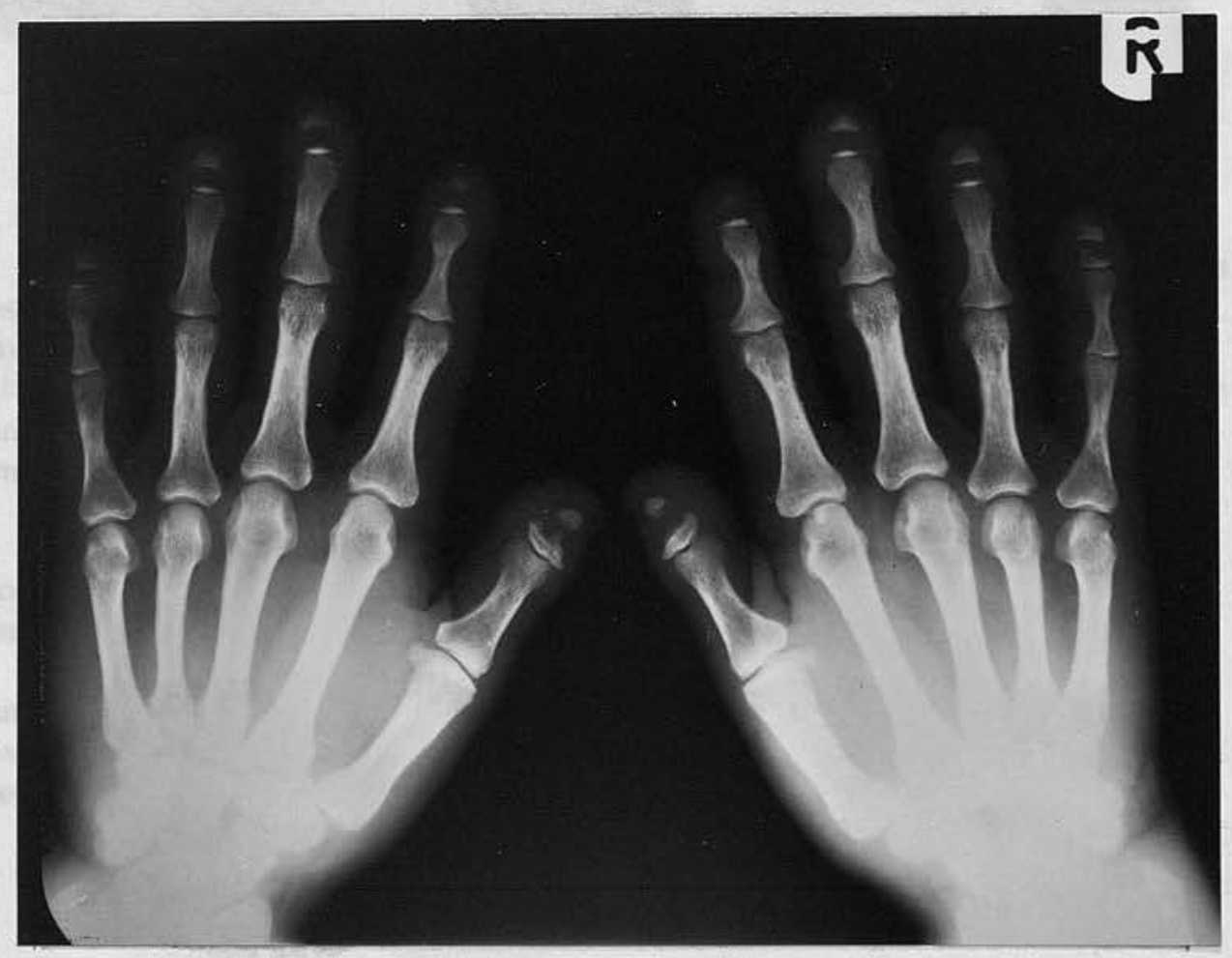

Fig. 6

MR. A.D. Radiograph of hands showing osteolysis of terminal phalanxes, crescent-shaped erosions of the middle phalanges, a well defined sclerotic margin at the base of the $R$ first metacarpal. A case of severe acro-osteolysis. 


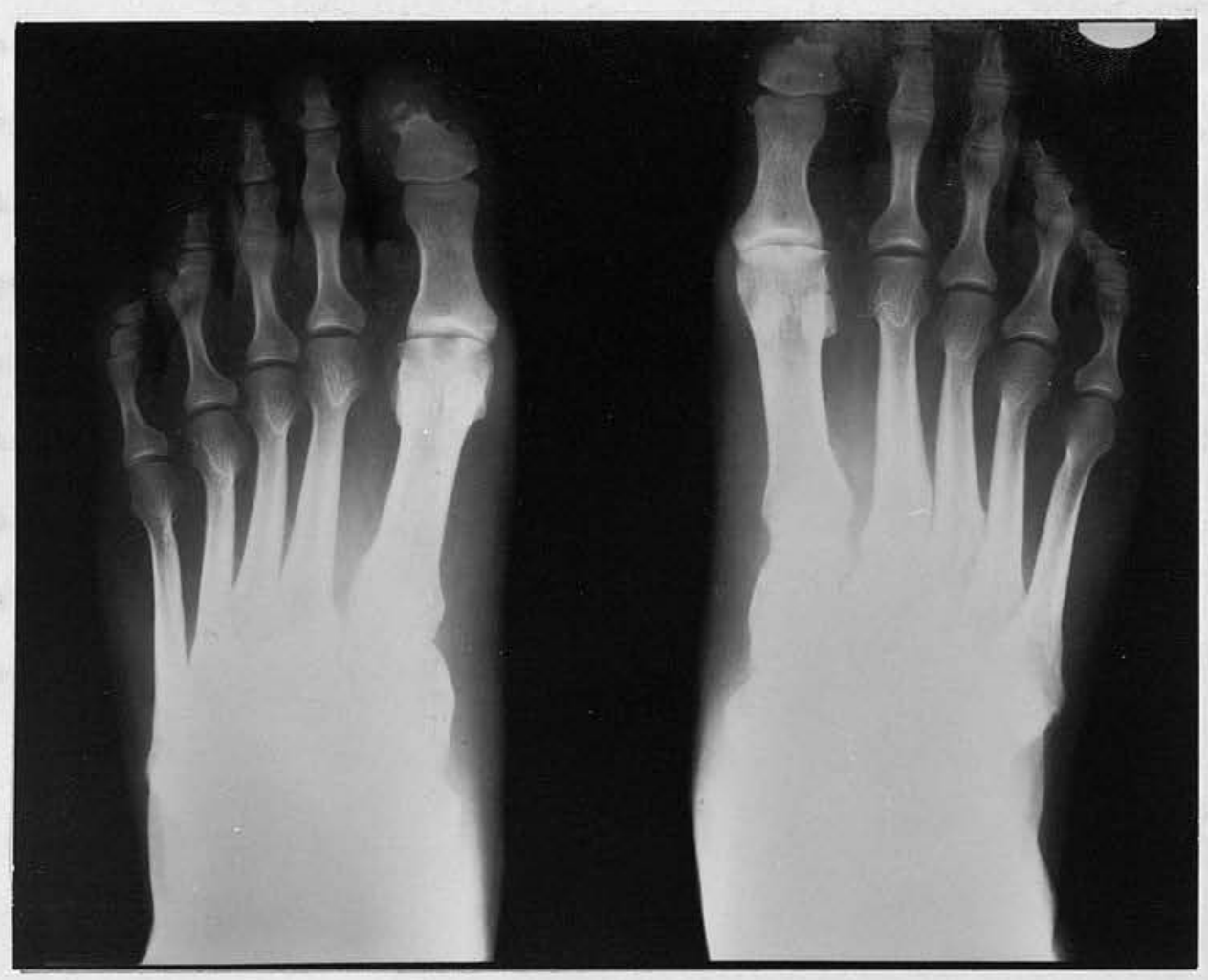

Fig。 7

MR。A.D. Vinyl Chloride Monomer (VCM) Worker. Radiograph of feet showing acro-osteolysis of the terminal phalanges of both big toes, a large erosion in the head of the left first metatarsal bone and small erosions in the head of the $\mathrm{R}$ first metatarsal bone and the $\mathrm{R}$ medial and intermediate cuneiform bones.

The radiograph of the pelvis revealed large erosions around both sacro-iliac joints at the tips of the greater trochanters and along both ischial tuberosities.

Films of the mandible revealed considerable erosion of both ascending rami causing marked thinning of the bone. On the left side this extended upwards to involve the condyle. 
process. It is given as an example of Raynaud's phenomenon presenting in a new process one hundred years after Raynaud's first description. The author (W.T.), called in to assist and to evaluate the vibration hazard associated with the autoclave cleaning, had no difficulty in assessing the small part, if any, played by hand-held tools. The disease is a multisystem one with simultaneous involvement of blood vessels, subcutaneous tissue and bone, the aetiology of which is as yet obscure (Taylor, 1976). 


\section{Skin Necrosis or Gangrene of the Digits}

The clinical case reports contained in

Maurice Raynaud's Thesis of 1862 were all characterised by advanced circulatory disturbances with gangrene of fingers and toes. He believed that increased sympathetic vasomotor activity led in time to such vasoconstriction of the digital arteries that the blood supply was diminished and finally non-existent, leading inevitably to tissue necrosis of the finger tips. In ascribing gangrene of the finger tips to Raynaud's disease (or phenomenon), all other causes of digital artery obstruction require to be excluded, necessitating a full medical examination. Obstructive vascular lesions, for example, have not been excluded in the majority of cases of gangrene quoted in the literature.

Teleky in the 1925 Annual Report of the Occupational Medicine authorities, cited by Seyring (1931), described two cases both users of compressed air hammers in fettling operations. The first aged 52 years with 12 years exposure, had suffered Raynaud's phenomenon for 7 years, developed gangrene of the tip of the left 4 th finger which required amputation. The second, aged 62 years; had permanently blue-black fingers in cold weather..Eleven cases of traumatic occlusive arterial disease of the dominant hand in vibration exposed workers were reported by Barker and Hines (1944). Five of these had small ulcers or scarring of the tips of the fingers and haemorrhages under the nails. In 1964, Kuzelova 
reported gangrenous changes in the fingers of two uranium ore mine workers with a long, unspecified drill usage time.

These cases are insufficiently documented to be of value. That the final stage of Raynaud's phenomenon in pure uncomplicated cases, whether of Primary or Secondary, is uncommon, can be deduced from the lack of published cases. The author asked for such cases through the medical press (BMJ, 1974) but received no replies. Two cases, which came to survey with advanced pathology are described in the Appendix.

In all cases in which a meticulous anatomical study has been made, gangrene has been associated with an obstructive vascular lesion, commonly a thrombosis, following vascular lesions of the vessels with advanced pathological changes in the media and especially the intima. The question which remains as yet unanswered is "Can long standing increased sympathetic vasoconstrictor tone alone give rise to these severe (to the point of obliteration) secondary vascular changes?" (Thulesius, 1976). 


\section{VIBRATION MEASUREMENT}

In the field of occupational medicine there is growing concern regarding the medical hazards associated with intense noise and vibration, both of which may be regarded as aspects of the same continuum. In intense noise the body is shaken to such an extent that sensory receptors for touch pressure and joint movements are stimulated causing disorientation. If the body or parts of the body such as hands are exposed to or are in contact with mechanical vibration, sensory, circulation and vision irregularities may arise. (Von Gierke, 1961, Guignard, 1965, Griffin, 1974).

The medical problems, however, associated with hand-arm have remained unexplored. The reason for the present lack of positive information lies in the complexity of the hazards associated with vibration stimuli since research covers various disciplines - physics, physiology, anatomy and engineering.

To understand the processes involved in the hand-arm system exposed to vibration, it is necessary to correlate the measured vibration stimuli with the observed medical changes. As a first step therefore in alleviating the medical effects of vibration, the characteristics of the vibration must be known.

But for the work of Agate and Druett (1947) little attention has been paid to the vibration characteristics of various industrial processes known to give rise to Raynaud's phenomenon. Reviewing the 
technical problems arising in the field measurement of vibration applying to the hand-arm system, Acton (1974) emphasised the lack of agreement and standardisation of vibration measurement methods and of criteria for the assessment of exposure. Furthermore there has been no clear indication of these aspects of vibration which is responsible for the clinical damage. Hempstock and O'Connor (1974) studied a number of engineering processes hoping to define the vibration characteristics known to cause damage to the circulation in the hands but the collection of the vibration data and the subsequent analyses presented numerous technical difficulties, particularly associated with impact or impulse sources of vibration found in pneumatic and electrical hammers, chisels and drills.

Vibration Measurement. The parameters measured in the $1930^{\prime} \mathrm{s}$ were (a) surface displacement, detecting the oscillatory motion of a point on the surface to which a suitable sensor is attached, and (b) vibration frequency. Displacement has been found technically difficult to measure directly so that the velocity of the oscillatory movement or its acceleration have been adopted in practice. Both metric and imperial systems of units are in common usage but difficulties with units may be successfully overcome if acceleration is used, as this may be expressed in terms of acceleration due to gravity $(\mathrm{g})$. Conversion of acceleration measurements to velocity or displacement is invariably achieved by use of the following relationship: Acceleration $=2 \pi f($ velocity $)=4 \pi^{2} f^{2}$ (displacement) 
This standard formula relationship holds only for sinusoidal vibration and leads to errors if used for impact or complex sources of vibration. It assumes an accurate knowledge of the frequency characteristics of the vibration. Sinusoidal sources of vibration excitation produce totally frequency dependent spectra with a fundamental frequency equal to the sinusoidal repetition ratio. The principal sources of sinusoidal vibration encountered in industrial machinery or hand-held vibratory tools are the out of balance forces of rotating machines and magnetic excitation. The classical example of out of balance forces is the power chain saw used in forestry operations.

Transducers. Transducers are available giving outputs to each of the three parameters discussed above acceleration, velocity or displacement. Since 1970 efficient electronic integrators are available enabling the output to be read off directly as velocity or displacement. Alternatively accelerometers are available (Fig. 7 ), an electromechanical transducer which gives at the output terminals a voltage proportional to the acceleration to which it is subjected. The active element consists of two piezo-electric discs separated by a contact plate. When the ferro-electric ceramic material or quartz is subjected to vibration the force applied by the mass on the discs varies and is proportional to the acceleration to which the mass is subjected. A voltage is thus generated across the discs which is proportional to the force and thus to the 
acceleration of the mass.

A typical measurement system is illustrated

in Fig. 7 .

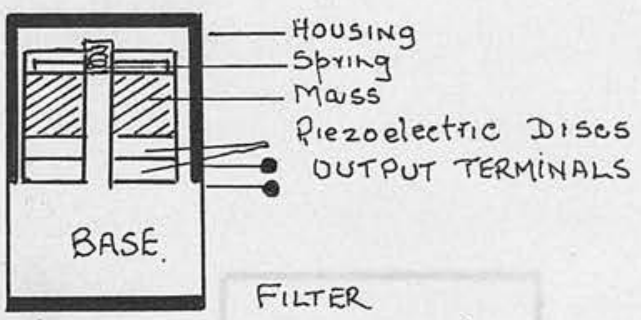

Schematic dron'wing of the construction of aN ACCELERometer.

Accelerometer

II

$$
\text { Pre amplifier }
$$

III

$$
\text { Frequency Analyser (Bandwidth) Real-time analyser }
$$

IV

$$
\text { Read-out (Recorder) }
$$

Throughout this investigation of the medical aspects of vibration-induced white finger in the hand-arm system, vibration measurements of the various processes (grinding, sawing) and of hand-held tools (pneumatic chippers) have been made using a Bruel and $\mathrm{Kjaer}$ triaxial accelerometer (Type 4340) attached rigidly to the vibrating surface and measuring in three mutually perpendicular directions (X, Y, Z). In the field the amplified signal was recorded on an Elliott Tandberg frequency modulated tape recorder with a flat frequency response between 2 and $3000 \mathrm{~Hz}$. Analysis of the recorded 


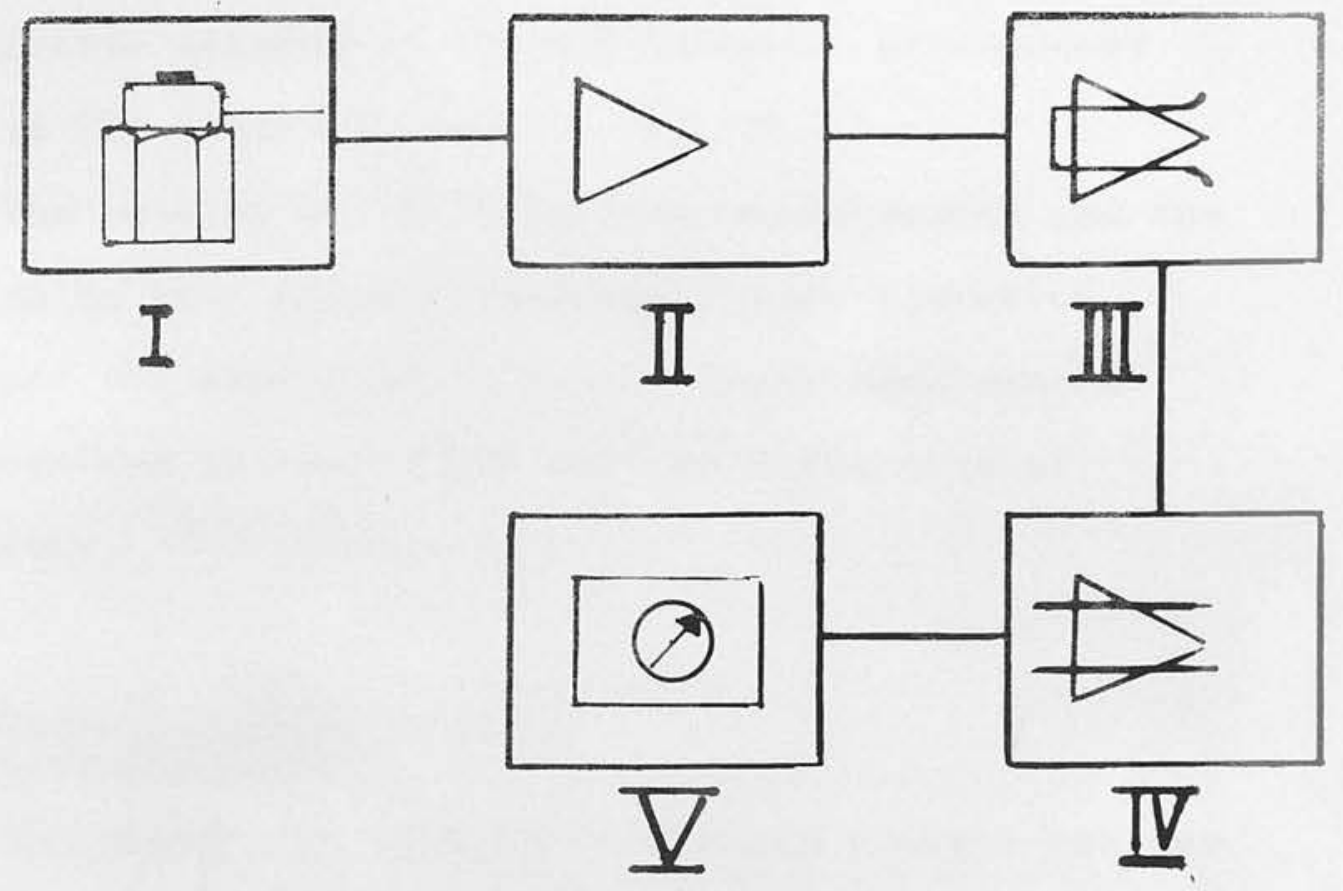

\section{ACCELEROMETER}

II PRE.AMPLIFIER

III EM.TAPE RECORDER

IV EREOUENCY ANALYSER.

$\nabla$ READ OUT RECORDER

FIE. TA VIBRATION MEASUREMENT 
signal was then done in the laboratory with a Bruel and Kjaer real-time analyser (Type 3347) which measures the r.m.s. values in all the third octaves from $12.5 \mathrm{~Hz}$ to $3000 \mathrm{~Hz}$ simultaneously. The recorded signal was then stored in a Digital Event Recorder and recycled until a satisfactory time average of the spectrum was obtained. A schematic diagram of the experimental arrangement used in the study is shown in Fig $7 \mathrm{~A}$.

The results of the vibration measurements and the spectra in this project (and for future vibration surveys) are expressed as r.m.s. (root mean square) acceleration in metres per $\sec ^{2}$ as a function of frequency.

\section{Difficulties encountered in}

\section{Vibration Measurement}

Throughout the 1969-1976 research project serious technical difficulties were encountered which have been responsible in large part for the lack of progress in measuring and controlling the amount of vibration energy to which human subjects are subjected. The problems were (a) the choice of accelerometer, (b) the method of mounting and (c) the stability of the crystal giving rise to fluctuating base lines, instability and inability to return to zero, (d) destruction of the accelerometers when exposed to high acceleration values particularly with high impact vibration sources. In order not to change the characteristics of the motion of the object, it is necessary that the mass of the accelerometer used 
be small in relation to the mass of the object. In low energy sources it is sufficient to mount the accelerometer with a jubilee clip but in high impact sources a steel stud with a plastic washer tapped directly into the workpiece is necessary. Since piezo-electric accelerometers have a high output impedance problems have also arisen with disturbing signals induced in the connecting cables either from vibration of the cable itself or because faulty grounding has created an earth loop which in turn induces hum.

in reciprocating pneumatic tools and during the fettling of castings acceleration peaks in excess of $1000 \mathrm{~m} / \mathrm{s}^{2}$ may be present. On a pneumatic paint scraper acceleration transients upwards of $4000 \mathrm{~m} / \mathrm{s}^{2}$ have been observed on an oscilloscope at frequencies around $30-40 \mathrm{kHz}$, a region well outside the VWF frequencies investigated in this project. The piezo disc prototype mechanical filters ( $\frac{1}{2} "$ dia metal disc bonded to a plastic disc $3 / 32^{\prime \prime}$ thick) filter out these offending high frequencies. From 1975 standards have been set and the following must be specified -

(a) method of loading the tool,

(b) method of holding the tool and simultaneous measurement of grip and static force,

and(c) repeatibility of measurements and the test tolerances to be specified. 
The research work on Raynaud's phenomenon commenced in 1968 with a survey of chain saw forestry workers in the West of Scotland, following complaints of vibrationinduced white finger by the sawyers. This work was extended to cover all forestry employees in Britain in 1969 and reported by Taylor et al (1971). By 1970 the use of chain saws in forestry in Britain initially confined to felling and cross-cutting was increased with the introduction of debranching (snedding) by chain saw in 1967. The saw usage time or vibration exposure through the handles to the hands thus showed a steady increase from $1 \frac{1}{2}$ to 2 hours per day (late 1950's) to $5-5 \frac{1}{2}$ hours (in Britain) and $6 \frac{1}{2}-7 \frac{1}{2}$ hours (Axellsson) in Sweden. This new tool now used universally in timber operations throughout the $1960^{\prime} \mathrm{s}$ proved to be a potent source of Raynaud's phenomenon in Britain, Sweden (Kylin et al 1968), Australia (Barnes et al 1969), Japan (Miura et al 1966) and New Zealand (Allingham and Firth 1972).

The Dundee research showed that the prevalence was highest in those areas where chain saws had been in use for the longest period. The Forestry Commission (Britain) offered facilities for medical examination of saw users at one of their largest feeling centres, Thetford Chase, Norfolk. This population included men with the longest exposure time to chain saw vibration in the $U_{0} K$. Examined in December 1969, the same population was then examined prospectively in January of 1971, 1972, 1973, 1974, 1975 and 1976。 Whilst the Forestry VWF Survey 
was being carried out, the author was urgently requested to examine a population of pedestal grinders, a large proportion of whom had complained of white finger attacks during the winter of 1969. A grey iron foundry had been in existence at Cwmbran since 1800. In 1960 a malleable foundry was established adjacent and on survey a very high proportion of the pedestal grinders had Raynaud's phenomenon. There was in this Works a well equipped and staffed medical centre with a weekly visit of a General Practitioner but no case of white finger had been reported until this epidemic from June-December 1969. Management remained unaware of Raynaud's phenomenon and no case had been reported in the population of pedestal grinders in the malleable foundry. On investigation it was ascertained that until 1965 silicone carbide wheels had been used in both foundries but in April 1965 the malleable foundry changed to zirconia wheels using a more abrasive, stiffer bonding material. Subsequently all the pedestal grinders on zirconia wheels developed Raynaud's phenomenon but no complaints had been received until the author carried out the first survey of VWF in 1969, on this population which hitherto had been unaware of vibration-induced white finger In their Interim Report on the Vibration Syndrome in 1970, the Industrial Injuries Advisory Council asked for further data on and research into vibration-induced white finger (VWF) in employees handling vibration tools. The author was asked by the Chief Medical Adviser, Department of Health and Social Security to set up a research project to provide further evidence on VWF for the Industrial 
Injuries Advisory Council. The following areas were required to be investigated:

(a) To investigate the degree of severity of the vibration signs and symptoms - the extent of interference with work and social activities。

(b) To answer the question whether severe VWF cases leave their employment because of the severity of their signs and symptoms.

(c) To what extent a change of occupation brought about by VWF affects the level of earnings.

(d) Whether the signs and symptoms of VWF are reversible after the vibration stimulii have been withdrawn.

(e) The D.H.S.S. Committee wishes this enquiry to extend beyond the area in which the author has already reported, namely chain saw employees. 
The following Research Team was organised by

the author -

CHAIRMAN AND LEADER OF RESEARCH TEAM

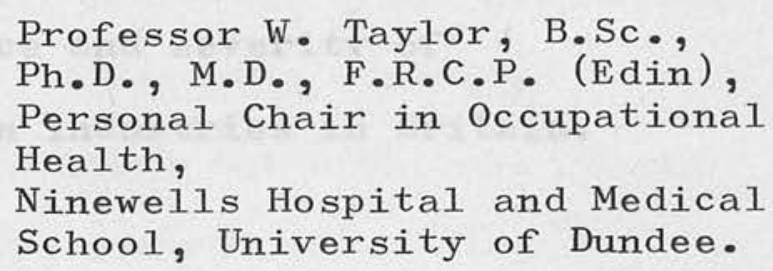

(A) MEDICAL SURVEY TEAM

Professor W. Taylor

Dr. P.L. Pelmear, M.D., M.F.C.M., D.P.H.,

D.I.H., D.R.C.O.G., Senior Medical Officer,

G.K.N. Forgings and Castings Ltd., Bromsgrove

Dr. P.B. James, Ph.D., M.B. Ch.B., D.I.H.,

Lecturer in Occupational Medicine,

University of Dundee.

(B) VIBRATION MEASUREMENT AND STANDARDS

Dr. T.I. Hempstock, B.Sc., Ph。D.

Department of Applied Physics,

University of Salford

Mr. D.E. O'Connor, M.Sc. do. do.

Mr. R。 Kitchener, B.Sc.,

Group Technological Centre, Wolverhampton

(c) RADIOLOGISTS

Dr. R.O. Murray, M.D., F.R.C.P., D.M.R.,

Consultant Radiologist, Royal National Orthopaedic

Hospital, London.

Dr. G.F.A. Howie, M.D., D.M.R.D., F.F.R.,

F.R.C.P. (Edin), Senior Lecturer in Diagnostic

Radiology, Ninewells Hospital and Medical

School, University of Dundee.

Dr. J.K. Davidson, M.P•, F.R.C.P., F.R.C.R.,

Consultant Radiologist, Western Infirmary, Glasgow.

(D) PHYSICS

Professor J.H. Martin,

Department of Biophysics, University of Dundee.

(E) STATISTICIANS

Dr. J.C.G. Pearson, B.Sc., Ph.D., M.Sc. (Harvard)

Lecturer in Medical Statistics, Department of

Community \& Occupational Medicine, University of Dundee

Mrs. S.C. Murray, M.A., do. do. do. 


\section{$\underline{(1968-1976)}$}

1. To determine the prevalence and severity of Raynaud's phenomenon in industries in Britain.

2. To evaluate clinical tests for the severity of Raynaud's phenomenon.

3. To correlate the vibration characteristics of the industrial processes producing Raynaud's phenomenon with the prevalence of vibration white finger and thus to establish safe working vibration limits for hand-held vibratory tools.

4. To ask the Health and Safety Executive to derive a Code of Practice for (a) reducing the exposure of work people to vibration with particular reference to the hand-arm system and hand-held vibratory tools, and (b) preventing the severe complications of vibration to the hand-arm system (e.g. tissue necrosis of the terminal digits). 
The original plan for this study envisaged a survey of four populations of workers exposed to vibration with age and sex-matched controls. There was great difficulty obtaining sufficient numbers of suitable controls and a one to one matching was therefore not achieved. Where results for control groups are quoted, these subjects were all in a similar environment whether in factory or forest as the exposed subjects. In all a total of 19 populations of vibration exposed subjects were investigated in industries where Raynaud's Phenomenon was known to be an occupational hazard and a total of 2332 subjects were examined over the period 1969-1976 (Table 1.). For statistical analyses these were divided into four broad categories -

1. CHAIN SAWYERS (felling, snedding and cross-cutting).

2. GRINDING (hand and pedestal).

3. CHIPPING (with pneumatic tools).

4. SWAGING (of copper tubes).

A total of 1283 subjects in 18 population groups were examined in 1971 and 1972, of which 91 reported a mixed occupational history with exposure to different vibration characteristics from various hand-held tools. Since it was desired to confine the investigation to a single known source of vibration in order to equate vibration and exposure time, 1192 subjects remained for analyses. In this total there were 827 vibration exposed and 365 controls. The overall response rate was $97 \%$, the rates in different factories varying from 95 to $99 \%$. 
Site

1. Thetford

2. Cwmbran

(Foundry)

3. Kielder

4. Dumfries

5. Liverpool (Copper Tube Factory)

6. Birkenhead (Propeller Factory)

7. Leamington (Foundry)

8. Halesowen (Foundry)

9. Rosyth (Dockyard)

Riveting

Caulking

10. Bromsgrove Grinding (Forge)

Swaging

Grinding

Grinding

Fettling

Grinding

Fettling
Forestry

Chain Sawyers

Grinding

Fettling

Forestry

Chain Sawyers

Forestry

Chain Sawyers

Fettling

149
107

$1971,72,73$

70

1972

Date of

Survey

68

1971

$91 \quad 1971,1973$

33

1972

166

1972

1972 


\section{POPULATION GROUPS (Cont.)}

Site

Occupation

Number

Date of

Examined Survey

11. Witton

(Forge)

Grinding

15

1972

12. Old Cwmbran Grinding

(Forge)

36

1972

13. Smethwick

Grinding

(Forge)

14. Lincoln

Grinding

Forge

15. Great Barr Grinding (Forge)

(Forge)

16. Darlaston Grinding
(Forge)

Grinding

(Forge)

18. Ayr

(Forge)

Miners

Blackdene

)

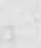

Allenhead

Groverake ) 


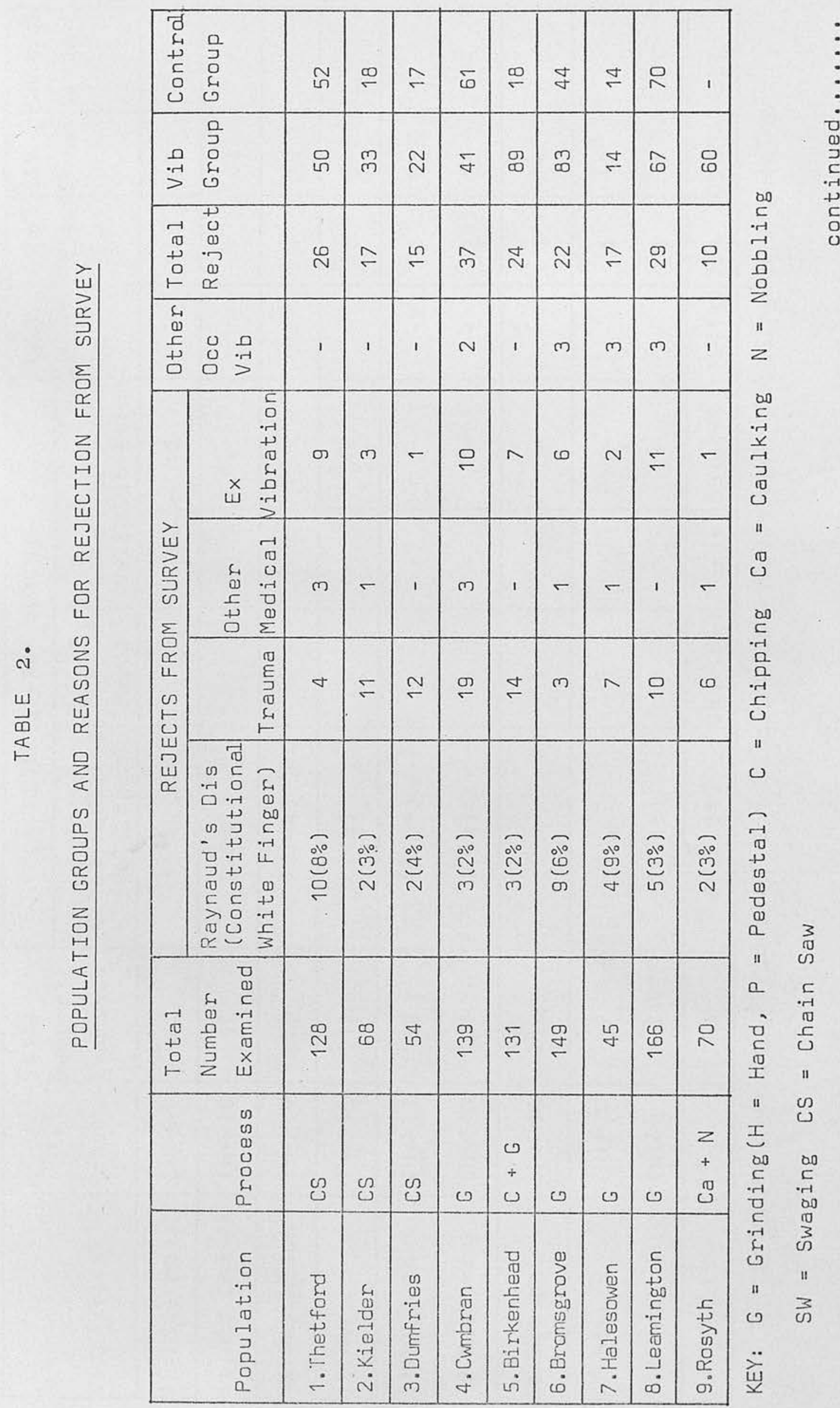




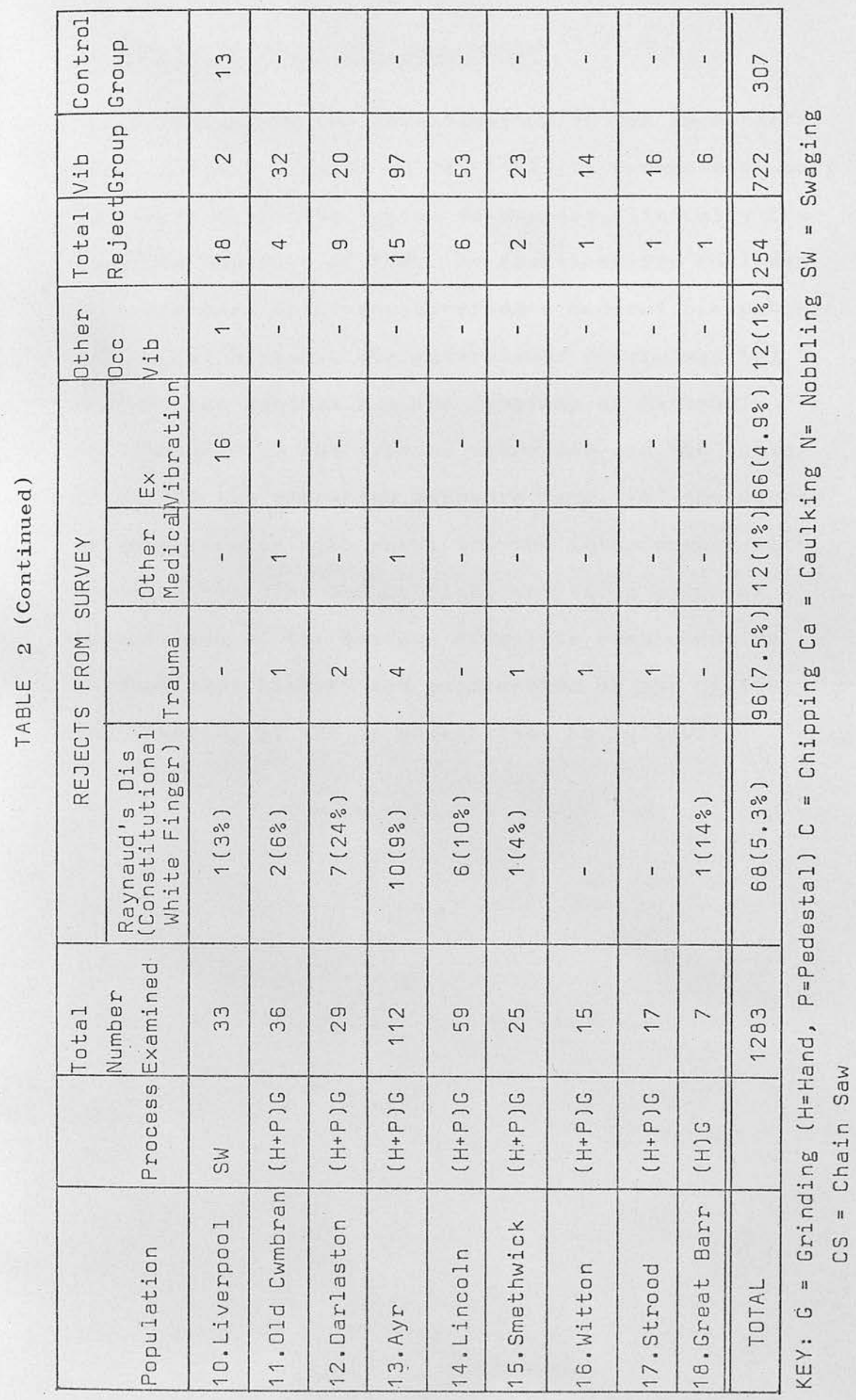




\section{STAGES OF RAYNAUD'S PHENOMENON}

Following the investigation of VWF in Forestry Chain Sawyers (Taylor et al, 1971) it became necessary to evolve a grading system to express clinically the stage of severity of VWF. By questionnaire followed by a personal interview covering a medical occupational and social history, the interviewer determines (a) whether the subject has the symptoms of Raynaud's phenomenon, (b) the type of vibration and the tools used, (c) the vibration exposure time, (d) the degree of interference with work, (e) the interference with social activities and hobbies, and $(f)$ a clinical examination of the hands. From this comprehensive occupational history and examination of the digits, the severity of VWF is categorised as follows: 
TABLE 3 .

2 . Stages of Raynaud's Phenomenon

Stage Condition of Digits

o No blanching of digits or other signs

$\mathrm{O}_{\mathrm{T}} \quad$ Intermittent tingling of digits

$\mathrm{O}_{\mathrm{N}} \quad$ Intermittent numbness of digits

1

2

3

4

Blanching of one or more fingertips with or without tingling and numbness

Blanching (with numbness) more extensive than fingertips. Attacks usually confined to the winter

Extensive blanching with numbness during attacks. Frequent episodes summer and winter

Extensive blanching All digits Frequent episodes summer and winter
Work and Social Interference

No complaints

No complaints

No complaints

No interference with activities

No interference at work. Slight or minor interference with home and social activities.

Interference with work at home and with social activities. Restriction of hobbies.

Occupation changed to avoid further vibration exposure because of severity of signs and symptoms.

Note: Complications are not used in this grading. 
When, for example, a forestry worker commences on chain sawing (Stage 0) and as the vibration exposure time increases, the sawyer will pass through the tingling $\left(O_{T}\right)$ and numbness $\left(\mathrm{O}_{\mathrm{N}}\right)$ stages to Stage 1. The interval between Stage 0 and stage 1 is known as the LATENT INTERVAL, usually measured in years. The value of this figure is that it gives an indication of the amount of vibration entering the hands - the higher the vibration in terms of acceleration (metres per $\sec ^{2}$ ), the shorter the latent interval. As the vibration exposure time increases, attacks of white finger occur more frequently especially in the early morning or going to work on a bicycle or motor-cycle. Touching a cold steering wheel early morning will precipitate an attack. The morning break (rest period) also brings on attacks if the rest is in an unheated shelter. With further vibration exposure there is interference with activities outside their work associated with their leisure and hobby activities gardening, fishing, bathing (even in summer), car washing and woodwork or car maintenance in the evenings - all attacks being precipitated by a cold stimulus. In Stage 2 there is interference with these activities and in Stage 3 cessation of hobbies. In Stage 3 there is usually a permanent sensory loss reflected in the inability to do fine work. Fingers are reported to be "clumsy" and with increasing stiffness there is difficulty doing and undoing items of personal clothing (buttons) and in picking up and differentiating small coins (the British half-penny is particularly troublesome). In the final grading, Stage 4 in Table 3 , the severity of the signs and symptoms of 
Raynaud's phenomenon and the resulting interference with work, home and recreational activities is such that the subject changes his occupation and thereby removes himself from further vibration exposure. In severe cases, however, Raynaud's phenomenon remains stationary or increases whereas in early Stages 1 or 2 there is a slow but definite improvement as judged by the decreasing number of attacks of VWF. 
1. Forestry Chain Sawyers (felling and debranching) with resulting Raynaud's Phenomenon. Figs. 8, 9, 10 and 11 .

2. Grinding (Pedestal). Figs. 12 and 13.

3. Chipping (Pneumatic Tools). Figs 14 and 15.

4. Swaging of Copper Tubes. Figs 16 and 17 . 


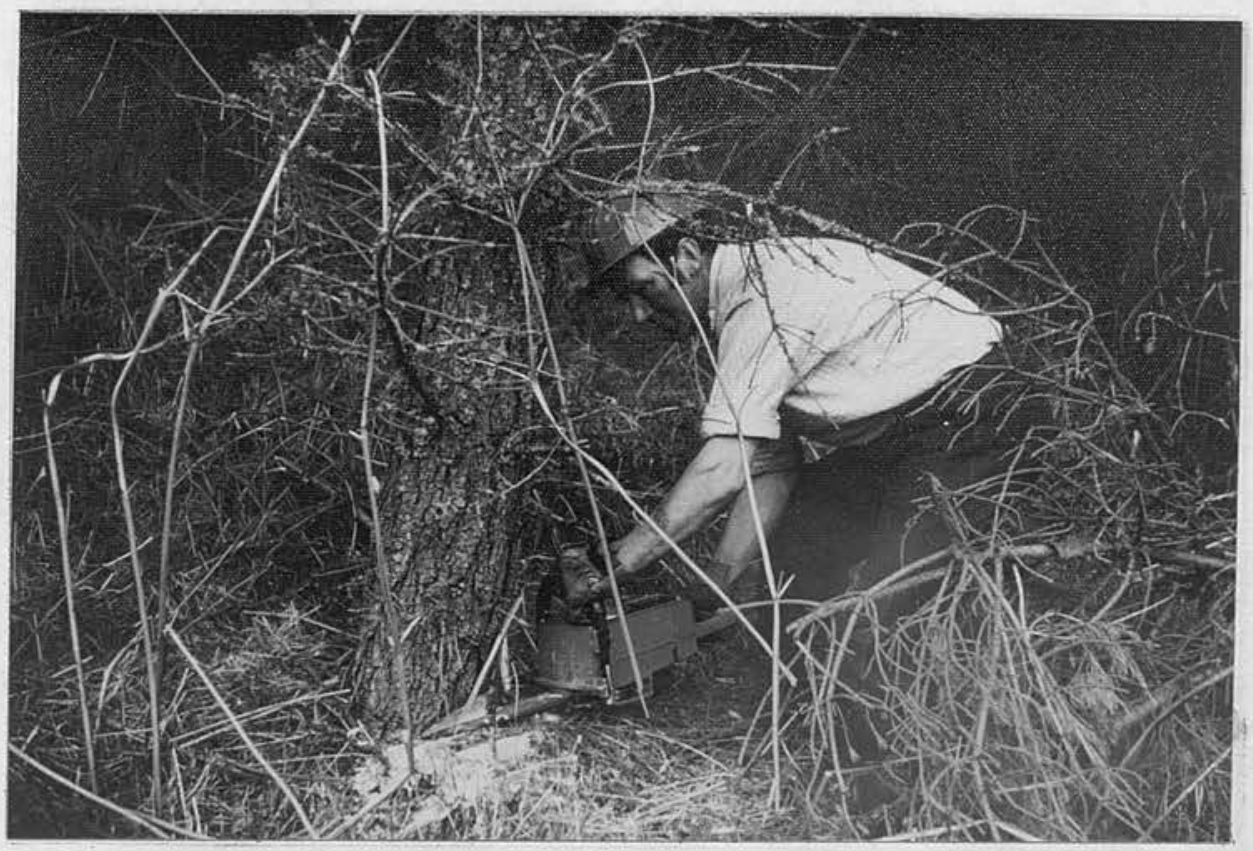

Fig. 8

CHAIN SAW OPERATOR - FELLING

Forestry Commission (Britain)

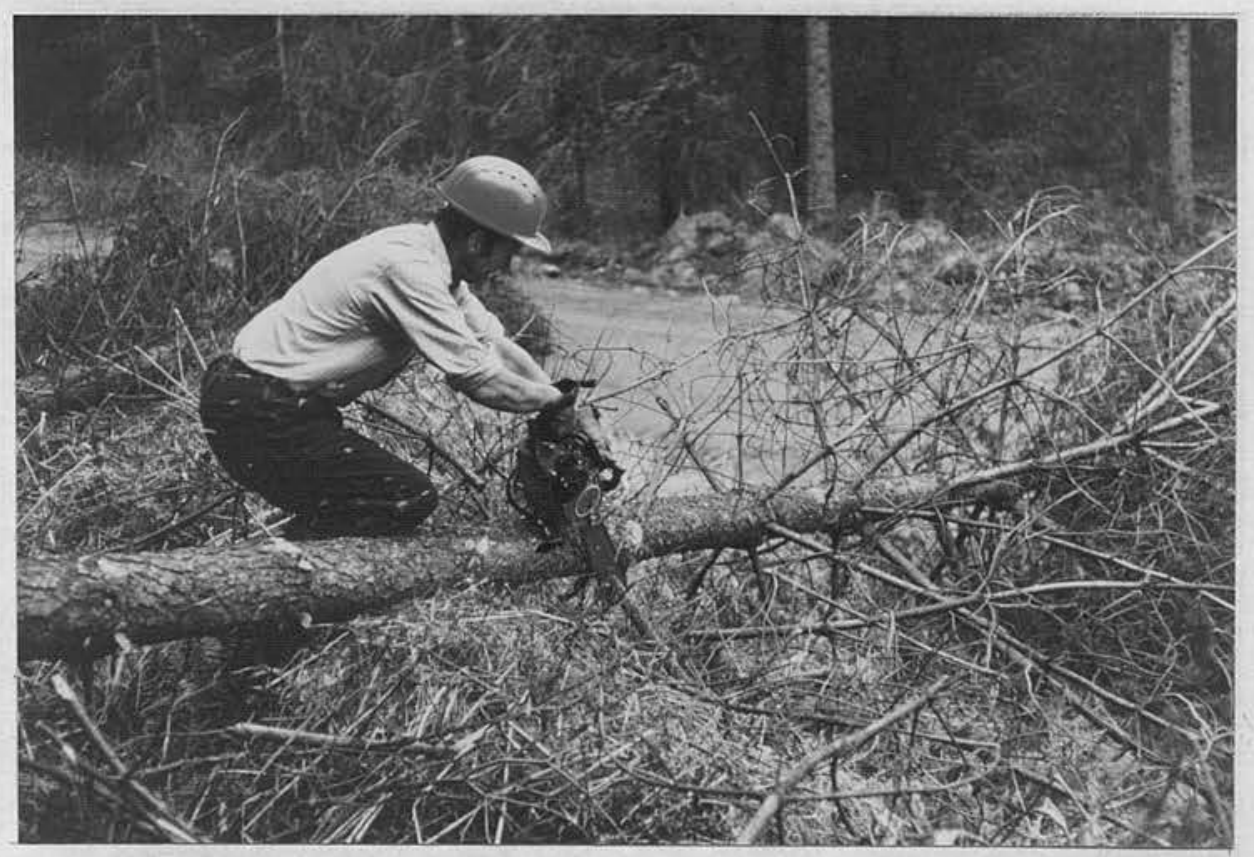

Fig. 9

CHAIN SAW OPERATOR - DEBRANCHING

Forestry Commission (Britain) 


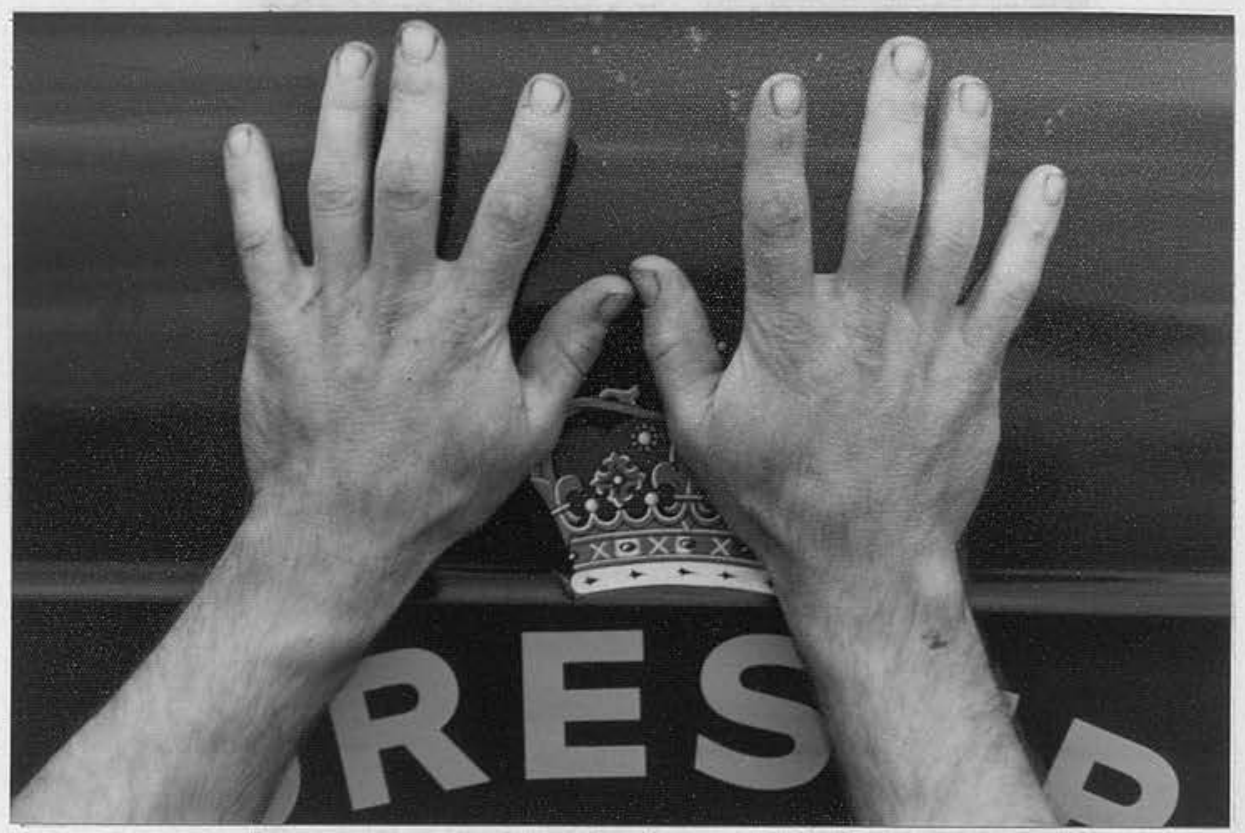

Fig. 10

RAYNAUD'S PHENOMENON IN A CHAIN SAW OPERATOR

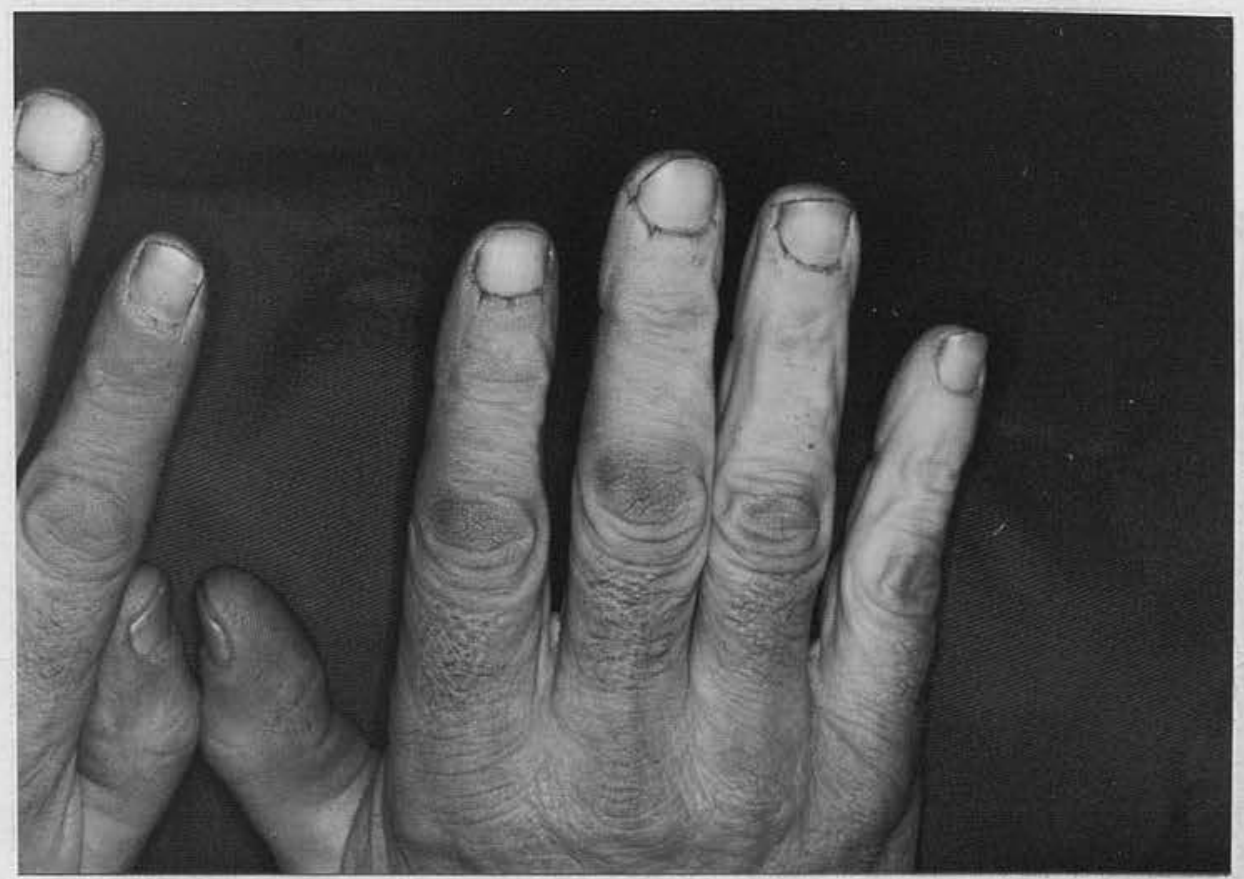

Fig. II

RAYNAUD'S PHENOMENON HYPERAEMIC PHASE PRIOR TO RETURN OF CIRCULATION 


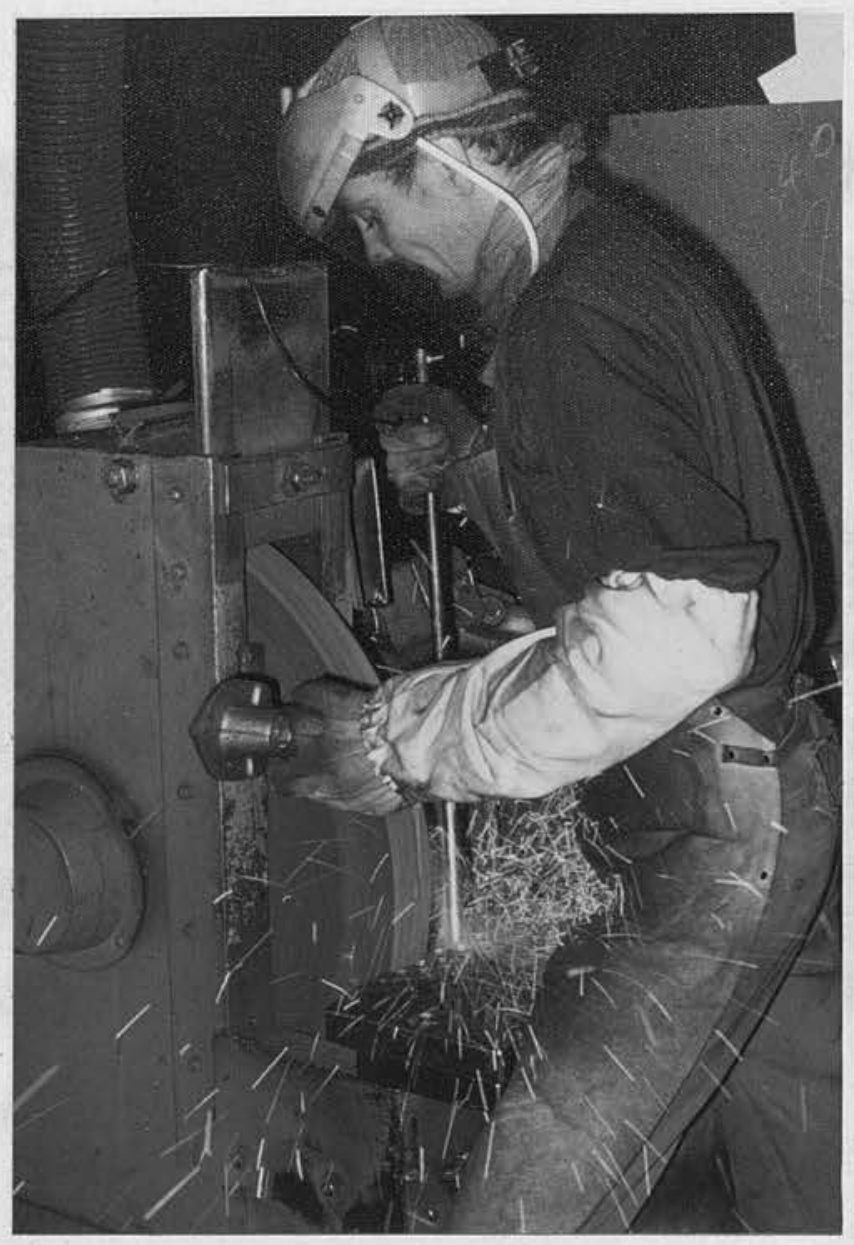

Fig. 12

PEDESTAL GRINDING - CASTINGS

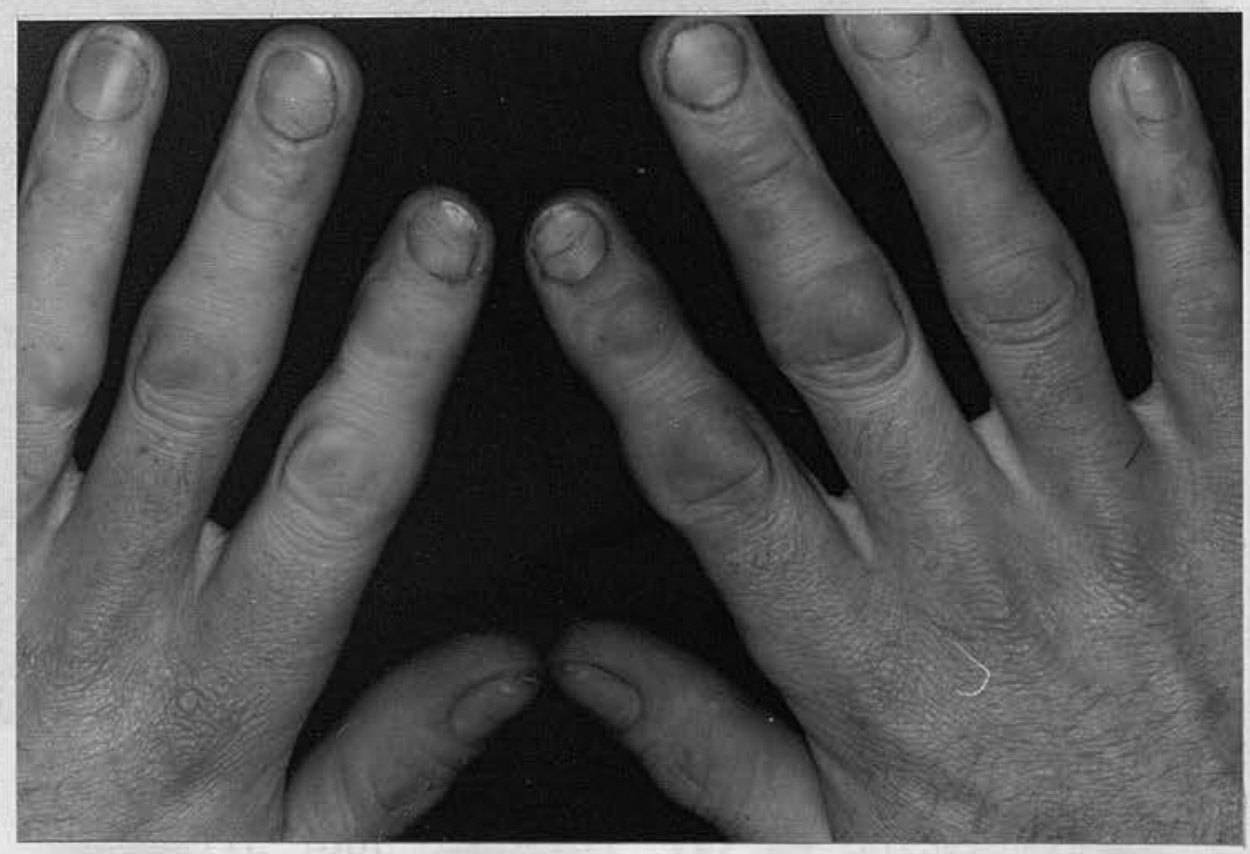

Fig. 13

PEDESTAL GRINDER - VWF and DORSAL PADS. 


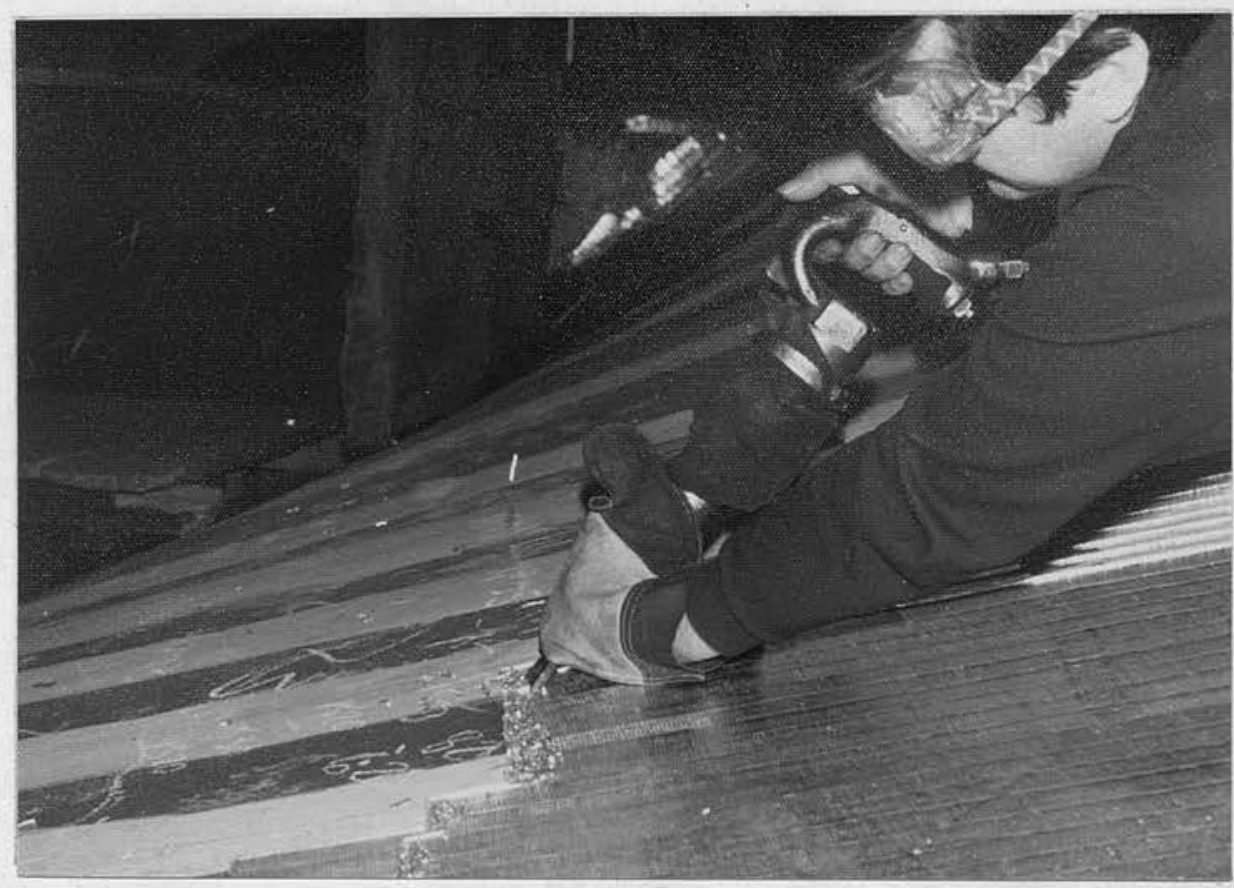

Fig. 14

PNEUMATIC TOOL OPERATOR - CHIPPING

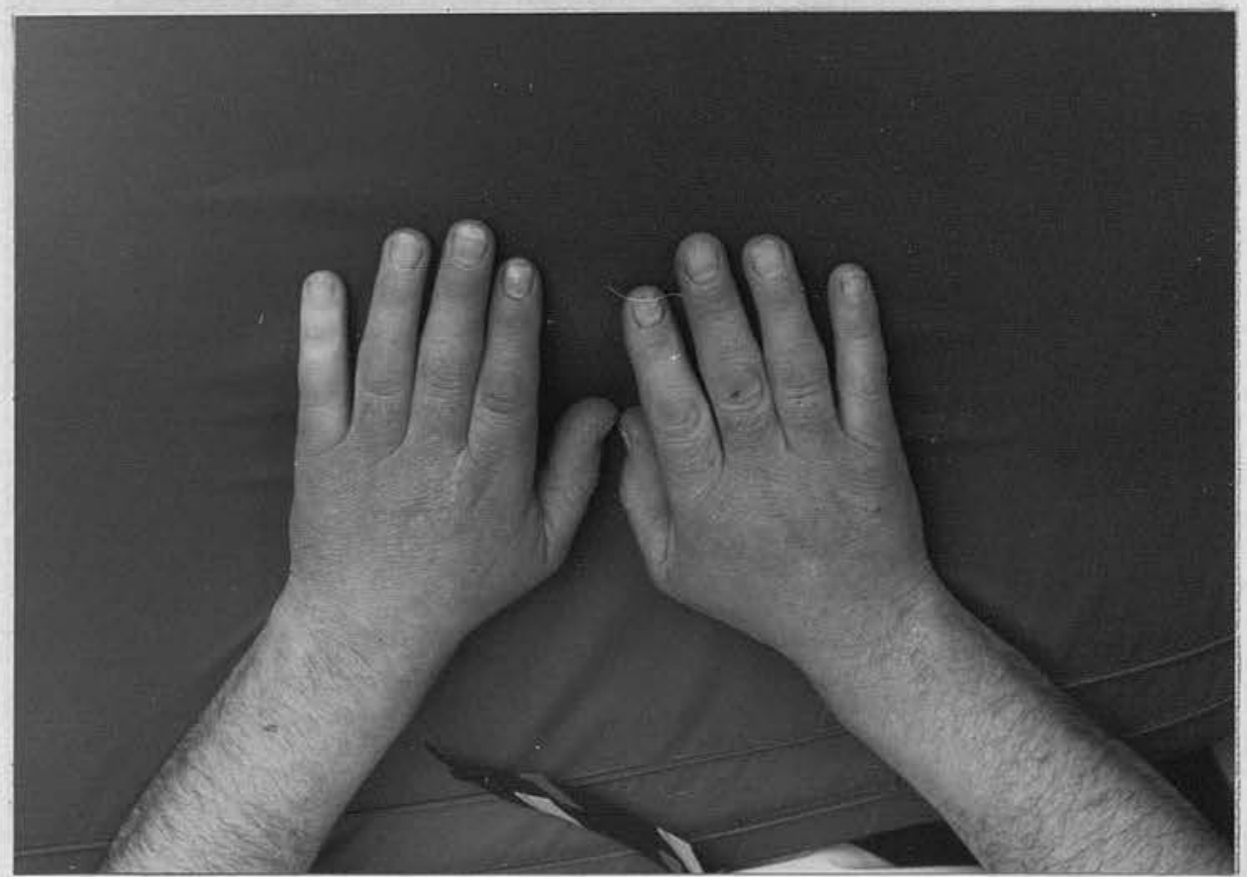

Fig. 15

PNEUMATIC TOOL OPERATOR VWF ON CHISEL FINGER 


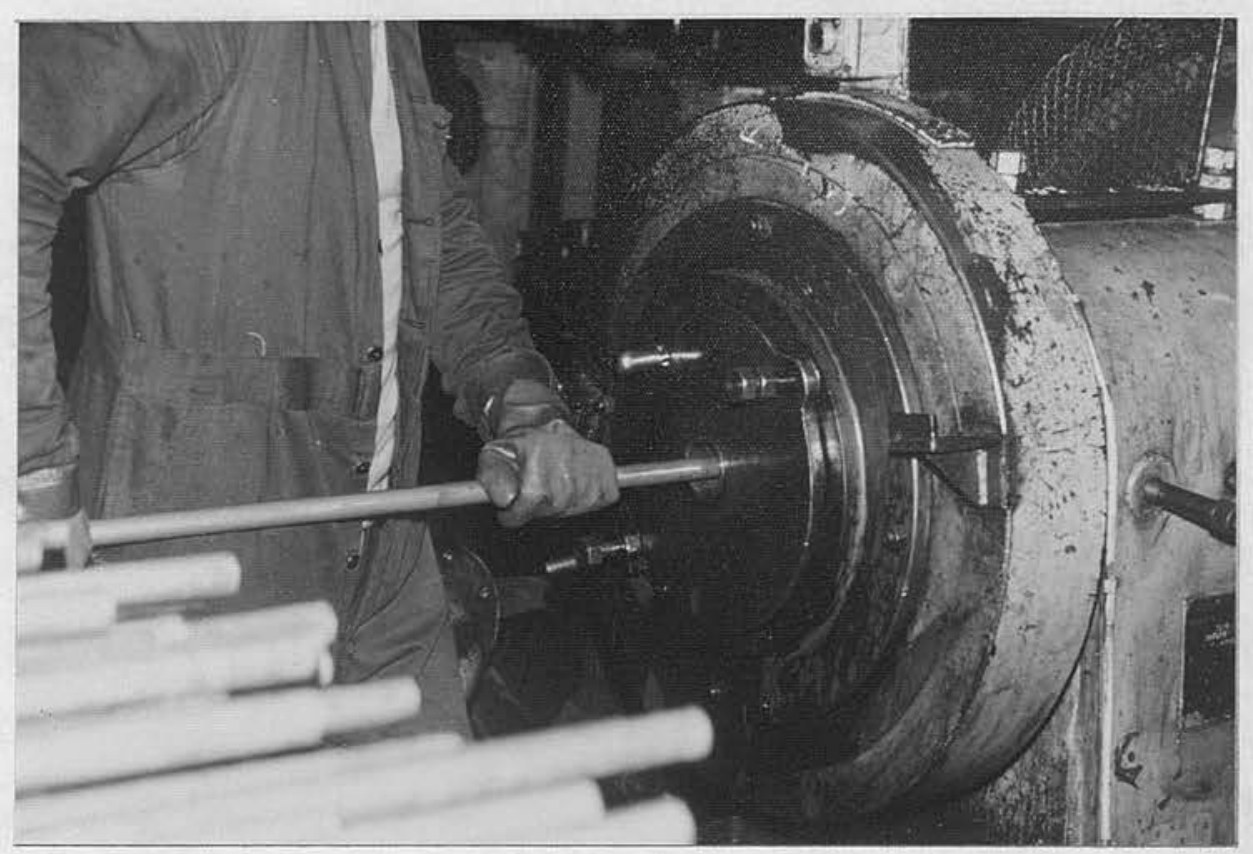

Fig. 16

COPPER TUBE SWAGING HAND-HELD

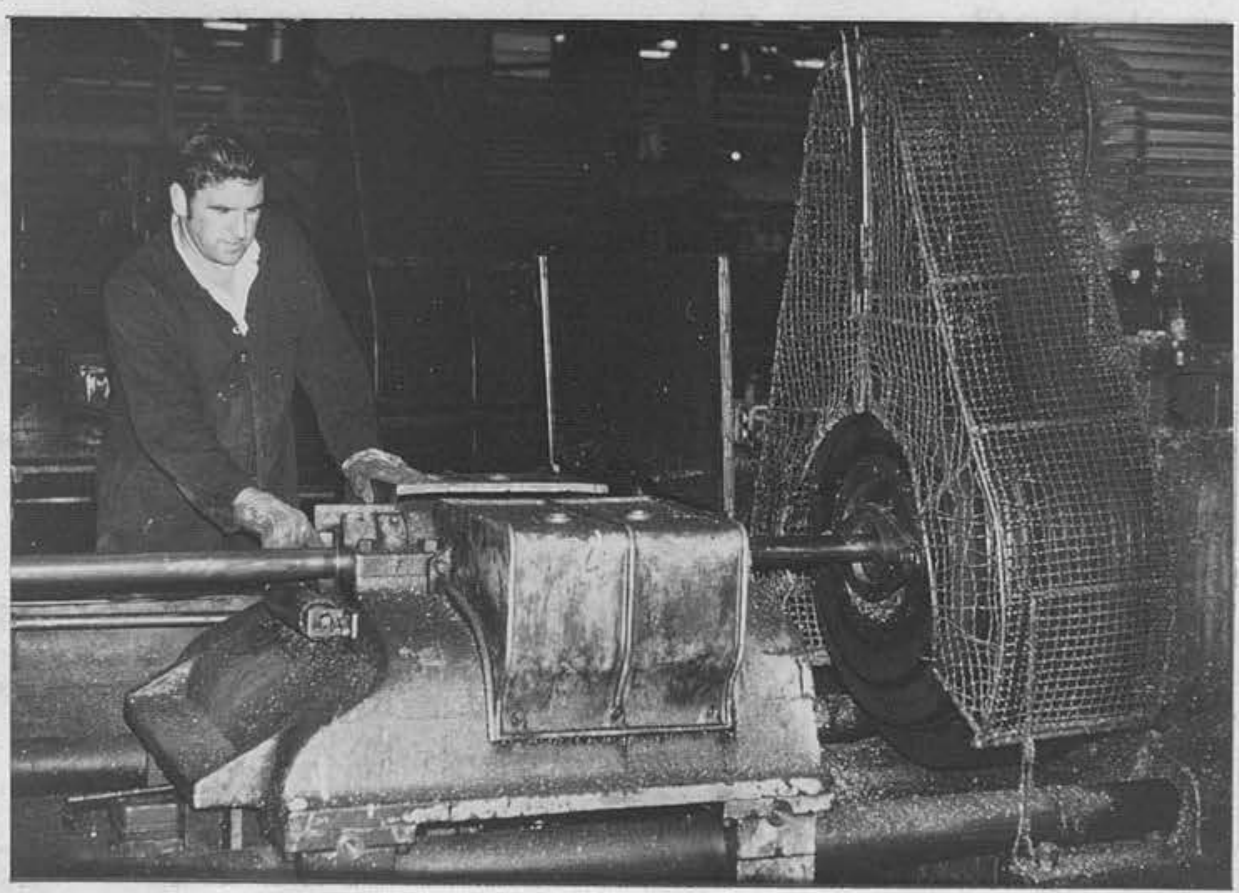

Fig. 17

COPPER TUBE SWAGING AUTOMATED 
OBJECTIVE TESTS FOR DEGREE OF.

SEVERITY OF RAYNAUD'S PHENOMENON.

For the majority of people exposed intermittingly to noise and vibration, the occupational hazard arising is trivial in the sense of loss of faculty or ability to carry out a normal day's work. With continuous exposure, however, as in industry 8 hours per day/5 days per week for a life-time (say 30 years), the occupational risk may be considerable. In the case of noise the resultant noise-induced deafness is measureable by audiometry, but in vibration no satisfactory objective test for assessing the severity of Raynaud's phenomenon or the degree of disability has yet been found. In previous attempts to prescribe the Vibration Syndrome under the National Insurance (Industrial Injuries) Act, 1946 - the 1954 and 1970 Reports - the difficulty of distinguishing Raynaud's phenomenon arising from industrial causes (including vibration) from Primary Raynaud's disease was emphasised (occupational from non-occupational). The necessity of finding an objective test for VWF was also emphasised in these Reports in order to avoid assessing disability based solely on the subjects own occupational history. The subjects own history of attacks of VWF and their progression over years would not be accepted for prescription purposes.

Hence the main emphasis of this study was on a search for a clinical, objective test for VWF and the following programmes were carried out: 
1. MEDICAL EXAMINATION

2. FINGER CIRCUMFERENCE MEASUREMENT

3. SKIN SENSORY TESTS

(a) DEPTH SENSE AESTHESIOMETER

(b) TWO-POINT DISCRIMINATION

4. SKIN TEMPERATURE: HOT AND COLD WATER TMMERSION TESTS

5. THERMOGRAPHY : HEAT EMISSION DETECTION

6. BONE CYSTS (X-RAY OF HAND). BONE DENSITY

7. BRACHIAL ARTERIOGRAPHY

8. VIBRATION MEASUREMENT - VIBRO TACTILE SENSATION

9. GRADING INTO STAGES (TWO INDEPENDENT ASSESSORS).

\section{Medical Examination and Blood Pressure}

The object of the medical examination was to exclude Primary Raynaud's Disease and all other Secondary causes of Raynaud's phenomenon such as hypertension, trauma and lacerations and connective tissue diseases (scleroderma, rheumatoid arthritis). Due to the time available for examination away from work (20-30 minutes), it was not possible to complete an exhaustive medical examination, the main emphasis being on a previous history of white fingers, previous illnesses, previous trauma and any history of occlusive vascular disease or diabetes. 
2. Finger Circumference Measurements

Fingers subjected to continued vibration for long periods tend to swell and thicken, e.g. the formation of dorsal pads (Fig. 13 ). If the force factor (or grip), as in grinding of castings, is high, the fingers increase in size. Where it is low, as in chain sawing, the fingers remain more or less normal. The finger measurements were taken on a Geighy circumference finger measurer, at mid shift of the middle and proximal phalanges and at the proximal inter-phalangeal joint of the index and middle fingers of both hands. At Birkenhead (propeller factory), the 4th finger of the left hand was in direct contact with the vibrating chisel and this finger was included in this factory survey•

\section{Skin Sensitivity and Sensory Tests}

Two instruments have been developed by the neurologists for skin sensory tests.

The depth sense aesthesiometer consists of a ridge ( 1 m.m. wide) centred on a piece of clear acrylic ( $2 \times 10 \mathrm{cms})$ commencing flush with the plate at one end and rising progressively to $1 \mathrm{~m} . \mathrm{m}$. at the other. Along the ridge are marks at $\frac{1}{4}, \frac{1}{2}$ and $\frac{3}{4} \mathrm{~m} . \mathrm{m}$. intervals. The examiner grasps the patient's finger tip, presses it on the flat end at an angle of $45^{\circ}$ and moves the instrument slowly lengthwise. At first, with his finger on the flat, the subject feels nothing, but as the finger is advanced, he becomes aware of the ridge and this point is noted on the scale. An agreement 


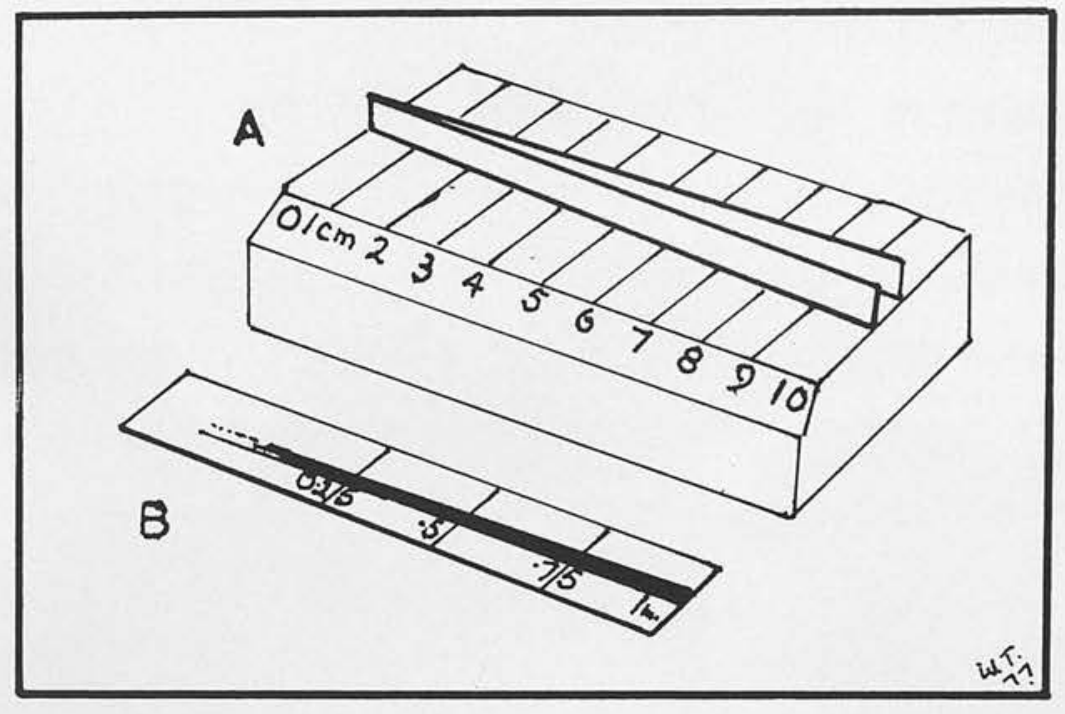

\title{
A TWO POINT DISCRIMINATION TEST
}

\section{B DEPTH SENSE AESTHESIOMETER}

\author{
Fig. 18. FINGER PULP SENSORY TESTS.
}


of two out of three is required. The upper limit of normality is $0.25 \mathrm{~m} \cdot \mathrm{m}$.

The two point discriminator consists of two sharp edged ridges which fuse or touch at one end and separate progressively to $4 \mathrm{~m} \cdot \mathrm{m}$. (centre of ridges are $5 \mathrm{~m} \cdot \mathrm{m}$. apart). The patient's finger-tip is held at the fused end and progressively moved lengthwise. At some point he will feel two ridges, i.e. a separation. The upper limit of normality is $3 \mathrm{~m} \cdot \mathrm{m}$. found after 3 tests, (two of which agree) on all fingers.

\section{Skin Temperature}

The recording of skin temperature, as an indirect method of measuring blood flow in the digits, was carried out on chain sawyers at Kielder, Dumfries and on Cwmbran pedestal grinders. Thermocouples attached to all the fingertips and thumbs of both hands (Fig.20) led to a controlled cold junction, and then to a 16 point read-out recorder. The hands were immersed for 3 minutes in water at $45^{\circ} \mathrm{C}$. Immediately after immersion the skin temperature of the thumb, each finger and palm of both hands was recorded and further readings taken after $1 \frac{1}{2}, 2,3$ and $5 \frac{1}{2}$ minutes. The hands, on returning to normal temperature, were then immersed in water at $15^{\circ} \mathrm{C}$ for 3 minutes, after which the skin temperature of the thumb, fingers and palm were recorded at $0,1 \frac{1}{2}, 3$ and $5 \frac{1}{2}$ minutes after removal. The ear temperature, by means of a probe thermocouple, and the ambient room temperature, were also noted. 
Twenty eight pedestal grinders with VwF signs and symptoms were matched with 28 controls and the Cwmbran population used as a test population for this heating and cooling test which many research workers had claimed was an excellent method of assessing VWF disability. The claim was based on the theory that Raynaud's phenomenon subjects would take longer to warm up and longer to cool down because of the restricted blood flow. (Fig.20).

\section{Thermography}

On the Thetford and Cwmbran populations, a thermographic camera to detect infra-red heat emission was used (Fig. 23). Again heating and cooling experiments were used in conjunction with direct vision skin temperature heat emission. For subsequent analyses polaroid pictures were taken.

\section{Bone Cysts: Bone Density}

A straight X-ray (A.P.) examination of the hands of the Cwmbran, Thetford, Kielder and Dumfries populations was made, using the National Coal Board mobile X-ray Units. Subsequently the films were read by three experienced, independent N.C.B. doctors for the presence of bone cysts.

A bone density and mineral distribution estimation of the metacarpals of the chain sawyers and pedestal 


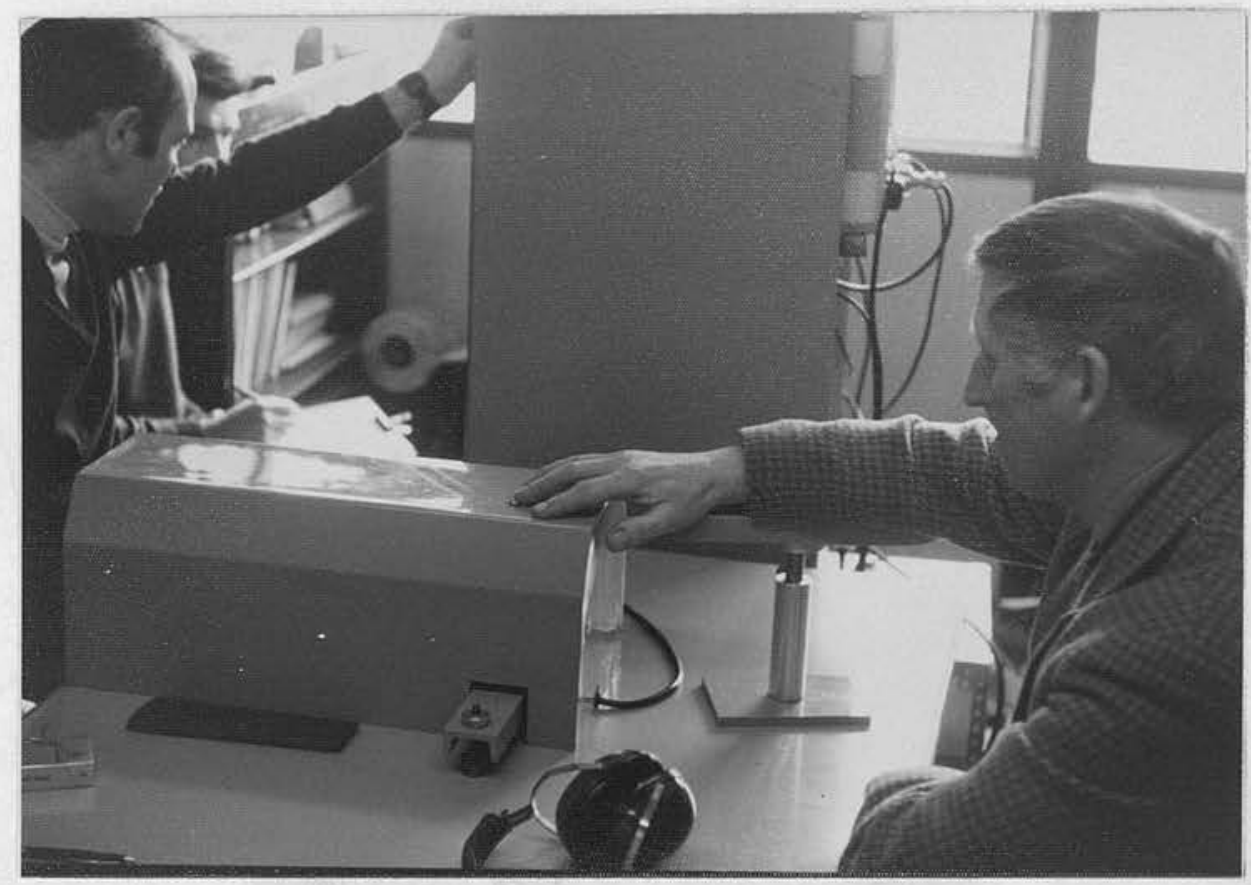

Fig. 19

OBJECTIVE TEST - VIBRO-TACTILE THRESHOLD FINGER TIP

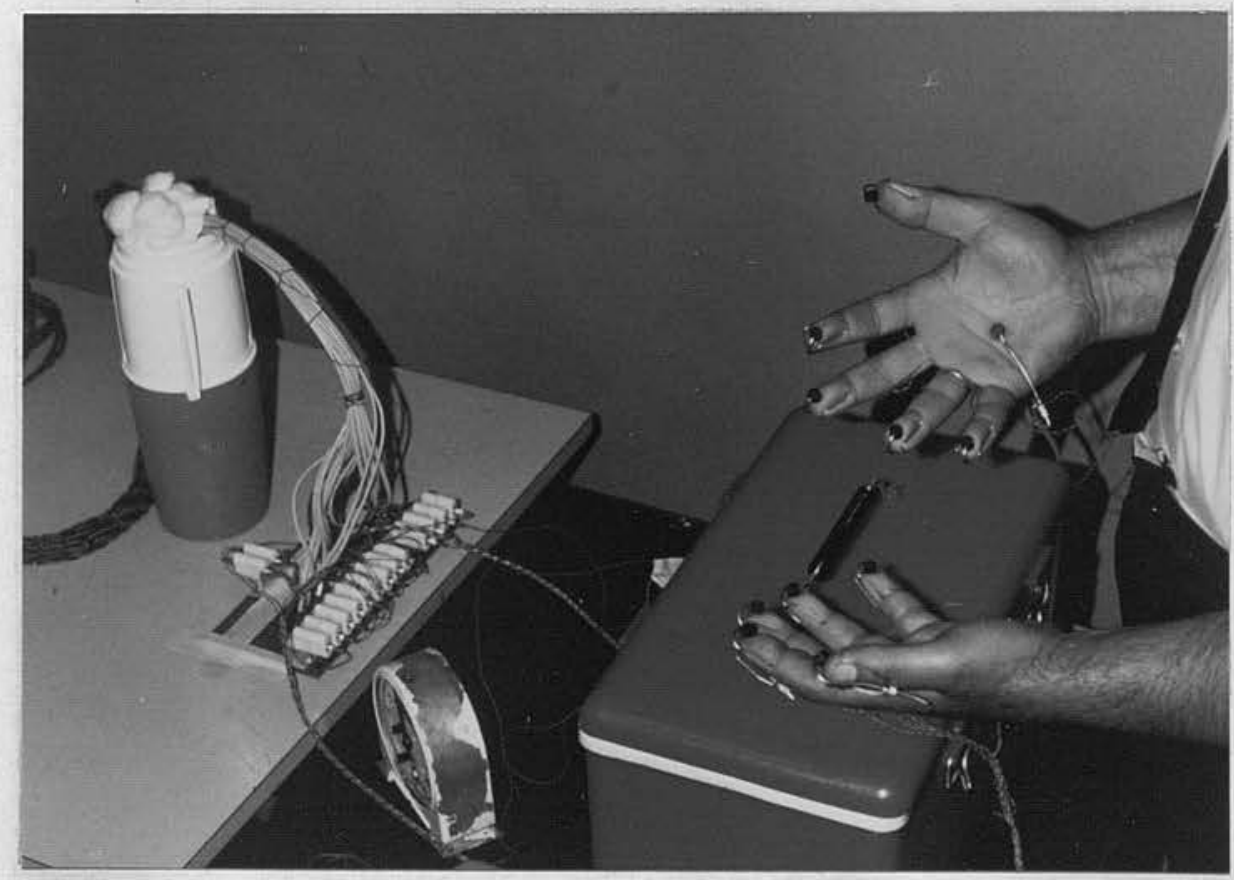

Fig. 210

OBJECTIVE TEST - HEATING AND COOLING (HANDS) 


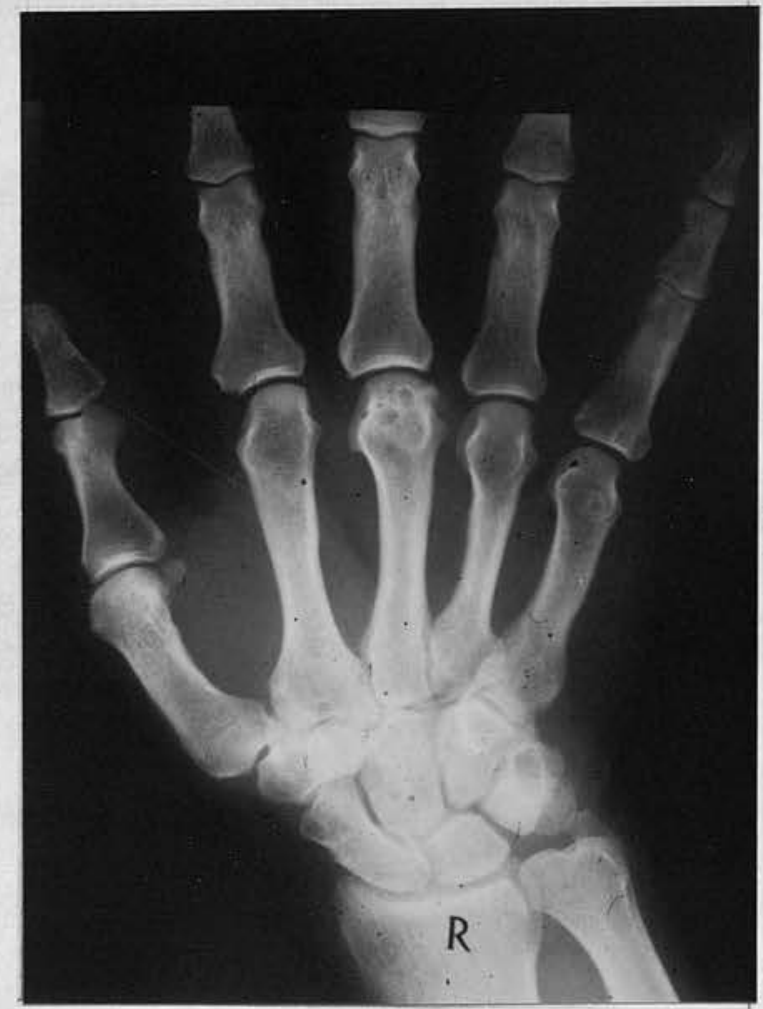

Fig・そI

OBJECTIVE TEST - BONE CYSTS

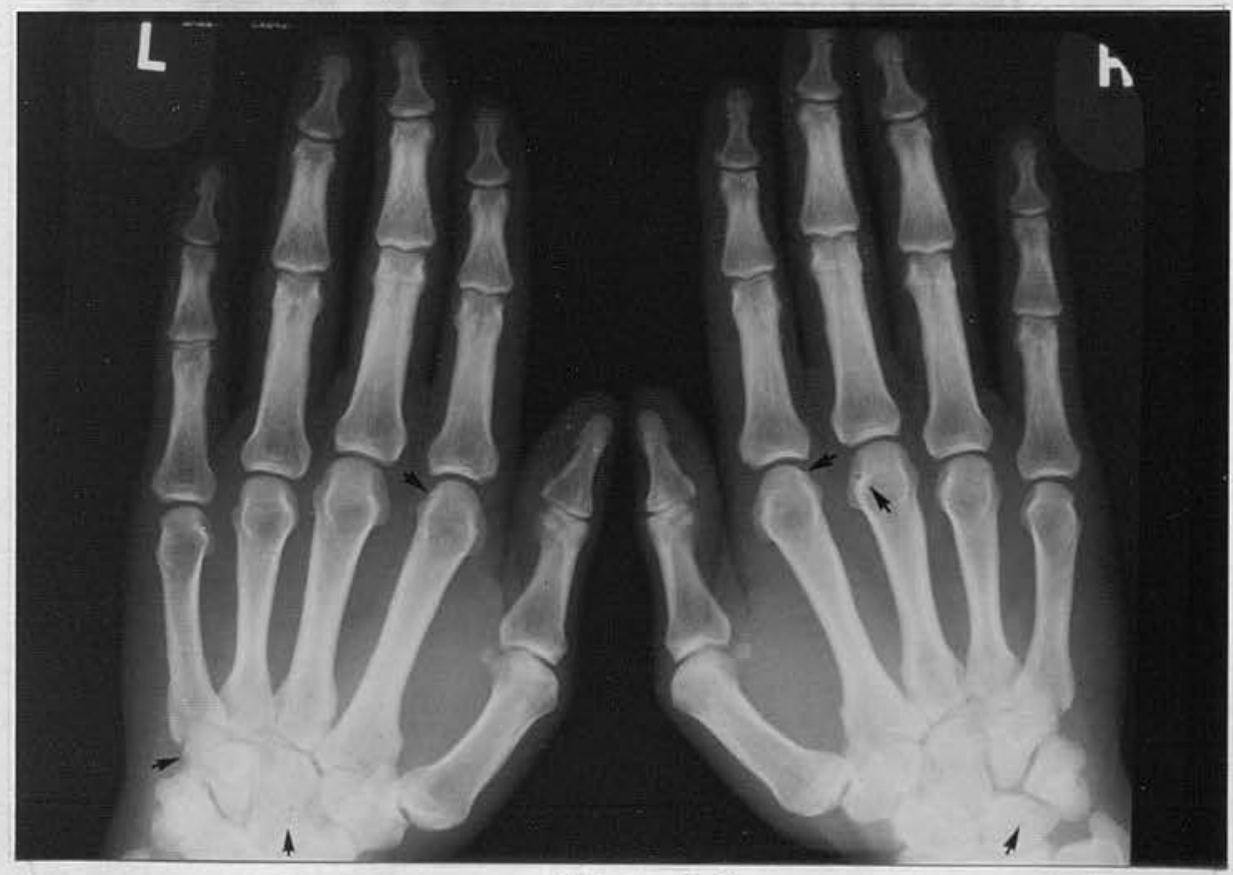

Fig. 22

OBJECTIVE TESTS - BONE CYSTS 


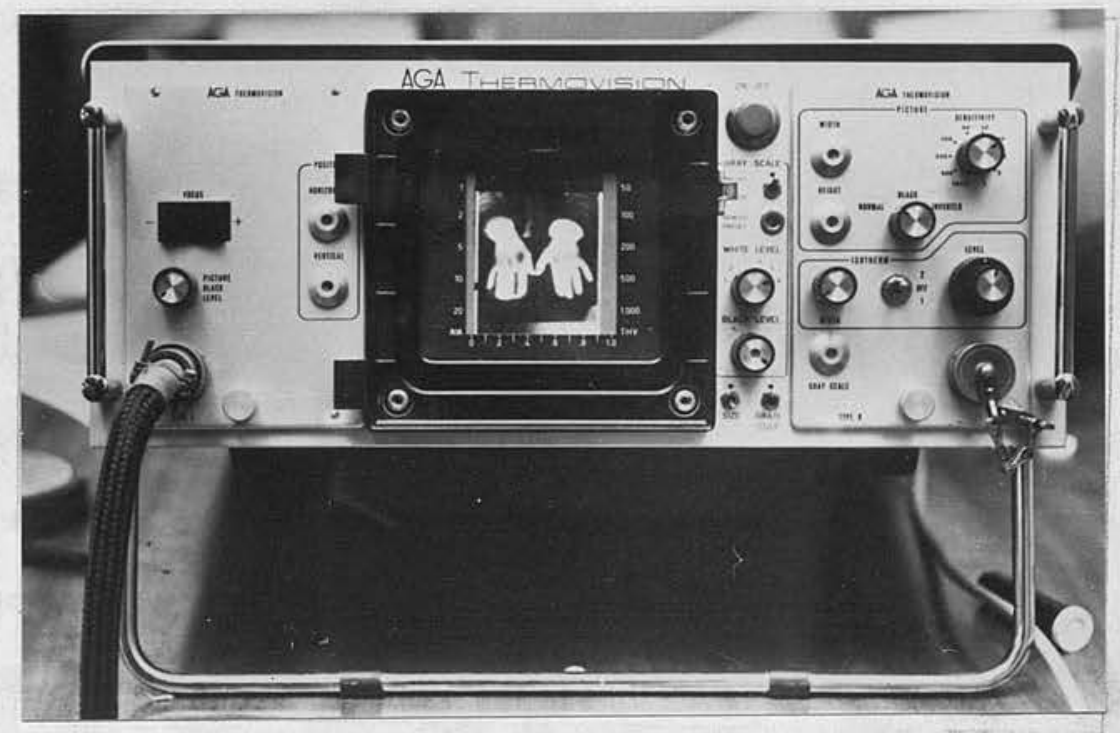

Fig. 23

OBJECTIVE TEST - THERMOGRAPHY

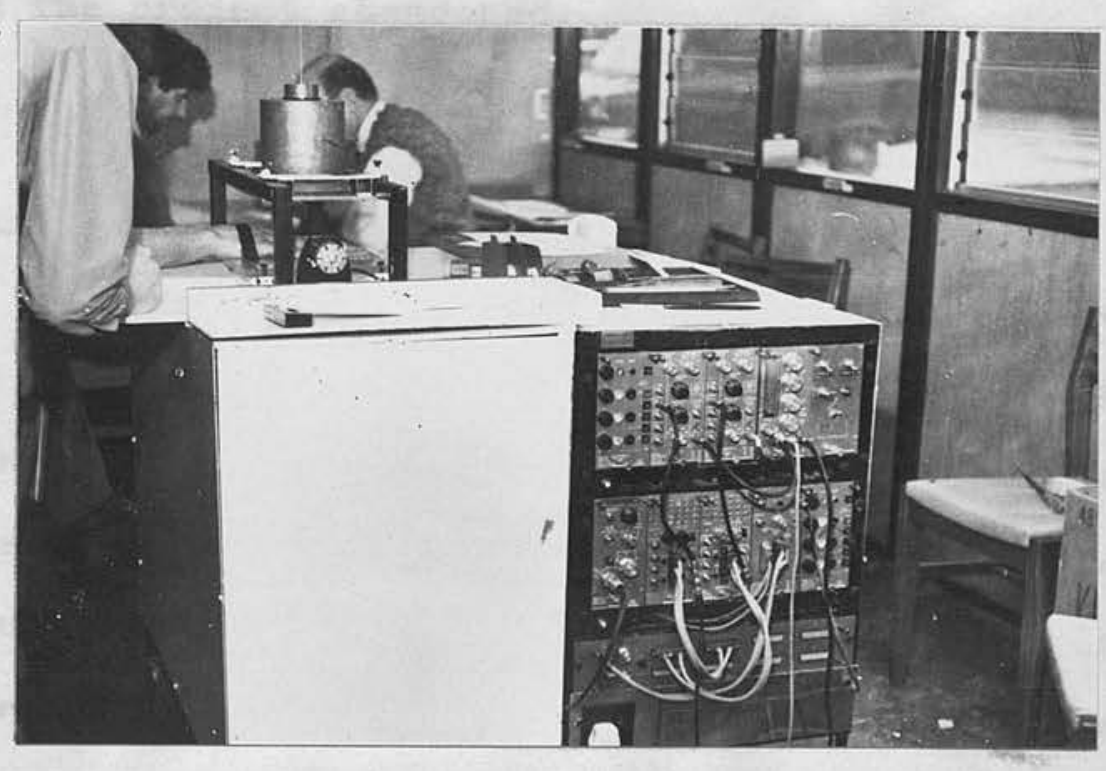

Fig. 24

OBJECTIVE TEST - BONE DENSITY 
grinders were carried out using a sealed source, double isotope scanning technique. The gamma rays from two isotopes - Caesium 137 and Americium 141 with different energies were transmitted across the skin, subcutaneous tissue and bone of the proximal phalanx of the middle fingers, the hand of the subject being moved across the double gamma beam by a mechanical platform. (Fig. 24). The source was held in a lead container operated by a manual shutter. The absorption was calculated by computer analyses. This method has been successfully used on geriatric patients but, regrettably, a fault in the technique by a member of the biophysics team allowed radioactive contamination of the apparatus, stage and surroundings. The data collected over a period of 6 months had to be rejected and the project abandoned.

\section{Brachial Arteriography}

Dr. R.W. Galloway of the University of Liverpool and $\mathrm{Dr}$. P.B. James of the University of Dundee had been collaborating in outlining the hand and arm vessels in cases of Raynaud's disease (Primary). A group of 18 pedestal grinders from Cwmbran, severally affected by vibration-induced white finger, were subjected to brachial arteriography using a portable $\mathrm{X}$-ray set to obtain a single film. This work was done at the Cwmbran factory within the Works surgery. The author and his colleague were also injected prior to 


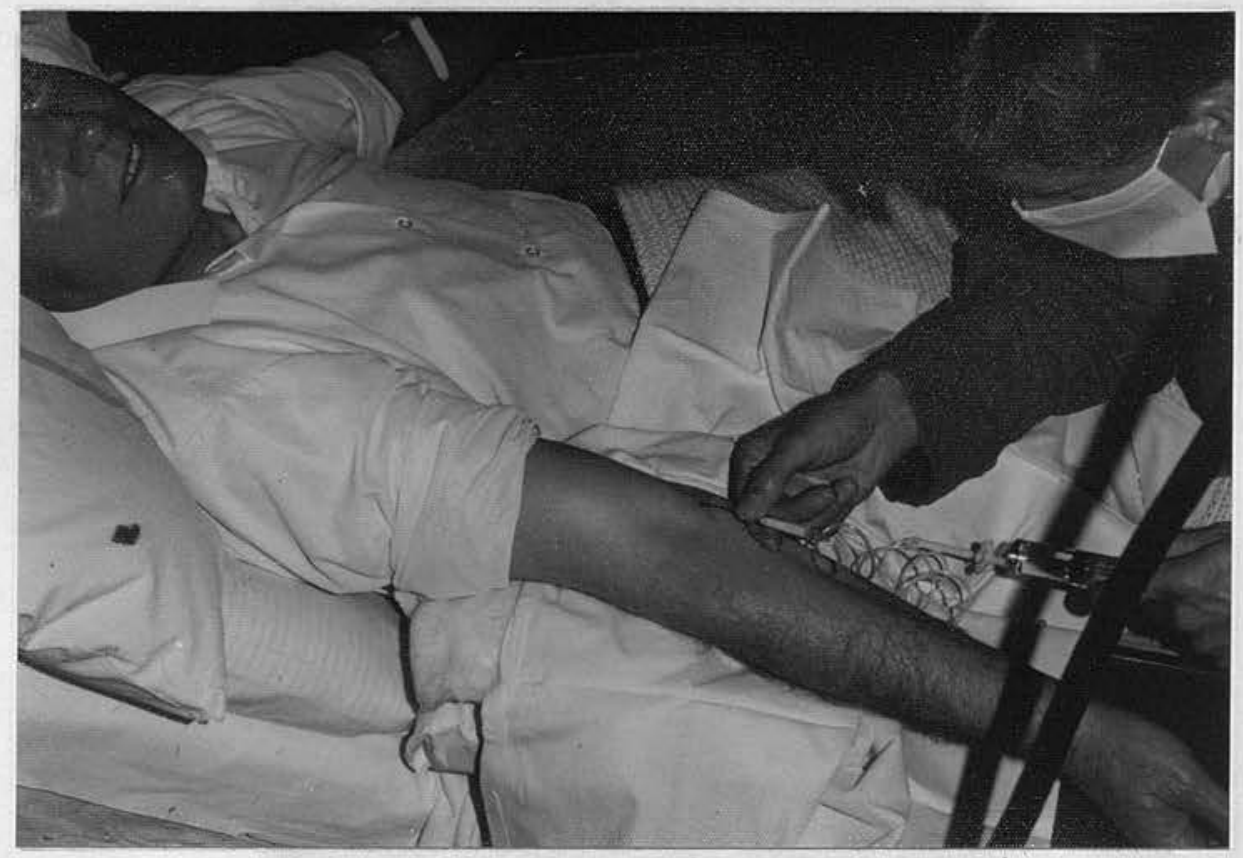

Fig. 25

BRACHIAL ARTERIOGRAPHY. SUBJECT - THE AUTHOR (W.T. )

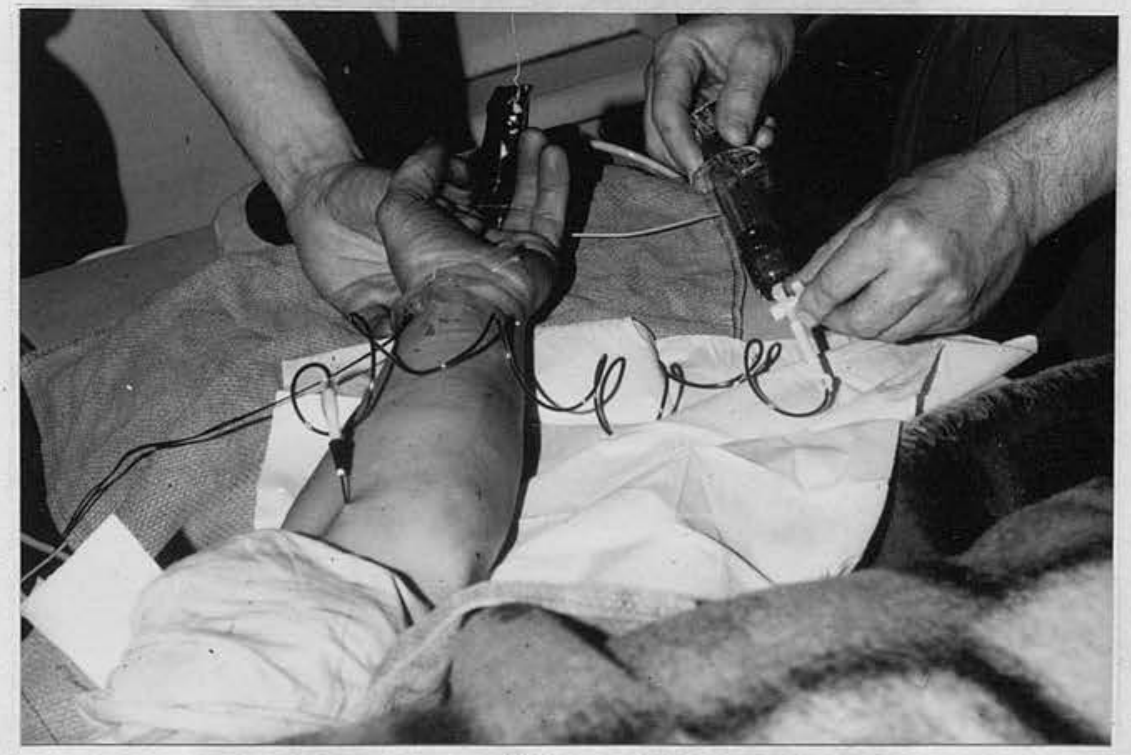

Fig. 26

INJECTION OF DYE MEDIUM - SUBJECT - THE AUTHOR (W.T.) 


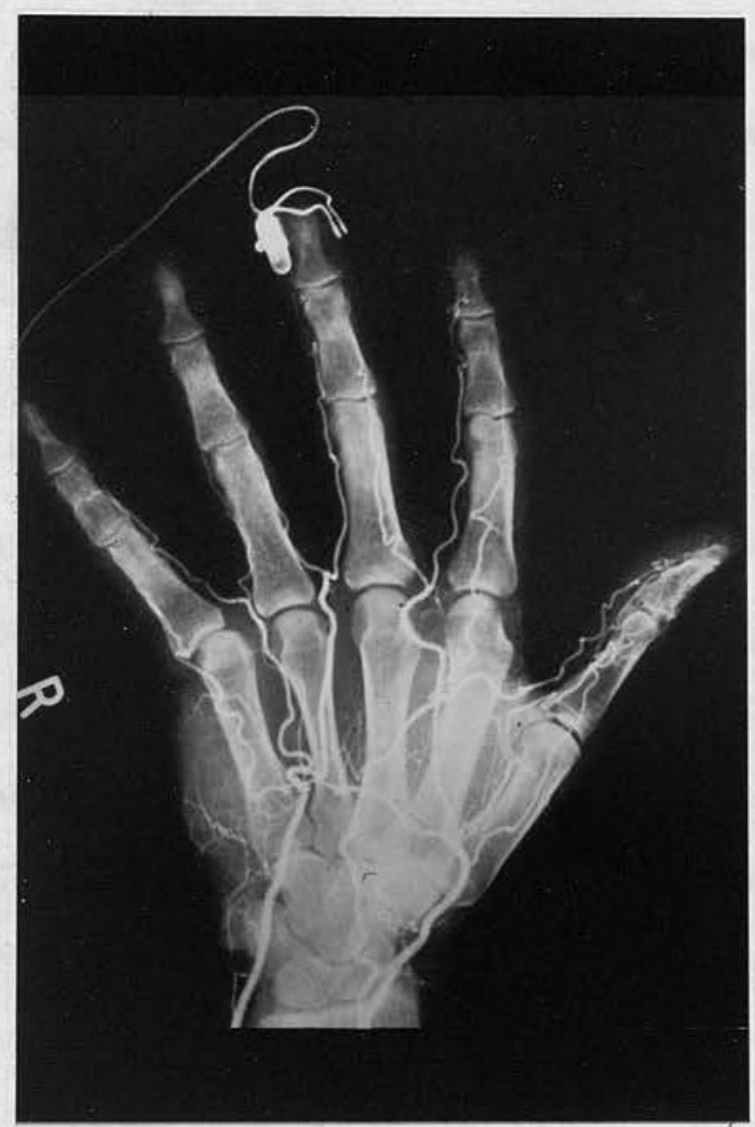

Fig. 27

ARTERIOGRAM - Control (W.T.)

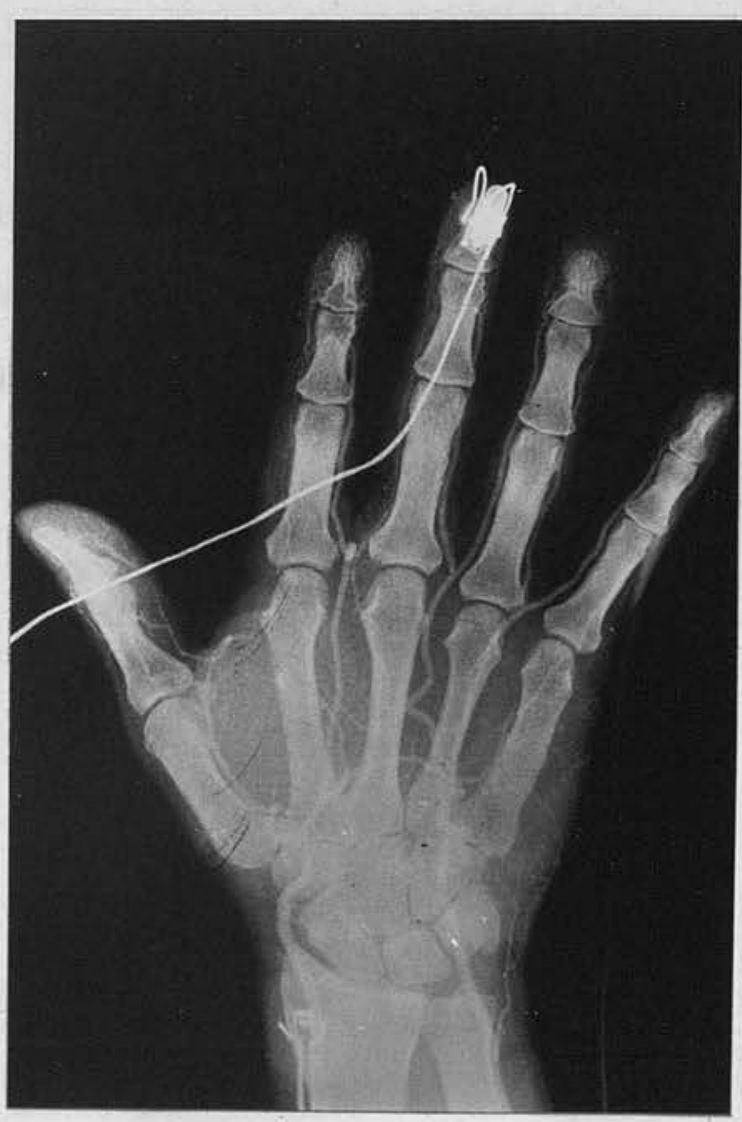

Fig. 28

ARTERIOGRAM - PEDESTAL GRINDER 
the survey on pedestal grinders to assess the severity of what was thought to be an invasive technique.

(Figs 25, 26, 27 and 28).

8. Vibration Measurement. Vibro- Tactile Sensation.

Since Miura et al (1966) and Mikulinskii (1966)

had shown that the threshold for the perception of vibration through the finger pulps is higher for persons with vibration injury than for controls, attempts have been made to use vibro-tactile tests to assess disability arising from VWF. Bjerker et al (1970) confirmed the practicability of vibration tests. The National Engineering Laboratory, East Kilbride designed a vibro-tactile meter (Fig. 19) which is essentially a beam balance. The vibrator mounted on the beam produces a sinusoidal force which is then applied to the finger pad by means of a piston $22 \mathrm{~m}$. in diameter with a flat top. It is necessary to apply a constant force of 15 grammes. The frequencies used were $80,140,250$ and $400 \mathrm{~Hz}$. 


\section{RE SULTS}

I. Prevalence of VWF in some Industrial processes in Britain.

In the present epidemiological survey, the response rate in every population group was greater than $95 \%$ and up to $99 \%$. All subjects were volunteers and failure to attend for medical examination and the battery of clinical VWF tests were entirely due to absence or sickness. The response rates and prevalence rates for VWF are shown in Table 3 . It will be seen from Table 3 that the prevalence of Raynaud's phenomenon in any one process in industry varies widely from $7 \%$ in one grinding process to $90 \%$ in chain sawyers in Thetford forest. It is tempting to use prevalence percentage as an indication of the severity of VWF in any one process, and indeed prevalence data has been used for this purpose in other countries, notably Sweden. Examination of the data in this survey shows that prevalence will vary, dependent on the vibration exposure time of the population, the variation of latent intervals of the individuals and the mobility of the labour force, a rapid turn-over giving a completely misleading prevalence percentage.

The process of determining the prevalence percentage entails noting the number of Primary Raynaud's disease found in the 18 populations surveyed. Raynaud (1862) thought that the figure in the community (non-occupational) would be around $10 \%$. In this study of males in an industrial setting the prevalence of Raynaud's disease was $5.3 \%$ in the vibration exposed subjects and $6.6 \%$ in the 
controls (Table 4 ). To determine whether subjects with Raynaud's disease were more at risk when subsequently exposed to vibration, each subject with Raynaud's disease was matched with a subject of the same process group and age. No significant difference could be demonstrated. Therefore on this data Raynaud's disease subjects are no worse in severity of VWF than other subjects with the same amount of vibration exposure. Using the Stage criteria as an indication of severity of VWF, the combined data from the 18 populations shows that as the vibration exposure time is increased, there is a corresponding increase in Stage indicating that as the total vibration energy into the hands increases, there is a corresponding increase in severity of VWF (Table 5 ).

\section{Latent Interval.}

In the previous literature little attention has been paid to the so-called latent interval - the interval between commencing exposure to vibration and the onset of Raynaud's phenomenon (Stage 1). There will undoubtedly be differences in the time taken to reach Stage 1 and produce the first white finger tip (dependent on artery size, finger size, sympathetic nerve control) but given sufficient numbers in any one process, the mean latent interval will then be a better guide to the extent of the hazard involved in the process. The mean latent intervals are shown in Table 6 with a variation from 0.6 years (Swaging) to 27 years (Hand-grinding). 
For the clinical objective tests the total population was reduced from 1283 by a further 254 subjects together with 9 small population groups making the total excluded 496 subjects. The reasons for rejection were (Table 2 )

(a) those previously exposed to vibration,

(b) those no longer vibration exposed (Ex-vibration)

(c) those with anatomical deformities of the hands and particularly the fingers due to trauma,

(d) those with Primary Raynaud's Disease, and (e) those with Secondary Raynaud's Phenomenon (causes other than vibration).

The statistical analyses were then made on 402 vibration exposed subjects and 294 controls. 


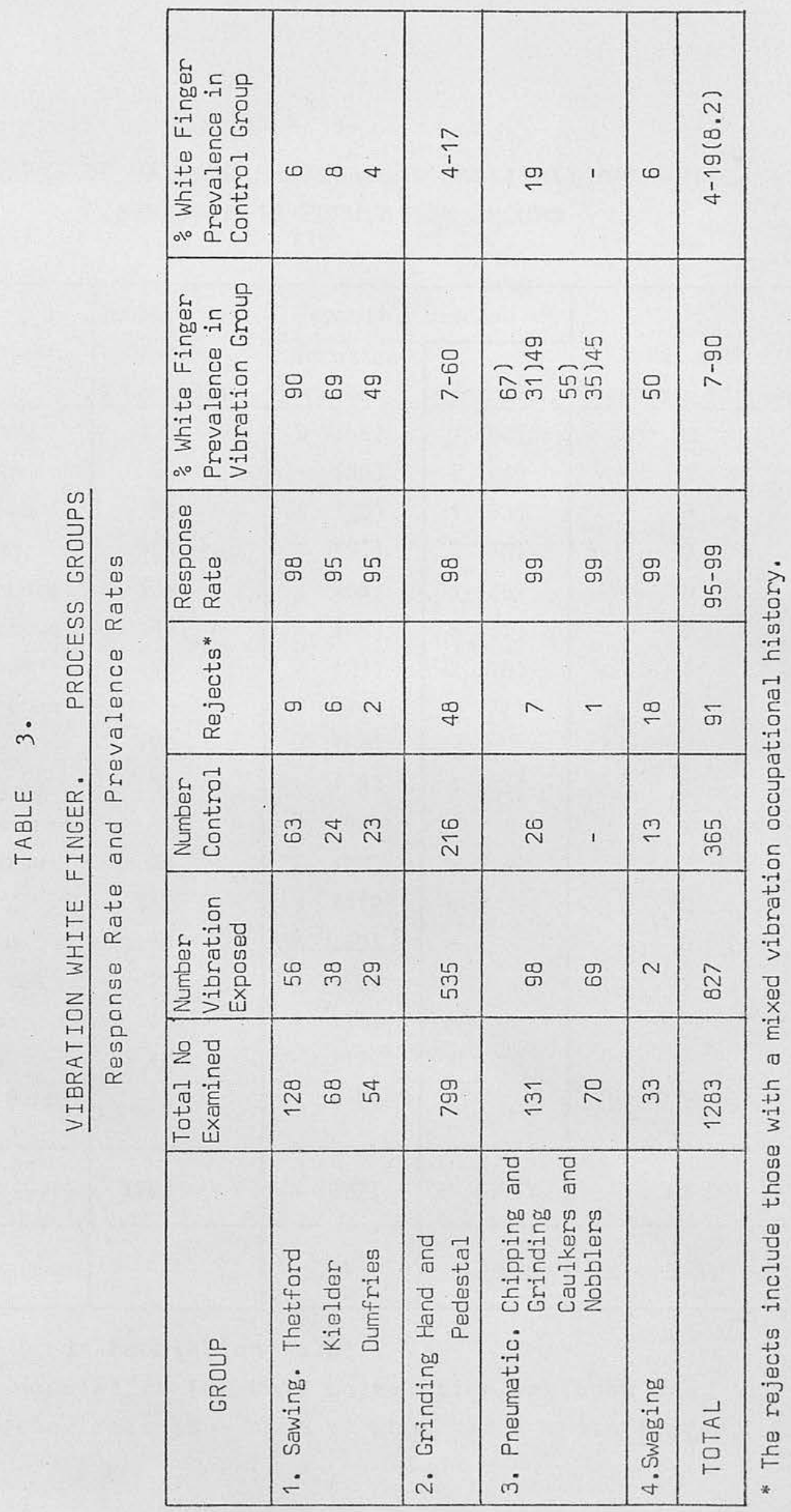


TABLE 4 .

PREVALENCE OF RAYNAUD'S DISEASE (CONSTITUTIONAL WHITE FINGER) IN 18 POPULATION GROUPS

\begin{tabular}{|c|c|c|c|c|}
\hline \multirow[b]{2}{*}{ Population } & \multirow{2}{*}{$\begin{array}{l}\text { Number } \\
\text { Vibration } \\
\& \text { Controls } \\
\end{array}$} & \multicolumn{2}{|c|}{ Raynaud's Disease } & \multirow[b]{2}{*}{$\begin{array}{c}\text { Total with } \\
\text { Raynaud's Disease }\end{array}$} \\
\hline & & $\begin{array}{l}\text { Vibration } \\
\text { Exposed }\end{array}$ & Controls & \\
\hline Thetford & 128 & $3 \quad(56)$ & 7 (63) & 10 \\
\hline Kielder & 68 & $-(38)$ & $2(24)$ & 2 \\
\hline Dumfries & 54 & $1 \quad(29)$ & $1(23)$ & 2 \\
\hline Cwmbran & 139 & $1 \quad(51)$ & $2(70)$ & 3 \\
\hline Birkenhead & 131 & $2(98)$ & $1(26)$ & 3 \\
\hline Bromsgrove & 149 & $3(89)$ & $6(51)$ & 9 \\
\hline Halesowen & 45 & $2(21)$ & $2(18)$ & 4 \\
\hline Leamington & 166 & $3 \quad(74)$ & $2(77)$ & 5 \\
\hline Rosyth & 70 & 2 (69) & - & 2 \\
\hline Liverpool & 33 & $-(2)$ & 1 (13) & 1 \\
\hline Old Cwmbran & 36 & $2(36)$ & - & 2 \\
\hline Darlaston & 29 & $7 \quad(29)$ & - & 7 \\
\hline Ayr & 112 & $10 \quad(112)$ & - & 10 \\
\hline Lincoln & 59 & $6 \quad(59)$ & - & 6 \\
\hline Smethwick & 25 & $1 \quad(25)$ & - & 1 \\
\hline Witton & 15 & $-\quad(15)$ & - & - \\
\hline Strood & 17 & $-\quad(17)$ & - & - \\
\hline Great Barr & 7 & $1(7)$ & - & 1 \\
\hline TOTAL. & 1283 & $44(827)$ & $24(365)$ & 68 \\
\hline \% Prevalence & - & $5.3 \%$ & $6.6 \%$ & $5.3 \% *$ \\
\hline
\end{tabular}

KEY: $(\quad)$ = Population Total

* The population for this calculation includes the occupation rejects - none of whom had a white finger 
TABLE 5 .

VIBRATION EXPOSURE TIME BY STAGE OF WHITE FINGER BY POPULATION GROUP

\begin{tabular}{|c|c|c|c|c|c|c|c|}
\hline \multirow{2}{*}{ Population } & \multirow{2}{*}{$\begin{array}{l}\text { Process } \\
\text { Group }\end{array}$} & MEAN & \multicolumn{4}{|c|}{ Stage of White Finger } & \multirow[b]{2}{*}{3} \\
\hline & & $\begin{array}{l}\text { Exposure } \\
\text { Time } \\
\text { (Yrs) }\end{array}$ & 0 & OT & 1 & 2 & \\
\hline \multirow[t]{2}{*}{ Thetford } & Chain Saw & 7.3 & 3.7 & 5.0 & 5.6 & 7.1 & 8.3 \\
\hline & & & (3) & (3) & (5) & (16) & (29) \\
\hline \multirow[t]{2}{*}{ Kielder } & Chain Saw & 5.9 & 4.5 & 4.5 & 5.8 & 6.3 & 10.8 \\
\hline & & & $(2)$ & (10) & (6) & (14) & $(6)$ \\
\hline \multirow[t]{2}{*}{ Dumfries } & Chain Saw & 4.3 & 2.3 & 4.7 & 3.0 & 5.4 & 6.5 \\
\hline & & & (7) & $(8)$ & (4) & (8) & (2) \\
\hline \multirow[t]{2}{*}{ Cwmbran } & Grinders & 4.7 & 9.0 & 1.7 & 3.2 & 3.4 & 5.7 \\
\hline & & & (9) & (12) & $(12)$ & (8) & (10) \\
\hline \multirow[t]{4}{*}{ Birkenhead } & Chippers & 15.4 & 8.9 & 14.1 & 15.3 & 16.6 & 21.6 \\
\hline & & & $(11)$ & $(12)$ & $(1 /)$ & & \\
\hline & Grinders & 16.0 & 6.0 & 18.7 & 25.0 & 15.0 & - \\
\hline & & & $(12)$ & (6) & $(2)$ & (6) & \\
\hline \multirow[t]{3}{*}{ Bromsgrove } & H.Grinders & 17.5 & 15.6 & 16.8 & 9.53 & 18.4 & - \\
\hline & & & (29) & (5) & $(15)$ & (5) & \\
\hline & Ped.Grinders & 12.5 & $\begin{array}{l}7.0 \\
(1)\end{array}$ & - & $\begin{array}{c}10.9 \\
(12)\end{array}$ & $\begin{array}{l}13.3 \\
(15)\end{array}$ & $\begin{array}{r}15.7 \\
(4)\end{array}$ \\
\hline \multirow[t]{4}{*}{ Halesowen } & H.Grinders & 10 & 11.6 & 2 & - & - & - \\
\hline & & & (5) & (1) & & & \\
\hline & Ped.Grinders & 5.6 & 5.4 & 6 & - & - & - \\
\hline & & & $(6)$ & (2) & & & \\
\hline \multirow[t]{2}{*}{ Leamington } & Ped.Grinders & 5.9 & 5.5 & 1.5 & 12.1 & 15.0 & - \\
\hline & & & $(64)$ & $(2)$ & (7) & (1) & \\
\hline \multirow[t]{4}{*}{ Rosyth } & Caulkers. & 24.0 & 18.4 & 22.0 & 21.0 & 31.0 & - \\
\hline & & & (15) & (2) & $(8)$ & $(13)$ & \\
\hline & Nobblers & 14.0 & 8.0 & 16.0 & 21.0 & 21.0 & - \\
\hline & & & $(17)$ & (3) & (9) & $(2)$ & \\
\hline Liverpool & Swagers & 11 & - & $\begin{array}{l}5 \\
(1)\end{array}$ & - & $\begin{array}{r}17.5 \\
(1)\end{array}$ & - \\
\hline
\end{tabular}

KEY: Exposure Time given is Mean in Years $(j)$ Number of subjects in the stage 
TABLE 5 (Cont.)

\begin{tabular}{|c|c|c|c|c|c|c|c|}
\hline \multirow{2}{*}{ Population } & \multirow{2}{*}{$\begin{array}{l}\text { Process } \\
\text { Group }\end{array}$} & \multirow{2}{*}{$\begin{array}{c}\text { Mean } \\
\text { Exposure } \\
\text { Time } \\
\text { (Yrs.) }\end{array}$} & \multicolumn{5}{|c|}{ Stage of White Finger } \\
\hline & & & 0 & OT & 1 & 2 & 3 \\
\hline \multirow[t]{2}{*}{ Old Cwmbran } & H.Grinders & 3.1 & $\begin{array}{l}3.4 \\
(17)\end{array}$ & $\begin{array}{l}3 \\
(2)\end{array}$ & $\begin{array}{l}3 \\
(3)\end{array}$ & - & - \\
\hline & Ped.Grinders & 1.3 & $\begin{array}{l}0.4 \\
(9)\end{array}$ & - & $\begin{array}{l}7.0 \\
(4)\end{array}$ & $\begin{array}{l}1.0 \\
(1)\end{array}$ & - \\
\hline \multirow[t]{2}{*}{ Darlaston } & H.Grinders & 7.0 & $\begin{array}{l}5.5 \\
(8)\end{array}$ & - & $\begin{array}{r}15.0 \\
(1)\end{array}$ & - & - \\
\hline & Ped.Grinders & 11.0 & $\begin{array}{l}9.0 \\
(14)\end{array}$ & $\begin{array}{r}12.0 \\
(2)\end{array}$ & $\begin{array}{r}15.0 \\
(4)\end{array}$ & - & - \\
\hline \multirow[t]{2}{*}{ Ayr } & H.Grinders & 11.0 & $\begin{array}{r}10.0 \\
(74)\end{array}$ & $\begin{array}{r}10.0 \\
(1)\end{array}$ & $\begin{array}{r}22.0 \\
(6)\end{array}$ & - & - \\
\hline & Ped.Grinders & 9.0 & $\begin{array}{l}8.0 \\
(26)\end{array}$ & - & $\begin{array}{r}13.0 \\
(5) \\
\end{array}$ & - & - \\
\hline \multirow[t]{2}{*}{ Lincoln } & H.Grinders & 13.0 & $\begin{array}{r}11.0 \\
(32)\end{array}$ & $\begin{array}{r}12.0 \\
(3)\end{array}$ & $\begin{array}{r}21.0 \\
(7)\end{array}$ & - & - \\
\hline & PedGrinders & 12.0 & $\begin{array}{r}13.0 \\
(7)\end{array}$ & - & $\begin{array}{c}11.0 \\
(10)\end{array}$ & - & - \\
\hline \multirow[t]{2}{*}{ Smethwick } & H. Grinders & 24.0 & $\begin{array}{r}20.0 \\
(8)\end{array}$ & $\begin{array}{r}24.0 \\
(2)\end{array}$ & $\begin{array}{r}33.0 \\
(3)\end{array}$ & - & - \\
\hline & Ped.Grinders & 15.0 & $\begin{array}{r}16.0 \\
(7)\end{array}$ & $\begin{array}{r}12.0 \\
(2)\end{array}$ & $\begin{array}{r}13.0 \\
(2)\end{array}$ & $\begin{array}{r}20.0 \\
(1)\end{array}$ & - \\
\hline \multirow[t]{2}{*}{ Witton } & H. Grinders & 18.7 & $\begin{array}{r}17.0 \\
(2)\end{array}$ & $\begin{array}{r}13.0 \\
(1)\end{array}$ & $\begin{array}{r}26.0 \\
(1) \\
\end{array}$ & - & - \\
\hline & Ped.Grinders & 8.9 & $\begin{array}{l}5.6 \\
(8)\end{array}$ & $\begin{array}{r}13.5 \\
(2)\end{array}$ & $\begin{array}{r}10.0 \\
(1) \\
\end{array}$ & - & - \\
\hline \multirow[t]{2}{*}{ Strood } & H. Grinders & 12.4 & $\begin{array}{l}4.7 \\
\text { (3) }\end{array}$ & $\begin{array}{l}4.5 \\
(1)\end{array}$ & $\begin{array}{r}11.0 \\
(2)\end{array}$ & $\begin{array}{r}46.0 \\
(1)\end{array}$ & - \\
\hline & Ped.Grinders & 5.3 & $\begin{array}{l}5.0 \\
(7)\end{array}$ & $\begin{array}{l}6.0 \\
(3)\end{array}$ & - & - & - \\
\hline Great Barr & H.Grinders & 5.0 & $\begin{array}{l}5.0 \\
(7)\end{array}$ & - & - & - & - \\
\hline
\end{tabular}

KEY: Exposure Time given is Mean in Years

$($ ) = Number of subjects in the stage 
TABLE 6

\section{Latent Interval}

Interval Between First Exposure to Vibration and First Appearance of a Blanched Fingertip.

\begin{tabular}{|l|c|c|}
\hline \multicolumn{2}{|c|}{ POPULATION } & $\begin{array}{c}\text { LATENT INTERVAL } \\
\text { (in years) }\end{array}$ \\
\hline Location & Process & 2.8 \\
\hline Thetford & CS & 3.6 \\
Dielder & CS & 3.0 \\
Cwmbran & CS & 1.8 \\
Birkenhead & C PG & 5.3 \\
Birkenhead & G & 8.7 \\
Bromsgrove & HG & 13.7 \\
Bromsgrove & PG & 4.5 \\
Leaminton & PG & 14.0 \\
Rosyth & Ca & 14.0 \\
Rosyth & N & 16.5 \\
Liverpool & SW & 0.6 \\
Old Cwmbran & HG & 1.6 \\
Old Cwmbran & PG & 2.5 \\
Darlaston & HG & 5.0 \\
Darlaston & PG & 12.0 \\
Ayr & HG & 18.0 \\
Ayr & PG & 11.0 \\
Lincoln & HG & 15.0 \\
Lincoln & PG & 7.0 \\
Smethwick & HG & 27.0 \\
Smethwick & PG & 3.3 \\
Witton & HG & 20.0 \\
Witton & PG & 8.0 \\
\hline
\end{tabular}

KEY: $G=$ Grinding $(H=$ Hand, $P=$ Pedestal $)$ CS = Chain Saw $C a=$ Caulking $S W=$ Swaging $N=$ Nobbling $C=$ Chipping 
II. Latent Intervals and Vibration Levels

The use of "percentage prevalence VWF" for a population to assess the severity of Raynaud's phenomenon has been abandoned in the U.K. Emphasis has now been placed on "Latent Interval" described as the time interval between the operator's first exposure to vibration and the first appearance of a blanched fingertip. The Latent Intervals for chain sawyers, grinders, chippers, caulkers and nobblers, are shown in Table 7 . 


\section{TABLE 7 •}

VIBRATION MEASUREMENTS (LINEAR) AND LATENT INTERVAL BY OCCUPATION GROUP.

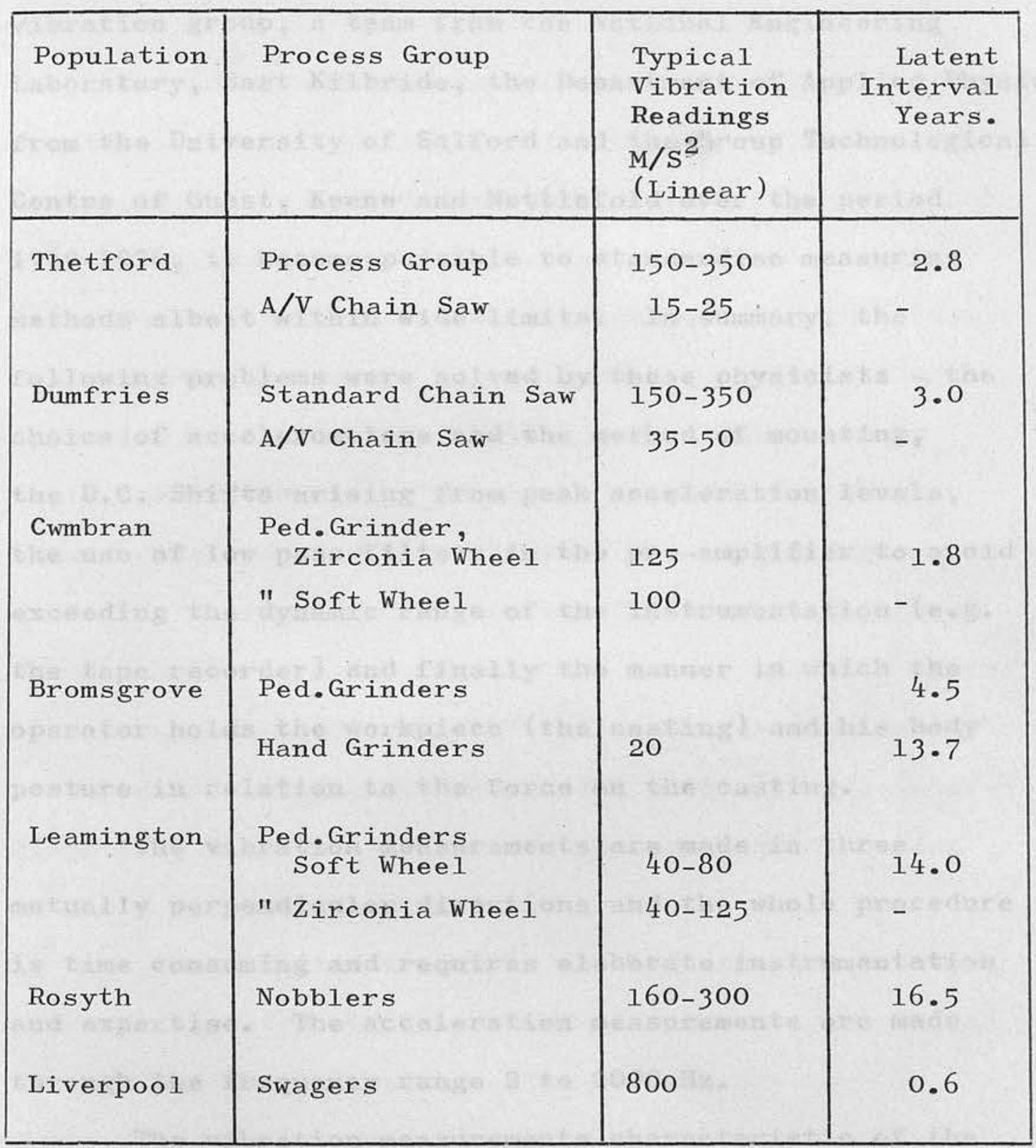

N.B. 1. The Chain Saw readings vary because of the variety of saws.

2. The variation in grinders is due to the different size and shape of the castings and forgings. 
When the techniques of vibration measurement

were worked out by the University of Southampton noise and vibration group, a team from the National Engineering Laboratory, East Kilbride, the Department of Applied Physics from the University of Salford and the Group Technological Centre of Guest, Keene and Nettlefold over the period 1969-1976, it became possible to standardise measuring methods albeit within wide limits. In summary, the following problems were solved by these physicists - the choice of accelerometers and the method of mounting, the D.C. Shifts arising from peak acceleration levels, the use of low pass filters in the pre-amplifier to avoid exceeding the dynamic range of the instrumentation (e.g. the tape recorder) and finally the manner in which the operator holds the workpiece (the casting) and his body posture in relation to the force on the casting.

The vibration measurements are made in three mutually perpendicular directions and the whole procedure is time consuming and requires elaborate instrumentation and expertise. The acceleration measurements are made through the frequency range 2 to $2000 \mathrm{~Hz}$.

The vibration measurements characteristic of the seven work processes in this study were then compared with the mean latent intervals found for the processmen. The results are shown in Table 7 . 
It became clear from the workload involved in vibration measurement that simplification of techniques was desirable. In the noise field a single meter reading, the dB(A) Unit, had been evolved to replace time consuming octave analyses requiring sophisticated instrumentation. By introducing a weighted network, with a response which was the inverse of the recommended vibration exposure limit curves, into the measuring equipment in this case a standard noise meter, it was possible to express the vibration in terms of a single figure. This reading would then indicate the amount by which a spectrum exceeds the proposed limit curve. The single figure vibration unit was designated the " $K$ " weighting, after Mr. Kitchener of G.K.N. Technology Group. At this stage of development (1977) the ' $\mathrm{K}$ ' rating measurement is but a simple screening procedure which, with suitable interpretation, takes its place with the noise $d B(A)$ rating in field vibration measurement.

The weighted $K$ average has been applied to our vibration spectra and correlated with the average latent interval of the processmen. The results are seen in Table 8, and Fig。 29

TABLE 8 .

VIBRATION MEASUREMENTS (K WEIGHTING) AND LATENT INTERVAL

$\begin{array}{llllllll}\text { Latent Interval (Yrs.) } & 0.6 & 1.8 & 2.9 & 14.0 & 4.5 & 13.7\end{array}$

K Weighting $\begin{array}{llllll}70 & 50 & 25 & 20 & 12.2 & 3\end{array}$ 


\section{LATENT INTERVAL IN YEARS AND ' $K$ ' ACCELERATION IN METERS PER SEC ${ }^{2}$ BY OCCUPATIONAL GROUPS.}

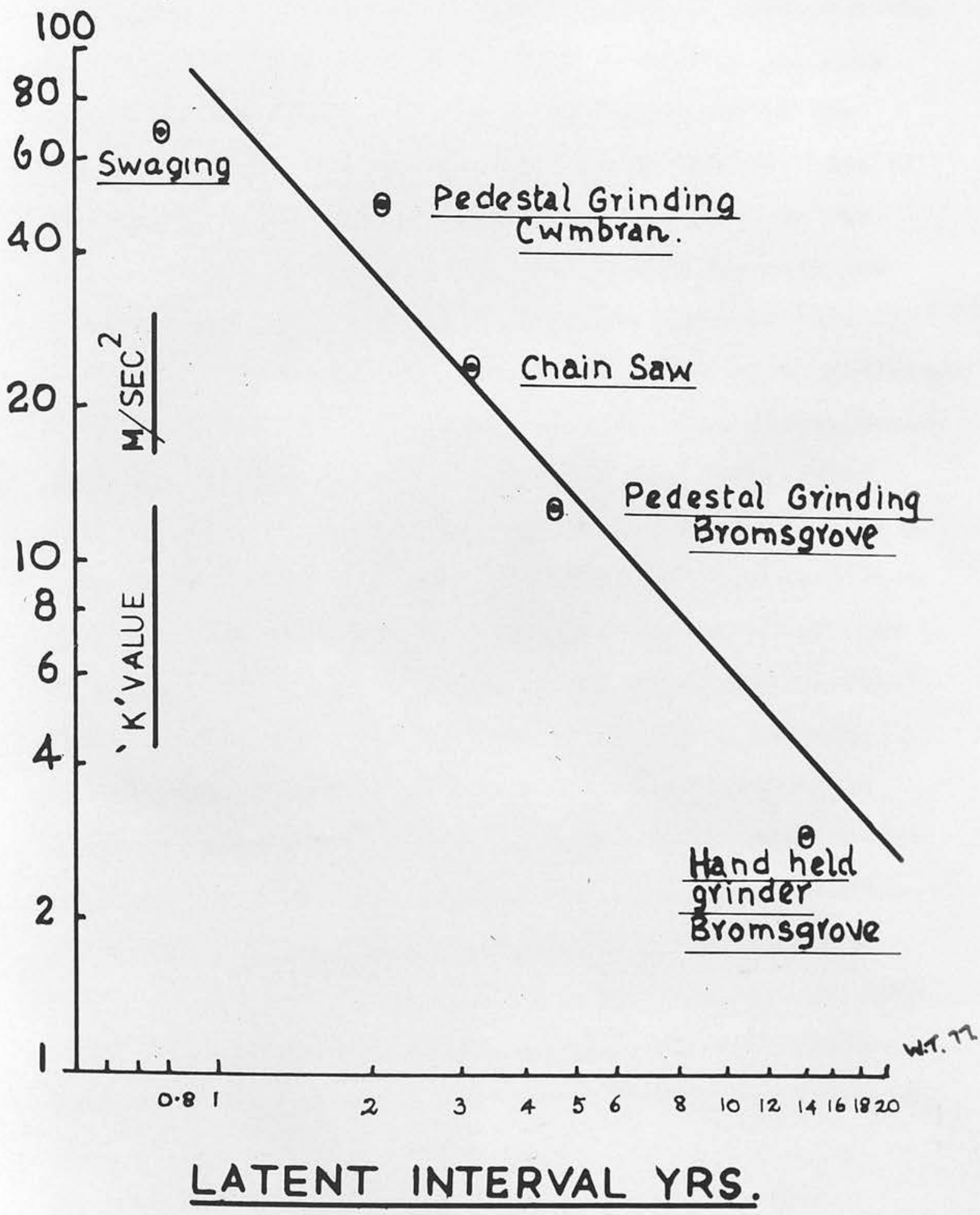


III. Vibration-Induced White Finger in Forestry Chain Saw Operators - A seven-year Prospective Study.

Early in this vibration project it was realised that with different vibration tools, varying work methods and changing study populations, retrospective studies were of limited value. If the main objective is to establish the prevalence of Raynaud's phenomenon in each of the work processes and thus to determine the magnitude of the hazard then retrospective studies would suffice. One of the criticisms of such studies would, however, be the follow-up of the subjects who have previously left the working group and for what reason. To overcome this difficulty it was decided in 1969 to follow up a population of Forestry Commission sawyers from Thetford Chase, Santon Downham, Norfolk known to be at risk from the results obtained in a survey carried out in December 1969. From 1961 to June 1970, the Thetford Chain saw operators were handling saws with high acceleration values on both the front and rear handles in the region $200-400$ metres $/ \mathrm{sec}^{2}$. Prior to June 1970 the saws had no vibration damping. In 1969 the Forestry Commission convened a meeting of chain saw manufacturers and requested design alterations limiting the vibration reaching the handles. From June to December, 1970, anti-vibration saws, conforming to limits laid down by the Forestry Commission of less than 60 metres per $\sec ^{2}$ on either handle, were introduced. Thus by the end of 1970 all sawyers in the Thetford area were on anti-vibration saws.

By 1976 the A/V saw usage would be at least 5 years. 
This population from the Forest of Thetford

Chase has been surveyed by the author at annual intervals (January) for seven years. Of this population the same 46 sawyers were examined in January $1970,71,72,73$ and 1974. In 1975 and 1976 the numbers actively sawing were reduced to 44 and 40 .

Method. In the seven surveys 1970-1976, the author took an occupational history and graded the VWF signs and symptoms (Stage Assessment) according to the criteria already reported. This Stage Assessment was then assessed by the Treasury Medical Officer who joined the team for the Thetford Surveys. In the clinical tests, in addition to the blood pressure determinations, the depth sense aesthesiometer and the two point discrimination sensory tests were carried out in the survey years $1972,73,74,75$ and 76.

In addition to the regular chain saw operators seen at each survey all new trainees and new sawyers fresh from training school were examined medically and with special reference to Raynaud's phenomenon, e.g. history of white fingers, sensory tests and secondary causes of Raynaud's phenomenon.

Results. Of the 54 sawyers originally seen in December 1969, 52 remained within the Thetford Chase area of Forestry operations. The two who had left the Commission did not leave on the grounds of VWF. Of the 52 remaining for survey, 40 were still active sawyers in 1976, the 
remainder having been transferred to tractor work, or other forestry duties such as tariff work (occasional sawing). If the active sawyers (40) and the exsawyers are grouped together, then at the 1976 survey $50 \%$ of this group still had vibration-induced white finger at various Stages (Table 9 ).

TABLE 9.

\begin{tabular}{|c|c|c|c|c|c|}
\hline $\begin{array}{l}\text { Number of } \\
\text { Sawyers } \\
\text { Surveyed }\end{array}$ & $\begin{array}{l}\text { Mean Saw } \\
\text { Usage Time } \\
\text { (Years) }\end{array}$ & $\begin{array}{l}\text { No. of Saw } \\
\text { in Stage } \\
0\end{array}$ & $\begin{array}{l}\text { rs } \\
\text { VWF } \\
2 \\
\end{array}$ & & $\begin{array}{c}\text { Prevalence } \\
\% \\
\end{array}$ \\
\hline 52 & 10 & $\begin{array}{lc}26 & 8 \\
(50 \%) & (15 \%)\end{array}$ & $\begin{array}{c}16 \\
(31 \%)\end{array}$ & $\begin{array}{c}2 \\
4 \%\end{array}$ & 50 \\
\hline
\end{tabular}

The percentage VWF prevalence is arrived at by adding the number of sawyers in Stages 1, 2 and 3 and expressing this as a percentage of the total number of sawyers. There are two active sawyers in Stage 3 (severe) with the majority of sawyers and ex-sawyers in Stage 2.

To assess the VWF situation from 1970 to 1976

it is necessary to compare the same individuals at each annual survey (prospective study). Wastage of sawyers due to retirement, transfer to other departments, e.g. tractors (and sometimes absence at survey due to illness) reduces the numbers, but the population at Thetford has shown excellent stability of employment 
with low absenteeism. Of the 46 sawyers seen in 1970 , 40 remained for survey in 1976. In assessing the VWF of this long service group (with a saw usage time of 12.6 years) it is important to emphasise that all were exposed to the early hazardous saws and that only by the end of 1970 had $A / V$ saws been issued. Thus the survey data for 1970, 1971 and possibly 1972 will reflect the results of high vibration saws whilst the 1973, 74, 75 and 1976 data will refer to $A / V$ saws, with any irreversible factor remaining from previous vibration exposure on now $A / V$ machines. The results of the seven annual surveys are shown in Table 10 . 


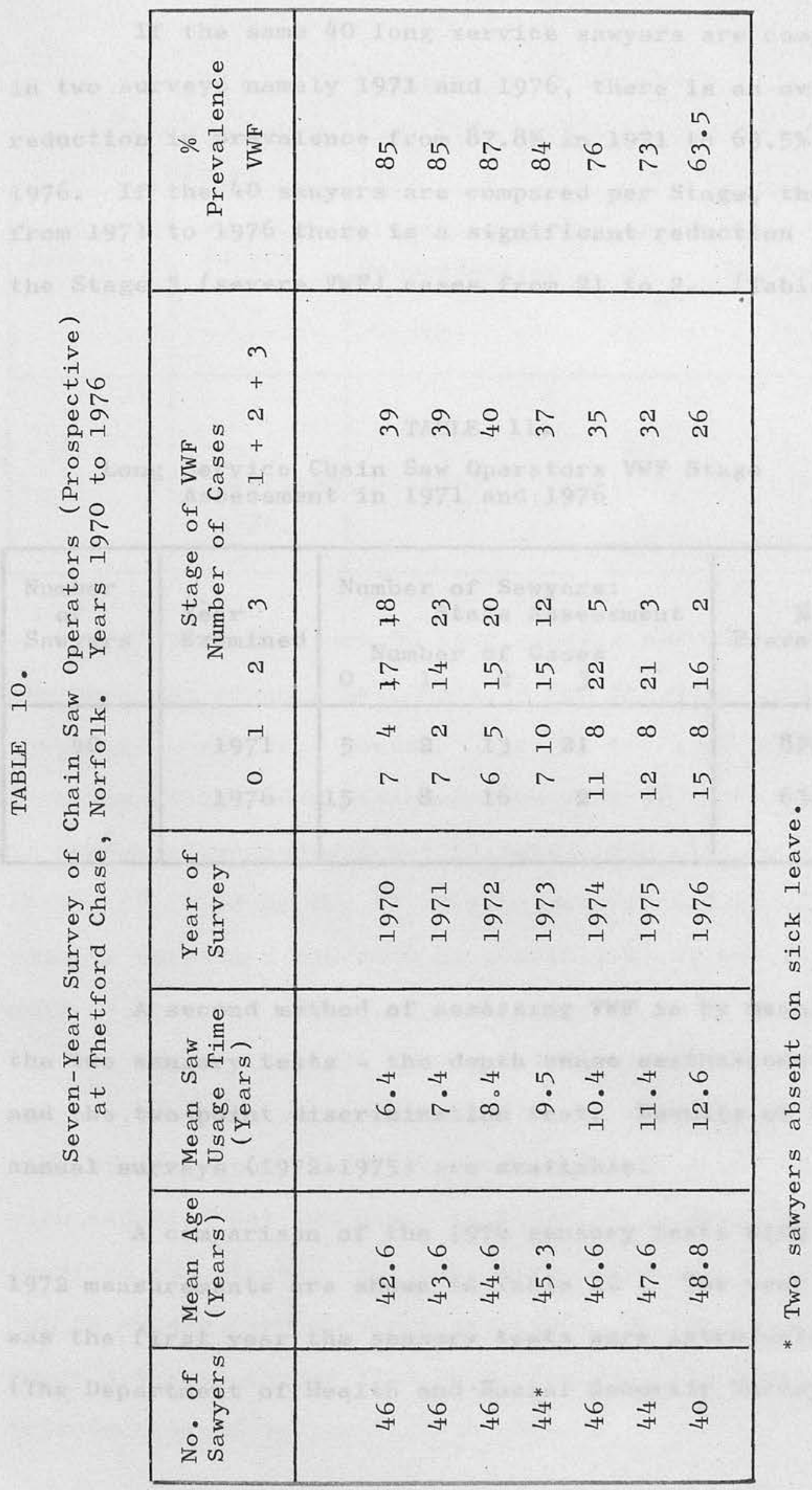


If the same 40 long service sawyers are compared in two surveys namely 1971 and 1976, there is an overall reduction in prevalence from $87.8 \%$ in 1971 to $63.5 \%$ in 1976. If the 40 sawyers are compared per Stage, then from 1971 to 1976 there is a significant reduction in the Stage 3 (severe VWF) cases from 21 to 2. (Table 11.)

TABLE 11.

Long Service Chain Saw Operators VWF Stage Assessment in 1971 and 1976

\begin{tabular}{|c|c|cccc|c|}
\hline $\begin{array}{c}\text { Number } \\
\text { of } \\
\text { Sawyers }\end{array}$ & $\begin{array}{l}\text { Year } \\
\text { Examined }\end{array}$ & $\begin{array}{r}\text { Number of Sawyers: } \\
\text { Stage Assessment } \\
\text { Number of }\end{array}$ & $\begin{array}{c}\% \\
1\end{array}$ & $\begin{array}{r}\text { Cases } \\
\text { Prevalence }\end{array}$ \\
\hline 40 & 1971 & 5 & 2 & 13 & 21 & 87.8 \\
1976 & 15 & 8 & 16 & 2 & 63.5 \\
\hline
\end{tabular}

A second method of assessing VWF is by means of the two sensory tests - the depth sense aesthesiometer and the two-point discrimination test. Results of five annual surveys (1972-1975) are available.

A comparison of the 1976 sensory tests with the 1972 measurements are shown in Table 12 . The year 1972 was the first year the sensory tests were introducted. (The Department of Health and Social Security Survey Year) 
TABLE 12 .

Sensory Tests: Long Term Sawyers

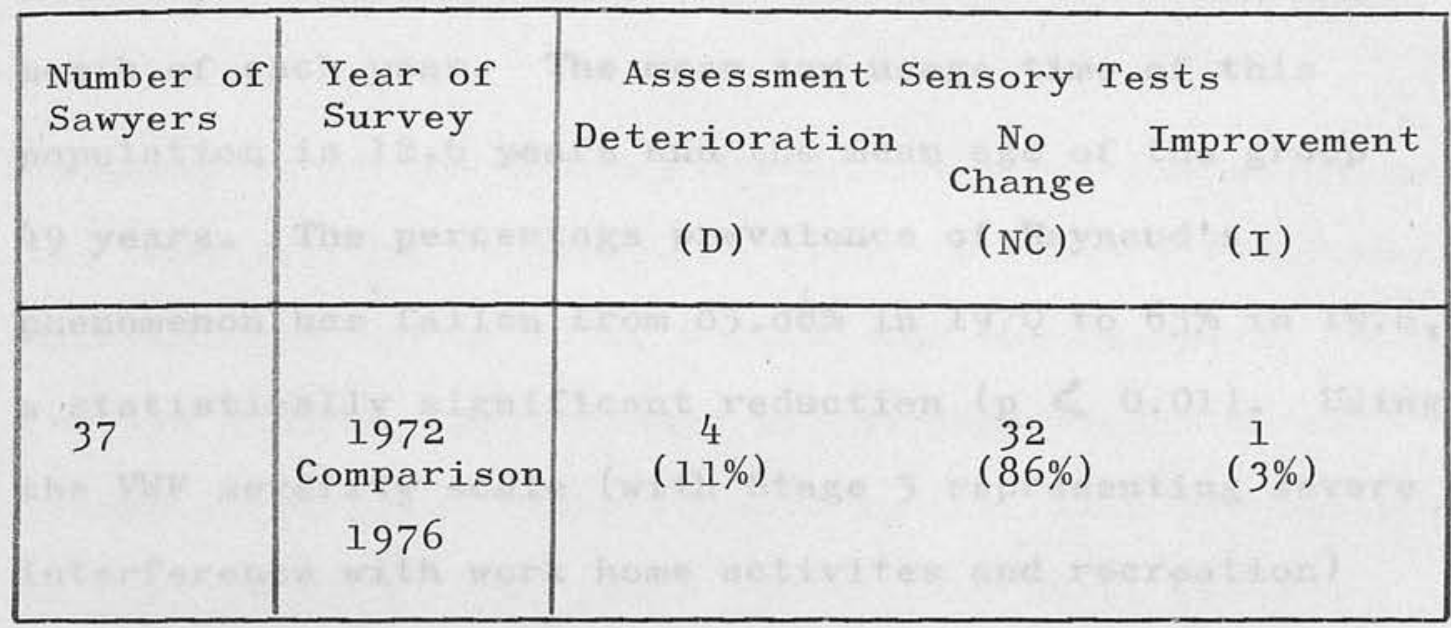

Taking the same 37 long service sawyers, for whom the earliest sensory test data is for the year 1972, and comparing these same sawyers' sensory tests in 1976 , 4 sawyers (11\%) show deterioration with $32(86 \%)$ in a no change situation and 1 (3\%) improving. The 1975 survey showed 18 ( $41 \%)$ of the 44 sawyers deteriorating. These results suggest a decrease in sensitivity of the finger pulp sensory end organs.

During the 1976 survey all new sawyers and all sawyers, who had worked from 1971 onwards with antivibration treated saws, were surveyed. No cases of VWF were reported but two cases of tingling in the hands were reported $\left(\mathrm{O}_{\mathrm{T}}\right.$ Stage). The saws were immediately examined but no excess vibration was detected. No new cases of Stage 1 (white finger tip) have been reported since the introduction of anti-vibration saws. 
Conclusions of Prospective Forestry Commission Survey.

(1) Forty (40) long term sawyers have been examined annually from 1970 to 1976 in the same week and the same month of each year. The mean saw usage time of this population is 12.6 years and the mean age of the group 49 years. The percentage prevalence of Raynaud's phenomenon has fallen from $85.88 \%$ in 1970 to $63 \%$ in 1976 , a statistically significant reduction $(\mathrm{p}<0.01)$. Using the VWF severity scale (with Stage 3 representing severe interference with work home activites and recreation) there were 21 Stage 3 cases in 1971 compared with 2 Stage 3 cases in 1976. There are, however, 21 Stage 2 cases still present in Thetford Chase which appear to be stationary implying that digital artery damage from the early excessive vibration saws is irreversible.

Examining the whole population of sawyers seen in 1976 (long and short term service sawyers) the percentage prevalence of VWF is 50\%. The figure in 1970 was in the region of $85-90 \%$, a significant improvement with the introduction of $\mathrm{A} / \mathrm{V}$ saws.

(2) No new cases of VWF have arisen since the introduction of anti-vibration saws in 1970. The epidemiological data obtained over a 7 -year period indicates a gradual improvement in VWF following the introduction of these anti-vibration models. However, further monitoring of VWF will be required to show whether the 
British Standard Draft Vibration limits (DD43:1975) are safe over a working lifetime of a sawyer taken as 30 years.

(3. Analyses of the sensory tests show a deterioration in the long service sawyers. In 1975, 18 sawyers (41\%) had deteriorated and in $1976,4(11 \%)$ had deteriorated. These results would suggest damage to the superficial dermal plexus sensory end organ receptors, (Pacinian corpuscles) in sawyers with $12-15$ years saw usage. These changes may relate to the symptom of "clumsiness" frequently reported by sawyers.

These tests (depth sense and two point) are in the early stages of development for the assessment of the severity of VWF and more epidemillogical survey work is required for validation. They are also capable of refinement. The whole area of sensory testing in the search for an objective test for VWF is under review by the Medical Research Council for further study. 


\section{DISCUSSION}

The results of the surveys (see individual papers in Appendix) established that in vibration-exposed populations blanching of the middle and ring fingers most commonly occurs. The exception to this rule is where the vibration stimulus is localised as in chippers or caulkers, where the left 4 th finger (little finger) is most frequently affected being adjacent to or gripping the loose chisel. It is not surprising to find that blanching, when a special tool position is not adopted, is most frequently encountered in the longer digits.

Arteriographic studies, on the other hand, indicate maximum digital artery damage in the index digital artery adjacent to the thumb and on the digital artery on the lateral side of the 4 th digit. There is evidence of general narrowing of the digital arteries in all of the fingers of both hands, more pronounced in the middle and distal phalanges areas. All arteriographic studies show blocked vessels, the regular paired digital vessels being replaced by irregular, fine collateral arteries. Laws et al (1963 and 1967) could not distinguish between cases of rheumatoid arthritis and Raynaud's disease, both showing occlusive lesions and reduced calibre of the vessels. Arteriograms cannot distinguish between spasm and permanent narrowing of the lumen of the arteries. It is nevertheless a useful diagnostic technique which also indicates any abnormality of the forearm arteries (reduced calibre of radius or ulnar) or palmar arches including 
anatomical variation.

In the study on Cwmbran pedestal grinders, arteriography confirmed the narrowing and obstruction of the radialis indicis arteries in both hands (James et al, 1975). Large bore arteries in this study tended to produce longer latent intervals. Notwithstanding these advantages, arteriography was abandoned at the request of the Department of Health and Social Security as a survey procedure on ethical (invasive technique) grounds. It is a procedure only for hospital practice.

Changes in blood flow in the fingers in Raynaud's phenomenon have been studied by using venous occlusive plethysmography and the majority of vascular clinics are equipped for, and the staff expertise in, this technique. By a photo-electric light method or by attaching a writing arm to the volume recorder, the pulse wave pattern may be traced and this method has been successfully used by many workers (Rohter et al, 1962; Miura et al, 1966; Miura et al, 1970 and Matoba et al, 1975). As a laboratory exercise finger pletysmography is invaluable in detecting peripheral vascular changes (Kozminska et al, 1969 and 1970) but the technique cannot distinguish between occlusive vascular pathology and the lumen narrowing due to Raynaud's phenomenon. Furthermore without a constant temperature room, a constant core temperature and a controlled psychological state, it is difficult to establish base line, normal values. In a controlled series (not reported here) the research team (Dr. James) found the usual overlap between vibrationexposed and control subjects. Therefore plethysmography 
in our hands was not a valuable diagnostic method. Where control subjects have not been sought, the results always appear promising. It is intended to repeat the U.K. experiments in a large U.S.A. survey planned for October 1977 .

The depth sense aesthesiometer test and the two-point discrimination tests described by Renfrew (1969) and used extensively here have confirmed that impairment of sensation does occur in Raynaud's phenomenon and that the thresholds rise with increasing vibration exposure and increasing Stage assessment. The formation of callus will however affect the sensitivity and measurements are confined therefore to the region between the finger pulp (whorl) and the nail end. Of the two tests, the depth sense test (ridge test) shows the smaller scatter on normal population, has a sharper cut-off and is more acceptable to subjects as a neurological, clinical test.

The finger circumference measurements in this study confirm that swelling is localised to the finger in close proximity to the source of vibration. When vibration exposure is discontinued, the fingers usually diminish in size. Finger swelling in grinding, where the castings are held against wheels, and a considerable force factor is in evidence, precedes blanching. In vibration exposure with little or no force factor such as guiding a chain saw (top handle), there is no increase in finger size and no callus formation due to friction, but the inevitable blanching may yet be present (Taylor, 1974). Progressive enlargement of the digits with increasing vibration exposure is a serious finding in routine in-plant monitoring. 
Routine X-raying of the hands has been called for by early research workers, (Cazamian et al, 1936; McLaren, 1937) in the belief that bone cysts were associated with exposure to vibration. Kumlin et al (1973) confirmed this association. In the Dundee study a statistically controlled assessment by three radiologists failed to find a significant difference between the number of bone cysts in vibration-exposed and control subjects $(327$ total). The controls in this survey were predominantly manual workers in the same factory or forest environment, and differ therefore from the controls found in the studies of earlier research workers. In the assessment of severity of Raynaud's phenomenon, routine $\mathrm{X}$-ray of hands for bone cyst formation has, as yet, no place.

Similarly skin temperature tests in our hands have proved to be of limited value. A normal result does not indicate the absence of Raynaud's phenomenon. In a controlled laboratory situation, the induced blanching on cooling and the abnormally slow return of finger temperature on warming suggest occlusive vascular disease but not necessarily an abnormal reaction to a cold stimulus.

At present the search for a single test of disability assessment has been unsuccessful. In those cases where the blanching cannot be demonstrated but where the occupational history, with specific reference to vibration exposure and blanching attacks, is unclear, most or all of the tests described should be undertaken. 
The results are then assessed as a battery. Where doubt still remains, the tests are repeated after a suitable time interval (say one year), thus providing prospective data. The tests may also be used to assess reversal of signs and symptoms of VWF after vibration exposure has ceased, e.g. Stage 4 cases

\section{Vibration Threshold Limits and Standards.}

In the late thirties the formulation of provisional vibration-exposure limits appeared desirable as guidance even when at this time it was realised that such tentative limits and their frequency dependence were based on subjective psychophysical response data. In 1957 Miura et al determined limit values for vibratory tools specifying maximum amplitudes of $0.1 \mathrm{~mm}$ at $20 \mathrm{~Hz}, 0.055 \mathrm{~mm}$ at $50 \mathrm{~Hz}$, $0.045 \mathrm{~mm}$ at $100 \mathrm{~Hz}$ and $0.035 \mathrm{~mm}$ at $150 \mathrm{~Hz}$. The U.S.S.R. was also prominent in setting standards (Lyarskii, 1966) as well as giving guidance on the conditions for measuring the values, the permissable weight limits of tools or devices held by the hands, and the pressure force on the handles (not exceeding $20 \mathrm{kgs}$ ). In 1968, Axellson concluded from his researches in Sweden and Russia that the vibration injury range lay within the frequency band $50-500 \mathrm{~Hz}$, the risk of finger damage being dependent on the intensity of vibration, the duration of exposure, off-duty breaks within the shift, and the cumulative exposure in years. He produced tolerance limits for chain saws indicating that 
maximum clinical damage would occur around the 100-150 Hz frequency area. Despite a vigorous search the data on which those tolerance curves were based has not been found.

By the end of the sixties Draft Standards were being prepared for the International Standards Organisation. Louda of Czechoslovakia in 1969 submitted a Draft Standard for the guidance and evaluation of human exposure to hand-arm system vibration and these proposals were implemented by the authorities as hygiene regulations. Miura of Japan and Von Gierke of U.S.A. also submitted proposals to I.S.O. based on subjective assessment of the sensation of vibration. These proposals are shown in Figs. 30 and 31 along with those from a British Standards Institution panel MEE/158/7/1 proceeding along similar lines.

Draft for Development. BSI (Feb. 1975) D.D.43.

In 1974 it was felt within the U.K. that the time had come to give guidance to designers and manufacturers so that they may be aware of the extent to which they should attempt to reduce vibration levels without making their tools bulky or giving rise to excessive costs. The data on which the recommended limits were based were (a) vibration sensation levels from Japan, Sweden, U.S.A. and Czechoslovakia, and (b) the data made available from the 18 populations exposed to vibration in this study. 


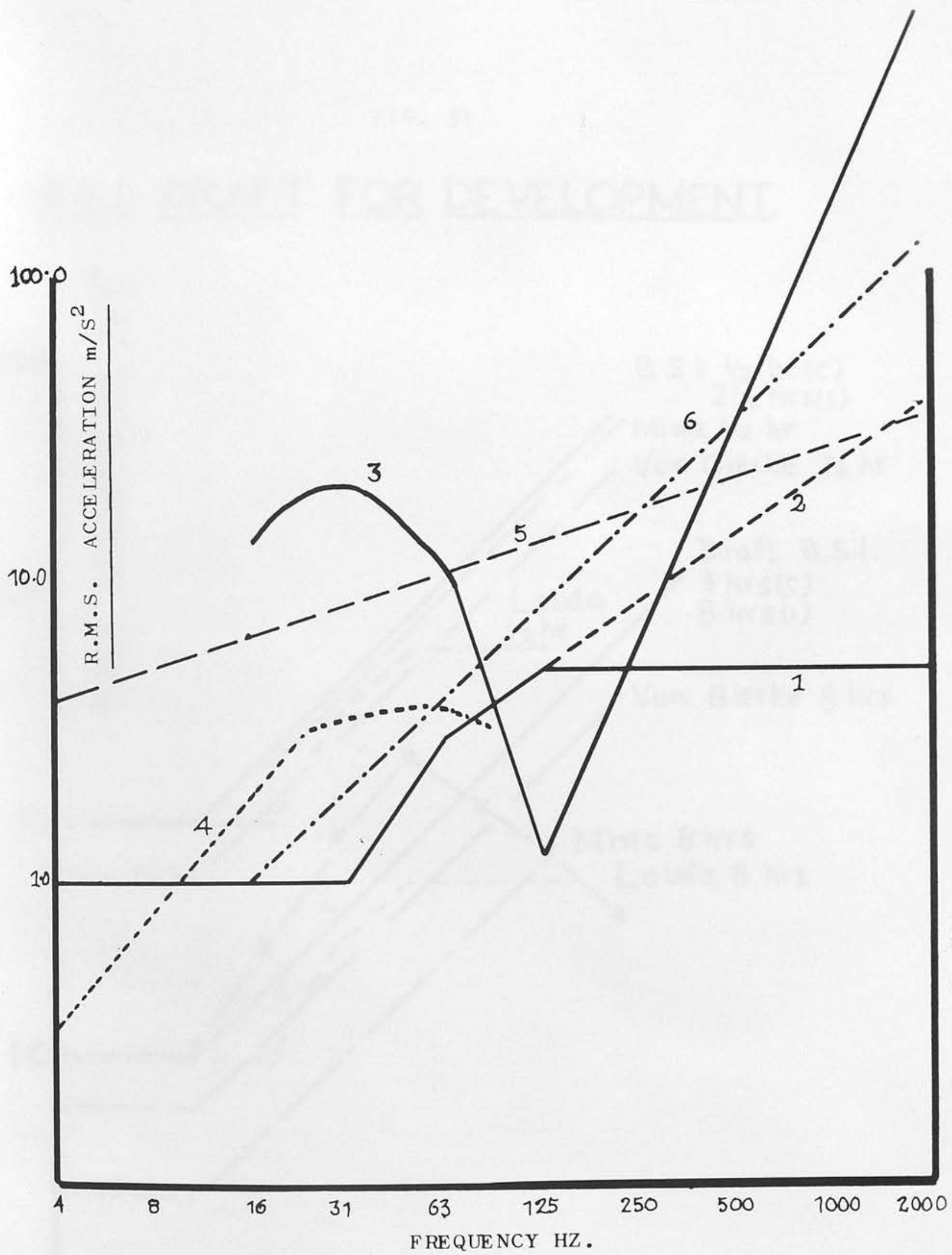

1. Czechoslovakian Hygiene Regulation No. 33 (1969).

2. Teisinger \& Louda Czechoslovakia 1966.

3. USSR Hygiene Regulation 1955.

4. USSR Gataninas Proposal after 1955.

5. USSR Hygiene Regulation 1966.

6. Britain Proposed Draft Standard 400 minutes per day.

Fig. 30 Hand-Arm Proposed Vibration Standards. 


\section{B.S.I. DRAFT FOR DEVELOPMENT.}

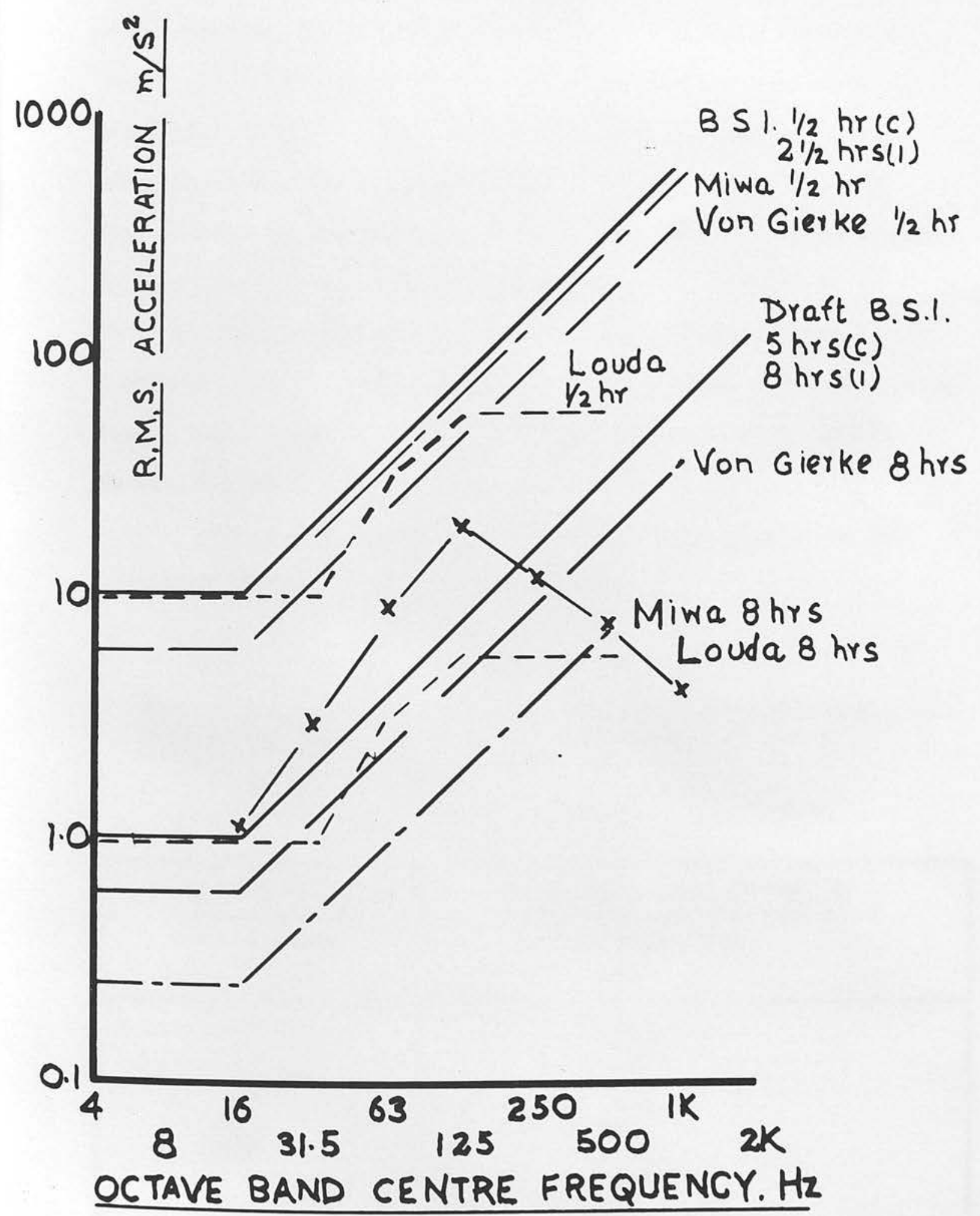


Draft Proposal: Guide for the Measurement and Evaluation of Human Exposure to Vibration Transmitted to the Hand (Sept. 1975). ISO/TC $108 / \mathrm{SC}$.

It is unfortunate that parallel to the efforts in the United Kingdom to publish guide lines for vibration exposure, the International Standards Organisation has been drawing up similar draft proposals, the latest of which followed an international meeting in the U.K. in September, 1975. The collection of reliable data on vibration exposure conditions affecting human health has proved to be more difficult than at first envisaged. In particular the I.S.O. Committee drew attention to the paucity of quantitative data concerning the occupational health effects of hand transmitted vibration. Until this data is available firm standards or limits cannot be set.

The values proposed by the I.S.O. Committee are shown in Table 13 and Fig. 32.

\section{TABLE 13.}

Tentative Exposure Boundary for Hand Transmitted Vibration for 2 to 8 hours uninterrupted daily exposure (I.S.O.)

\begin{tabular}{|c|c|}
\hline $\begin{array}{c}\text { Frequency: Centre } \\
\text { frequency of } \\
\text { octave band }\end{array}$ & $\begin{array}{c}\text { Maximum r.m.s. value of } \\
\text { vibration acceleration } \\
\text { in each axis } \\
\mathrm{m} / \mathrm{s}^{2}\end{array}$ \\
\hline 8 & 1.4 \\
16 & 1.4 \\
31.5 & 2.7 \\
63 & 5.4 \\
125 & 10.7 \\
250 & 21.3 \\
500 & 42.5 \\
1000 & 85 \\
\hline
\end{tabular}


I.S.O. Tentative Exposure Boundaries

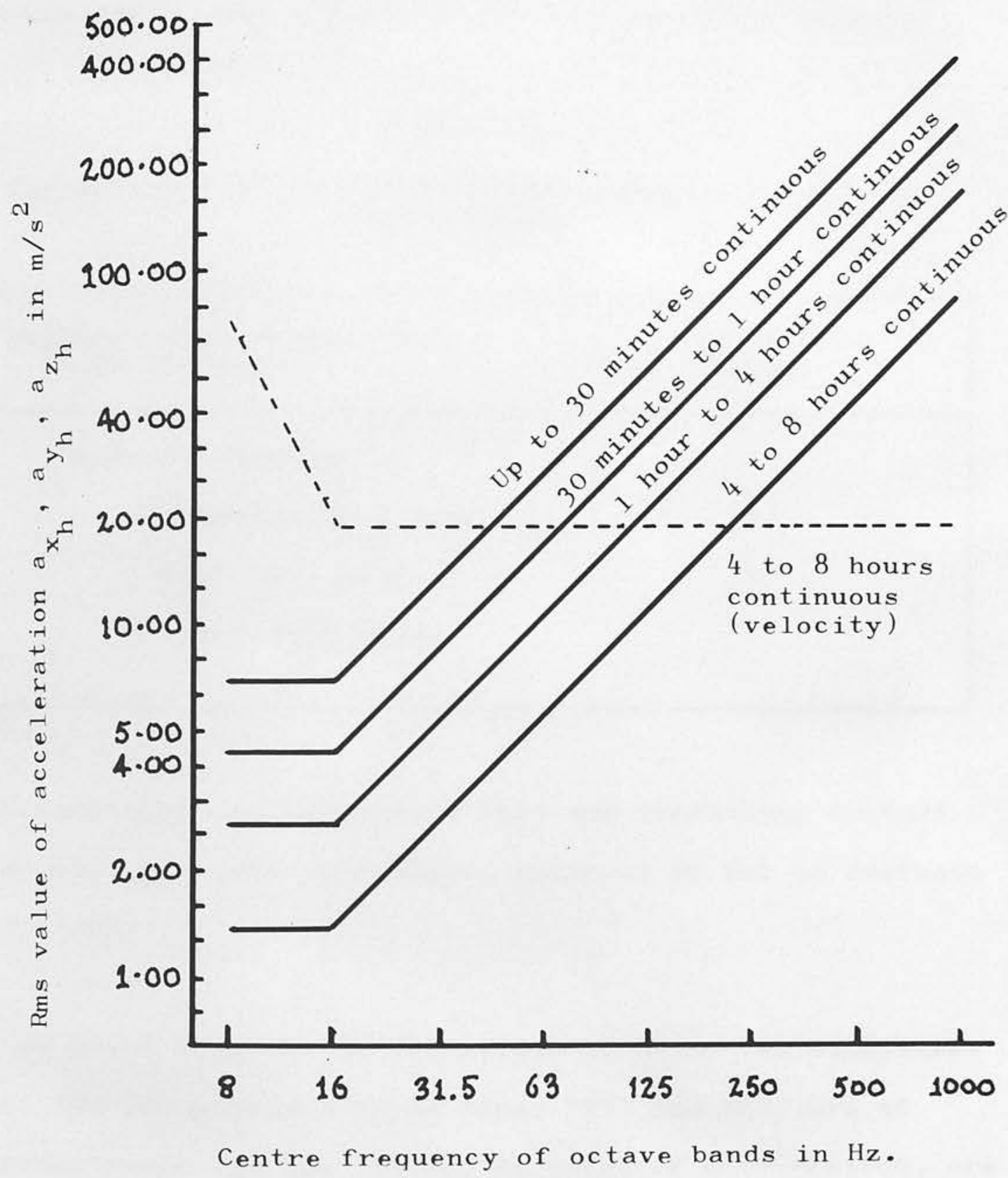


For total daily exposure times of less than 8 hours, uninterrupted or not regularly interrupted, exposure limits are raised by the correction factors shown in Table 14.

Table 14.

Correction factors for total daily exposures of less than 8 hours.

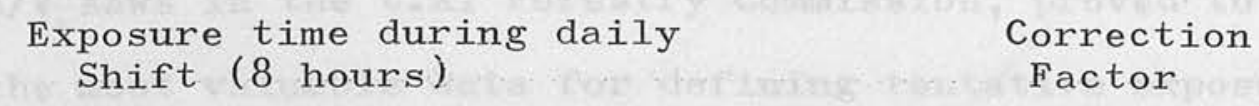

30 minutes to 1 hour

1 hour to 4 hours

4 hours to 8 hours

The Committee has emphasised that the correction factors can only give very approximate guidance on how to evaluate vibration:

It is clear from the deliberations of these two Committees that the two proposed guide lines (BSI and ISO) are of similar shape and the limits, in terms of acceleration, are within 10 metres/ $\mathrm{sec}^{2}$. Above $500 \mathrm{~Hz}$, the ISO proposals show higher limits. Both sets of curves, Figs. 32 and 33 indicate that above centre frequency $16 \mathrm{~Hz}$ there is a decreasing risk with increasing frequency shown by the $45^{\circ}$ slope of the guide lines. 
The vibration 'dose' has been difficult to assess with changing tools, work patterns and variable grip but dose-response danger areas having been highlighted in this study, it was felt that adherence to the limits suggested in the Draft Code would result in a significant decrease in prevalence of VWF throughout industry. In this connection the experience with non $A / V$ and recently $\mathrm{A} / \mathrm{V}$ saws in the U.K. Forestry Commission, proved to be the most valuable data for defining tentative exposure limits, particularly the follow-up prospective study of chain saw operators. Table 15 below gives the recommended vibration exposure limits (maximum permissible acceleration for (a) 400 minutes in an 8 hour day, and (b) a cumulative total of 150 minutes in an 8 hour day.) These values are shown in Fig. 33

TABLE 15

Recommended Vibration Exposure Limits for Regular Users of Vibration Tools (BSI, 1975)

\begin{tabular}{|c|cc|}
\hline $\begin{array}{c}\text { Octave Centre } \\
\text { Frequency } \\
(\mathrm{Hz})\end{array}$ & $\begin{array}{c}\text { Maximum } \\
\text { Permissible Acceleration } \\
\mathrm{m} / \mathrm{s}^{2}\end{array}$ \\
\cline { 2 - 3 } & $\begin{array}{c}\text { 400 minute } \\
\text { 8-hour day }\end{array}$ & $\begin{array}{c}\text { Cumulative 150 min. } \\
8 \text {-hour day }\end{array}$ \\
\hline 4 & 1 & 10 \\
8 & 1 & 10 \\
16 & 1 & 10 \\
31.5 & 2 & 20 \\
63 & 4 & 40 \\
125 & 8 & 80 \\
250 & 16 & 160 \\
500 & 32 & 320 \\
1000 & 64 & 640 \\
2000 & 128 & 1280 \\
\hline
\end{tabular}


Fig. 33

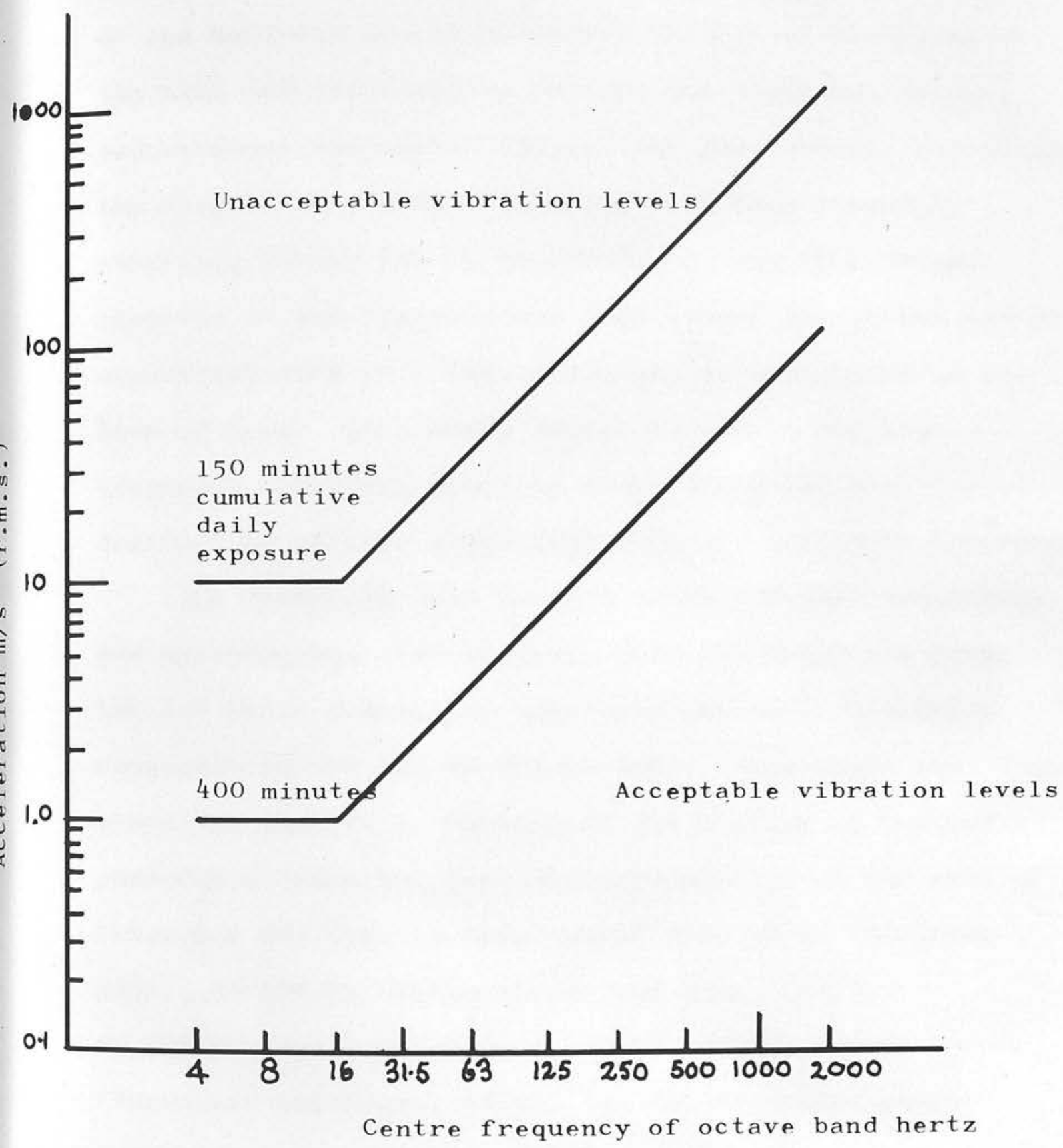

RECOMMENDED HAND-ARM VIBRATION EXPOSURE LIMITS FOR REGULAR USERS. 
The recent theoretical work of Suggs (1974) and Reynolds (1977) on the dynamic vibration characteristics of the Hand-Arm system following mechanical modelling of the hand and its coupling between the epidermis, dermis, subcutaneous and muscle tissues and the skeletal system in the fingers and hands, indicates that high frequency vibration (above $100 \mathrm{~Hz}$ to $200 \mathrm{~Hz}$ ) is absorbed in and isolated to the fingers, and that almost all of the energy associated with this high frequency is dissipated in the form of heat. This would imply that it is the high frequency vibration which is responsible for the destructive effects associated with the vibration syndrome. The vibration data in this study obtained from Chain Saw measurements also suggests that the frequency range 100-150 $\mathrm{Hz}$ is a damaging area with the major vibration component in the $125 \mathrm{~Hz}$ Octave band. (See Chain Saw (Fig.34) vibration spectra). Throughout the history of Raynaud's phenomenon there has been much speculation on the role of frequency and figures have ranged from $48 \mathrm{~Hz}$ (Telford, 1945), 33-100 Hz (Biden-Steele and King, 1947), 40-125 Hz (Agate and Druett, 1947) and 20-1000 Hz (Teisinger and Louda, 1972). In two fluorspar mines recently surveyed by the author (1976), the prevalence of VWF in the first mine was around $75 \%$ whilst in the second, the prevalence was approximately $10 \%$. Similar pneumatic drilling tools were being used in both mines and the miners had similar vibration exposure times. A difference in vibration spectrum was found in that in the high 
Fig* 34

CHAIN SAW VIBRATION. Standard (untreated) and new $A / V$ Saws.

VIBRATION - Highest level on any axis $\mathrm{X}, \mathrm{Y}, \mathrm{Z}$ on either handle.

HUSQUVARNA 70

JONSE RED 75

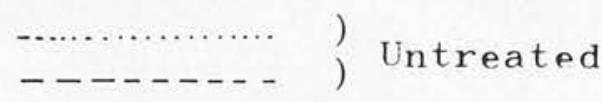

PARTNER R22

HUSQUVARNA 1605
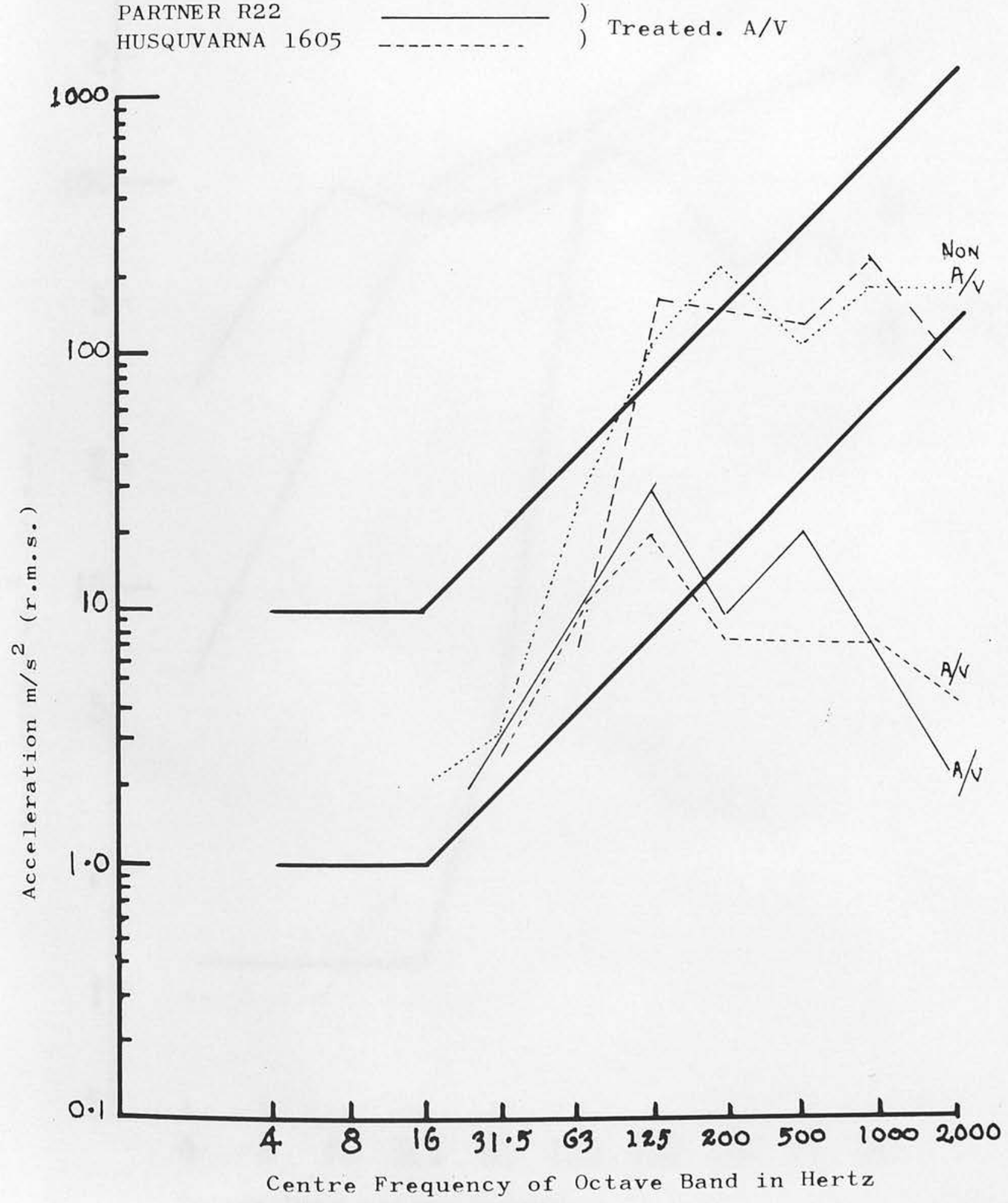
$-126-$

Fig. 35

VIBRATION SPECTRA OF CHAIN SAWS (untreated), Grinding and Swaging in octave bands.

A - Swaging

B - Pedestal Grinding

C - Chain sawing

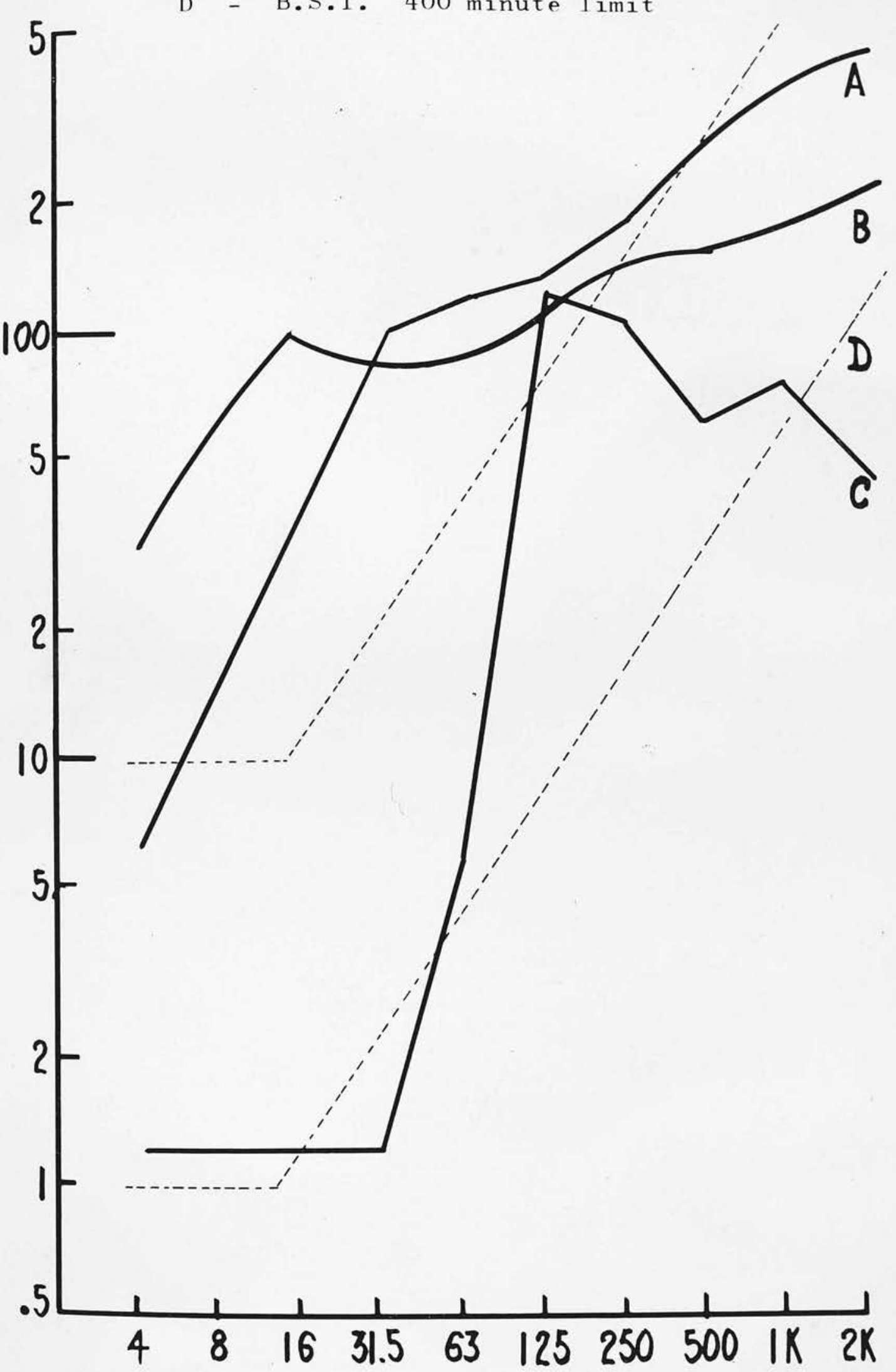

Octave band centre frequency in Hertz. 
prevalence mine there were higher frequency components in the drill spectra, i.e. above $100 \mathrm{~Hz}$. Further mine surveys are planned in order to provide more evidence to define the damaging frequency area. The present industrial evidence does not support the curve shapes adopted by both BSI and ISO (Fig.35).

\section{Prescription}

A disease or injury may be prescribed in relation to an insured person if the Minister is satisfied that (a) it is "a risk of their occupation and not as a risk to all persons", and (b) the attribution of particular cases to the nature of the employment can be established or presumed with reasonable certainty.

In February 1946, in Fitzsimmons $*$ Ford Motor Company Limited, the workman concerned had contracted Raynaud's phenomenon through using an electrically operated rotating fettling tool. The Court of Appeal awarded him compensation under the Workmen's Compensation Act based on the concept that the vibrations of the tool caused a series of blows to the man's hands and arm. His condition was due to an injury which had resulted from the cumulative effect of these blows, each of which was considered to be an accident. In a second case in 1949, the Tribunal reversed the Fitzsimmons judgment, holding that the claimant's incapacity was the result not of an injury by accident but of a continuous process and 
accordingly disallowed his claim. Following this case, the Minister asked the Industrial Injuries Advisory Council, in 1950, to consider whether Raynaud's phenomenon should be added to the list of prescribed diseases.

The Council reported in 1954, with a majority report against prescription on the grounds that (a) it was difficult to distinguish between occupational and nonoccupational cases, (b) the difficulty of defining the occupational cover, (c) the problem of diagnosing the condition and assessing the disablement resulting from it, and (d) the triviality of the disablement in the great majority of cases. Disability in the majority of cases would be assessed at less than $1 \%$ which the Act lays down as the minimum to attract benefit.

This Report is weak in that once it is established that cases of significant disablement may occur, then it is clearly wrong to accept that the high incidence of other cases of trivial nature is a justification for refusing prescription in the small number of reported severe cases of disablement. It was admitted, at this early date, that those who contract Raynaud's phenomenon may suffer change of occupation with loss of earnings and loss of faculty in relation to social life and the enjoyment of hobbies. Five of the 17 members of the Council associated themselves with the minority, i.e. in favour of prescription but one member - the late Dr. L.G. Norman could not support either the majority or minority Report. He recommended that Raynaud's 
phenomenon should be prescribed but that disablement benefit should not be awarded unless the loss of faculty exceeded $10 \%$ (loss of a ring finger, for example, would equal $7 \%$ ). This was, in the author's view, a very balanced judgment as one would expect from an experienced Medical Officer to London Transport.

The Minister made a second approach to Council in 1967. On this occasion the Minister asked for advice on the question whether diseases of the bones, joints, muscles, blood vessels or nerves of the hand, arm or shoulder (including Raynaud's phenomenon) caused by vibrating machines should be prescribed. At the request of the Industrial Diseases Sub-Committee, Dr. Alice Stewart (1968) was asked to undertake a fact-finding survey of over 1,000 vibratory tool users in 27 industrial occupations. Based on this evidence the Council issued an Interim Report in 1970.

The majority of Council now felt that given a reliable occupational history, including a history of the particular tools in use, there should be no difficulty in distinguishing occupational from non-occupational cases of vibration-induced white finger (VWF). However, the problem of diagnosis and assessment remained because there were still no generally recognised clinical tests which could be used to assess objectively the degree of disablement resulting from VWF. The question of muscle pains associated with vibration was disregarded and considered inappropriate for compensation. The question 
of damage to bones and nerves was still under investigation and incomplete. It was left over.

In its 1975 Report on the Vibration Syndrome, the Industrial Injuries Advisory Council again declined to recommend prescription and again on a majority vote. While recognising that there is no doubt that vibrating tools lead to a condition in the fingers affecting several thousands of people, the condition was not considered disabling and amounted to no more than a temporary inconvenience. In a few cases it was admitted it can lead to a change of job and a substantial loss of earnings. The basic reason for refusing prescription was the absence of objective clinical tests to enable a Board to make an accurate assessment of the disablement. The Council Report (Vibration Syndrome, 1975) made a strong plea for prevention by referring to the BSI Draft Code on Vibration (1975) and to other measures open to industry to reduce the exposure of employed persons to vibration.

It is admitted that serious cases are difficult to find for the reason that remedial action is sought by the subject before tissue necrosis or permanent cyanosis of the digits occurs. The written evidence submitted to the Council from the work reported here and in personal evidence stressed that serious disabling cases do occur (Appendix. A.H. and W.P.). The evidence from our surveys (not considered in depth by Council) was the evidence of cumulative energy with resulting deterioration in the digital artery circulation. In the chain saw data 
there is strong evidence showing increasing Stage assessment with increasing saw exposure time. Therefore if there is continuing exposure to vibration, the characteristics of which are known to be outside the tentative limits set by ISO and BSI, clinical deterioration will inevitably result.

The author has experienced no difficulty in (a) diagnosing Raynaud's phenomenon and (b) assessing the Stage. After a careful history to exclude primary Raynaud's disease and secondary causes other than vibration, the presence of the following signs are noted: cold hands at normal room temperatures, blanching of the fingers on cold water immersion, progressive enlargement of the fingers and impaired finger sensation (depth sense, two point, light touch and pain). A history of exposure to vibration at work, where one or more cases of VWF are known to have occurred, is subjective information which may be easily verified. If the vibration measurements of the tool used are also known (and these are around or above the recommended limits) then the evidence is beyond reasonable doubt.

In doubtful cases, in vascular clinics, dealing with obliterative vascular disease, plethysmography and arteriography could be undertaken to exclude abnormal vessel anatomy, e.g. absence of ulnar artery, arch abnormalities.

Finally, now that there is increasing emphasis on time off and leisure activities for the great majority of working people both noise-induced deafness and VWF 
have to be considered more seriously than in the past in relation to the quality of life outside working hours and to their effect on hobbies, (McCallum, 1971). When alternative work has to be obtained because of a deteriorating VWF situation, a considerable financial sacrifice is usual (Pelmear, 1975) of the order of $£ 628$ per annum.

Note: From published sources, VWF is recognised as an occupational induced disease in the following countries - Czechoslovakia, Finland, Federal Republic of Germany, Italy, Luxemburg, Norway, Poland and Sweden.

The Lancet (1970) makes a relevant comment:"this condition has been known for a long time. Is it really beyond the capacity of industrial medicine and the Law to evolve a formula which would allow compensation to the significantly affected but guard against the trivial or questionable claim. In each case, a judgment would be called for - but there is nothing new in that." 
Code of Practice.

The Health and Safety Commission, replacing the Industrial Injury Advisory Committees, is concerned with a safe working environment, and the encouragement of the best standards of occupational medicine. With reference to Raynaud's phenomenon, a Code of Practice is urgently required to (a) reduce the vibration exposure of employed persons, and (b) prevent the severe complications of VWF. One enlightened management has already embarked on the following action - (1976) :-

1. To identify and analyse all vibration processes within the Works.

2. To avoid human exposure to vibration above the BSI Draft Proposals for Vibration Limits.

3. Pre-employment and periodic clinical examination of all personnel exposed to vibration. (Routine monitoring for VWF).

4. The use of $\mathrm{A} / \mathrm{V}$ equipment, for example, where tools are available with low vibration levels on handles. These should be incorporated in the Work process.

5. The gradual introduction of alternate work methods (e.g. lathes, turning machines, milling).

6. The surveillance of VWF cases and in deteriorating cases to transfer to non-vibration work, particularly in Stage 2 .

A large engineering firm has implemented the above programme. Since Prescription has been disallowed, litigation for Common Law Compensation will increase. 
There has been one successful Common Law claim (Lambert $\forall$ Vauxhall Motors, The Times, May 26, 1973). The cost of claims and the additional insurance cover will encourage managements to assess their vibration work situations and to avoid producing advanced VWF cases. 
1. Epidemiological data $(1968-1976)$ is presented from 18 industrial processes in four broad categories chain sawing, pedestal and hand grinding, chippers using pneumatic tools and swagers of copper tubes representing 827 vibration exposed personnel and 365 control subjects. In 1976 a further three populations of fluorspar miners (Northumberland) have been added. Plans have been made to survey chippers and grinders using pneumatic tools in the U.S.A. in October 1977, a joint project with the U.S. Government (National Institute for Occupatinnal Safety and Health) involving 1800 vibration exposed pneumatic tool operators.

2. In 827 male vibration subjects, 44 cases (5.3\%) of Raynaud's disease (constitutional white finger) were found. In 365 controls, 23 cases $(6.3 \%)$ were found.

3. A large variation in the prevalence of Raynaud's phenomenon was found in the four broad categories ranging from 0 to $89 \%$. Statistically VWF prevalence was shown to be an inaccurate measure of the vibration hazard inherent in industrial processes since the prevalence will be dependent on the vibration exposure time of the subjects, the turnover, and the subjects leaving the work process. 
The latent interval - the interval between first exposure to vibration and the first appearance of a white finger tip, was found to be a better guide to the clinical course of VWF.

4. The shortest latent interval was found with copper swaging (6-8 months, with some cases at 1-2 months). Then followed pedestal grinding ( 1 to 1.8 years), with some cases at 6 months. Chain sawing with the older type, untreated saws gave a latent interval of 2.8 to 3.6 years.

5. As well as assessing the medical VWF stage, the vibration team measured the vibration stimulus for all the work processes including pneumatic tools. In both the retrospective and prospective surveys of chain sawyers of the U.K. Forestry Commission, there was a correlation between the vibration exposure times and the resulting stage of VWF - the longer the vibration exposure, the higher the Stage (clinical deterioration) of VWF. This correlation suggests that vibration (analagous to noise and hearing loss) is cumulative in the hands, particularly the fingers.

6. The vibration measurements for chain saws (measured on saw handles) indicated that the early pre 1970 models had unacceptably high vibration levels. The 11 regular Forestry Commission chain saw operators were, in 1970, issued with vibration damped saws (A/V). 
These new saws were within the 150-300 minute levels of vibration and it was therefore not necessary to change the working system. The prospective study reported here shows that no new case of VWF has arisen with 6 years of A/V saw usage. The prevalence of VWF first reported in 1970 at $88 \%$ has now been reduced to $50 \%$ in 1976. In summary, Raynaud's phenomenon in chain saw operators has been controlled and is no longer an occupational health hazard within the Forestry Commission.

7. The measurement of vibration in pneumatic tools with high energy peaks has proved to be a difficult technical problem and only in 1976-77 are the engineers now perfecting and standardising a method of measurement to be used throughout the world. It has also proved difficult to redesign pneumatic tools to conform to BSI and ISO Vibration Limit proposals. The tool designers themselves are requesting vibration design criteria, particularly relating the vibrational energy to the medical VWF data. In all countries the research emphasis is now on pneumatic tools, and the collection of engineering and medical data. The U.S.A. is embarking on its first major project in this research area in October 1977, with a survey of chippers and grinders using hand-held pneumatic tools 
8. From 1968 a large amount of research time, energy and finance has been made by the Dundee team to find an objective test for the assessment of VWF. The neurological, temperature and vascular tests when executed with precision on an age-sex matched control group from the same environment, failed separately on an individual basis, whilst differentiating statistically between vibration exposed and control groups. It must now be accepted that where there is large individual biological variation (particularly obvious in blood flow), retrospective surveys using these tests for assessment will fail. On the other hand, these tests will detect a deteriorating case prospectively and are therefore of value in routine monitoring of VWF situations.

9. In one of the work processes examined in this series pedestal grinding - brachial arteriography was carried out on 18 pedestal grinders. In 14 subjects, 68 digital arteries were outlined of which 34 showed definite evidence of occlusion. At least one occlusion was present in each grinder. This invasive technique should be reserved for diagnostic purposes to define abnormal artery anatomy. It is not a recommended works procedure.

10. From the limited number of case histories of severely affected VWF patients documented, it is clear that with 
continued high energy vibration inputs to the hands in the frequency range $100-250 \mathrm{~Hz}$, attacks of white finger progress to a chronic state of congestive ischaemia or cyanosis, the final outcome of which is likely to be tissue anoxia and necrosis of the finger tips.

If vibration exposure is discontinued at an early stage (Stages 1 or 2), apparent clinical recovery may occur (from chain saw prospective data). In advanced Stage 3 cases and in all Stage 4 cases, the VWF appears to be irreversible and indeed may be progressive even after the vibration stimulus is withdrawn. Therefore it is strongly recommended that all Stage 3 cases should avoid further vibration exposure and be removed from the damaging work process.

11. In association with this research project, a draft for a proposed British Standard for Hand-Arm Vibration has been developed. It is hoped that a Code of Practice for Vibration will follow.

12. As a result of this work, the author and research team are strongly of the opinion that Raynaud's phenomenon should be accepted as a Prescribed Industrial Disease. The evidence that, in the majority of cases the disablement is trivial but that cases of significant disablement do occur, is no justification for refusing prescription. 
13. Since 1862, when Raynaud produced his famous M.D. Thesis, little is known about the basic physiology involved in Raynaud's disease or on the subject of this study of Raynaud's phenomenon. The mechanisms why vibration causes stresses to arise in the hand-arm system leading to discomfort, trauma and digital artery damage are unknown. It is accepted that artery wall shear stress has a direct effect on the transport of blood elements if shear becomes too high, this can result in endothelial damage. Vibrating tools such as jack hammers and pneumatic chisels produce shear stresses in the digital arteries of 1200 dynes $/ \mathrm{cm}^{2}$. Both Magos (1974) and Nerem (1973) believe the development of Raynaud's as follows, Fig. 36.

\section{Build up of Shear Stress \\ Transformation of vibrational energy into heat \\ Increased capillary permeability \\ Release of biochemically active substances \\ Vessel wall changes (deposition of fibrin and elastin)}

All workers react to the first phase of the defense mechanism, the body defense against cooling namely vasoconstriction, whether or not they suffer from Raynaud's disease. It is in the second phase, namely cold dilation which is depressed in Raynaudsensitive individuals. The blood vessels of the fingers and hand are unable to react appropriately 
to allow sufficient dilation in cold environments thus displaying increased sensitivity to cold.

14. In those Stage 3 cases who have come for medical help, both vaso-dilators and surgery (sympathectomy) have proved unsuccessful. A similar view was expressed in a review of a hundred operations in 1934 (Telford).

15. On the engineering side the BSI and ISO proposals recommending safe vibration exposure limits, are based on subjective reactions and do not represent reliable field data. The variation between the two sets of proposals is such that application to the plant situation must be performed with caution. Vibration levels are judged noticeable, unpleasant, intolerable. Regular interruption of exposure are beneficial and the ISO proposals recognise this in their correction factors. The U.K. has adopted a more flexible approach and only the total duration of exposure to vibration is regarded as important. Interruptions are not quantified. In summary, in 1977 we have guidelines rather than risk criteria - levels exceeding these values are however likely to be hazardous.

16. It has been concluded by the engineers that the medical assessment of risk would be easier to evaluate if the energy into the hand was measured rather than the vibration on the tool itself. Attempts will be made in the 1977 American surveys to measure mechanical impedance and energy transmissibility as well as 
vibration measurements on the tool itself.

17. The lack of general agreement on the principles upon which vibration proposals are to be applied makes the evaluation of mixed exposures impossible at this stage. These problems will not be resolved until more medical epidemiological data related to vibration exposure patterns in specific work situations has been collected. Therein lies the survey work of the future. 
Arterial Wall Shear Stress and ondothelium damage (after Norem)

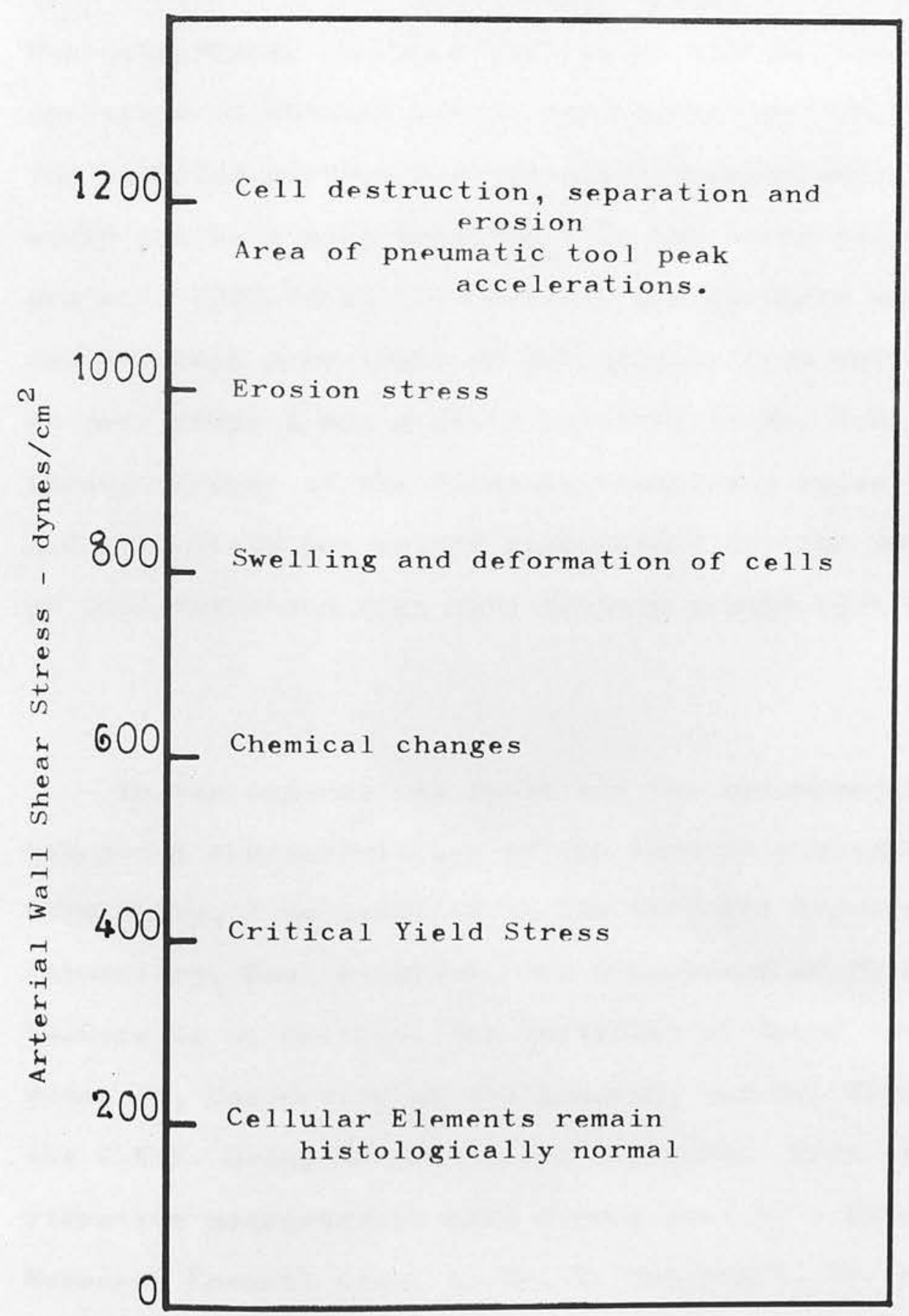




\section{ACKNOWLE DGMENTS.}

From 1968 to 1977 throughout this vibration research project I have been associated with my colleague Dr. P.L. Pelmear, Senior Medical Officer of Guest, Keen and Nettlefolds, Forgings and Castings of Bromsgrove, Worcestershire. Without his assistance and the cooperation of the management and men of the G.K.N. factories the clinical surveys for vibration-induced white finger would not have been possible. In the early years of the project, 1968-1972, the emphasis was on chain saw operators and the high prevalence of VWF arising from untreated saws. At that stage I was greatly indebted to Mr. G.D. Keighley, Safety Officer of the Forestry Commission whose interest and enthusiasm was mainly responsible for the introduction of anti-vibration saws into Britain around 1970-71.

In the engineering field and the measurement of the vibration characteristics of the various processes surveyed clinically, I am indebted to the National Engineering Laboratory, East Kilbride, the Department of Physics, University of Salford, the Institute of Sound and Vibration Research, University of Southampton, and Mr. Kitchener of the G.K.N. Group Technological Services. From 1972 the vibration measurements have formed part of a Science Research Council Grant to Dr. I. Hempstock, Mr. D. O'Connor and the author. 
From 1968 to 1976 I thank my colleague Dr. J. Pearson (now at the University of Nottingham) for his active participation and assistance in the statistical analyses, particularly in the area of clinical objective tests and their assessment.

Finally, Miss E. Simpson has been associated with the Vibration Research Project since 1968 and I am indebted to her for her assistance in preparation of papers and typing this Thesis. 
PUBLISHED PAPERS

on RAYNAUD'S PHENOMENON

1. Vibration Syndrome in Forestry Commission

Chain Saw Operators (1971).

Brit. J. Indust. Medicine, 28, 83-89.

2. The Vibration Syndrome. Introduction

to British Acoustical Society Special

Volume No. 2. Proceedings of a

Conference on the Medical Engineering and Legal Aspects of Hand-Arm Vibration, University of Dundee (1972), Academic Press.

3. Raynaud's Phenomenon in Forestry Chain Saw Operators (1972). Taylor, Pelmear and Pearson. Vibration Syndrome (1974). Edited, W. Taylor. (Academic Press).

4. Raynaud's Phenomenon in Pedestal Grinders. (1972). Pelmear, Taylor and Pearson. Vibration Syndrome. Edited, W. Taylor (Academic Press).

5. Vibration-induced White Finger Epidemiology,

(1975). Taylor, Pelmear and Pearson. Vibration White Finger in Industry. Edited, W. Taylor and P.L. Pelmear. Academic Press, London \& New York.

6. A Longitudinal Study of Raynaud's Phenomenon in Chain Saw Operators (1975). Taylor,

Pelmear and Pearson. Vibration White Finger

in Industry. Edited, W. Taylor and P.L. Pelmear. Academic Press, London and New York.

7. Clinical Objective Tests for Vibration White Finger (1975). Pelmear, Taylor and Pearson. Vibration White Finger in Industry. Edited, W. Taylor and P.L. Pelmear.

8. The Results of Long-Term Vibration Exposure with a Review of Special Cases of Vibration White Finger. Pelmear and Taylor (1975). Vibration White Finger in Industry. Edited, W. Taylor and P.L. Pelmear. 
9. Correlation of Epidemiological Data and the Measured Vibration (1975). Taylor, Pelmear, Hempstock, O'Connor and Kitchener. Vibration White Finger in Industry. Edited, W. Taylor and P.L. Pelmear, Academic Press.

10. Vibration-Induced White Finger. (1975).

Leader, The Lancet. Nov. 8, 911-912.

11. Raynaud's Phenomenon of Occupational

Origin - An Epidemiological Survey (1975).

W. Taylor and P.L. Pelmear.

Acta Chirurgica Scandinavia

Supplement 465. Primary and Secondary

Raynaud's Phenomena.Symposium.

Departments of Clinical, Physiology

and Surgery, Central Hospital,

Vaxjo, Sweden.

12. Raynaud's Phenomenon in Chain Sawyers in Britain (1977). W. Taylor and P.L. Pelmear. (In press). International Symposium on Hand-Arm Vibration, National Institute for Occupational Safety and Health (NIOSH) United States Department of Health, Education and Welfare, Cincinnati, Ohio, held October, 1975. 
(A)

1. The Vibration Syndrome - Edited by W. Taylor. British Acoustical Society Special

Volume No. 2 (1974). The Academic Press, London and New York.

2. Vibration White Finger in Industry - Edited by W. Taylor and P.L. Pelmear (1975). Report submitted to the Department of Health and Social Security in December, 1973. The Academic Press, London and New York.

3. Proceedings of an International Conference on Hand-Arm Vibration. Edited by

D. Wasserman and W. Taylor (1977).

(B) CONSULTANT AND ADVISER TO -

1. Forestry Commission (Britain) 1968-1976

2. Guest, Keen and Nettlefolds.

Forgings and Castings Division

Bromsgrove, England.

$1969-1975$

3. British Steel Corporation,

Consett Works and

1975

Teeside Division

continuing

4. United States Department of Health, Safety and Welfare

Oct. 1975

National Institute of

Occupational Safety and

Health (NIOSH)

Cincinnati, Ohio.

U.S. Government, NIOSH, Cincinnati.

Jan.1977 Survey planning 2-week period with Statistical team

Do. October 1977-1978. Survey of Pneumatic Tool Chippers and Grinders. 
CONFERENCES AND INTERNATIONAL MEETINGS

On RAYNAUD'S PHENOMENON - LECTURES

Date

MAY, 1970

DECEMBER， 1970

SEPTEMBER 5 th -8 th $\underline{1971}$

NOVEMBE R, 1971

FEBRUARY, 1972

JULY, 1972

OCTOBER, 1972

OCTOBER, 1973

NOVEMBER, 1973
Place

Clinical Conference, Dundee

British Acoustical Society, London

Royal College of Forestry, Stockholm National Board of Industrial Safety National Swedish Testing Institute, Uppsala.

National Institute for Public Health Karolinska Institutet, Stockholm.

Royal Navy, Davenport, England

International Conference on Vibration, University of Salford

International Conference on the Medical Engineering and Legal Aspects of Hand-Arm Vibration (Organiser - W. Taylor)

Gruppo Di Ricerca Per La Cibernetica Pisa, Italy.

Society of Occupational Medicine, London

Annual Meeting, Royal College of Nursing, London 
Date

SEPTEMBER, 1974

OCTOBER, 1974

MARCH, 1975

SEPTEMBER, 1975

OCTOBER， 1975

SEPTEMBER， 1976

JANUARY, 1977
National Institute of Public Health, Karolinska Institutet, Stockholm, Sweden.

Caledonian Branch of Clinical Pathologists, Dundee.

International Conference Acta Chirurgica, Scandinavia, Vaxjo, Sweden.

International Cardiovascular Society, Edinburgh

International Hand-Arm Conference, U.S. Health, Safety and Welfare Department, Cincinnati, Ohio, (Organisers: W. Taylor and D. Wasserman)

Mankind and Medicine in the Third Millenium, Tygerberg Hospital, Cape Town, Republic of South Africa.

National Institute for Occupational Safety and Health (NIOSH); Working Party Conference on Future U.S. Vibration White Finger Surveys, to commence October, 1977. 


\section{REFERENCES}

ACTON, W.I. (1974). Aspects of Field Vibration Measurements. The Vibration Syndrome. Ed: W. Taylor. Academic Press, London.

AGATE, J.N. (1949). An outbreak of Cases of Raynaud's Phenomenon of Occupational Origin. Brit. J. industr. Med., 6, 144.

AGATE, J.N. and DRUETT, H.A., (1946). A Method for Studying Vibrations, Transmitted to the Hands. Brit. J. industr. Med., 3, 159 .

AGATE, J.N. and DRUETT, H.A. (1947). A Study of Portable Vibrating Tools in relation to the Clinical Effects which they Produce. British J. industr. Med., 4, 141.

AGATE, J.N., DRUETT, H.A. and TOMBLESON, J.B.L. (1946). Raynaud's Phenomenon in Grinders of Small Metal Castings. Brit. J. industr. Med., 3, 167 .

ALLEN, E.V., BARKER, N.W. and HINES, E。A. (1962). Peripheral Vascular Diseases. 3rd Edition. W.V. Saunders Co., Philadelphia.

ALLINGHAM, P.M. and FIRTH, R.D. (1972). Vibration Syndrome. The New Zealand Med. Journal. $76,486,317-320$.

ASHE, W.F., COOK, W.T. and OLD, J.W. (1962). Raynaud's Phenomenon of Occupational Origin. Arch. Environ. Health 5, 333.

ASHE, W.F. and WILLIAMS, N. (1964). Occupational Raynaud's II. Arch. Environ. Health, 9,425 .

AXELSSON, S. (1968). Analysis of Vibration in Power Saws. Monograph No. 59, Royal College of Forestry, Stockholm, Sweden.

AXELSSON, S. (1975). V.W.F. in Swedish Forestry Workers. Proceedings of International HandArm Vibration Conference, Cincinnati. (In press).

BARKER, N.W. and HINES, E.A. (1944). Arterial occlusion in the Hands and Fingers associated with repeated occupational trauma. Proc. Staff Meet. Mayo Clinic, $19,345$. 
BARNES, A.W. (1976). Vinyl Chloride and the production of P.V.C. Proc. Royal Soc. of Med. $69,4,277$.

BARNES, R., LONGLEY, E.O., SMITH, A.R.B. and ALLEN, J.G. (1969). Vibration

Disease. Med. J. Aust. 1, 901.

BERNARD, C. (1813-1878) - Discovered that the "sympathetic" is the constrictor nerve for the blood vessels.

BIDEN-STEEL, K., and KING, F.H. (1947). "Dead Hand" in operators using electrically-driven Cutting Tools. The Medical Press, 218,144 .

BJERKER, N., KYLIN, B. and LIDSTROM, I.M. (1970). Changes in the Vibratory Sensation Threshold after Exposure to Powerful Vibration. A preliminary Report. Work Environment Health, 7, 1, 3 . Excerpta Medica. 1, 8, 1440.

BRITISH STANDARDS INSTITUTION, LONDON. Draft for Development (DD43, 1975). Guide to the Evaluation of Exposure of the human hand-arm system to vibration.

BROCKLEHURST, T. (1945). Pseudo-Raynaud's Disease due to Electric Vibratory Tools. The Medical Press. 213, 10.

CARY, N.A. (1918). Report on 8 cases at Camp Shelby, Miss. Bulletin 236, U.S. Bureau of Labor Stat. 19, 97.

CAZAMIAN, P., DRIVET, J., and SOULE, J.L. (1936). An investigation into Vibration Disease in Coal Mines. Systematic Examination of 100 miners in the Cavennes Coal Mines. Arch. Maladies Profess 15,44.

COOK, W.A., GIEVER, P.M., DINMAN, B.D. and MAGNUSON, H.J. (1971). Occupational Acro-osteolysis II. An Industrial Hygiene Study. Arch. Environ. Health 22, 74 .

CORDIER ET AL (1966). Acro-ostéolyse et lésions cutanées associées chèz deux ouvriers affectés aunettoyage d'autoclaves. Cahiers de Médecine du Travail, 4, 14-19. 
cotTINGHAM, C.E. (1918). Statements of Physicians Reporting on behalf of the Employees and the Employers. Bulletin 236, U.S. Bureau of Labor Stat. 19, 125.

CREECH, J.L. and JOHNSON, M.N. (1974). Angiosarcoma of liver in the manufacture of polyvinyl chloride. J. occup. Med., 16, 150.

DINMAN, B.D., COOK, W.A., WHITEHOUSE, W.M. MAGNUSON, H.T. and DITCHECK, T. (1971). Occupational Acroosteolysis 1. An Epidemiological Study. Arch. Environ. Health, 22, 61.

DODSON, V.N., DINMAN, B.D., WHITEHOUSE, W.M., NASR, A.N.M., MAGNUSON, H.J. and ARBOR, A. (1971). Occupational Acro-osteolysis III. A clinical study. Arch. Environ. Health, 22, 83.

EDSALL, D.L. (1918). Report to Surg. Gen. Blue on the supposed Physical Effects of the Pneumatic Hammer on the Workers in Indiana Limestone.

Bulletin 236, U.S. Bureau of Labor Stat. 19, 144 .

EDWARDS, E.H. (1954). Varieties of Digital Ischaemia and their Management.

VON GIERKE, H.E. (1971). Guide for the evaluation of human exposure to hand transmitted vibration. Draft document prepared for I.S.0. Technical Committee 108 Working Group 7 .

GRIFFIN, M.J. (1974). Some problems associated with the Formulation of Human Response to Vibration. The Vibration Syndrome. Ed: W. Taylor. The Academic Press, London.

GROUNDS, M.D. (1964). Raynaud's Phenomenon in Users of Chain Saws. Med. J. Aust. 1, 270.

GUIGNARD, J.C. (1965). Chapter 29. Vibration in Textbook of Aviation Physiology. Pergamon Press.

GURDJIAN, E.S. and WALKER, L.W. (1945). Traumatic Vasospastic Disease of the Hand (White fingers). J.A.M.A. 129, 668. 
HAMILTON, A. (1918). A study of Spastic Anaemia in the Hands of Stonecutters.

Bulletin 236, U.S. Bureau of Labor Stat. 19, 53.

HAMILTON, A. (1930). A Vasomotor Disturbance in the Fingers of Stonecutters. Arch. Gewerbepath, 1, 348 .

HARDGROVE, M.A.F. and BARKER, N.W. (1933). Pneumatic

Hammer Disease. A Vasospastic

Disturbance of the Hands in

Stonecutters. Proc. Staff Meet. Mayo Clinic, 8, 345.

HELLSTROM, G. and ANDERSEN, K.L. (1972). Vibration

Injuries in Norwegian Forest

Workers. Brit. J. industr. Med.

$29,255$.

HEMPSTOCK, T.I. and O'CONNOR, D.E. (1974). The

Vibration Characteristics of several

Engineering Processes which produce

white finger. The Vibration

Syndrome. Ed; W. Taylor,

Academic Press, London.

HUNT, J.H. (1936). The Raynaud's Phenomena. A

critical Review. Quart J. Med.

New Series 19, 399.

HUNT, J.H. (1936)。 Raynaud's phenomenon in Workmen

using Vibrating Instruments.

Proc. Roy. Soc. Med. 30, 171.

HUNTER, D., McLAUGHLIN, A.I.C. and PERRY, K.M.A. (1945).

Clinical Effects of the use of

Pneumatic Tools. Brit. J. industr.

Med. 2, 10 .

HUTCHINSON, J. (1893). Med. Week, 1, 85.

INDUSTRIAL INJURIES ADVISORY COUNCIL REPORT (1954).

Raynaud (s Phenomenon.

Cmnd. 9347. H.M.S.O., London.

INDUSTRIAL INJURIES ADVISORY COUNCIL REPORT (INTERIM) (1970).

Vibration Syndrome. Cmnd. 4430,

H.M.S.O., London.

INDUSTRIAL INJURIES ADVISORY COUNCIL REPORT (1975).

Vibration Syndrome. Cmnd. 5965.

H.M.S.O., London. 
JAMES, P.B., and GALLOWAY, R.W. (1975). Arteriography of the Hand in men exposed to

Vibration. Vibration White Finger in Industry. Ed: W. Taylor and P.L. Pelmear, Academic Press, London.

INTERNATIONAL STANDARDS ORGANISATION (I.S.O.). 1976 Guide for the Evaluation of Human Exposure to hand-transmitted vibration.

JEPSON, R.P. (1954). Raynaud's Phenomenon in Workers with Vibratory Tools. Brit. J. industr. Med. 11, 180.

KOZMINSKA, A. and ZAWADZKA, M. (1969). Detection of Lesions in Small Blood Vessels of the Hands in Patients with Vibratory Disease. Polish Med. J. 8,227 .

KOZMINSKA, A•, ROZANSKI, J• and LANGNER, B. (1970). Studies on the effect of vibration on the peripheral blood vessels. Polish Med. J. 9, 5, 1236.

KUMLIN, T. (1970). Densitometric Studied on Metacarpal Bones of Workers exposed to Vibrating Tools. Work Environ. Health $7,1,57$.

KUMLIN, T., WIIKERI, M. and SUMARI, P. (1973). Radiological Changes in Carpal and Metacarpal Bones and Phalanges caused by Chain Saw Vibration. Brit. J. industr. Med. 30, 71 .

KUZELOVA, M. et al (1964). Contributions to the Differential Diagnosis of Vascular Disease in Work with Pneumatic Tools. Pracovni Lekarstvi, 16, 7, 328.

KYLIN, B. , GERHARDSSON, G. , HANSSON, J. LIDSTROM, S. , LIGENBERG, B. SVENSSON, A. and ASTRAND, I. (1968). HALSO-OCH Miljoundersok_ning bland skogsarbetet (Health and Environmental Research in Forestry). Etave Al-Rapporter.

LANCET, Editorial: W. Taylor (1975). The Vibration Syndrome. Nov. 8th, 911-912.

LANCET, Editorial (1970). 2, 350. 
LAWS, J.W. LILLIE, J.G. and SCOTT, J.T. (1963). Arteriographic Appearances in Rheumatoid Arthritis and other Disorders. Br. J. Radiol. 36, 477 .

LAWS, J.W., EL SALLAB, R.A. and SCOTT, J.T. (1967). An Arteriographic and Histological Study of Digital Arteries. Br. J. Radiol. 40, 740 .

LEAKE, J.P. (1918). Health Hazards from the use of the air hammer in cutting Indiana Limestone. Public Health Rep. Wash. 33, 379. Bulletin 236, U.S. Bureau of Labor Stat. 19, 100.

LEWIS, T. (1929). Experiments Relating to the Peripheral Mechanism Involved in Spasmodic Arrest of the Circulation in the Fingers, a variety of Raynaud's Disease. Heart, 15, 7 .

LEWIS, T. (1938). The Pathological Changes in the Arteries Supplying the Fingers in warm-handed people and in cases of so-called Raynaud's Disease. Clin. Sc. 3, 287 .

LEWIS, T. and PICKERING, G.W. (1934). Observations upon Maladies in which the blood supply to digits ceases intermittingly or permanently, and upon bilateral gangrene of digits. Observations relevant to so-called Raynaud's Disease." Clin. Sc. 1, 327.

LIDSTRÖM, I.M. (1975). Vibration Injury in Rock Drillers, Chiselers and Grinders. International Hand-Arm Conference, NIOSH, Cincinnati, U. S.A.

LORIGA, G. (1911). Pneumatic Tools. Occupation and Health Supplement (Sep. 1938). International Labour Office, Geneva.

LORIGA, G. (1913). Il Lavoro Coi Martelli Pneumatic. Bo11. Inspett Lavoro 6, 524.

LOUDA, L. (1969). The Czechoslavakian Hygiene Regulations on protection against Vibration. Environ. Health 7, 1, 51.

LYARSKII, P. (1966). Sanitary Standards and Regulations for work with Tools, Machines and equipment creating vibrations transmitted to the Hands of Workers. Cig. Tr. Pro. Zabol. 626, 66. 
MAGOS, L. (1961). A Physiological study of the Effects of Vibration on the Fingers.

Brit. J. industr. Med. 18, 157.

MAGOS, L. (1974). Development of Raynaud's Phenomenon. Arch. Environ. Health 28, 235.

MAGOS, L. and OKOS, G. (1963). Raynaud's Phenomenon. The Situation in the Hungarian Iron, Steel and Engineering Industry. Arch. Environ. Health 7, 341.

MAGOS, L. and OKOS, G. (1963). Cold Dilation and Raynaud's Phenomenon. Arch. Environ Health, 7,402 .

MIWA, T. (1967/1968). Evaluation methods for Vibration Effect, Part 3, Measurements of Threshold and equal sensation contours for vertical and horizontal senusoidal vibration. Ind. Health $(1967)$, 5, 213. Part 4. Measurements of vibration for whole body and hand in vertical and horizontal vibrations. Ind. Health (1968) 6, 1.

MALTONI, C., CRESPI, M. and BURCH, P.J.R. (1973). Excerpta Medica International Congress. Series No. 275.

MATOBA, T., KUSUMOTO, H. OMURA, H. et al (1975). Digital plethysmographic responses to auditory stimuli in patients with vibration disease. Tohoku J. Exp. Med. $115(4), 385$.

McCALLUM, R.I. (1971). Vibration Syndrome, Brit. J. industr. Med. 28, 90 .

McKINNON, C.R. and KEMP, W.N. (1946). Vibration Syndrome. Abst in Occup. Med. 2, 85. Canad. M.A.J. 54, 472 .

McLAREN, J.W. (1937). Disability of Workers using Pneumatic Drills. Lancet 2, 1296.

MIKULINSKII, A.M. (1966). The Effect of Vibration of Various Ranges of High Frequency on some physiological functions of the organisms of Working Men. Gig. Truda; Prof. Zabolavaniya, 48.

MILLS, J.H. (1942). Pneumatic Hammer Disease in Unusual

Location. Northwest Medicine 41, 282.

MIURA, T., KIMURA, K, TOMINAGA, Y. and KIMOTSUKI, K. (1957). On the Occupational Hazards of Vibrating Tools. Report of the Institute for Science and Labour 52, 12. 
MIURA, T., KIMURA, K., TOMINAGA, Y• and KIMOTSUKI, K. (1966). On the Raynaud's phenomenon of Occupational Origin due to vibrating tools - its incidence in Japan. Report of the Institute for Science and Labour, $65,1$.

MIURA, T•, TAKAMATSU, M., JOSOKAWA, M• et al (1970).

Evaluation of the Vibration Hazards of Vibrating Tools.

J. Science Labour (Tokyo), 46, 7, 399.

PECORA, L.J., UDEL, M. and CHRISTMAN, R.P. (1960). Survey of Current Status of Raynaud's phenomenon of Occupational Origin. Amer. Industr. Hyg. Ass. J. 21, 80.

PELMEAR, P.L. and TAYLOR, W. (1975). The Results of Longterm Vibration Exposure with a Review of Special Cases of V.W.F. Paper 7. Vibration White Finger in Industry. Academic Press. p. 107.

PETERS, F.M. (1946). A Disease resulting from the use of Pneumatic Tools. Occup. Med. 2, 55.

RAMAZZINI, BERNARDINO. (1723). De Morbis Artificium Diatriba.

RAYNAUD, M. (1862). Local Asphyxia and Symmetrical Gangrene of the Extremities. Selected Monograph. New Sydenham Society, 1888, London.

REYNOLDS, D.D. (1977). Hand-arm Vibration Review of Three Years Research commissioned by NIOSH, Cincinnati and submitted U.S. Govt. Cincinnati, Jan. 1977 .

RENFREW, S. (1969). Fingertip Sensation. A Routine Neurological Test. Lancet 1, 396.

ROHTER, F.D. and HYMAN, C. (1962). Blood flow in Arm and Finger during muscle contraction and joint position changes. J. appl. Physiol. 17, 819.

SEYRING, M. (1930). Diseases resulting from work with Compressed Air Tools. Arch. Gewerbepath Gewerbhyg 1, 359.

SEYRING, M. (1931). Maladies from work with Compressed Air Drills. Bull. Hyg. 6, 25.

STEWART, A.M. and GODA, D.F. (1970). Vibration Syndrome. Brit. J. industr. Med. 27, 19.

STREETER, H. (1970). Effects of Localised Vibration on the Human Tactile Sense.

Amer. Ind. Hyg. Assoc. J. 31,87 
SWEENEY, E. (1965). Osteo arthrosis and Occupation. MD Thesis. SUCIU, I., DREJMAN, I. and VALASKAI, M. (1967). Etude des maladies dues au chlorure de vinyle. Med. Lav. 58, 261 。

SUGGS, C.W. (1974). Modelling of the Dynamic Characteristic of the Hand-arm System. The Vibration Syndrome. Ed: W. Taylor. Academic Press, London.

TAYLOR, W. (1974). Introduction: The Vibration Syndrome. Ed: W. Taylor. Academic Press, London.

TAYLOR, W. (1976). British Medical Journal. Editorial: Vinyl Chloride Monomer. $2,134-135$.

TAYLOR, W. PEARSON, J., KELL, R.L. and KEIGHLEY, G.D. (1971). Vibration Syndrome in Forestry Commission Chain Saw Operators. Brit. J. industr. Med. 28, 83 .

TAYLOR, W. and PELMEAR, P.L. (1975). Vibration White Finger in Industry. Academic Press, London.

TEISINGER, J. and LOUDA, L. (1972). Vascular Disease Disorders resulting from Vibrating Tools. Journal Occup. Med. $14,2,129$.

TELEKY, L. (1938). Pneumatic Tools.I.L.O. Occupational and Health. Supplement. September, 1938.

TELFORD, E.D. (1934). Sympathectomy. A Review of One Hundred Operations. Lancet $1,44$.

TELFORD, E.D., McCANN, M.B. and MacCORMACK, D.H. (1945). "Dead Hand" in Users of Vibrating Tools. Lancet 2, 359.

THULESIUS, O., (1975). Primary and Secondary Raynaud's Phenomena. Acta Chirurgica Scandinavia. Supplementum 465.

VIOLA, P.L•, BIGOTTI, A. and CAPUTO, A. (1971). Oncogenic response of rat skin, lungs and bones to vinyl chloride. Cancer Res. 31, 516.

WALTON, K.W. (1974). The Pathology of Raynaud's Phenomenon of Occupational Origin. The Vibration Syndrome. Ed: W. Taylor. Academic Press, London. 
WHITWELL, N.T., (1945). Dead, Hand. Lancet 2, 449.

WILLIAMS, N. and RIEGERT, A.L. (1960). Raynaud's Phenomenon of Occupational Origin in Uranium Miners. Proc. 13th International Congress in Occupational Medicine. 819.

WILSON, R.H•, MCCORMICK, W.E., TATUM, D.F. and CREECH, J.L. (1967). Occupational Acro-osteolysis. J. Amer. Med. Assoc. 201, 577 . 


\section{APPENDICE S}

\section{APPENDIX 1. CASE HISTORIES.}

CASE 1. MR. R.P. Date of birth $17 / 6 / 21$, age 55 years.

Present

Occupation: School Janitor. Interviewed-W.T. (1972).

Previous Medical

History: There is no history of circulatory

complaints in hands, feet or ears, or chilblains. There is no trauma affecting fingers, wrists, elbows or shoulders.

He had never seen a white finger prior to his vibration exposure.

Occupational

History:

MR. R.P., on leaving school, joined the

Forestry Commission (son of a gamekeeper)

intending to proceed to Forestry School

but World War II intervened and he served

from 1939-1946. Subsequent to his war

service he became a gamekeeper for a

period of 4 years on the estate of the

Earl Roseberry. This work entailed

shooting and trapping over the winter

months, during which he never at any time

noted a white, blanched finger. Due to

his wife's influence he moved to the

Gas Board in Armadale, working for 6 years

followed by 4 years with the Town Council.

Up to this stage he had never been exposed

to vibration. 
At age 43 he joined the North British

Steel Foundry, Bathgate as a "dresser" of heavy castings (up to 13 tons weight). This dressing operation consists of chipping "necks", "feeders" or "risers" and cleaning long welds with a variety of pneumatic tools with loose chisels varying from 6 inches to 8 feet in length. Being R. handed the loose chisel in all these tools was held or guided by the 4 th finger of his L. hand which was then exposed to the vibration of the chisel and had the greatest force upon it. The metal on which these chisels was S.G. iron or/and stainless steel. At the end of 5 years of this pneumatic tool dressing he was compelled to leave his occupation because of his white fingers. On the advice of his doctor he left the foundry mainly because his practitioner noted the rapid deterioration in his circulation (number of attacks, all digits involved) and recommended registration 
as a Disabled Person. After rehabili-

tation he had great difficulty obtaining employment, finally accepting a tractor driver's post. Again he was having difficulty with white fingers, especially in the early morning and transferred to his present post as janitor of a new school - Armadale Academy. He has had no further vibration exposure since $1968-3 \frac{1}{2}$ years.

Medica1 Examination: (W.T.) 1972 (a) All digits involved on exposure to cold, always worse in the early morning. His thumbs have not been involved. There is fairly severe pain on return of circulation.

(b) He has cramps at night accompanied by pins and needles from which he has failed to obtain relief by medication. There is interference with sleep.

(c) Being a gamekeeper's son he is a keen and knowledgeable fisherman. He has been compelled, because of his white fingers, to give up this hobby being unable to tie 
knots or dress flies. He describes his

fingers as "clumsy". He is keen on foot-

ball but cannot stand at matches since

this invariably brings on an attack in

the winter. He is a keen gardener but has

an attack immediately on touching cold soil.

He has had to give up cycling. He cannot

change his clothes in a cold room.

(d) He has to suffer continuous complaints

from his wife on two counts - his

restlessness at night which causes

interrupted sleep and his cold hands.

On examination on $12 / 4 / 72$ by the author,

his fingers were cyanosed and cold, the

left more than the right. On cooling,

the fourth finger of his L. hand blanched

and the picture (Fig. 15) was obtained.

The skin sensitivity test measurements

were raised as follows: 


\begin{tabular}{|c|c|c|c|}
\hline & Index Finger & Middle & Finger \\
\hline tavier & $\begin{array}{ll}\mathrm{R} & \mathrm{L}\end{array}$ & $\mathrm{R}$ & $\mathrm{L}$ \\
\hline Ridge & $0.75 \quad 0.75$ & 0.80 & 0.75 \\
\hline -Point & $7.5 \quad 8.5$ & 8.0 & 9.0 \\
\hline
\end{tabular}

His blood pressure was, R-arm $\frac{145}{95} \mathrm{~mm} \mathrm{Hg}$; $\mathrm{L}-\operatorname{arm} \frac{148}{98} \mathrm{~mm} \mathrm{Hg}$.

There was no albumen or sugar in his urine.

\section{Note on this Typical Case:}

We have available a consultant's report dated 6th May, 1969 - Western Infirmary, Glasgow which is of interest in our study:

"I interviewed MR. R.P. at the Western Infirmary, 6/5/69. His principal complaint is of recurrent attacks of white, numb and painful fingers on both hands. The symptoms first appeared in 1966 and have increased in severity since then. The attacks are regularly precipitated by exposure of the hands or even of other parts of the body, to cold. The degree of cold which is required to precipitate the attacks appears to vary and even a reasonably cool day is enough to bring on attacks whenever he goes out into the open. During the attacks of white discolouration, numbness and pain, his fingers are clumsy and he is not able to feel things normally. He 
notices difficulty when out in the cold in performing tasks involving any reasonable manipulation of the fingers such as fastening his clothes, fixing buttons or perhaps more distressing, attending to his own toilet requirements. Occassionally he has noticed attacks of the usual sequence on a reasonably warm day when he is carrying heavy loads. Occassionally, also, he has been awakened from his sleep at night with pain and tingling and numbness in the fingers, brought on by his hands becoming exposed outside the bed clothes.

A thorough clinical examination of this patient revealed no abnormality in the heart, chest, abdomen or neck. An X-ray of the upper chest showed that there was no congenital abnormality such as a cervical rib. His blood pressure appeared to be normal for his build and age at $\frac{155}{95} \mathrm{~mm} \mathrm{Hg}$.

The legs and feet showed no abnormality and the circulation appeared quite normal. He smokes $1 \frac{1}{2}$ oz. of tobacco per week (pipe) and has occassionally cigarettes in addition.

Turning to his hands, these had the typical appearances of Raynaud's phenomenon, with slight tapering of the pulps mainly the first and second fingers in each hand but also to a lesser extent on the other fingers. The colour of the palmar skin was unduly pink while they were exposed to the warm environment of the consulting room, but after 3-4 minutes of being immersed in running 
cold water and then exposed to the air marked blanching of all fingers and thumbs was noted. With gentle rewarming, the fingers gradually changed from a white appearance to a blotchy cyanosed colour. This in turn was replaced by an exaggerated redness. After 10-15 minutes the colour gradually returned to its previously normal state. There was no abnormality in the pulses or other aspects of the circulation to the upper limbs.

In summary, I have no doubt that this patient has typical Raynaud's phenomenon, and the colour changes in his fingers appear to be particularly easily induced by cold. It would seem therefore that he has quite a marked degree of Raynaud's changes. I was unable to detect any other abnormality on physical examination. The history presented would suggest that there may be a relationship between his working with vibrating machinery in recent years and the disorder in his fingers".

Case 2. MR. W.P. Date of birth 10/5/10. Died 25/1/69 Aged 58 years.

Occupation: Pneumatic Road Driller or Ripper for 26 years. City of Birmingham Public Works Department.

Present The patient lived alone, was a bachelor

Medical History:

and little is known of his previous medical history other than his neighbours, 
Occupational History: with whom he had good friendly relations, stated that he always had good health.

He had been a keen gardener and fisherman. Two years before his death he became more detached from the community and, during the year before his death, he wore gloves constantly.

From 1941 to 1967 (26 years) he had used a pneumatic road ripper. His white fingers had occurred "for many years". A history obtained from his colleagues established that he was constantly being recalled to the depot to take his drill and compressor to another site so much so that in 1967 he was transferred to become a "yard" man at his own request. We were informed that he was seen during 1967 and 1968, constantly rubbing his hands presumably attempting to improve the circulation. During his drilling period of employment he was seen applying rags to the handles of his pneumatic drill to reduce the blast of cold air issuing from the tool. About 3 months before his death he was conscious of his hands becoming progressively more stiff and clumsy especially in cold weather. When gangrene of his fingers developed, the first-aider bandaged his 
fingers and advised him to seek help from his medical practitioner. There is no history of a visit to a practitioner but on 8 th Jahuary, 1969 his neighbours, discovering the state of his hands, took him to the casualty department of Selly Oak Hospital, Birmingham. (Fig. 1).

Present History

On examination there was tissue necrosis of the $\mathrm{R}$ index and middle fingers and necrosis of the $\mathrm{L}$ index and ring fingers. He was well nourished but looked older than his stated age of 58 years. Radial and ulnar pulses were present bilaterally and the leg pulses were normal. There was no gross cardiac enlargement, (B.P. 140/90), no ankle oedema, R A latex test negative and normal serum proteins with no cryoglobulin present. Brachial arteriography was carried out on the left side and this showed that " the radial and ulnar arteries were tortuous but patent. There was normal filling of the superficial and deep palmar arches and the thumb digital artery, but there was patchy obliteration and generalised narrowing of the proximal portions of the digital arteries to all four fingers with no evidence of filling distal to 
the proximal interphalangeal joints.

There was decreased bone density of the phalanges with necrosis of the terminal phalanges especially marked on the ring finger ".

To attempt to provide some relief, the surgeons decided to carry out bilateral sympathectomy. This was successfully performed on the R side, but, during the L side operation, cardiac arrest supervened. External cardiac massage restored the circulation but an ECG indicated a massive myocardial infarct. The patient did not regain consciousness and died some twenty hours later. We are indebted to Walton (1974) for the detailed pathology of this case. In summary examination of the great vessels did not show undue involvement by athersclerosis especially the sub-clavian, brachial and radial arteries. There was no evidence anywhere in the body of connective tissue disease. The main digital artery was almost completely occluded in each finger at all levels by marked intimal proliferation and sub-intimal hyaline change (Fig. 1 ). The media showed diffuse fibrosis. There was evidence of platelet thrombi in veins and venules. In other sections of the digital arteries the material occluding the lumen, examined by immunofluorescence techniques, was fibrin suggesting an obliterative endarteritis due to the organisation of 
previous thrombosis rather than an embolic process. Degenerative changes (peri-neural infiltration by small round cells (Fig.37) were confined to the end organs of the superficial dermal plexus (Pacinian bodies) whilst the main digital nerve trunks and pressure receptors (Meissner's corpuscles) in the deeper sub-cutaneous tissues were unaffected. "This distribution of the pathological changes in the neural elements is consistent with the clinical symptomatology, suggesting that the changes in the more superficial nerves and nerve-endings could have preceded the final gross ischaemic damage associated with arterial obstruction and have originated from vibration damage.

Case 3. MR. A.H. Date of birth 22/2/12. Age 65 years.

\section{Occupation: Cleaner, Labourer.}

Previous

Medical

History:

There is nothing significant in the family history. No history of white finger before exposure to vibration.

\section{Occupational}

History:

In 1960 he began to notice a bluishwhite discolouration of his fingers on both hands, associated with watching football matches, gardening in cold weather and if he had to immerse his hands in cold water. The attacks at this time were more frequent in winter. 
From 1929-63 the patient was employed by British Rail in the Bromsgrove Carriage and Wagon Department, where he used a large compressed air tool for approximately 10 years (1953-63) to chisel off fixed and rusted bolts. Around 1961 his fingers became swollen and painful around the tips.

Medical

Examination: He was referred to Bromsgrove General Hospital in 1961 where, on examination, he had normal pulses at the wrists on both hands and no rib cage abnormality could be seen on X-ray of the chest. There was no evidence of connective tissue disease or rheumatic conditions and the blood picture was normal. His blood pressure is $155 / 70 \mathrm{~mm} \mathrm{Hg}$.

Treatment: He did not respond to Priscol or other vasco-dilators and it was decided therefore to carry out a left transaxillary cervical sympathectomy (1961), the second, third and fourth and fifth thoracic ganglia being removed. The effect of this operation was dramatic (as in cases of Primary Raynaud's Disease), the hand and fingers became pink and the necrotic areas at the ends of the 
fingers disappeared. These effects lasted only four months.

He was seen in 1966, again at the Bromsgrove General Hospital. The fingers were cyanosed and swollen especially in cold weather. Again there was no clinical evidence of scleroderma. Skin trophic changes appear intermittently at the tips of his fingers (Fig. 38 ). He is a moderate smoker with 15 cigarettes daily.

VWF Examination: His Ridge Test and Two Point

Discrimination Test are normal - a very surprising result, if we assume that his condition is due to the use of a large pneumatic hammer.

Mr. A.H. has been registered a Disabled Person (1967) and his present occupation, in a warm area of his factory, is satisfactory. A right cervical sympathectomy was considered but was not undertaken. 


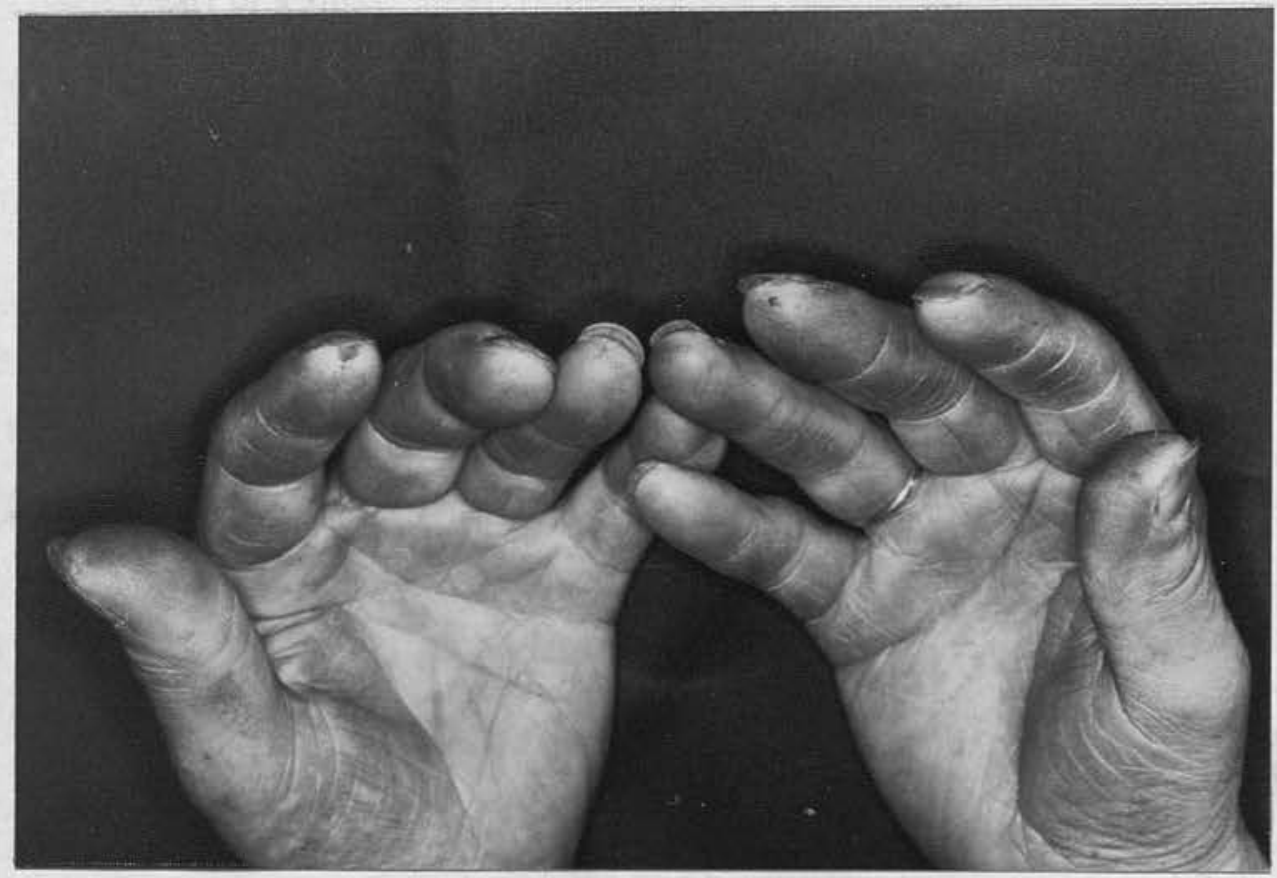

Fig. 38

RAYNAUD'S PHENOMENON - TEN YEARS PNEUMATIC TOOLS ADVANCED STAGE - PERMANENT CYANOSIS

TISSUE ULCERATION

PATIENT - MR. A.H. 


\section{CONFIDENTIAL}

\section{NOTES ON FILLING IN THE FORM}

This questionnaire is part of a study designed to identify the effects of using vibrating tools. If you do not use any vibratory tool it is still important that you answer the relevant questions, so that in future it would be possible to compare between different occupations. To fill in this form please follow these instructions:-

Please do not write in the spaces which are headed as "For Office Use only".

2. Most of the questions should be answered by placing a tick $(\checkmark)$ or number on the appropriate line or lines for example, if you are male you would fill in the answer to Question 1:-

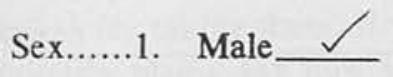

2. Female

3. Sections A. B. and C. are to be answered by everyone. Only those who use vibrating tools $\underline{\text { now }}$ should fill in section D, and only those with white or blue fingers should fill in Section $\mathrm{E}$.

4. If you cannot answer a question please say why.

5. If you have any comments which you think will be helpful please write on the page No. 13 which has been left blank.

6. All information in the questionnaire will be treated with the strictest confidence and therefore please seal the envelope after your use.

7. Please check that you have answered all the sections that refer to you. 
S.N.

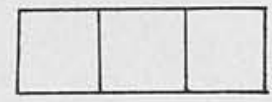

SECTION A - TO BE FILLED IN BY EVERYONE

Q1. Sex: 1. Male

2. Female

Q2. Age last birthday:

years

Q3. Are you:

1. Right handed

2. Left handed

3. Able to use both hands equally

\section{SMOKING HISTORY:}

Q4. Do you smoke?

1. Yes

2. No

If your answer to $\mathrm{Q} 4$. is 'Yes' please state:

(a) The number of cigarettes you smoke each day on average

(b) The number of cigars you smoke each day on average

(c) The number of ounces of tobacco you smoke each week on average

Q5. Are you an ex-smoker?

1. Yes

2. No

If your answer is yes how long is it since you stopped smoking?

Years

(If recently Months)
[FOR OFFICE USE ONLY:

\section{CARD 1}

$\begin{array}{ll}1 & 1 \\ & 1\end{array}$

SURVEY $\begin{aligned} & 2 \\ & \text { SU. }\end{aligned}$
No.

JOB

CODE
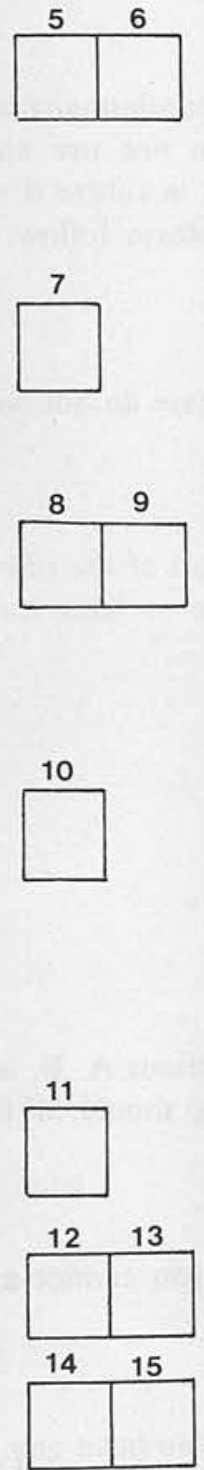

16

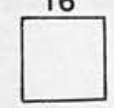

17
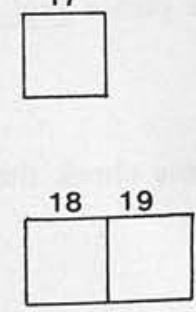
S.N.

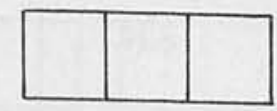

ALCOHOL CONSUMPTION:

Q6. Do you drink (alcoholic drinks)?

i. Yes

2. No

If your answer is yes please try to estimate the following:

(a) The number of pints of beer you drink per day on average

(b) The number of singles of spirits you drink per week on average

(c) The number of glasses of wine you drink per week on average

\section{TABLETS AND Medicine:}

Q7. Have you taken any kind of tablets, pills or medicine during the last six months?

$$
\text { 1. Yes }
$$

2. No

If you answered yes, please name the tablets or medicines if you can and give the reason for taking them. If you take any medicine etc. continuously please say how long you have been taking it.

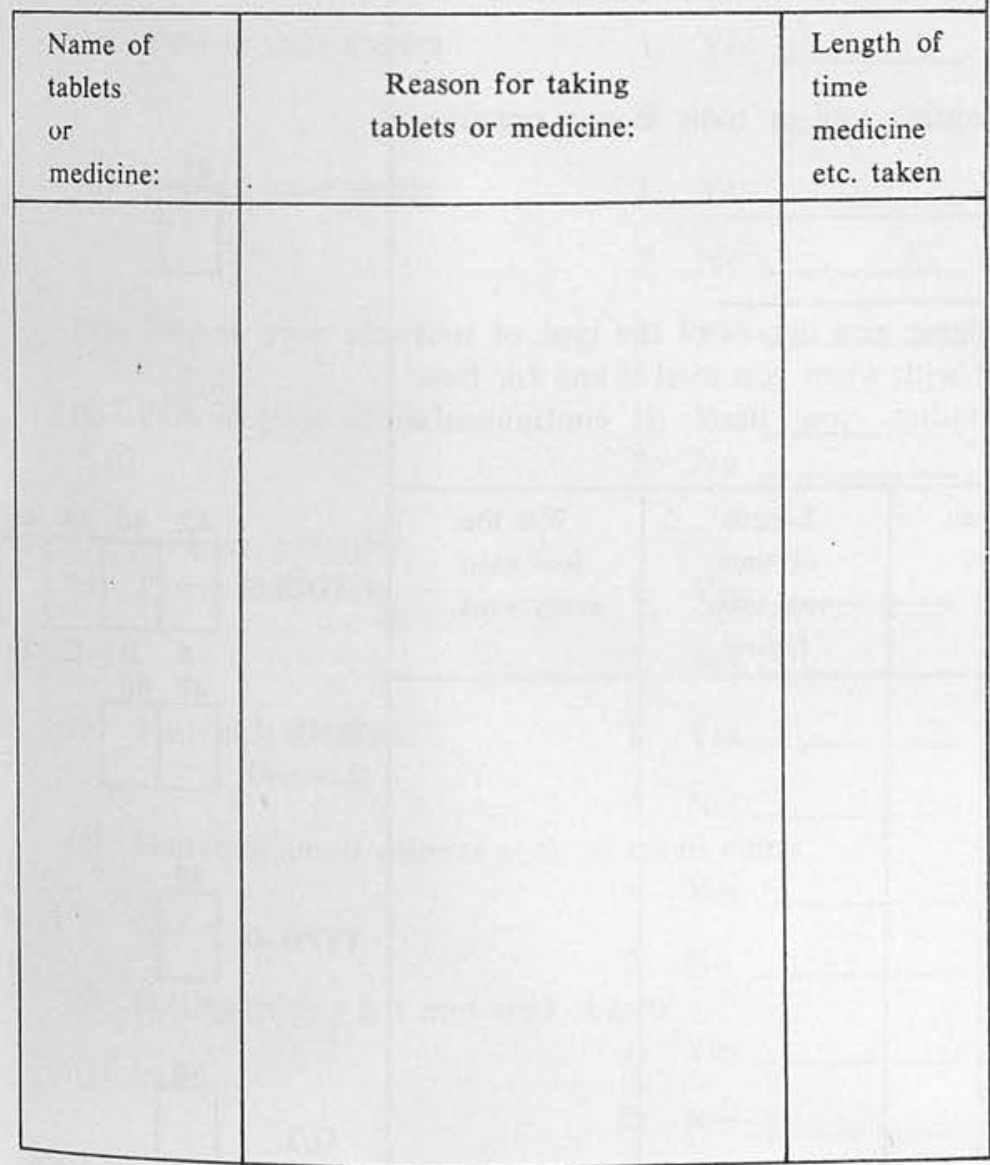

\section{FOR OFFICE USE ONLY}

CARD 1

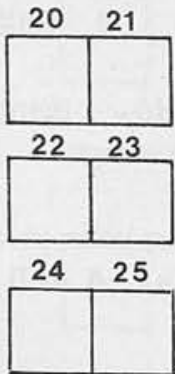

26

SIG.
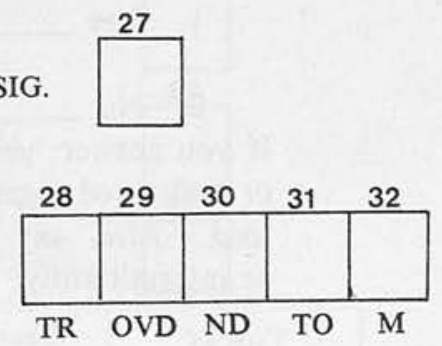

TIME

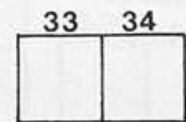


S.N.

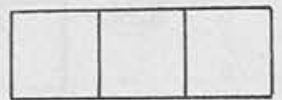

SECTION B - TO BE FILLED IN BY EVERYONE

Q8. What hours do you work?

1. Day shift only

2. Shift work

Q9. How many shifts do you work per week on average?

Q10. In your present job do you use:

(a) A drill

1. Yes

2. No

(b) A windy pick

1. Yes

2. No

(c) Any other vibrating tool

1. Yes

2. No

If your answer is 'yes' to Q10.(c) please say what the tool is

NOTE: If you answer 'yes' to any of questions $10 \mathrm{a}, 10 \mathrm{~b}$ or 10 c you will be asked to fill in Sections $D$.

Q11. Have you used a vibrating tool or tools in any previous job?

1. Yes

2. No

If you answer 'yes' please give details of the type of tool or tools used together with when you used it and for how long. Also say whether you used it continuously or intermittently:

\begin{tabular}{|c|c|c|c|}
\hline $\begin{array}{c}\text { Type of } \\
\text { tool }\end{array}$ & $\begin{array}{c}\text { Year when } \\
\text { vou last } \\
\text { used it }\end{array}$ & $\begin{array}{c}\text { Length } \\
\text { of time } \\
\text { tool used } \\
\text { (years) }\end{array}$ & $\begin{array}{r}\text { Was the } \\
\text { tool used } \\
\text { every week }\end{array}$ \\
\hline & & & \\
& & & \\
& & & \\
\hline
\end{tabular}

FOR OFFICE USE ONLY:

\section{CARD 1}

35

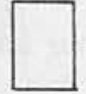

36
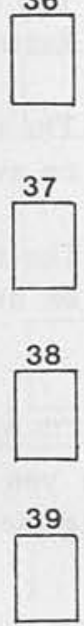

40

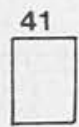

TOOLS

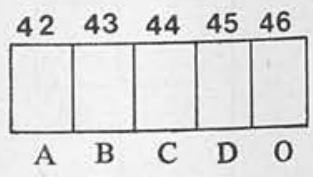

TIME

(Longest)

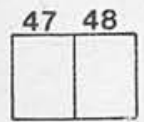

TYPE O

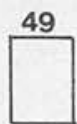

G/I

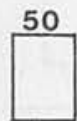


S.N.

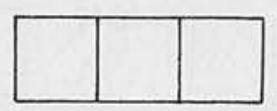

\section{SECTION C - TO BE FILLED IN BY EVERYONE}

Q12. Do your fingers ever turn white?

1. Yes

2. No

Q13. Are your fingers ever blue?

1. Yes

2. No

NOTE: If you answer yes to either of Q.12 or Q13. you will be asked to fill in Section E later.

Q14. Do you regularly notice any of the following either at work or home:-

(a) Tingling in your hands or fingers

1. Yes

2. No
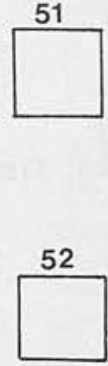

(b) Numbness of your hands or fingers

2. No

(c) Pain in your fingers

1. Yes

2. No

(d) Pain in your wrists

1. Yes

2. No

(e) Pain in your elbows

1. Yes

2. No

(f) Pain in your shoulders

1. Yes

2. No

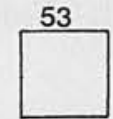

54
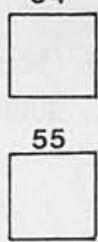

56

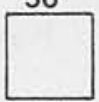

57

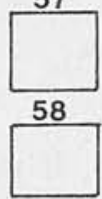

Q15. Do you have difficulty

(a) Doing fine work

1. Yes

2. No

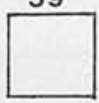

60

(b) Fastening buttons

1. Yes

2. No

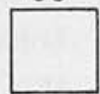

61

(c) Handling small objects such as small coins

1. Yes

2. No

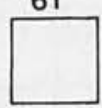

(d) Distinguishing hot and cold objects

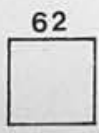


S.N.

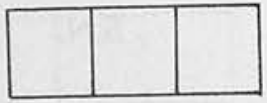

Q16. Do you experience pain, tingling or numbness of the hands and fingers when:-

(a) Swimming

(b) Gardening

(c) Washing the car

(d) Fishing

(e) Watching football matches etc. outdoors

(f) Playing games
1. Yes

2. No

3. Don't know

1. Yes

2. No

3. Don't know

1. Yes

2. No

3. Don't know

1. Yes

2. No

3. Don't know

1. Yes

2. No

3. Don't know

1. Yes

2. No

3. Don't know

\section{CARD 1}

63

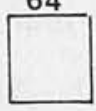

65

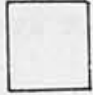

66

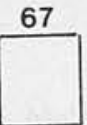

68

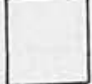

69 hobbies, sports or anything else

2. No

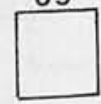

If yes, please specify

3. Don't know
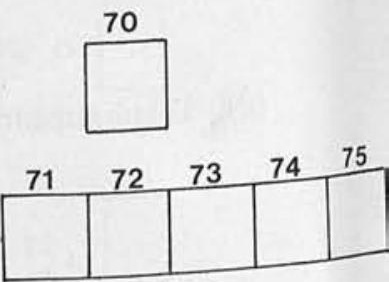
S.N.

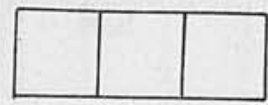

Q17. Have you had any injuries, other than minor ones to your fingers, hands or wrists?
(a) Fractures
1. Yes
(b) Deep Cuts or lacerations
(c) Crush Injuries
(d) Dislocations
(e) Frost-bite
(f) Other Injuries
2. No
1. Yes
2. No
1. Yes
2. No
1. Yes
2. No
1. Yes
2. No
1. Yes
2. No

If 'yes' please say what they were

Q18. Do you ever suffer from chilblains?

1. Yes

2. No

Q19. Do any of your blood relatives (e.g. parents, grandparents, brothers, sisters, cousins etc.) suffer from white finger?
1. Yes
2. No

3. Don't know

If 'yes' please state the relationships and whether they use or have used vibratory tools.

\begin{tabular}{|l|l|l|}
\hline \multirow{2}{*}{ Relationship } & \multicolumn{2}{|c|}{ Vibratory Tools } \\
\cline { 2 - 3 } & Yes/No & If yes, type used \\
\hline & & \\
& & \\
& & \\
\hline
\end{tabular}

FOR OFFICE USE ONLY:

CARD 2

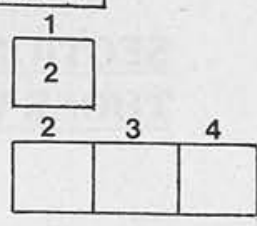

S.N.

5
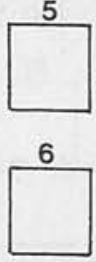

7

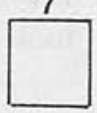

8

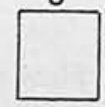

9
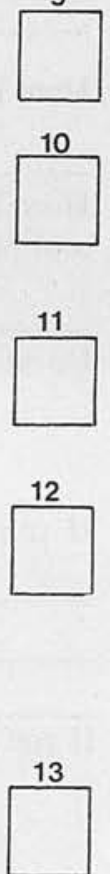

P/G
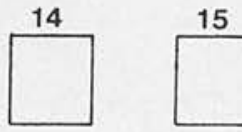

S/B
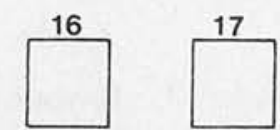

Other

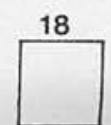


S.N.

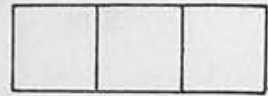

Q20. Do you use the vibrating tool every shift?

1. Yes

2. No

If 'No' please say when you do use it.

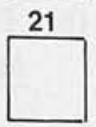

Q21. Do you do any overtime involving the use of vibrating tools?

1. Yes

2. No

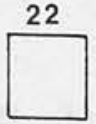

Q22. How many hours a week on average do you use a vibrating tool?

Q23. How long have you been using the vibrating tool?

Q24. How long is it since you first regularly used a vibrating tool of any sort?

Q25. Do you wear gloves when operating the vibrating tool?

1. Always

2. Sometimes

3. Never

If you wear gloves please give the reason
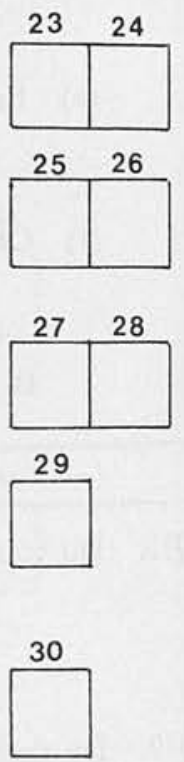

If you do wear gloves, do you change them if they get wet?

1. Yes always

2. Yes sometimes

3. No

Q26. Describe the vibration to your hands when you are operating the tool: -

1. Barely noticeable

2. Acceptable

3. Unpleasant

4. Very Unpleasant

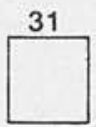

Q27. Is the vibratory tool you use powered by compressed air?
1. Yes
2. No

If your answer is 'yes' does the air from compressed air exhaust ever affect your hands?

1. Yes occasionally

2. Yes often

3. No
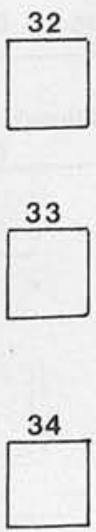
S.N.

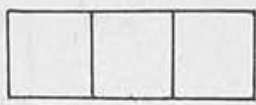

\section{SECTION E - TO BE FILLED IN ONLY BY THOSE WHO SUFFER FROM 'WHITE' OR 'BLUE' FINGERS}

Q28. How long is it since you first noticed any symptoms? years months

Q29. What was the first symptom that you noticed?

Q30. Did you ever have 'white' or 'blue' fingers before using a vibrating tool?
1. Yes
2. No

Please note: Approximately 5-10\% of people suffer from white finger without ever having used a vibrating tool. We wish to know whether you are among these.

Q31. If you suffered from 'white' or 'blue' finger after using a vibrating tool only, how soon after starting to use the tool did you first notice symptoms?

years months
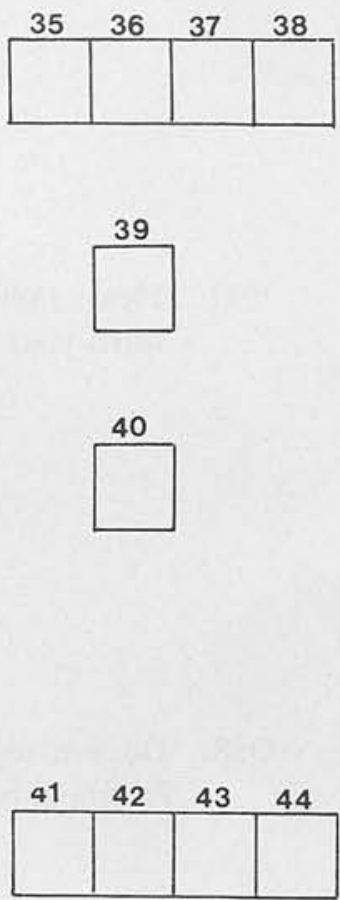

Q32. What, in your opinion, causes your fingers to turn white or blue? If your attacks do not seem to be related to anything in particular please say so:-

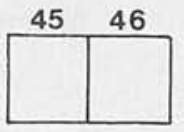

Q33. Are your fingers permanently blue in winter?

1. Yes

2. No

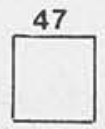

Q34. Are your fingers permanently blue in summer?

1. Yes

2. No

Q35. How often do your fingers turn white or blue in an average winter?

1. Never

2. Less than once per month

3. 1-3 times per month

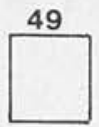

4. 1-4 times per week

5. More than 5 times per week

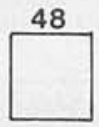


S.N.

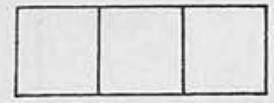

Q36. How often do your fingers turn white or blue in summer?

1. Never

2. Less than once per month

3. 1-3 times per month

4. 1-4 times per week

5. More than 5 times per week

Q37. Please indicate by a tick or ticks the time or times of day when your fingers most often turn white or blue.
1. Morning
2. Afternoon
3. Night
4. Not applicable

Q38. Do you regularly experience numbness in your hands or fingers in bed?

1. Yes

2. No

Q39. Please indicate by a tick or ticks the places where your fingers turn white or blue.
A. Home
B. Work
C. Other

Please specify the other places:-

Q40. After a severe attack how long does it take your fingers to return to normal?

1. Less than 5 minutes

2. 5 - 15 minutes

3. $16-30$ minutes

4. $31-60$ minutes

5. 1-2 hours

6. More than 2 hours
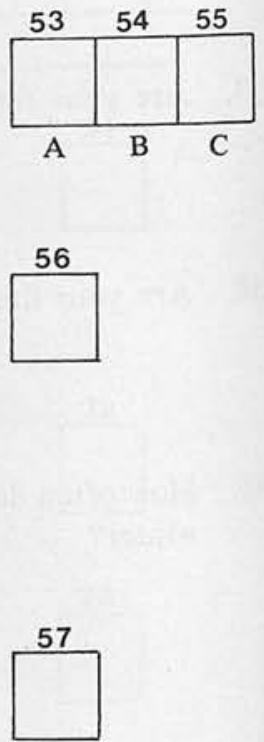
S.N.

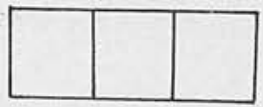

Q41. Please shade in the diagram the number of segments at each finger (including thumbs) on both hands which are white or blue in a severe attack.
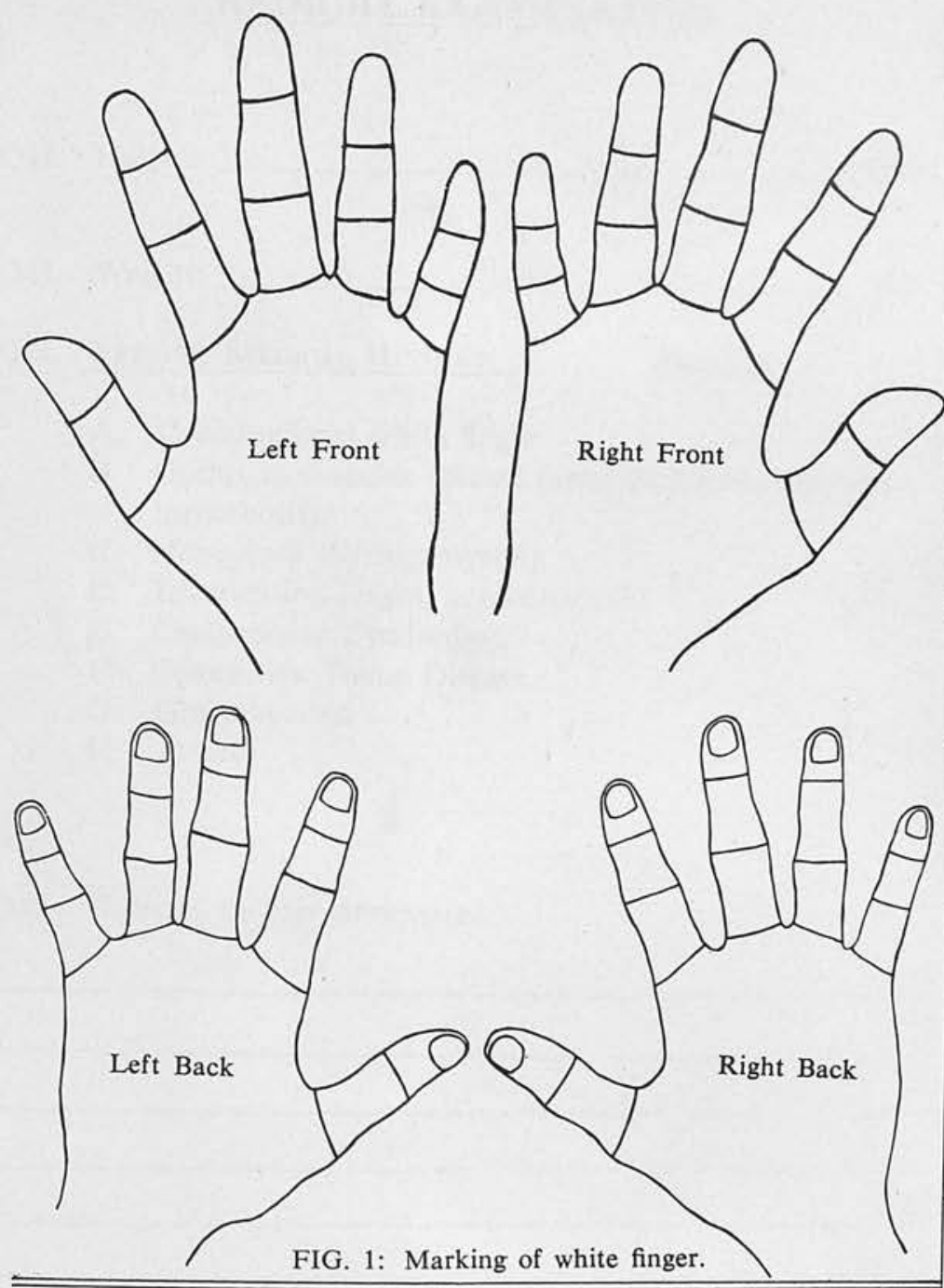

FOR OFFICE USE ONLY:

\begin{tabular}{|l|l|l|l|l|l|}
\hline & Index & Middle & Ring & Little & Thumb \\
\hline 0. None & & & & & \\
\hline 1. to D.I.P.Jt & & & & & \\
\hline 2. to P.I.P.Jt & & & & & \\
\hline 3. to M.P. & & & & & \\
\hline
\end{tabular}

\begin{tabular}{|l|l|l|l|l|l|}
\hline & Index & Middle & Ring & Little & Thumb \\
\hline 0. None & & & & & \\
\hline 1. to D.I.P.Jt & & & & & \\
\hline 2. to P.I.P.Jt & & & & & \\
\hline 3. to M.P. & & & & & \\
\hline
\end{tabular}

FOR OFFICE USE ONLY:

CARD 2
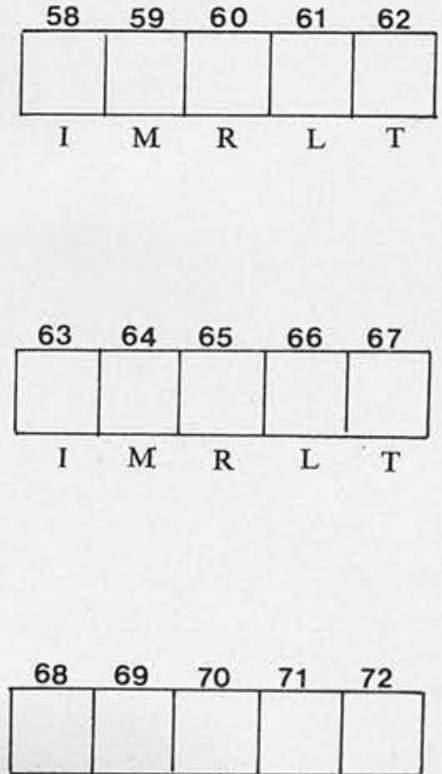


\section{S.N.}

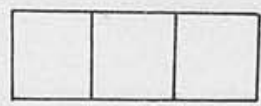

VIBRATION INDUCED WHITE FINGER

SURVEY

MEDICAL EXAMINATION

Q42. Height:

cms.

Q43. Weight:

$\mathrm{kg}$.

Q44. Present Medical History:

SPECIFY:

A. Constitutional white finger.

B. Occlusive vascular disease (arteriosclerosis, embolism, thrombosis).

C. Neuogenic (Syringomyelia).

D. Intoxication (ergot, acroosteolysis).

E. Compression Syndrome.

F. Connective Tissue Disease.

G. Globinaemias.

H. Other

Q45. History OF ANY OPERATION:
FOR OFFICE USE ONLY:

CARD 3

1

S.N.
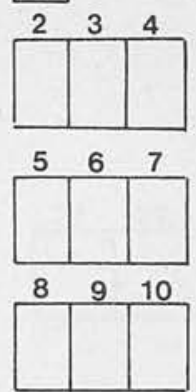

Sig./NS. $\square$

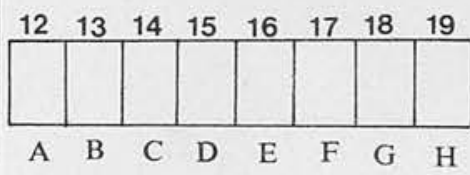

S/NS. $\stackrel{20}{\square}$

SIG./NOT SIG. 
S.N.

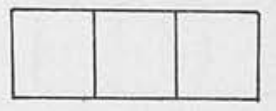

GENERAL EXAMINATION:
(1. Normal)
(2. Abnormal)
(3. Don't know)

Q46. Pulse:

Q47. Blood Pressure:

Q48. Lungs:

Q49. Heart:

Q50. Abdomen:

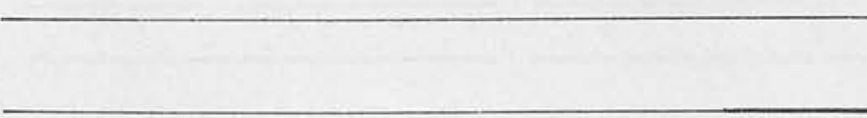

Q51. Joints:

Q52. Psychological make-up:

Q53. Local examination of hands and fingers:

Q54. Stage assessment of V.W.F.
FOR OFFICE USE ONLY:

\section{CARD 3}
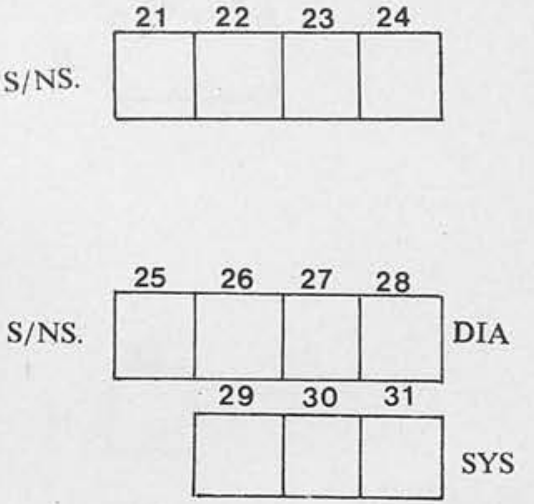

S/NS. $\square$

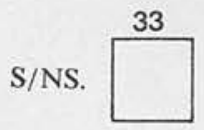

S/NS.

S/NS.

S/NS.

S/NS.

38

S/NS. 
S.N.

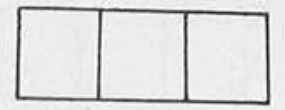

SENSORY TESTS:

Q55. Finger Circumference:

Left $\mathrm{mm}$.

Right $\mathrm{mm}$.

Q56. TACTILE SENSIBILITY:

(a) Light Touch

\section{LEFT}

RIGHT

1. Normal/2. Abnormal/ 3. Don't know

Specify abnormal:

(b) Pressure Touch

\section{LEFT}

1. Normal/2. Abnormal/ 3. Don't know

Specify abnormal:

(c) Two point discrimination:

$$
\text { LEFT }
$$
$\mathrm{mm}$

1. Normal/2. Abnormal/

$\begin{array}{ll} & \begin{array}{l}\text { 2. Abnormal } \\ \text { RIGHT_ Don't know }\end{array} \\ & \text { 1. Normal } \\ & \begin{array}{l}\text { 2. Abnormal } \\ \text { 3. Don't know }\end{array}\end{array}$

(d) Ridge test:

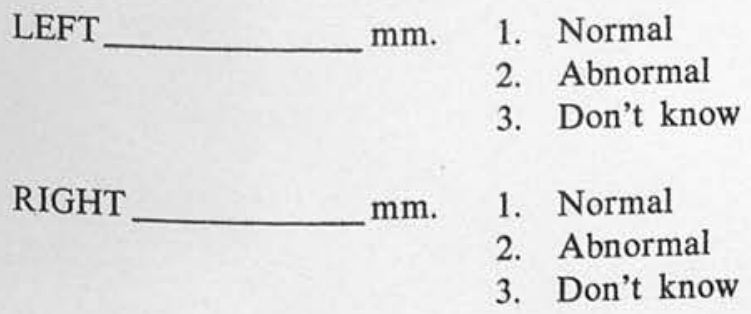

FOR OFFICE USE ONLY:

CARD 3

L.

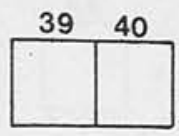

R.

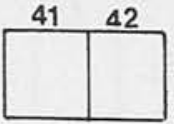

L.

R.

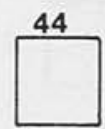

L.

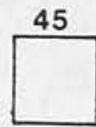

R.

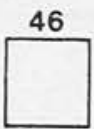

L. 4

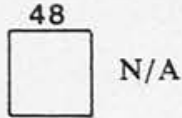

R.

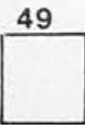

50

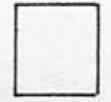

N/A
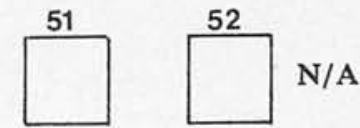

R.
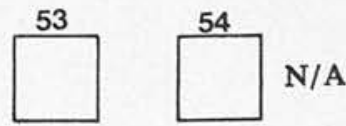
S.N.

Q57. SEnSIBILITY to PaIN:

(a) Superficial Pain:

LEFT

1. Normal/2. Abnormal/ 1. Normal/2. Abnormal/ 3. Don't know

Specify abnormal:

3. Don't know

(b) Pressure Pain:

\section{LEFT}

RIGHT

1. Normal/2. Abnormal/ 1. Normal/2. Abnormal/ 3. Don't know

Specify abnormal:

3. Don't know

Q58. SENSE OF POSITION:

\section{LEFT}

RIGHT

1. Normal/2. Abnormal/ 1. Normal/2. Abnormal/ 3. Don't know 3. Don't know
FOR OFFICE USE ONLY:

CARD 3

L

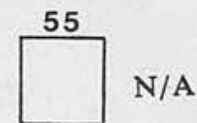

R.
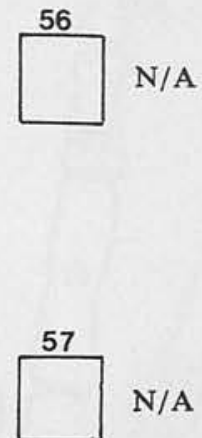

R.

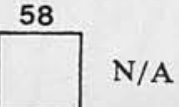

L

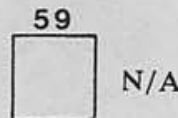

R.

60 N/A 

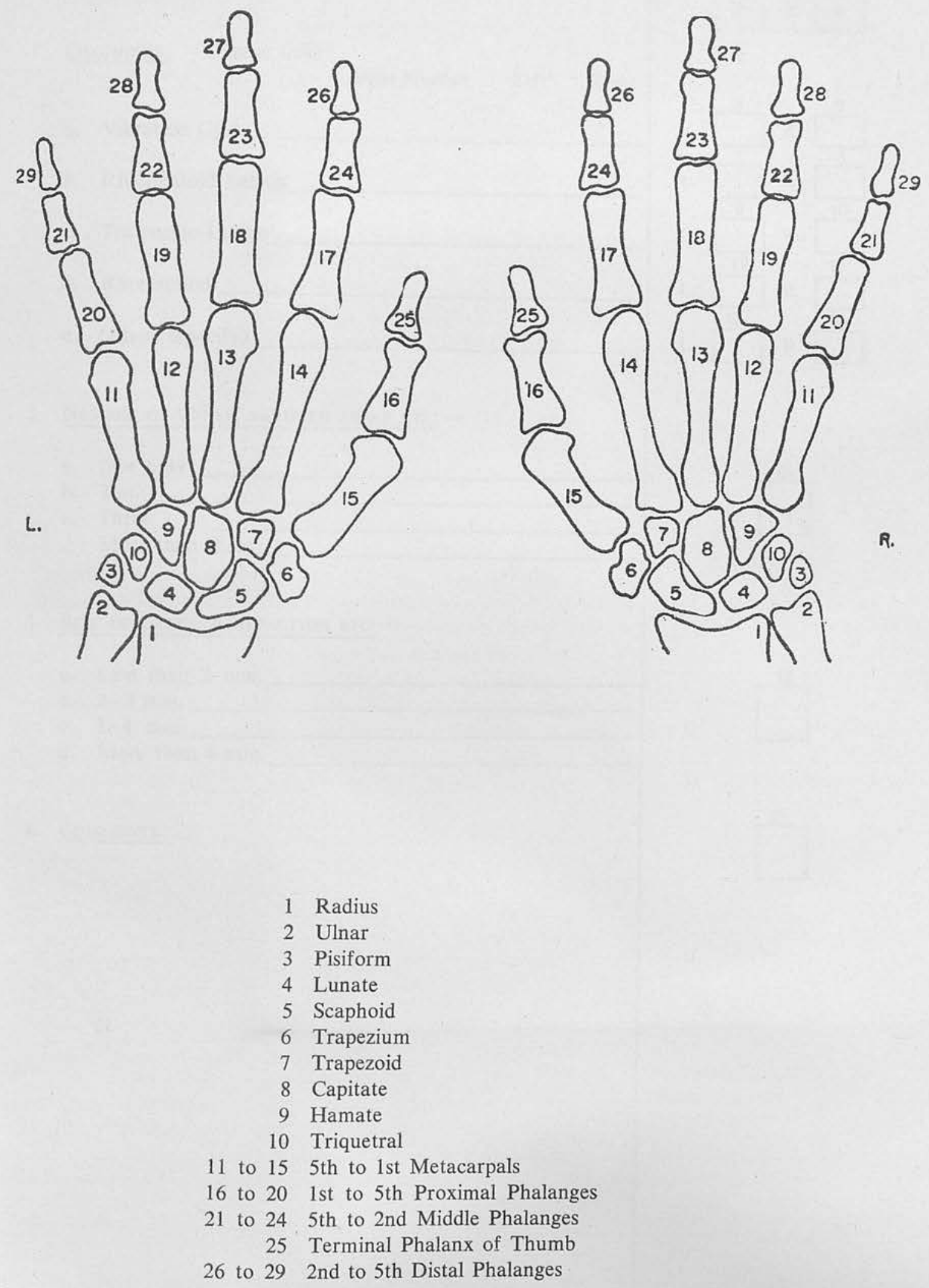
S.N.

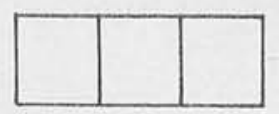

RADIOLOGICAL ASSESSMENT

1. Diagnosis: - (Please tick)

Bone Number

Left

Right
a. Vibration Cyst
b. Rheumatoid Lesion
c. Traumatic Lesion
d. Rarefaction
e. Others (specify)

2. NUMBER OF CYSTS, RARIFIED AREAS ETC:-
a. One only
b. Two
c. Three
d. More than three

3. Size OF CYSTS, RAREFACTION ETC:-
a. Less than $2 \mathrm{~mm}$.
b. $2-3 \mathrm{~mm}$.
c. $3-4 \mathrm{~mm}$.
d. More than $4 \mathrm{~mm}$.

4. COMMENTS:
FOR OFFICE USE ONLY:

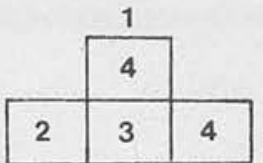
L.
5
L.

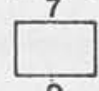
$\mathrm{R}$.
$\square_{8}^{6}$
R.
L.
R. $\square$
L.
11
L. ${ }_{13}^{11}$
L. $\mathrm{R}$.
$\frac{12}{14}$
R.
14
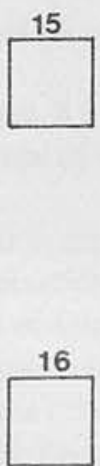

17

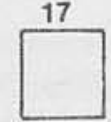




\section{Guide to the evaluation of exposure of the human hand-arm system to vibration}

\section{Introduction}

If the hand is subjected to vibration, either when holding a power tool or when holding material which is vibrating, after a period the fingers become liable to attacks of blanching. The descriptive term 'vibration-induced white finger (VWF)', used by the Industrial Injuries Advisory Council in the recent Interim Report on Vibration Syndrome*, has been adopted for this draft.

During attacks of VWF, which may last up to an hour, there is a loss of sensation in the affected fingers. The recovery phase is characterized by varying degrees of pain. Attacks are typically induced by handling cold objects on cold mornings and are rarely seen during a period of vibration exposure unless the work is in cold surroundings. Symptoms develop first in the tips of fingers applying pressure to the tool or material, extending in time to the whole of the finger.

Approximately $10 \%$ of the adult male population experience minor infrequent episodes of white finger without significant exposure to vibration; in a very small proportion of these the occurrence of white finger is the first manifestation of serious progressive disease.

Exposure to vibration in industry may produce prevalence rates of VWF as high as $100 \%$, most cases resulting in social disablement rather than a restriction of the ability to work. However, cases are occasionally encountered where there is considerable impairment of hand function which may necessitate a change of employment.

VWF does not result from the casual use of vibrating tools but from the regular prolonged use normally found only in industry. The length of the initial symptom-free period of vibration exposure ('latent period') is related to the intensity of the vibration. The shorter the latent period, the more severe the resulting VWF if vibration exposure continues. Present evidence suggests that in the early stages of the disease some recovery occurs when vibration exposure ceases. However, in the severe forms, the condition either remains static or gradually deteriorates.

Despite considerable research, little is known about how the attacks are caused but evidence is accumulating that in the severest forms of the complaint there are changes in the arteries and nerves of the fingers. The association of vibration exposure with other disorders, e.g. of bones and joints, is not proven and further research is in progress.

\section{Section one. General}

\section{Scope}

This Draft for Development gives recommended maximum values for vibration transmitted to the hands during an 8-hour working day (see clause 7). The levels on which these values are based are stated, and recommended methods of measurement are described. Appendices cover the information which it is thought should be recorded by those carrying out research in this field and measures which can be taken to reduce the incidence of vibration injury to workers exposed to it.

NOTE 1. Those responsible for formulating this Draft for Development have given full consideration to work being carried out under the auspices of an ISO Committee to which experts from Czechoslovakia, Japan, Sweden, USA and other countries have contributed.

NOTE 2. There may be risks in applying the recommended levels to impulsive vibration but users are urged to measure and record it wherever practicable in order to provide information which may enable guidance to be given in the future.

*'Vibration Syndrome' (1970), Interim Report by the Industrial Injuries Advisory Council, Department of Health and Social Security, Cmnd 4430, HMSO, London.

This publication is a Draft for Development and is therefore not to be regarded as a British Standard. See page 2. 


\section{Basis of the guide}

Although it is not yet possible to determine precisely the vibration factors which are most significant in regard to this disease, it is nevertheless necessary to give guidance to designers and manufacturers so that they may be aware of the extent to which they should try to reduce vibration levels without either making tools too heavy or bulky to operate efficiently or giving rise to excessive increase in costs.

This Draft for Development has accordingly been prepared but it should be emphasized that the data on which the recommended limits are based are taken from determinations of vibration sensation levels supplemented by the results of industrial experience in this country and by considerable information from abroad. The vibration 'dose' to which a man has been subject has proved difficult to assess with changing tools and work patterns and varying grip and vibration levels over a work cycle, and is thus difficult to relate reliably to the objective response of symptoms of disease (the 'dose-response' relationship). In spite of this, there is reason to believe that adherence to the vibration levels given in this document will result in a considerable decrease in the incidence of VWF, although it has not been proved that adherence to these limits will prevent vibration diseases over the working lifetime of a regular user.

It is also important for employers, operators of the tools and medical experts to be able to understand the level of reduction in vibration and the working methods which are required to minimize the effect of the residual vibration.

It is hoped that this Draft for Development will help to clarify the situation for those concerned with the problem and encourage monitoring so that, if the onset of VWF is observed, operators may be transferred to other work before the condition becomes irreversible. This would be of particular value in the case of the few operators who may be especially susceptible to injurious effects from vibration even though it is well within the limits recommended in this Draft for Development. (See the third paragraph of clause 0 .)

\section{Section two. Recommended limits of vibration}

Factors of primary importance in determining the risk of VWF include intensity (acceleration), frequency, duration of exposure to vibration and the susceptibility of the individual.

\section{Acceleration}

Acceleration is recorded as the root mean square value in metres per second per second ( $\mathrm{m} / \mathrm{s}^{2}$ r.m.s.).

\section{Frequency range}

The frequency range concerned is divided into octave bands with the following mid-band frequencies: $4,8,16$, $31.5,63,125,250,500,1000$ and $2000 \mathrm{~Hz}$.

\section{Duration of exposure}

Duration of exposure is the measured or estimated time for which the operator is exposed to vibration during a normal working day of a 5-day week in a normal year. In practice, given the normal breaks through the day, the cumulative exposure is unlikely to exceed $400 \mathrm{~min}$. In many operations there will be longer interruptions to the vibration exposure and the measurement of the actual exposure time will become increasingly important. It is expected that a regular user in industry will be subject to at least $150 \mathrm{~min}$ cumulative exposure per day.

\section{Susceptibility}

See last paragraph of clause 2 and clause 7.

\section{Recommended vibration exposure limits}

Recommended vibration limits are given in table 1 and apply to vibrations, independently measured as near as possible to the hand, in any of the three directions of a rectangular co-ordinate system. The directions used shall be the appropriate choice from those illustrated in figure 2.

It is recommended that cumulative exposure time to vibration should never exceed $400 \mathrm{~min}$; for intermediate periods between $150 \mathrm{~min}$ and $400 \mathrm{~min}$ some interpolation should be made; the values given for $150 \mathrm{~min}$ apply for all shorter periods. These latter values should not be exceeded by regular users of hand-held equipment.

This publication is a Draft for Development and is therefore not to be regarded as a British Standard. See page 2 . 
Table 1. Recommended vibration exposure limits

\begin{tabular}{c|c|c}
\hline \multirow{2}{*}{ Octave centre frequency } & \multicolumn{2}{|c}{ Maximum permissible acceleration } \\
\cline { 2 - 3 } & 400 min in an 8-hour day & $\begin{array}{l}\text { Cumulative total of } 150 \mathrm{~min} \\
\text { in an 8-hour day }\end{array}$ \\
\hline $\mathrm{Hz}$ & $\mathrm{m} / \mathrm{s}^{2}$ & $\mathrm{~m} / \mathrm{s}^{2}$ \\
4 & 1 & 10 \\
8 & 1 & 10 \\
16 & 1 & 10 \\
31.5 & 2 & 20 \\
63 & 4 & 40 \\
125 & 8 & 80 \\
250 & 16 & 160 \\
500 & 32 & 320 \\
1000 & 64 & 640 \\
2000 & 128 & 1280 \\
\hline
\end{tabular}




\section{DD $43: 1975$}

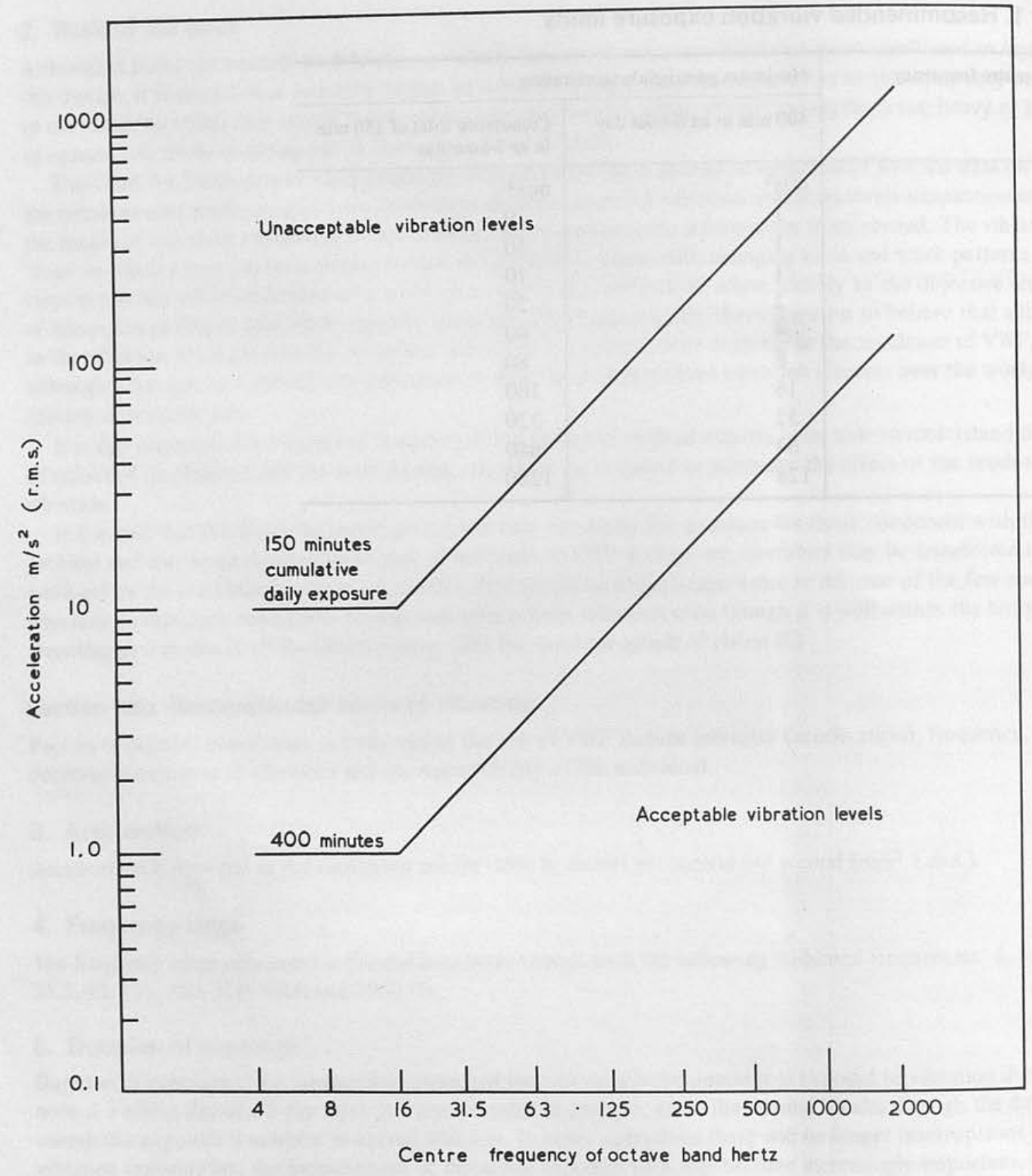

Figure 1. Recommended hand-arm vibration exposure limits for regular users 


\section{Vibration White Finger}

in Industry

A report, comprising edited versions of papers submitted to the Department of Health and Social Security in December 1973

Edited by

W. TAYLOR

Department of Community and Occupational Medicine University of Dundee, Scotland

P. L. PELMEAR

G. K. N. Forgings Ltd.

Bromsgrove, England

1975

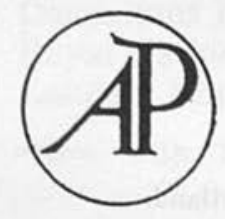

ACADEMIC PRESS London'New York·San Francisco A Subsidiary of Harcourt Brace Jovanovich, Publishers 


\section{ACADEMIC PRESS INC. (LONDON) LTD. 24-28 Oval Road, London NW1}

U.S. Edition published by ACADEMIC PRESS INC.

111 Fifth Avenue,

New York, New York 10003

Copyright (C) 1975 By W. TAYLOR and P. L. PELMEAR

\section{All Rights Reserved}

No part of this book may be reproduced in any form by photostat, microfilm, or any other means, without written permission from the publishers Library of Congress Catalogue Card Number: 7515487 ISBN: 0126845506 


\section{Vibration Research Team}

\section{MEDICAL SURVEY TEAM}

Professor W. Taylor, B.Sc., Ph.D., M.D., F.R.C.P. (Edin.).

Department of Community and

Occupational Medicine,

University of Dundee, Scotland.

Dr P. L. Pelmear, M.D., M.F.C.M., D.P.H., D.I.H., D.R.C.O.G.

Senior Medical Officer,

G.K.N. Forgings Ltd.,

G.K.N. Castings Ltd.,

Bromsgrove, Worcs., England.

Dr P. B. James, ${ }^{*}$ M.B., Ch.B., D.I.H.

Lecturer in Occupational Medicine,

University of Dundee, Scotland.

\section{VIBRATION MEASUREMENT AND STANDARDS}

$\mathrm{Mr}$ G. D. Keighley, B.Sc.

Forestry Commission of

Great Britain.

Dr T. I. Hempstock, B.Sc., Ph.D., and

Mr D. E. O'Connor, M.Sc.

Department of Pure and Applied Physics

University of Salford, England.

Mr R. Kitchener, B.Sc.

G.K.N. Group Technological Centre,

Wolverhampton, England.

\section{RADIOLOGISTS}

Dr R. O. Murray, M.D., F.R.C.P., D.M.R.

Consultant Radiologist, Royal National Orthopaedic Hospital, London, England.

*Now with The East of Scotland Occupational Health Service, Dundee, Scotland. 
Dr G. F. A. Howie, M.D., D.M.R.D., F.F.R., F.R.C.P.E. Senior Lecturer, Diagnostic Radiology, University of Dundee, Scotland.

Dr J. K. Davidson, M.D., F.R.C.P., F.R.C.R.

Consultant Radiologist in Administrative Charge, Western Infirmary, Glasgow, Scotland.

\section{STATISTICIANS}

Mr J. C. G. Pearson, B.Sc., Dip.Stat., M.Sc. (Hyg.). Lecturer in Medical Statistics, Department of Community and Occupational Medicine, University of Dundee, Scotland.

Mrs S. C. Murray, M.A., and Mr J. R. Yates, ${ }^{*}$ Department of Community and Occupational Medicine, University of Dundee, Scotland.

*Now with the Caledon Shipbuilding \& Engineering Co. Ltd., Dundee 


\section{Foreword}

It gives me great pleasure to introduce this volume which reproduces with editorial amendments a report submitted to the Department of Health and Social Security in December 1973. It contains the findings of a four year research project into vibration-induced white finger, a condition recognised by Occupational Health Physicians for many years but unknown even today to many industrialists.

My company has not been slow to recognise its responsibilities for the health, safety and welfare of work people and when approached by the Department of Health and Social Security through Professor W. Taylor, we readily agreed to support and assist this investigation by allowing the active participation of $\mathrm{Dr} \mathrm{P}$. L. Pelmear, one of our Senior Medical Officers and Mr R. Kitchener of the GKN Group Technological Centre.

In this field, the findings presented here indicate the necessity for a greater awareness of V.W.F. in industry, the need for better measurement of vibration and its control, and the development of safe hand-held vibratory tools.

To this end my company has gladly undertaken to sponsor publication of the report in the hope that a wider awareness of the subject matter will not only benefit those work people now at risk, but will motivate development engineers and designers to provide a safer working environment.

A history of GKN is currently being prepared and research among old information indicates that the present company and its forbears have, since the first records were kept in 1759, shown a keen regard for employee welfare.

In earlier days this regard was, to a large degree, paternalistic: if an employee suffered a severe illness or 
was injured at work he would often be assisted financially. But in this century, particularly since the 1930's, attitudes have changed. GKN now seeks the cause of industrial illnesses and accidents and attempts to obviate their recurrence. The company's medical services, environmental engineers and reseach teams work closely together with this end in view. As an example, GKN has for many years studied the problems of noise-induced deafness in industry and commenced a hearing conservation programme throughout its companies in 1970, two years before issue of the Government Code of Practice on this subject.

With the publication of the Robens Report and the subsequent requirements of the Health and Safety at Work Act, industry as a whole has an increasing role to play in identifying and controlling risks to health and safety. In assisting research and sponsoring publication of this report dealing with Vibration White Finger in Industry I trust that my company is showing its willingness to play its full part in helping provide a fuller and happier life for those who work in engineering and industrial fields.

Smethwick,
Barrie Heath, D.F.C.
Group Chairman,
Guest, Keen \& Nettlefolds Limited.

Warley,

West Midlands, B66 2RZ.

6th January, 1975. 
This Hand-Arm Vibration Research Project was financed by the Department of Health and Social Security in connection with an investigation by the Industrial Injuries Advisory Council into the Vibration Syndrome. The responsibility for the views expressed and the conclusions drawn are those of the authors of the Papers alone. 
"For we must admit that the workers in certain arts and crafts sometimes derive from them grave injuries, so that where they hoped for a subsistence that would prolong their lives and feed their families, they are too often repaid with the most dangerous diseases and finally uttering curses on the profession to which they had devoted themselves, they desert their post among the living."

Extract from "De Morbis Artificum Diatriba". Published in 1700 by Bernardino Ramazzini (1633 - 1714), Physician and Professor of Medicine in Modena and Padua. 


\section{Objectives}

1. The Industrial Injuries Advisory Council asked for further data on and research into vibration induced white finger (V.W.F.) in employees handling vibration tools (Interim Report, Industrial Injuries Advisory Council, 1970).

2. The Chief Medical Adviser, Department of Health and Social Security met Professor W. Taylor, Mr G. D. Keighley of Forestry Commission and $\mathrm{Mr}$ J. Tweedie, National Engineering Laboratory, East Kilbride, on 9th September, 1970 , to discuss setting up a research project to provide further evidence to I.I.A.C.

3. Authority for finance and permission to proceed was given on 28th October, 1970, to cover the following areas of Research:

(a) To investigate the degree of severity of the vibration signs and symptoms, i.e. the extent of interference with work and social activities.

(b) To answer the question whether severe V.W.F. cases leave their employment because of the severity of their signs and symptoms.

(c) To what extent a change of occupation brought about by V.W.F. affects the level of earnings.

(d) Whether the signs and symptoms of V.W.F. are reversible after the vibration stimuli have been withdrawn.

(e) The Committee wishes any enquiry to extend beyond the area in which Professor Taylor and Mr Keighley had already reported, namely chain saw employees. 


\section{Acknowledgments}

The research team gratefully acknowledge the award of a grant (1970) from the Department of Health and Social Security, and a supplementary grant (1971) to undertake additional vibration measurements.

We are indebted to three main concerns, the Forestry Commission through Mr G. D. Keighley and their Medical Adviser Dr R. M. Oliver, to G.K.N. Forgings Limited and G.K.N. Castings Limited. Prospective surveys of V.W.F. over five years have been possible only through their continued interest and co-operation. We are also grateful to Fords Limited, I.M.I. Limited, Stone Manganese Limited and H.M. Dockyard, Rosyth, for access to their plants and employees.

On vibration measurement the research team wish to express their appreciation for the advice, guidance and active participation of the G.K.N. Group Technological Centre, the Department of Pure and Applied Physics, University of Salford, and the National Engineering Laboratory, East Kilbride.

This project would not have been possible without the active participation and voluntary co-operation of the employees of the companies surveyed, and to them we offer our grateful thanks.

Thanks are also due to Professor Alex. Mair, Head of the Department of Community and Occupational Medicine, University of Dundee, for help and advice. Finally, we are indebted to Miss E. Simpson and Mrs J. Walker for secretarial help and assistance. 


\section{Vibration-induced White Finger Epidemiology W. TAYLOR, P. L. PELMEAR and J. C. G. PEARSON}

\section{POPULATION FOR STUDY}

The original plan for this study envisaged a survey of 4 populations of workers exposed to vibration, with age- and sex-matched controls for comparison of the rates of white finger. However, it was not always possible to obtain sufficient numbers of suitable control subjects and a one-to-one matching was therefore not achieved. In addition, as the study progressed, other populations were discovered and investigated, in some cases without control groups. Where results for control groups are quoted, these subjects are in a similar environment in the same industry as the exposed subjects and are in the same general age range although not necessarily matched on an individual basis.

In all, 18 populations of exposed subjects were investigated in industries where V.W.F. was known to be an occupational hazard. The industrial processes involved can be divided into four broad categories:

1. Chain sawing (felling, snedding and cross-cutting)

2. Grinding (hand and pedestal)

3. Chipping (with pneumatic tools)

4. Swaging (of copper tubes)

The total number of subjects examined was 1,283 but 91 subjects reported a mixed occupational history with exposure to different types of vibration. Since it was desired to investigate the effects of exposure to a single known source of vibration, these subjects were immediately excluded, leaving 1,192 with suitable occupational histories. In this population there were 827 exposed to vibration and 365 controls. The details of the numbers in the different 
groups are shown in Table 1 . The overall response to the survey was $97 \%$, the rates in the different industries varying from 95 to $99 \%$.

Table 1

Populations Studied

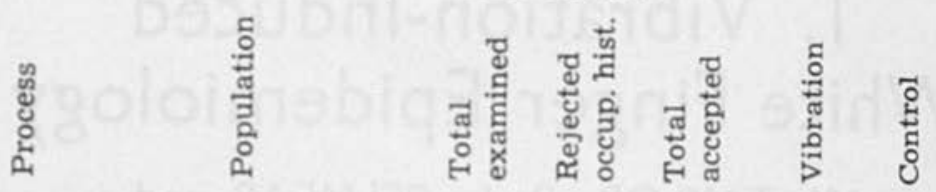

\begin{tabular}{|c|c|c|c|c|c|c|}
\hline \multirow[t]{4}{*}{ Sawing } & 'Thetford & 128 & 9 & 119 & 56 & 00 \\
\hline & "Kielder & 68 & 6 & 62 & 38 & \\
\hline & -Dumfries & 54 & 2 & 52 & 29 & \\
\hline & TOTAL & 250 & 17 & 233 & 123 & 110 \\
\hline \multirow[t]{13}{*}{ Grinding } & -Cwmbran & 139 & 18 & 121 & 51 & \\
\hline & -Bromsgrove & 149 & 9 & 140 & 89 & \\
\hline & Halesowen & 45 & 6 & 39 & 21 & 18 \\
\hline & -Leamington & 116 & 15 & 151 & 74 & 7 \\
\hline & Old Cwmbran & 36 & - & 36 & 36 & \\
\hline & Darlaston & 29 & - & 29 & 29 & \\
\hline & Ayr & 112 & - & 112 & 112 & \\
\hline & Lincoln & 59 & - & 59 & 59 & \\
\hline & Smethwick & 25 & - & 25 & 25 & \\
\hline & Witton & 15 & - & 15 & 15 & \\
\hline & Strood & 17 & - & 17 & 17 & \\
\hline & Great Barr & 7 & - & 7 & 7 & \\
\hline & TOTAL & 799 & 48 & 751 & 535 & 216 \\
\hline \multirow[t]{3}{*}{ Chipping } & -Birkenhead & 131 & 7 & 124 & 98 & 26 \\
\hline & Rosyth & 70 & 1 & 69 & 69 & \\
\hline & TOTAL & 201 & 8 & 193 & 167 & 26 \\
\hline \multirow[t]{2}{*}{ Swaging } & Liverpool & 33 & 18 & 15 & 2 & 13 \\
\hline & TOTAL & 33 & 18 & 15 & 2 & 13 \\
\hline GRAND & AL & 1283 & 91 & 1192 & 827 & 365 \\
\hline
\end{tabular}

* First 9 populations studied.

\section{RESULTS}

\section{Prevalence of V.W.F.}

In investigating the possible hazard it is necessary to compare the prevalence of symptoms in the exposed groups with that in the corresponding control groups. White finger subjects are defined as those in Stages 1,2 and 3 of the classification. Subjects in the intermediate stage Oт/ON are not considered to have reached the white finger stage. In 
calculating these prevalences, the source of the white finger is not considered. White finger can arise from a variety of sources - industrial and non-industrial - and the presence of a hazard will be indicated by an increased prevalence in the vibration exposed groups compared with that in the control groups where only sources other than vibration will contribute to white finger. These nonvibration sources will also apply in the vibration group and should produce a similar level of non-vibration induced white finger as that found in the control group.

The prevalence rates in the relevant populations are shown in Table 2.

Table 2

Prevalence of White Finger

Process Population Vibration exposed Controls

\begin{tabular}{llrrrrrr}
\multirow{5}{*}{ Sawing } & Total & No. & $\%$ & Total & No. & $\%$ \\
& Thetford & 56 & 50 & 89 & 63 & 4 & 6 \\
& Kielder & 38 & 26 & 68 & 24 & 2 & 8 \\
& Dumfries & 29 & 14 & 48 & 23 & 1 & 4 \\
& Cwmbran & 51 & 30 & 59 & 70 & 3 & 4 \\
& Bromsgrove & 89 & 53 & 60 & 51 & 7 & 14 \\
& Halesowen & 21 & 3 & 14 & 18 & 3 & 17 \\
& Leamington & 74 & 8 & 11 & 77 & 3 & 4 \\
& Old Cwmbran & 36 & 8 & 22 & - & - & - \\
& Darlaston & 29 & 5 & 17 & - & - & - \\
& Ayr & 112 & 11 & 10 & - & - & - \\
& Lincoln & 59 & 17 & 29 & - & - & - \\
& Smethwick & 25 & 6 & 24 & - & - & - \\
& Witton & 15 & 2 & 13 & - & - & - \\
& Strood & 17 & 3 & 18 & - & - & - \\
& Great Barr & 7 & 0 & 0 & - & - & - \\
Chipping & Birkenhead & 98 & 56 & 57 & 26 & 5 & 19 \\
Swaging & Rosyth & 69 & 32 & 46 & - & - & - \\
& Liverpool & 2 & 1 & 50 & 13 & 1 & 6
\end{tabular}

These rates confirm the wide variation found in published studies (Hamilton 1918; Seyring 1930; Hunter 1945; Agate and Druett 1946, 1947 and 1949; Grounds 1964; Miura 1966; Kylin 1968).

During the course of the present study potentially 
serious situations were identified in 3 of the 18 populations; (a) Thetford - chain sawing, (b) Cwmbran - pedestal grinding, and (c) Liverpool - swaging. It was considered possible that in all 3 the work situation was such that the V.W.F. prevalence rates would, within 2-3 years, affect the entire population. Indeed in the swaging process most of the workers had been forced to stop because of V.W.F. This accounts for the very small surviving groun exposed in this population. The Forestry Commission replaced existing saws with anti-vibration models conforming to set vibration limits; the grinding processes were assessed and a new method of trimming introduced to avoid oval wheels; and automation was introduced into the swaging process to avoid vibration transmission to the hands.

\section{Social Handicap}

It is known that one of the main factors involved in deterioration from Stage 3 to Stage 4 (when a vibration exposed employee decides to change his occupation because of increasing number and severity of V.W.F. attacks) is interference with home and leisure activities. As a guide to clinical deterioration and in the absence of objective tests accurately defining V.W.F., Stage 3 provides a useful criterion in that, by definition, curtailment or cessation of hobbies is implied.

The number and percentage of vibration exposed subjects at each stage of white finger in each of the populations investigated is shown in Table 3 . No attempt has been made to combine the results from the different populations, since the high degree of variation in the prevalence of V.W.F. in the different populations means that any combined figure depends more on the relative numbers from each population than on the individual rates of the disease.

In the vibration exposed populations the percentage of subjects in Stage 3 was as high as $52 \%$ in Thetford. No control subjects were in Stage 3. In 5 other exposed populations the percentage in Stage 3 varied from 4 to $20 \%$. Very few control subjects were found in Stage 2, but 7 exposed populations each had more than $20 \%$ in Stage 2 or above. In 2 of these populations it was more than $50 \%$. 


$$
\begin{aligned}
& \text { n }
\end{aligned}
$$

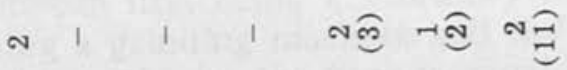

$$
\begin{aligned}
& \text { 夰 } \\
& \text { 苍 U }
\end{aligned}
$$

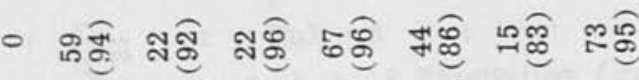

$$
\text { 芯 芯 }
$$

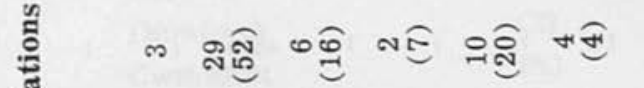

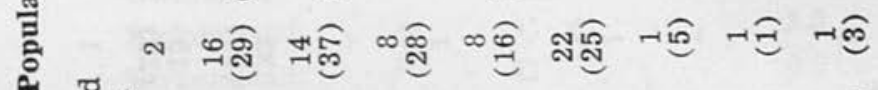

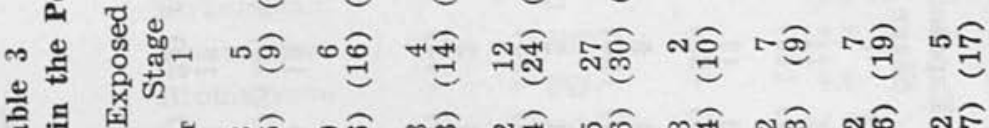

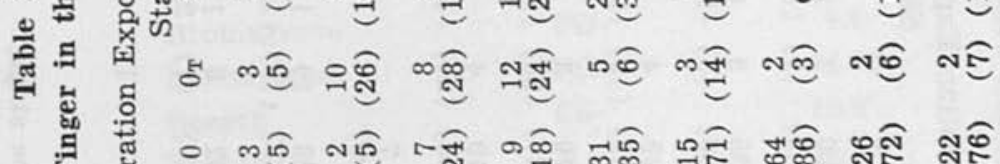

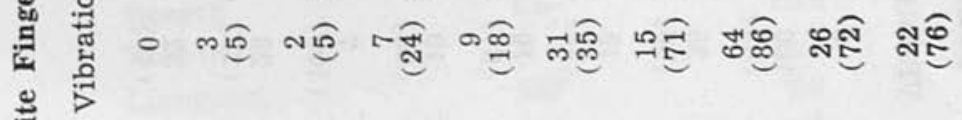

ப

迹

范

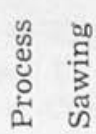




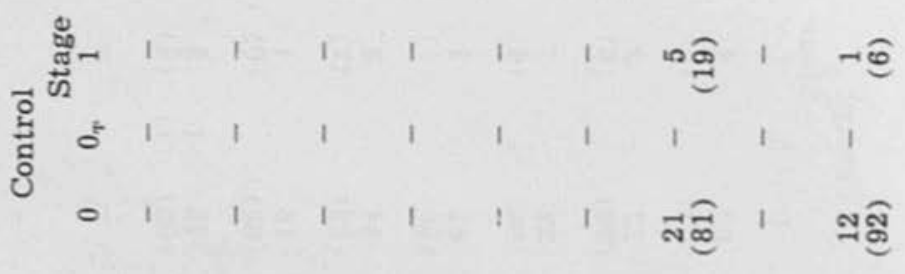

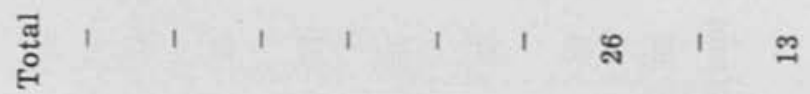
๓ $1 \quad 1 \quad 1 \quad 1 \quad 111$ ตอ 1

ङ

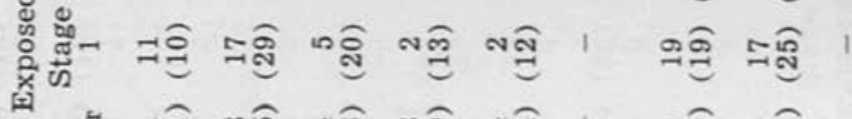

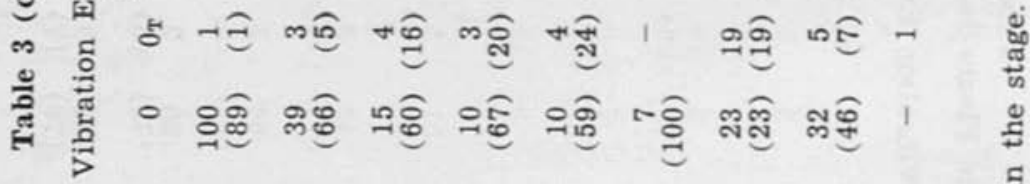

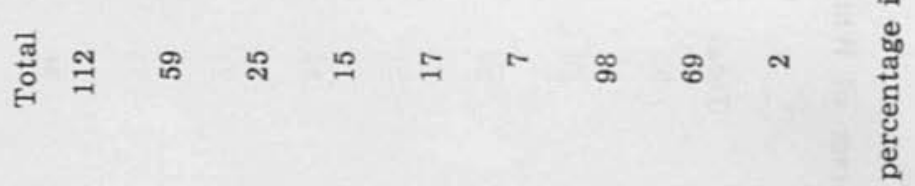

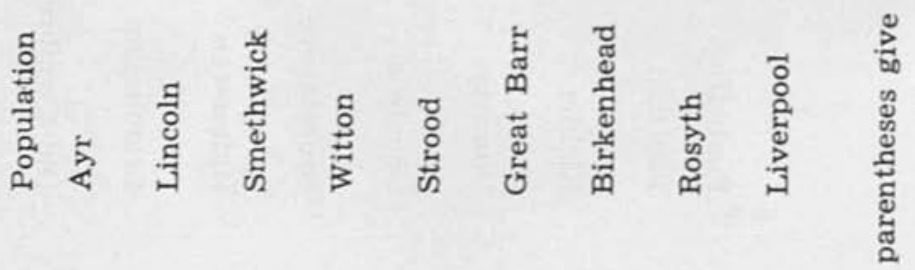

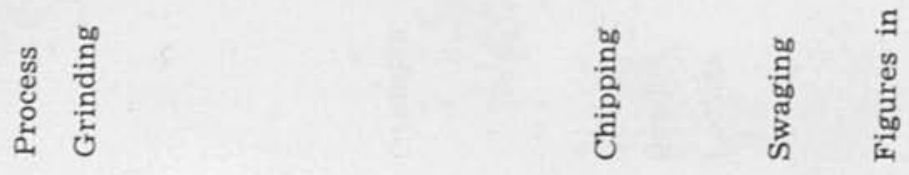




\section{Latent Interval}

Latent Interval or Latent Period is defined as the time interval between first using a vibratory hand-held tool or first operating a grinding machine and the first appearance of a white finger tip, i.e. the time interval between Stage 0 and Stage 1. The data for the present survey is shown in Table 4 and Fig. 1.

\section{Table 4}

Latent Interval (years) in 18 Population Groups.

\section{Population}

Location

Thetford

Kielder

Dumfries

Cwmbran

Birkenhead

Birkenhead

Bromsgrove

Bromsgrove

Leamington

Rosyth

Rosyth

Liverpool

Old Cwmbran

Old Cwmbran

Darlaston

Darlaston

Ayr

Ayr

Lincoln

Lincoln

Smethwick

Smethwick

Witton

Witton
Process

CS

CS

CS

PG

C

G

HG

PG

PG

$\mathrm{Ca}$

$\mathrm{N}$

SW

HG

PG

HG

PG

HG

PG

HG

PG

HG

PG

HG

PG
Latent Interval

(in years)

2.8

3.6

3.0

1.8

5.3

8.7

13.7

4.5

14.0

14.0

16.5

0.6

1.6

2.5

5.0

12.0

18.0

11.0

15.0

7.0

27.0

3.3

20.0

8.0

$\mathrm{KEY}-\mathrm{G}=$ Grinding $(\mathrm{H}=$ Hand, $\mathrm{P}=$ Pedestal $) ; \mathrm{CS}=$ Chain Saw; $\mathrm{Ca}=$ Caulking; $\mathrm{SW}=$ Swaging; $\mathrm{N}=$ Nobbling;

$\mathrm{C}=$ Chipping. 
Interval - vibration exposure to first V.W.F.

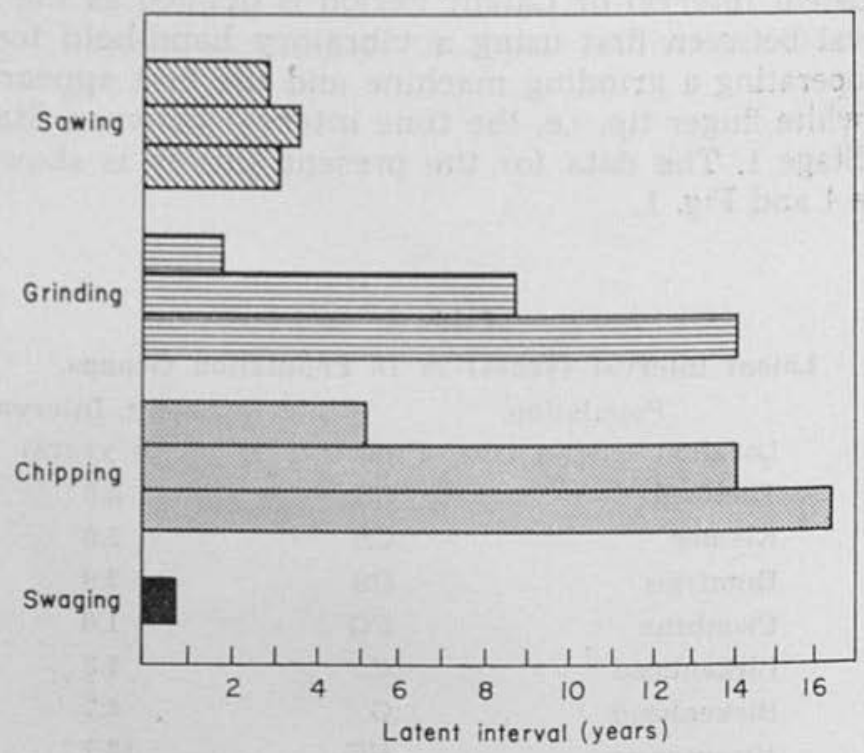

Fig. 1.

From Table 4 it is seen that swaging (Liverpool) represents the shortest latent interval - mean 6-8 months with some cases around 6 weeks. Pedestal grinding has a mean of 1.8 years, with some cases around 6-7 months. In forestry, the latent interval with conventional saws without antivibration treatment is from 2.8 to 3.6 years with a mean of 2.8 years. The latent interval for chipping is 5-9 years, for caulking 14 years and nobbling 16.5 years. The latter two operations at Rosyth represent a discontinuous or interrupted work situation where the subjects are exposed to vibratory tools (caulking and nobbling) and painting by hand brush (a non-vibrational process) on alternate weeks.

\section{Comparison of Vibration Exposure Time and Stage of V.W.F.}

To test the validity of the concept that vibration dosage is cumulative - analagous to that found in noise and resultant hearing loss - an attempt has been made to correlate vibration exposure time with the resulting stage of V.W.F. The complete data is given in the Appendix. A summary is shown in Table 5 and in Fig. 2. 
Table 5

Vibration Exposure Time by Stage of White Finger.

Mean

Population Process exposure

time (yrs.)

7.3

4.7

Mixed

Pedestal

Broms-

grove

Rosyth

Nobbling

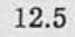

14.0

Thetford Chain saw

Cwmbran Grinding

Caulking

24.0

3.7

Stage of white finger

$\begin{array}{lllll}0 & 0 \mathrm{~T} & 1 & 2 & 3\end{array}$

Caulking

Vibration exposure and stage of V.W.F.

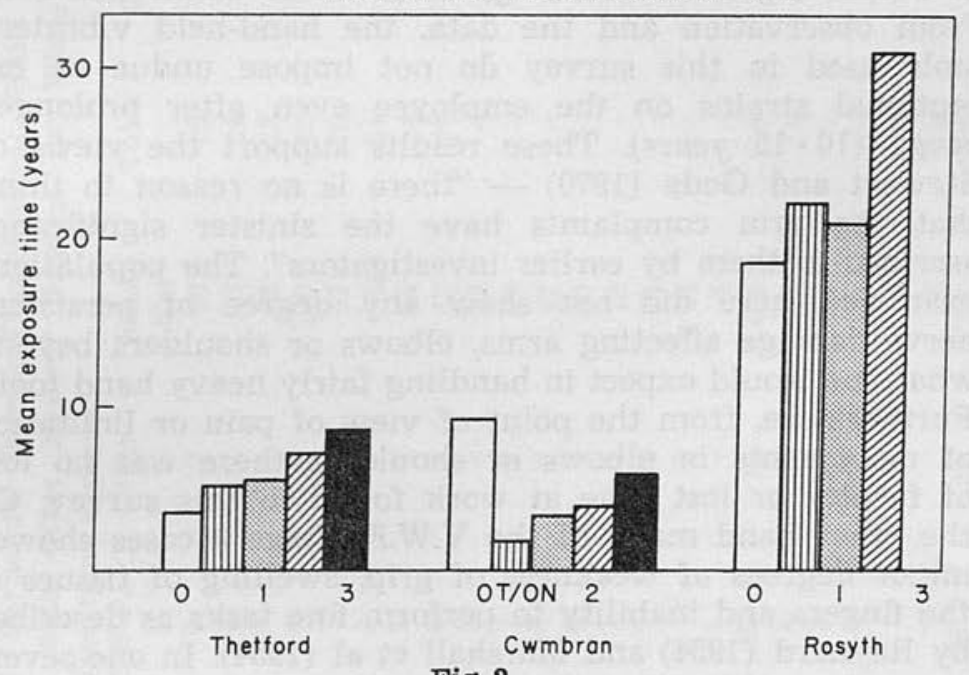

Fig. 2.

\section{Pain in Wrists, Arms and Shoulders}

At interview, vibration exposed and control subjects were questioned on clinical signs and symptoms with special reference to pain in the following areas - wrists, forearms, elbows, upper arms and shoulders associated with the use of their hand-held vibratory tools.

This factor (pain) was investigated only in the first 9 populations seen during the study (Table 1 ).

The results indicate that $12 \%$ of the 525 vibration exposed had aches in one of the following areas - wrists, muscles of the arm and in the shoulder joint - as against $0.5 \%$ in a control group of 352 . Of the 64 (12\%) complaining of wrist and/or arm pains, 23 (36\%) were chippers using 
Table 6

Vibration Syndrome. Pain in Wrists, Elbows, Arms and Shoulders.

$\begin{array}{lccc}\text { Population } & \begin{array}{c}\text { Pain in one or } \\ \text { more areas }\end{array} & \begin{array}{c}\text { No pain or } \\ \text { related } \\ \text { complaints }\end{array} & \begin{array}{c}\text { Total Number } \\ \text { in sample }\end{array} \\ \text { 1. Vibration } & 64(12 \%) & 461(88 \%) & 525 \\ \text { 2. Controls } & 2(0.5 \%) & 350(99.5 \%) & 352 \\ \text { 3. Rejects } & 9(12 \%) & 64(88 \%) & 73\end{array}$

pneumatic tools, $22(34 \%)$ were chain saw users and 7 $(4 \%)$ were hand and pedestal grinders. It is not possible to obtain significant findings from these small numbers. From observation and the data, the hand-held vibratory tools used in this survey do not impose undue or exceptional strains on the employee even after prolonged usage $(10-15$ years). These results support the views of Stewart and Goda (1970) - "there is no reason to think that the arm complaints have the sinister significance ascribed to them by earlier investigators". The populations examined here did not show any degree of persistent nerve damage affecting arms, elbows or shoulders beyond what one would expect in handling fairly heavy hand tools. Furthermore, from the point of view of pain or limitation of movements in elbows or shoulders there was no loss of faculty or lost time at work found in this survey. On the other hand many of the V.W.F. Stage 3 cases showed minor degrees of weakness of grip, swelling of tissues of the fingers and inability to perform fine tasks as described by Reynard (1954) and Marshall et al (1954). In one severe case where skin ulceration of the finger pulp occurred due to the obliteration and narrowing of the proximal portions of the digital arteries, the main nerve trunks in the arms remained normal. The superficial cutaneous plexus showed peri-neural infiltration and degeneration, suggesting that the nerve pathology is confined to the fingers, i.e. to the actual area of contact with the vibrating force (Walton 1974).

\section{Prevalence of Raynaud's Disease and Other Possible Non-Vibration Causes of White Finger}

The number of subjects reporting Raynaud's disease or constitutional white finger in the different populations is shown in Table 7, together with the number reporting 


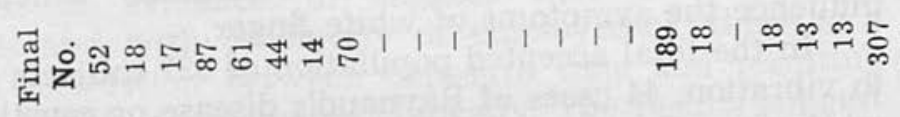

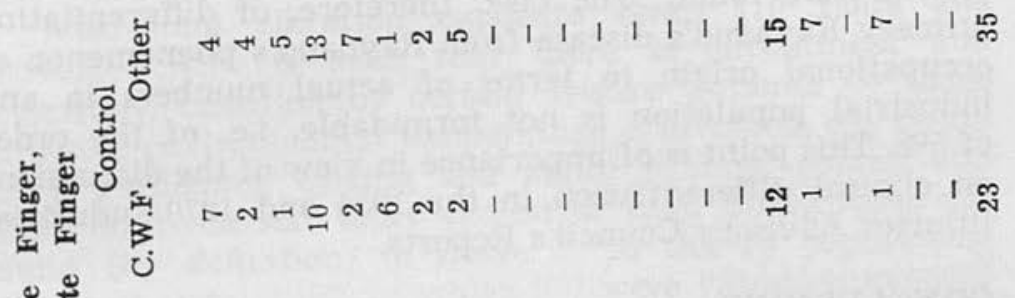

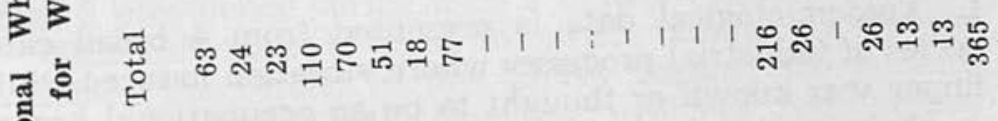

丞完

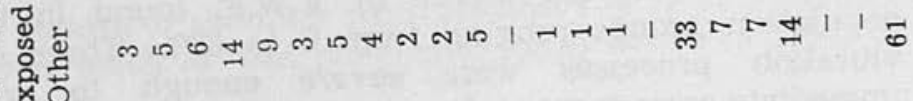
记 站

묭

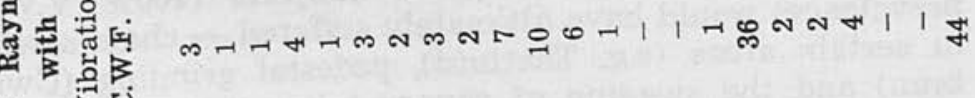

의 $\gg 0$

(1)

总

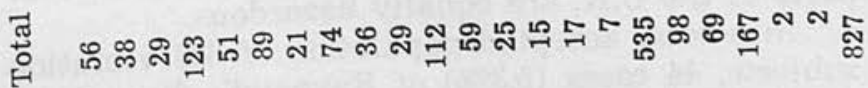

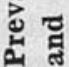

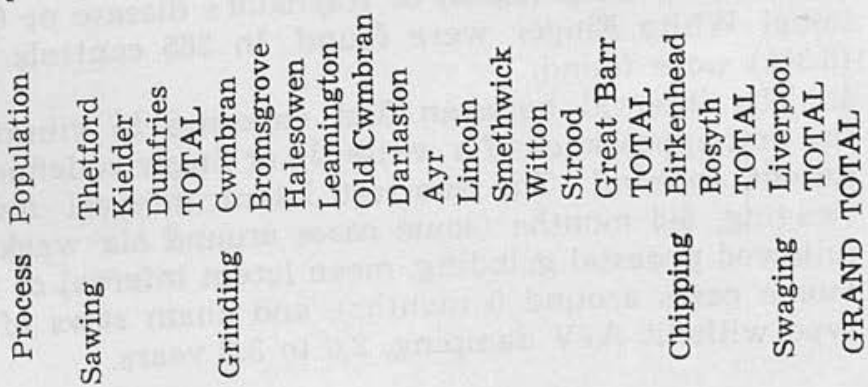


histories of trauma and other conditions which might influence the symptoms of white finger.

In the total accepted population of 827 subjects exposed to vibration, 44 cases of Raynaud's disease or constitutional white fingers were found $(5.3 \%)$. In 365 controls, 23 cases $(6.3 \%)$ were found. The task, therefore, of differentiating primary Raynaud's disease from Raynaud's phenomenon of occupational origin in terms of actual numbers in any industrial population is not formidable, i.e. of the order of $5 \%$. This point is of importance in view of the discussions on clinical differentiation in the 1954 and 1970 Industrial Injuries Advisory Council's Reports.

\section{CONCLUSIONS}

1. Epidemiological data is presented from 4 broad categories of industrial processes where vibration induced white finger was known or thought to be an occupational hazard - chain sawing, hand and pedestal grinding, chipping with pneumatic tools and swaging of copper tubes. In all 18 populations were surveyed yielding information on 827 vibration exposed and 365 control subjects.

2. As in previously published work there was a large variation in the prevalence of V.W.F. found in the 18 population groups ranging from 0 to $89 \%$. Three of the vibration processes were severe enough to warrant immediate assessment and modification in working methods, otherwise all vibration exposed subjects $(100 \%$ V.W.F. prevalence) would have ultimately suffered - chain sawing in certain areas (e.g. Thetford), pedestal grinding ( $\mathrm{Cwm}$ bran) and the swaging of copper tubes (Liverpool). It is not suggested that equivalent industrial processes in other parts of the U.K. are equally hazardous.

3 . In a total accepted population of 827 vibration exposed subjects, 44 cases (5.3\%) of Raynaud's disease or Constitutional White Finger were found. In 365 controls 23 cases $(6.3 \%)$ were found.

4. The interval between first exposure to vibration and the first appearance of a white tip or finger is defined as the Latent Interval. The shortest latent interval found was swaging, 6-8 months (some cases around six weeks). Then followed pedestal grinding, mean latent interval of 1.8 years (some cases around 6 months), and chain saws of the old type without $\mathrm{A} / \mathrm{V}$ damping, 2.8 to 3.6 years. 
5. There is evidence to suggest that in continuous processes and with continuity of employment, there is a positive correlation between exposure time and resulting stage of V.W.F. as estimated clinically. The results suggest that vibration is, in a similar manner to noise, cumulative. 6. With long vibration exposure times (10 years and above), V.W.F. is such that there is curtailment and ultimately cessation of certain leisure pursuits - those in which environmental temperature is involved, e.g. swimming, gardening, cycling and motor cycling, golfing and home do-it-yourself tasks (house or car). These cases are found (by definition) in Stage 3. In the 18 populations examined (total 1,192) of which 827 were vibration exposed Stage 3 prevalence varied from 4 to $52 \%$ (Table 3 ).

7. With reference to pain in wrists, elbows, arms and shoulders, the results in this survey support the findings of Stewart and Goda that no evidence was found of peripheral nerve involvement and no clinical impairment or handicap from pathology in forearm, elbow, upper arm or shoulder. There were, however, minor sensory changes in the hands similar to those reported by Reynard (1954). No lost time from work could be attributed in this survey to arm or shoulder pain. No heavy or large vibratory tool users (such as road pneumatic tools) were examined in this survey. 


\section{A Longitudinal Study of Raynaud's Phenomenon in Chain Saw Operators W. TAYLOR, P. L. PELMEAR and J. C. G. PEARSON}

\section{INTRODUCTION}

Since the first description of white fingers in pneumatic tool workers by Loriga in Italy in 1911, there have been many accounts of Raynaud's phenomenon in industry, from quarries in the 1920's, foundries in the 1930's, handgrinding shops in the 1940's and rock mines in the 1950's.

Throughout the 1960's in Britain and elsewhere, evidence was accumulating that a new tool, now used universally in timber operations - the power-driven chain saw - was giving rise to Raynaud's phenomenon. This was first reported by Grounds in 1964 after studying 22 "timber fellers" using chain saws in Tasmania. In this series, 20 men $(91 \%)$ showed signs of white finger but none felt it necessary to give up his job. As the use of chain saws spread, reports from other countries, e.g. Japan (Miura et al 1966), Sweden (Kylin et al 1968), Australia (Barnes et al 1969) and New Zealand (Allingham and Firth 1972), described essentially the same condition, that after 2-4 years saw operation, a proportion of the sawyers began to develop a condition in which first tingling and numbness were noted followed by blanching usually of one finger tip. After 8-10 years constant use of the chain saws (usually 6-7 hours per day, 5 days per week), all fingers on both hands were involved.

The use of chain saws in forestry in Britain, initially confined to felling and cross-cutting, was increased with 
the introduction of chain saw snedding (de-branching) in 1967. The saw usage time thus showed a steady increase from $1 \frac{1}{2}$ to 2 hours per day (late 1950's and early 1960's) to $6 \frac{1}{2}-7 \frac{1}{2}$ hours in 1968-70 (Axelsson 1968) in Sweden and 5-5 $\frac{1}{2}$ hours in Britain (Keighley 1970, personal communication).

In 1969 an investigation of the prevalence of Raynaud's phenomenon in Forestry Commission employees was carried out by a questionnaire given to a random sample of the employees (Taylor et al 1971). Following this investigation, which showed that the prevalence was highest in those areas where chain saws had been in use for the longest periods, the Forestry Commission offered facilities for medical examination of saw users at one of their largest felling centres, Thetford Chase, Norfolk. This population, which includes some of the men with the longest exposure to chain saw vibration in the U.K., has now been examined 5 times at yearly intervals. This paper presents the results of these prospective investigations.

\section{POPULATION FOR STUDY}

In the first survey in December 1969, all of the 50 sawyers employed agreed to take part in the study. They were age-matched with men in the same environment who had never been exposed to vibration, either from chain saws or from hand-held vibratory tools. This control group, however, was subsequently re-examined and those men whose occupational history indicated exposure to any form of vibration, e.g. drivers of excavators, heavy tractors and peeling machines, were rejected. This left only 48 in the control group. In January, 1971 a similar study with 56 sawyers and controls was undertaken as part of a wider survey covering several industries where V.W.F. was known or thought to be present. Three subsequent surveys in January 1972 , 1973 and 1974 dealt solely with sawyers already examined in the earlier surveys. The age distribution of these 46 men seen throughout the 5 surveys is seen in Table 1.

\section{Table 1}

\section{Age Distribution of 46 Chain Saw Operators}

$\begin{array}{lrrrrr}\text { Age (in years) } & 20-29 & 30-39 & 40-49 & 50-59 & 60+ \\ \text { Number } & 2 & 14 & 11 & 15 & 4\end{array}$




\section{VIBRATION CHARACTERISTICS}

From 1961 to June 1970, the Thetford chain saw operators were handling saws with high acceleration values on both the front and rear handles (200-400 metres/sec. $\left.{ }^{2}\right)$. Prior to June 1970, the saws had no vibration damping (See Appendix, Paper 2).

Anti-vibration saws, conforming to limits laid down by the Forestry Commission (less than 60 metres $/ \mathrm{sec}^{2}$ on either handle) were then gradually introduced throughout the year from June to December and by the end of 1970 , all sawyers in this study were on A/V saws. Thus by the January 1972 survey, the sawyers had at least one year on A/V saws and by the fifth survey in January 1974 the $A / V$ saw usage was at least 3 years.

\section{METHOD}

In all 5 surveys the same examiner (W.T.) took a full occupational history and graded the V.W.F. signs and symptoms (Stage assessment) according to the criteria described in the introduction. In addition, in the first 4 studies, sensory tests were also made, the results of which have been incorporated in Paper 6.

\section{PREVALENCE OF V.W.F. IN CHAIN SAW OPERATORS}

The mean saw usage time and the distribution by stage of V.W.F. for the same population over the 5 prospective surveys from 1969 to 1974 are shown in Table 2.

Table 2

Chain Saw Operators: Saw Usage Time, Stage of V.W.F. and $\%$ V.W.F. Prevalence

\begin{tabular}{ccccccccccc}
$\begin{array}{c}\text { Number } \\
\text { of } \\
\text { sawyers }\end{array}$ & $\begin{array}{c}\text { Mean } \\
\text { age } \\
\text { (years) }\end{array}$ & $\begin{array}{c}\text { Mean } \\
\text { saw } \\
\text { usage } \\
\text { time } \\
\text { (years) }\end{array}$ & $\begin{array}{c}\text { Year } \\
\text { of } \\
\text { survey }\end{array}$ & \multicolumn{4}{c}{$\begin{array}{c}\text { Stage of V.W.F. } \\
\text { No. of cases }\end{array}$} & $\begin{array}{c}\text { Prevalence } \\
\text { V.W.F. } \\
\text { (y) }\end{array}$ \\
46 & 42.6 & 6.4 & 1970 & 6 & 4 & 17 & 18 & 39 & 85 \\
46 & 43.6 & 7.4 & 1971 & 5 & 2 & 14 & 23 & 39 & 85 \\
46 & 44.6 & 8.4 & 1972 & 2 & 5 & 15 & 20 & 40 & 87 \\
$44^{*}$ & 45.3 & 9.5 & 1973 & 6 & 10 & 15 & 12 & 37 & 84 \\
46 & 46.6 & 10.4 & 1974 & 11 & 8 & 22 & 5 & 35 & 76
\end{tabular}


This population using saws without vibration treatment showed a V.W.F. prevalence of $85 \%$ in $1970,85 \%$ in 1971 , and $87 \%$ in 1972. With the introduction of antivibration saws, the prevalence in 1973 was $84 \%$ and in 1974 was $76 \%$. This reduction is not significant but there is a decreasing trend in V.W.F. with A/V saw treatment.

The prevalence rates for a control group, age- and sexmatched, working in the same environment but without vibration, was $6.0 \%$ in 1970 and $6.6 \%$ in 1971 .

\section{CLINICAL ASSESSMENT FROM V.W.F. HISTORY}

From the detailed occupational health history taken from the 46 sawyers seen on all 5 surveys (with the exception of 2 not available in 1973 because of sickness), a clinical assessment was made on each individual case using the following criteria:

1. Improved (I): if subject was reduced by one or more stages.

2. No change (NC): if subject remained in same stage.

3. Deteriorated (D): if subject had to be increased by one or more stages.

A stage shift was judged by an increase or decrease in number of blanching attacks, by the severity of the attacks, whether in Summer as well as Winter, and by the social and hobby interference (see Introduction).

Between December 1969 and January 1971, 3 sawyers improved, 32 showed no change and 11 had deteriorated. This does not represent a significant overall deterioration for the group $(\mathrm{P}>0.05)$.

At the 1972 survey, after at least one year of antivibration saw usage, 11 sawyers improved, 23 showed no change and 12 deteriorated compared with their stage in 1971. This again does not represent a significant departure from an overall "no change" situation $(\mathrm{P}>0.05)$ but it is a reversal of the trend in the previous year. By 1973 after at least 2 years of A/V saw usage, 18 sawyers showed improvement, 25 showed no change and only 1 had deteriorated compared with the 1971 assessment. This represents a significant overall improvement $(\mathrm{P}<0.001)$. At the 1974 survey, the fifth annual survey, after 3 years of $A / V$ saw usage, 29 of the 46 sawyers examined had improved by one or more stages ( 4 had improved two stages), 17 showed no change and none had deteriorated, compared with the 
1971 assessment. Again this represents a significant overall improvement $(\mathrm{P}<0.001)$.

The results of the assessments following the introduction of $\mathrm{A} / \mathrm{V}$ saws are summarized in Table 3.

\section{Table 3 \\ Vibration Group. Chain Saw Operators. \\ Progress of V.W.F. \\ Individual Case Assessment}

$\begin{array}{ccccc}\begin{array}{c}\text { Number } \\ \text { of }\end{array} & \begin{array}{c}\text { Year } \\ \text { of }\end{array} & \begin{array}{c}\text { Assessment of V.W.F. (Number of cases) } \\ \text { Deterioration }\end{array} \\ \begin{array}{cccc}\text { Nowyers } \\ \text { survey }\end{array} & \begin{array}{c}\text { (D) } \\ \text { (NC) }\end{array} & \begin{array}{c}\text { Improvement } \\ \text { (I) }\end{array} \\ 46 & 1971 & 11 & 32 & 3 \\ 46 & 1972 & 12 & 23 & 11 \\ 44^{*} & 1973 & 1 & 25 & 18 \\ 46 & 1974 & 0 & 17 & 29\end{array}$

* Two sawyers of the designated group absent through illness

Note: Survey years 1972, 1973 and 1974 are compared with 1971 assessment.

\section{SUMMARY AND CONCLUSIONS}

1. A population of 46 chain saw operators from the forest of Thetford Chase, Norfolk, England, exposed to hand-arm vibration for $5-5 \frac{1}{2}$ hours per day, 5 days per week, from 5 to 14 years, has been surveyed at annual intervals over a 5 year period.

2. The prevalence of V.W.F. in this population when first seen in December 1969 was 85\%. The population had at this initial examination, a mean saw usage time of 6.4 years. Throughout 1970 new anti-vibration saws were introduced so that by the 1972 survey all 46 sawyers were handling $A / V$ saws with vibration criteria within limits set by the Forestry Commission. Thus by the fifth survey (1974), this population had 3 years of anti-vibration saws. During this interval the percentage prevalence of V.W.F. was $85 \%$ in $1970,85 \%$ in $1971,87 \%$ in $1972,84 \%$ in 1973 and $76 \%$ in 1974 . The prevalence rate for a control group of forestry workers without exposure to vibration was $6.0 \%$ in December 1969 and 6.6\% in January 1971.

3. Assessing severity of V.W.F. by (a) occupational history and (b) stage of V.W.F., the annual surveys showed that in the first two annual surveys (with no vibration treatment on saws) V.W.F. appeared to be deteriorating but with the small numbers the deterioration was not significant 
W. TAYLOR, P. L. PELMEAR AND J. C. G. PEARSON

0.05). After 3 years of anti-vibration saws there is a ficant overall improvement in V.W.F. $(P>0.001)$. The epidemiological data obtained from this prospective ey over a 5 year period indicated that the vibration acteristics of the old-type, untreated saws were in ss of damage criteria vibration levels for V.W.F. (in is of acceleration above 200 metres/sec. ${ }^{2}$ ). The improveit in V.W.F. noted here, following 3 years' usage of -vibration saws conforming to the proposed B.S.I. ation limits (1974), suggests that the proposed limits 5-6 hours per day, 5 days per week vibration exposure on or below the V.W.F. safe limit. Further surveys be required to show whether these proposed limits indeed safe and will not produce V.W.F. during a in sawyers working life. 


\section{Raynaud's Phenomenon in Grinders}

\section{P. L. PELMEAR, W. TAYLOR and J. C. G. PEARSON}

\section{INTRODUCTION}

Grinding as a cause of Raynaud's Phenomenon was first reported by Seyring (1931). In a special investigation of cleaners of castings and analogous processes, it was found that the liability to vibration-induced white finger increased with increasing vibration exposure time: $4 \%$ suffering within 2 years; $48 \%$ within $2-3$ years; $55 \%$ within 10 years; and $61 \%$ after 10 years. It was most prevalent with cleaners who used air drills on very hard resisting material. Reports of V.W.F. in cutlery grinders (Cummins, 1940); foundry grinders (Agate et al, 1946; Agate, 1949); pneumatic drill operators (Gurdjian and Walker, 1945; Peters 1946; Dart, 1946; Jepson, 1954) and medical instrument grinders (Kakosy et al, 1970) followed. Electrically driven tools for polishing and cutting also caused the condition (Whitwell, 1945; Brocklehurst, 1945; Telford et al, 1945; Bidden-Steele and King, 1947).

From these reports it was apparent that the use of some forms of vibratory tools lead to a much higher incidence of Raynaud's Phenomenon with earlier onset. In some situations, nearly all the individuals exposed for one or more years were affected and it was common for the condition to be more severe in fingers to which most vibration was transmitted.

In 1969, an outbreak of Raynaud's phenomenon occurred in a factory in Cwmbran. A "grey" iron foundry had been in existence there since 1900, and in 1960 a "malleable" iron foundry was established adjacent to the original works. In spite of a well-staffed medical centre and a weekly visit 
from a general practitioner, management remained unaware of Raynaud's phenomenon and no cases were reported to the medical centre until June 1969. This paper is concerned with the investigation of this outbreak of vibration induced white finger at Cwmbran, and in 12 other population groups.

\section{POPULATION - CWMBRAN}

In January 1970, all 26 pedestal grinders were screened using a questionnaire and a medical examination. The age distribution of the population examined is shown in Table 1.

Table 1

Age Distribution

$\begin{array}{cccccccc}20- & 25- & 30- & 35- & 40- & 45- & 50- & 55-60 \\ 2 & 9 & 4 & 6 & 2 & 1 & 1 & 1\end{array}$

\section{RESULTS}

\section{Exposure Time and Prevalence of V.W.F.}

The prevalence of V.W.F. and the mean exposure time to vibration by stage of V.W.F. is shown in Table 2.

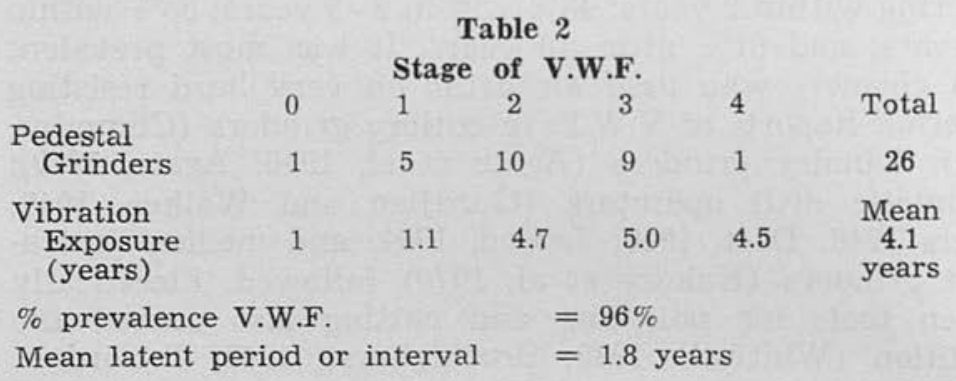

\section{Signs and Symptons of V.W.F.}

\section{Initial Survey}

In this population of 26 grinders, 9 men (35\%) were experiencing difficulty with V.W.F. during their home and leisure hours in as much as their pleasure in gardening, fishing, swimming and watching or playing outdoor games was impaired by blanching, numb and painful fingers. Fifteen $(5.8 \%)$ complained of signs and symptoms throughout the year, both summer and winter. The condition in 23 was considered to be deteriorating, and one grinder demanded a change of cccupation at the time of examination. 


\section{Follow-up Surveys}

Because this population of pedestal grinders appeared to us to be one of the most severely affected groups from the prevalance $(96 \%)$ and the short latent interval (1.8 years), it was decided to examine the group prospectively. This was done in 8 surveys from January 1970 to May 1974.

Of the 26 grinders examined in January, 1970, 23 of this group were in post for the D.H.S.S. survey of February 1971. For this survey all ex- and present vibration exposed personnel (pedestal grinders and fettlers) were invited for examination together with age-matched controls. The response rate was $95 \%$ and the results are given in Table 3 .

\section{Table 3}

Group Total Stage of white finger

\begin{tabular}{lcccccr} 
Vibration Exposed & $51 *$ & 0 & $0_{\mathrm{T}}$ & 1 & 2 & 3 \\
& & 9 & 12 & 12 & 8 & 10 \\
Controls & & $(18)$ & $(24)$ & $(24)$ & $(16)$ & $(20)$ \\
& \multirow{2}{*}{70} & 67 & - & 1 & 2 & - \\
& & $(96)$ & & $(1)$ & $(3)$ &
\end{tabular}

Figures in brackets are percentages.

*Stage 4's and rejects have been excluded.

From January 1970 to May 1974, 25 pedestal grinders were transferred to alternative work within the factory, 15 of them because of the severity of their V.W.F. (Stage 3 $\rightarrow$ Stage 4). In addition, several grinders discontinued their employment in the factory but it was not possible to ascertain whether cessation of grinding was due to the V.W.F. or for other reasons.

Eighteen grinders were examined at 6-monthly intervals between February, 1971 and May, 1974. Of these, 5 were Stage 4 when initially seen. Of the remaining 13,10 had deteriorated, 2 had improved and 1 had remained the same, when comparing the 1974 stage assessment with that of 1971. During this period new pedestal grinders were recruited to make up labour wastage and the picture was similar for all, namely rapid onset of V.W.F. and clinical deterioration.

\section{Discussion}

It was noted that in the February, 1971, survey the prevalence of V.W.F. in pedestal grinders was only $22 \%$ compared with $96 \%$ found in the January, 1970 survey. This 
was due to the intake of new grinders diluting the population. In a fluctuating population therefore prevalence rates may give a false indication of the risk unless the same population is examined prospectively. The latent interval estimate (interval between commencement of vibration exposure and appearance of first white finger), is probably a better indicator of risk. However, one disadvantage is that no latent interval estimate may be made for those subjects who are exposed and have not reached Stage 1. It must be conceded also that the latent interval risk estimate may not be entirely sound, because subjects with short latent intervals could elect to leave the job because of the early onset of V.W.F., leaving only the long latent interval subjects in situ. The mean latent interval figure may therefore - like the prevalence rate - indicate a false low risk situation.

\section{VIBRATION CHARACTERISTICS}

From the survey data of the malleable foundry population, it was clear that the rate of progression of V.W.F. was abnormally high. The latent interval was short (some cases at 6 months with a mean of 1.8 years), and subjects deteriorated to a severe state requiring removal from vibration exposure in $2 \frac{1}{2}-3$ years. Conversely in the grey iron foundry adjacent, the incidence was low with a longer latent interval and slow progression.

It was ascertained that until $1965,30^{\prime \prime}$ diameter silicon carbide wheels had been used in both foundries. In April of that year, the malleable foundry changed to zirconia wheels (zirconia: mixture of fused crystals of $70 \%$ aluminum oxide $\mathrm{Al}_{2} \mathrm{O}_{3}$ and $30 \%$ zirconium oxide $\mathrm{ZrO}_{2}$ ), with a recommended surface speed of 45 metres/sec. equivalent to 20 revs./sec. It seemed desirable, from the point of view of prevention of V.W.F. and to provide vibration data for a future standard, to compare the vibration characteristics at the two foundries. This programme was first undertaken by the University of Southampton, then by the National Engineering Laboratory, East Kilbride, and thereafter followed up with extended vibration measurement programmes by G.K.N. Group Technological Centre ( $\mathrm{Mr} \mathrm{R}$. Kitchener) and the Department of Pure and Applied Physics, University of Salford (Dr T. I. Hempstock and $\mathrm{Mr}$ D. O'Connor). The results are given in Paper 8. 
From the vibration measurement programmes the following facts emerged:

1. The softer the abrasive bond, the lower the vibration, i.e. wheels with a stronger bonding agent gave rise to "harder" wheels. The type of abrasive grain present within the bond was unimportant. The zirconia abrasive $\left(\mathrm{ZrO}_{2}\right)$ was in fact softer and more ductile than the previous abrasive Silicon Carbide ( $\mathrm{SiC}$ ), but the bonding medium was stronger, thus giving rise to a "harder" wheel.

2. The smaller the wheel eccentricity, the lower the vibrations (as measured by acceleration) particularly at the low frequency end of the spectrum.

3. There was considerable variation in the levels of acceleration from casting to casting and between one operator and another.

4. The dressing operation gave rise to the highest acceleration levels and was therefore the most dangerous.

5. The results obtained from 4 teams high-lighted the necessity of avoiding eccentricity developing in the grinding wheels, and focussed attention on the correct method of dressing wheels by using an anti-vibration dressing tool on a fixed location bar. It was thought that if the eccentricity were reduced to $0.005^{\prime \prime}$, regardless of the constituents of the wheel, a medically acceptable working situation would follow.

\section{POPULATION - OTHER GRINDERS}

Grinders and age-matched controls were examined in 4 population groups, and grinders only in 8 other groups during the period June, 1971 to March, 1974. In each factory all the vibration exposed were invited to attend for examination and the response rates varied from $95-100 \%$. The prevalence of white finger by occupation group by stage is given in Table 4 . The rates varied from $0-97 \%$.

The Bromsgrove grinders who were examined initially in March 1972 were re-examined in March 1974 and the results are given in Tables 5 and 6 . The work situation has remained unchanged and in the second survey there was $100 \%$ prevalence of V.W.F. in pedestal grinders and Brinell operators, $35 \%$ in hand grinders, and $67 \%$ in the mixed group. 
Table 4

Prevalence of White Finger by Occupation Group by Stage

Population

Birkenhead

Bromsgrove

Halesowen

Leamington

Old Cwmbran

Darlaston

Ayr

Lincoln

Smethwick

Witton

Strood

Great Barr

Figures in brackets are percentages.
P. Grinders

Controls

H. Grinders

P. Grinders

Chippers

Grinders

Controls

H. Grinders

P. Grinders

Controls

H. Grinders

P. Grinders

Controls

H. Grinders

P. Grinders

H. Grinders

P. Grinders

H. Grinders

P. Grinders

H. Grinders

P. Grinders

H. Grinders

P. Grinders

H. Grinders

P. Grinders

H. Grinders

Stage of white finger $\begin{array}{lllllll}\text { Process group Total } & 0 & 0_{\mathrm{T}} & 1 & 2 & 3\end{array}$

$\begin{array}{cccccc}72 & 11 & 13 & 17 & 26 & 5 \\ & (15) & (18) & (24) & (36) & (7) \\ 26 & 12 & 6 & 2 & 6 & - \\ & (46) & (23) & (8) & (23) & \\ 26 & 21 & - & 5 & - & - \\ & (81) & & (19) & & \end{array}$

$\begin{array}{lllll}55 & 30 & 5 & 15 & 5\end{array}$

$\begin{array}{llll}(55) \quad(9) \quad(27) & (9)\end{array}$

$341-12174$

(3) (35) (50) (12)

$51 \quad 44$

(86)

$9 \quad 7 \quad 1 \quad-\quad 1$

(12) (2)

(78) (11)

$\begin{array}{lll}12 & 8 & 2\end{array}$

(67) (17)

$18 \quad 15$

(83)

(17)

12

$\begin{array}{llll}74 & 64 & 2\end{array}$

(86) (3)

(6) (11)

$\begin{array}{lll}73 & 1\end{array}$

(95) (1)

$\begin{array}{lll}22 & 17 & 2\end{array}$

(77) $(10)$

(4)

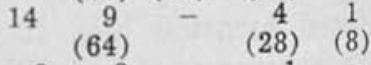

$\begin{array}{rr}9 & 8 \\ (89) & -\quad 1 \\ & \end{array}$

$\begin{array}{cccc}20 & 14 & 2 & 4 \\ & (70) & (10) & (20)\end{array}$

$\begin{array}{llll}81 & 74 & 1 & 6\end{array}$

(91)

(2)

(7)

$3126-5$

(84)

42

32

(76)

(7)

(16)

7

17

(41)

(17)

(59)

$\begin{array}{lll}13 & 8 & 2\end{array}$

3

(62) (15)

(23)

$\begin{array}{llll}12 & 7 & 2 & 2\end{array}$ (58) (17) (17)

(8)

$4 \quad 2 \quad 1$

(50) (25) (25)

$\begin{array}{llll}11 & 8 & 2 & 1\end{array}$

(73) (18)

(9)

$\begin{array}{lllll}7 & 3 & 1 & 2\end{array}$ (43) (14)

(29) (14)

10

(70) $(30)$ 


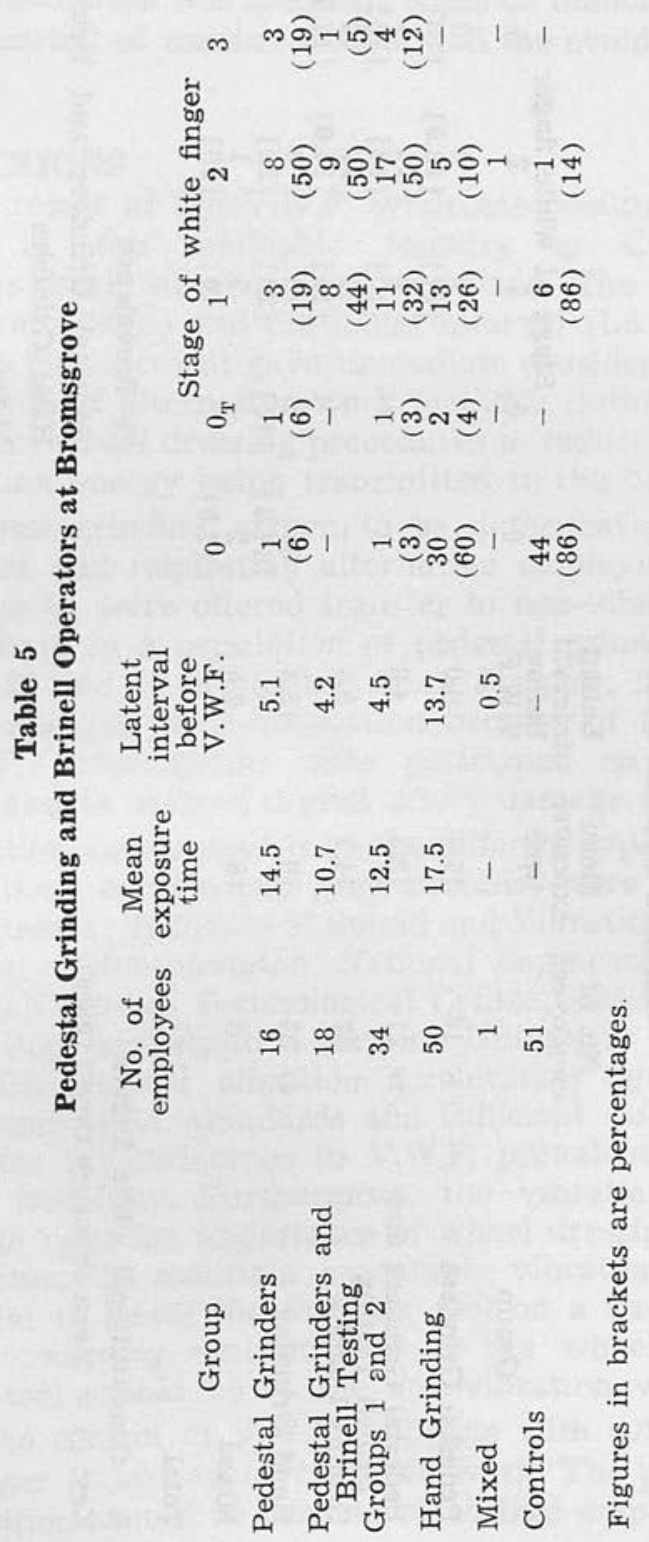




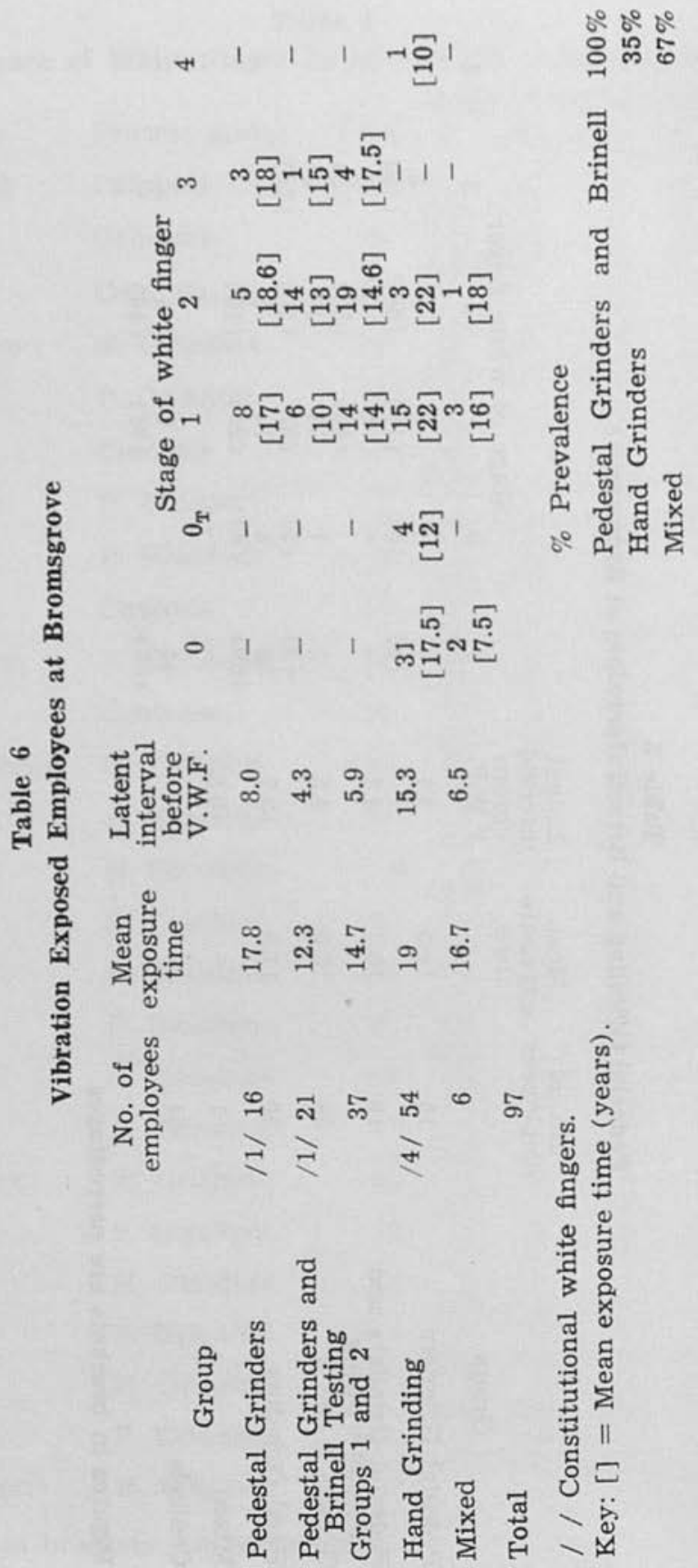


In $65 \%$ the V.W.F. condition was considered to be stationary, in $25 \%$ worse, and in $10 \%$ improved. Improvement may be achieved by a reduction in vibration exposure, or presumed from less frequent bouts of blanching because of the wearing of warmer clothes and the avoidance of cold stimuli.

\section{CONCLUSIONS}

1. As a result of the V.W.F. syndrome coming to light in $1969 / 70$ in the malleable foundry at Cwmbran, a dangerous work situation was examined. The V.W.F. prevalence rate $(96 \%)$ and the latent interval (1.8 years) were such that management gave immediate consideration to the introduction of alternative work methods (lathes, jigs, etc.) and correct wheel dressing procedures to reduce the amount of vibration energy being transmitted to the hands.

2. Pedestal grinders, shown to be deteriorating by stage assessment and requesting alternative employment (Stage $3 \rightarrow$ Stage 4), were offered transfer to non-vibration work. At $\mathrm{Cwmbran}$ in a population of pedestal grinders varying between 26 and 51 in number, from January, 1970 to May, 1974, 15 changed their occupation because of the severity of V.W.F. Arteriograms were performed on 18 of the grinders and 14 showed digital artery damage (Paper 4).

3. Vibration measurements on the different types of wheels (black silicon carbide and grey zirconia) were made by 4 research teams: Institute of Sound and Vibration Research, University of Southampton; National Engineering Laboratory; G.K.N. Group Technological Centre; and the Department of Pure and Applied Physics, University of Salford. The results showed vibration acceleration figures above the proposed B.S.I. standards and sufficient differences to account for the difference in V.W.F. prevalence between the two foundries. Furthermore, the vibration research brought to light the importance of wheel dressing to avoid eccentricities. To maintain acceptable vibration limits, it is essential to locate the dressing tool on a fixed location bar thus ensuring concentricity of the wheel, and the dressing tool should be of the anti-vibration variety.

4. For the control of V.W.F., subjects with constitutional white finger should avoid vibration work. The principle of work rotation should be considered so that employees may 
avoid constant exposure to a high level of vibration for 5-6 hours per day on 5 days a week. Stage 3 and preferably Stage 2 V.W.F. subjects should avoid further exposure. 5. A guide to allowable vibration levels and the suggested maximum permitted exposure times may be found in the proposed British Standard (Paper 10). If these are met, subjects will not be exposed to excessive and dangerous vibrations. 


\section{Clinical Objective Tests for Vibration White Finger}

P. L. PELMEAR, W. TAYLOR and J. C. G. PEARSON

\section{INTRODUCTION}

The commonest manifestation of the vibration syndrome is finger blanching. It is assumed to be associated with vasospasm of the digital arteries, but other tissues may be affected. The finger and arm complaints of vibrating tool users may be the result of permanent damage from trauma to nerve fibres, which in turn may affect the arteries, muscles and joints supplied by the brachial plexus. In 1918, Edsell observed that callous formation on the palmar surfaces of the fingers was particularly noticeable in pneumatic hammer users. This tissue reaction was confirmed in 1970 by Stewart and Goda who suggested that white fingers were probably the result of repeated minor injuries causing an over-growth of subcutaneous tissue, which in turn made it difficult for the capillaries to react quickly to temperature changes. The question of nerve injury in vibration workers was investigated as early as 1918 where there was evidence to show that fingers became numb and clumsy especially while an attack of white finger persisted. Similar findings were reported and confirmed by many investigators (Seyring, 1931; Junghanns, 1937; Marshall et al, 1954). From observations on pneumatic tool operators, Mikulinskii (1966) confirmed that exposure to vibration caused an increase in the threshold of sensitivity in the finger pulp in the hand most exposed to vibration. Miura et al (1966) measured thresholds for vibrating sensation at $125 \mathrm{~Hz}$. Neilson et al (1969) and Bjerker et al (1970) both 
described equipment for delivering and measuring the vibration thresholds to the fingertips.

Whilst considering tests as an aid to the diagnosis of Raynaud's phenomenon, a report from Manchester University in January 1954 to the Industrial Injuries Advisory Council through its Industrial Diseases Sub-Committee stated "Vascular tests used to provide objective confirmatory evidence of the presence of Raynaud's Phenomenon have proved disappointing. Precipitation of an attack by 'hand cooling' was achieved in about half of the cases." In 1945 , Telford et al used provocative cooling of the hands with ice-water immersion and found that this usually confirmed the presence of attacks but that it failed sometimes in subjects known to have V.W.F. Kylin (1968) extended this technique combining it with whole body cooling and then measured the time taken to return to normality as indicated by digital pulse plethysmography and skin temperature records. He found that whereas $93 \%$ of normal men reverted to a normal pattern within three minutes after cooling ceased, $26 \%$ of saw users without symptoms showed a delayed return, and when saw users with a history of symptoms were tested, $52 \%$ showed a delayed recovery.

In summary the published literature with respect to objective tests for VWF indicates that both vascular and neurological tests (a) must be rigidly controlled and (b) do not give positive evidence of the state of disability or degree of V.W.F. unless serial data for the subject is also available.

\section{Objective Clinical Tests - D.H.S.S. Survey 1970-73}

(A) Finger Circumference Measurements.

(B) Depth Sense Aesthesiometer - Ridge Test.

(C) Two Point Discrimination Test - 2-point Test.

(D) Vibro-Tactile Threshold Sensory Test.

(E) Skin Temperature Tests (Heating and Cooling).

(F) Skin Temperature - Thermography.

(G) Measurement of Bone Density.

\section{Finger Circumference Measurements}

Measurements of the circumference of the index and middle fingers (and at Birkenhead finger 4 - pneumatic 
chippers) revealed significant differences between vibration exposed and controls. At Birkenhead although there were no significant differences between chippers, grinders and controls in respect of index and middle finger circumferences, with finger 4 the measurements on the left hand (the finger to which direct pressure and vibration is applied from the chisel) were significantly larger at the $\mathrm{P}<0.01$ level. No such direct or localised finger contact with vibration is experienced by the grinders or any other of the 18 populations surveyed. This difference in finger circumference between left and right finger 4 is significant at the $\mathrm{P}<0.01$ level throughout four vibration exposure periods - namely 2, 5, 10 and 20-years. Within the vibration group itself there is no increase in circumference size of finger 4 with increasing exposure time. Here the evidence shows an increase in finger 4 circumference up to two years, but there is thereafter no further progress in tissue proliferation. (Tables $1 \mathrm{a}, \mathrm{b}$ and $\mathrm{c}$ ). The proximal interphalangeal joint and middle phalanx circumferences are likewise significantly larger. $(\mathrm{P}<0.01)$. (Table 1$)$.

The mean circumference measurements of the proximal phalanx of the index and middle fingers of nine population groups is tabulated in Table $1 \mathrm{~d}$. The data shows that in general vibration exposed subjects have larger fingers and joints (interphalangeal and middle phalanx) than controls, the difference being statistically significant at the $1 \%$ level. In the Thetford and Cwmbran populations there were no circumference increases either with stage of disease or increasing exposure time. The fingers increase in size and thereafter remain static with increasing vibration exposure time. 


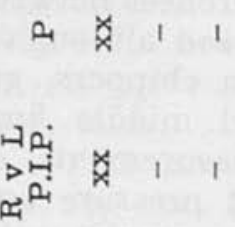

$\stackrel{x}{*} \quad 1 \quad 1$

重

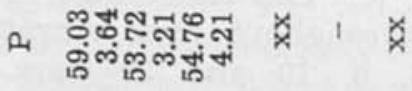

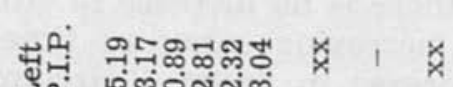

范苛离

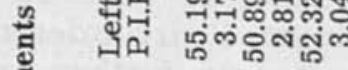

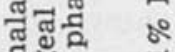

西

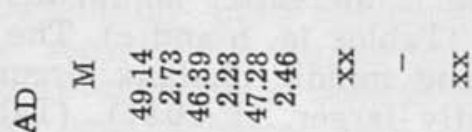
동ํㅁ

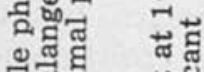

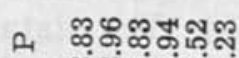

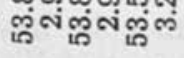

ตี

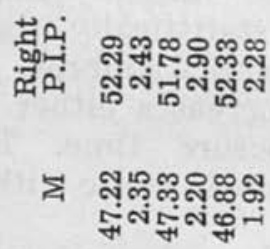

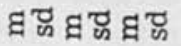

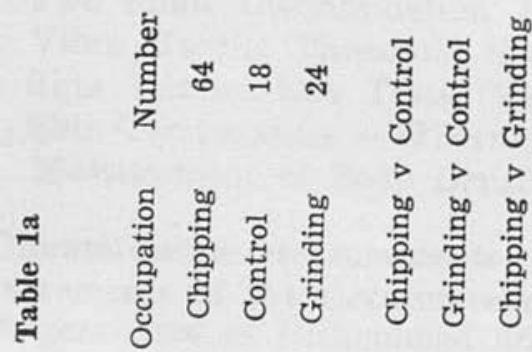

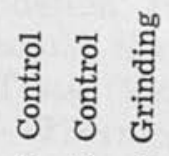

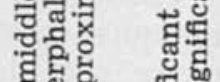

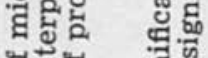
फ्ञ냉 वै कี

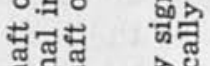
फ़्पू

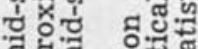
घี

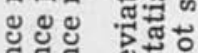
过嵒的

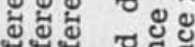

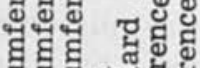

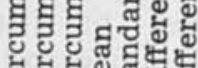

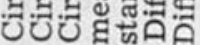

|| || || || || || ||

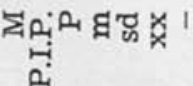


6. CLINICAL OBJECTIVE TESTS

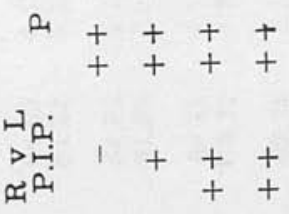

这 $1++$

A, 잉ํำ

르

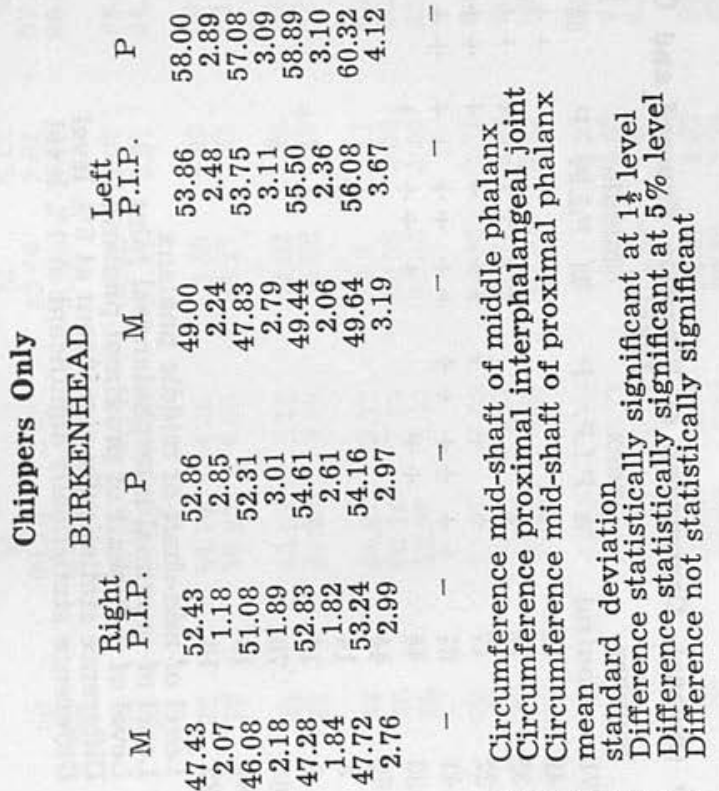

章

|| || || || || || || ||

वृ

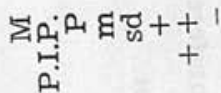

营

萑

है

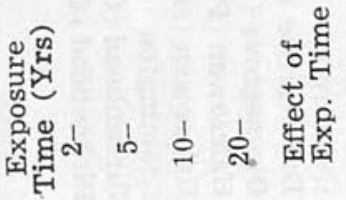




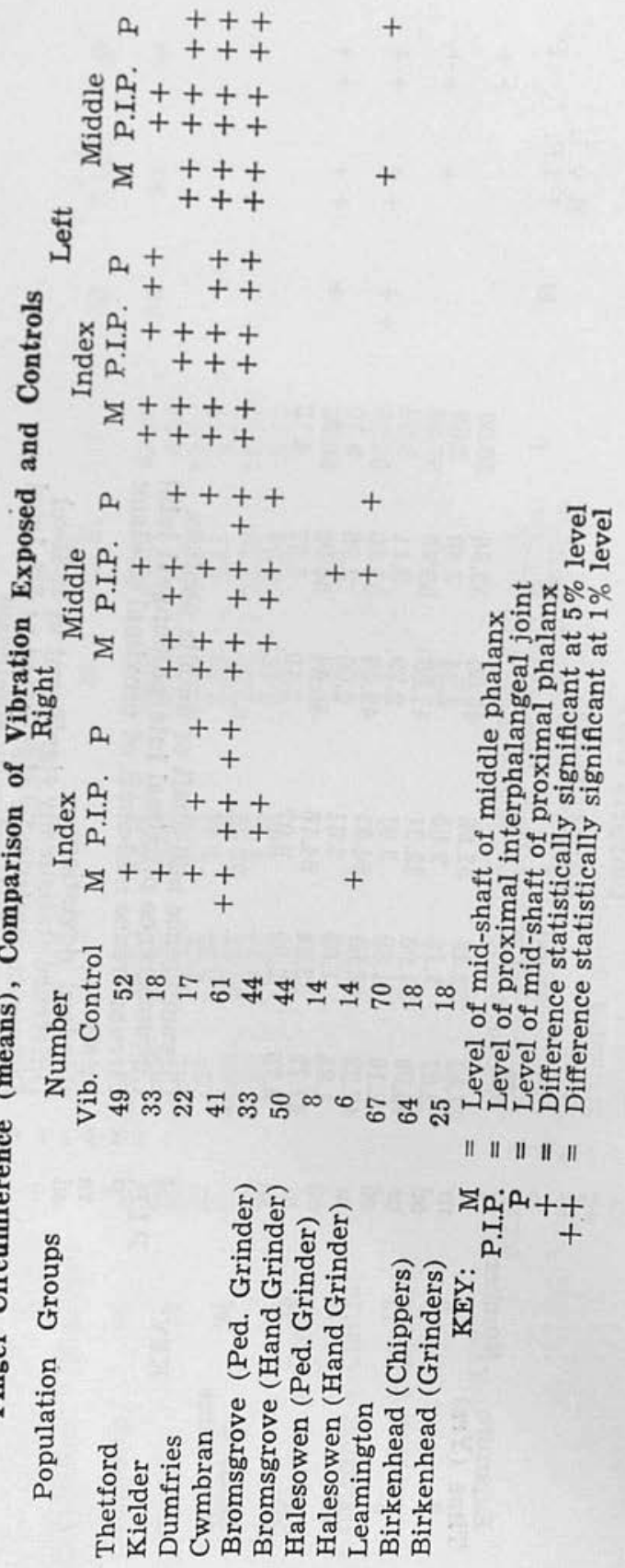




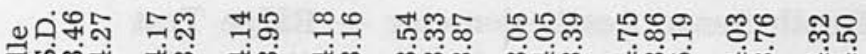

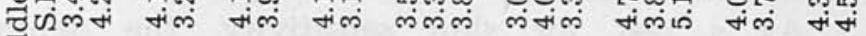
:

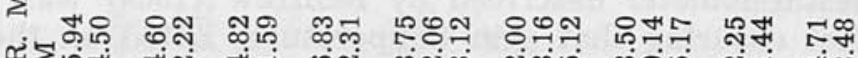

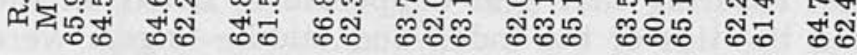

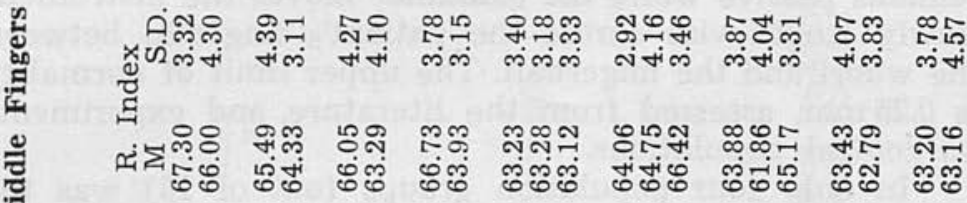

胥

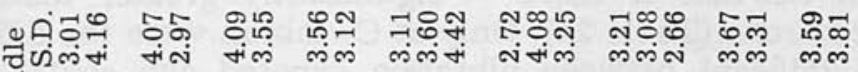
羟

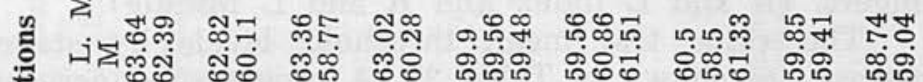

हี

๑

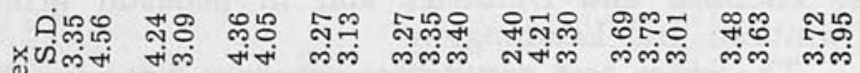
चु

⿷匚

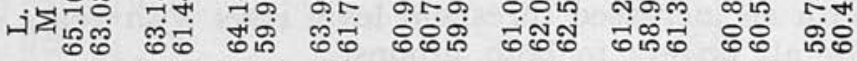

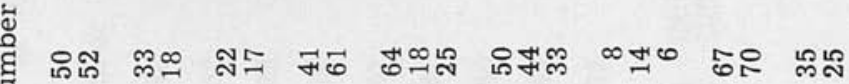
द

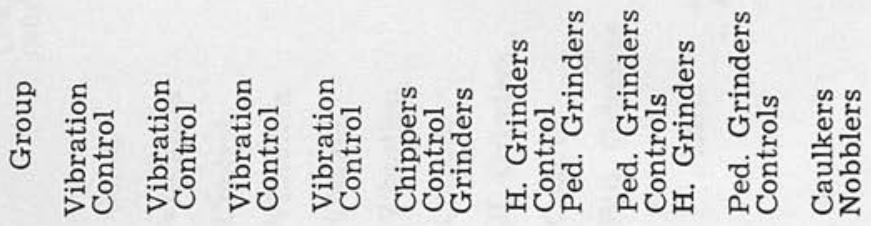

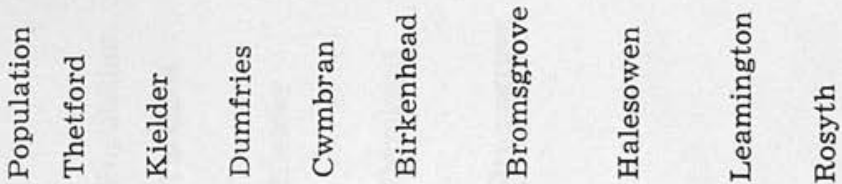




\section{Depth Sense Aesthesiometer - Ridge Test}

As a test for skin sensitivity, the depth sense aesthesiometer described by Renfrew (1969) was used first ensuring that skin temperatures noted on the palms and the tips of the index and middle fingers were above $25^{\circ} \mathrm{C}$. A technique was developed whereby the patient remains passive while the examiner moves the instrument slowly length-wise across the patient's fingertip between the whorl and the fingernail. The upper limit of normality is $0.25 \mathrm{~mm}$, assessed from the literature and experiments on control populations.

In only four population groups (out of 18) was the percentage of vibration exposed employees with readings of $0.25 \mathrm{~mm}$ or more - significantly greater than in the controls. (Table 2a). Only at Cwmbran were the differences significant between vibration exposed and controls in all fingers. ( $R$ and $L$ Index and $R$ and $L$ Middle).

The ridge test mean threshold levels by stage of disease are shown in Table $2 \mathrm{~b}$. A progressive increase in threshold by stage of disease is seen in chain saw operators at Thetford and Dumfries and in pedestal grinders at Cwmbran and Leamington.

The ridge test results by exposure time for Thetford and Cwmbran are shown in Table 2c. The percentage with an increased threshold level rises with years exposed for all fingers in both groups. 


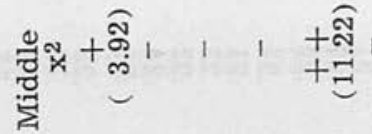

$$
\begin{aligned}
& \text { ณํํำ }
\end{aligned}
$$

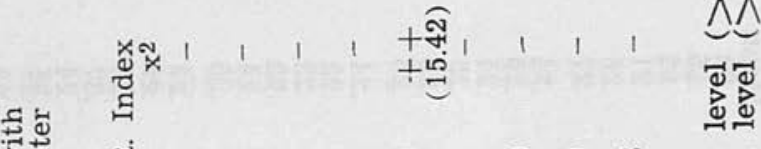
इ岕 设

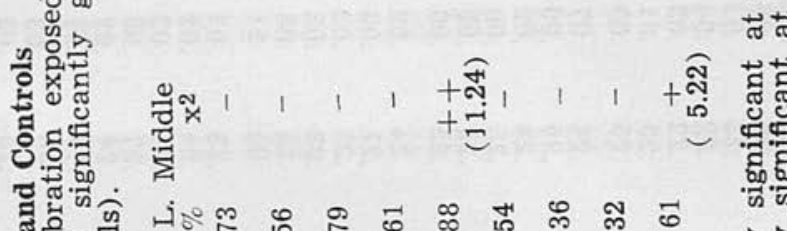
के

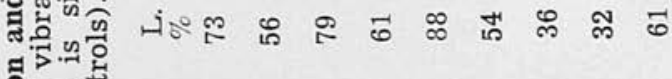

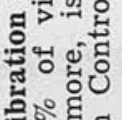

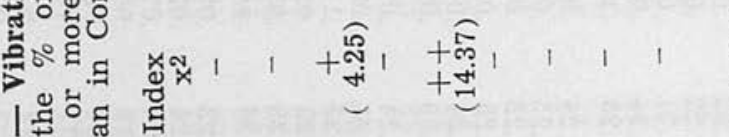

घ듀

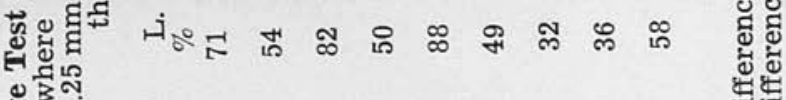
항 골 눙 을 骂 z अ 주 ๗ ¿․ّ

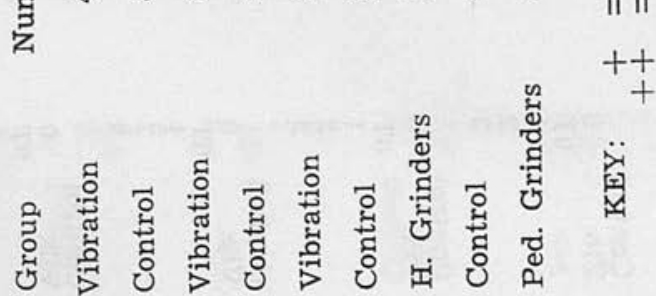
글 that 可哓 解

:

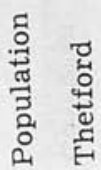

过

है है 


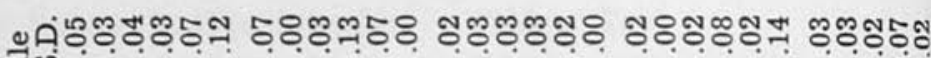
चुण

串

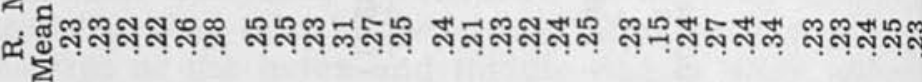

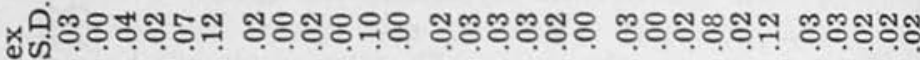
兽

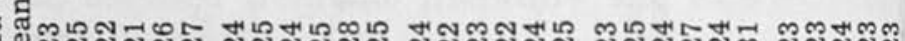

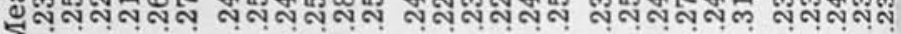

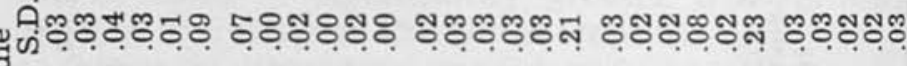
0

ㅍ

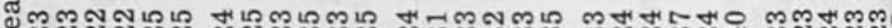

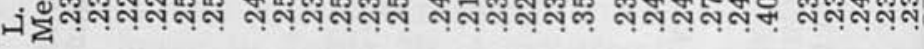

웅

Q.

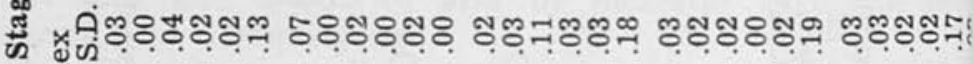

$\therefore$ 马्ठ

ట్ట

हैं

है

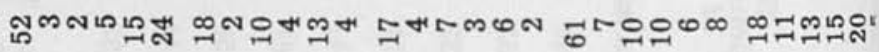

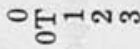

OfН-Nm

OHユNM

OH-NM

OH-NO

䒓
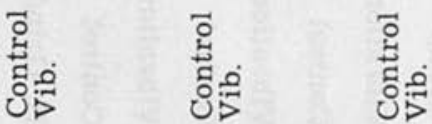

홍

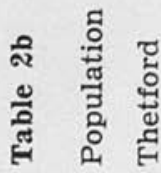

홇

疍

है

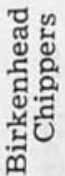




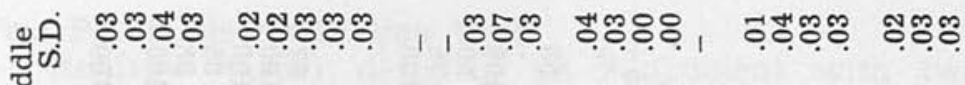

读

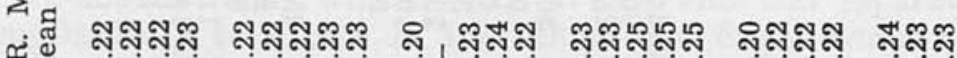
मૈ

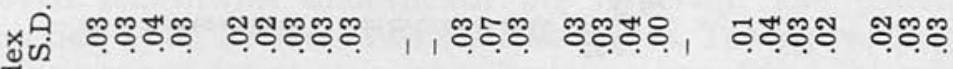
ت

䨌

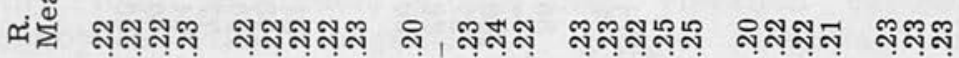

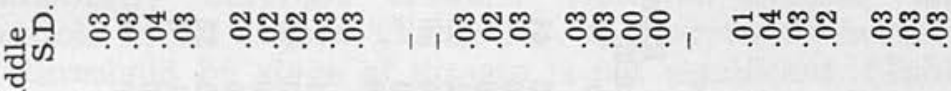

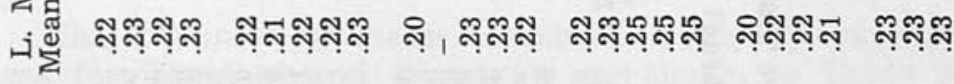

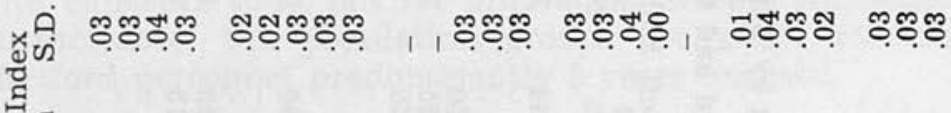

பં

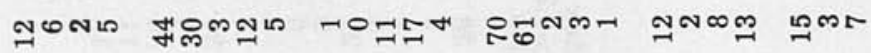

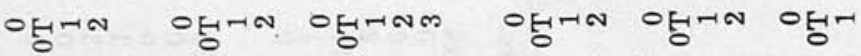

号

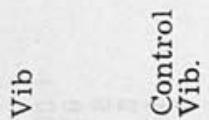

$\stackrel{0}{>}$

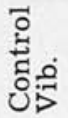

$\ddot{\text { ह }}$

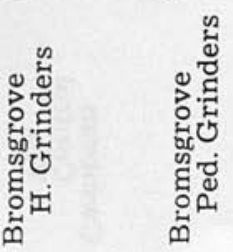

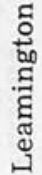
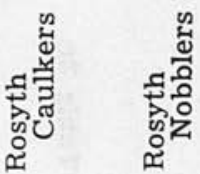


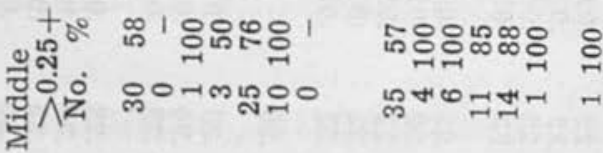

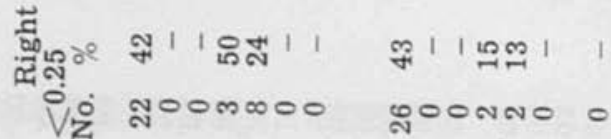

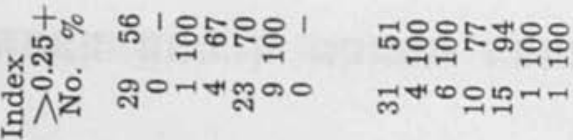

봉

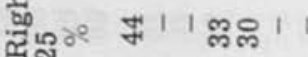

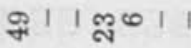

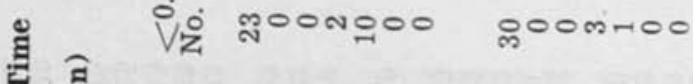

है

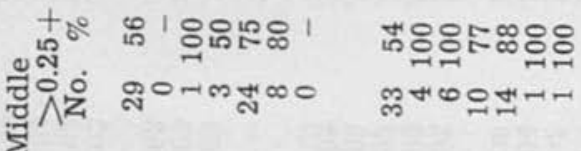

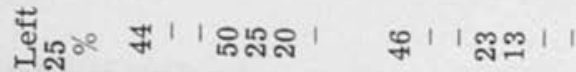

Vं

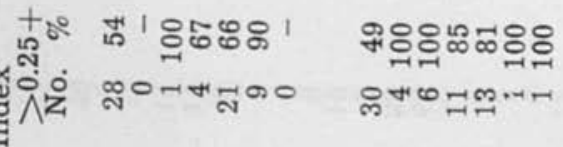

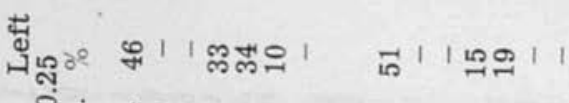

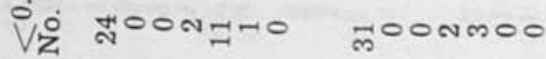

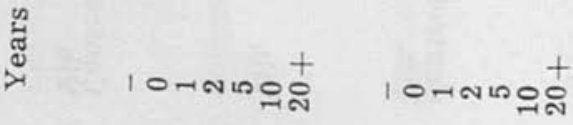




\section{Two Point Discremination Test}

Renfrew (1969) designed an instrument with two sharp-edged ridges which touch at one end and separate progressively to $10 \mathrm{~mm}$ at the other. The finger (midway between whorl and nail) is placed at the common junction of the two ridges (single point) and the instrument is moved lengthwise underneath the fingertip. The patient signifies when he feels two distinct ridges. Taking readings to the nearest $1 \mathrm{~mm}$, the upper limit of normality is $2.5 \mathrm{~mm}$. Only four population groups had vibration exposed employees with a significantly greater percentage of fingers with thresholds of $2 \mathrm{~mm}$ or more than controls. Both at Cwmbran and Thetford the differences were statistically different between vibration-exposed and controls in all fingers. (Table 3a). A progressive increase in threshold by stage of disease is not significant. (Table $3 b)$.

The 2-point test mean threshold levels by exposure time for Thetford and Cwmbran are shown in Table 3c. The mean readings show a steady threshold level increase with exposure time, but the differences are not significant. Furthermore, the population groups are small and the Thetford personnel predominantly 5 years exposed. 


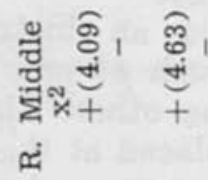

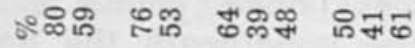

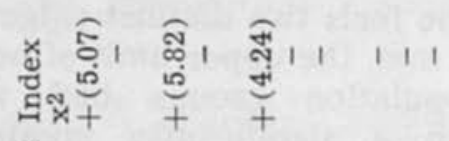

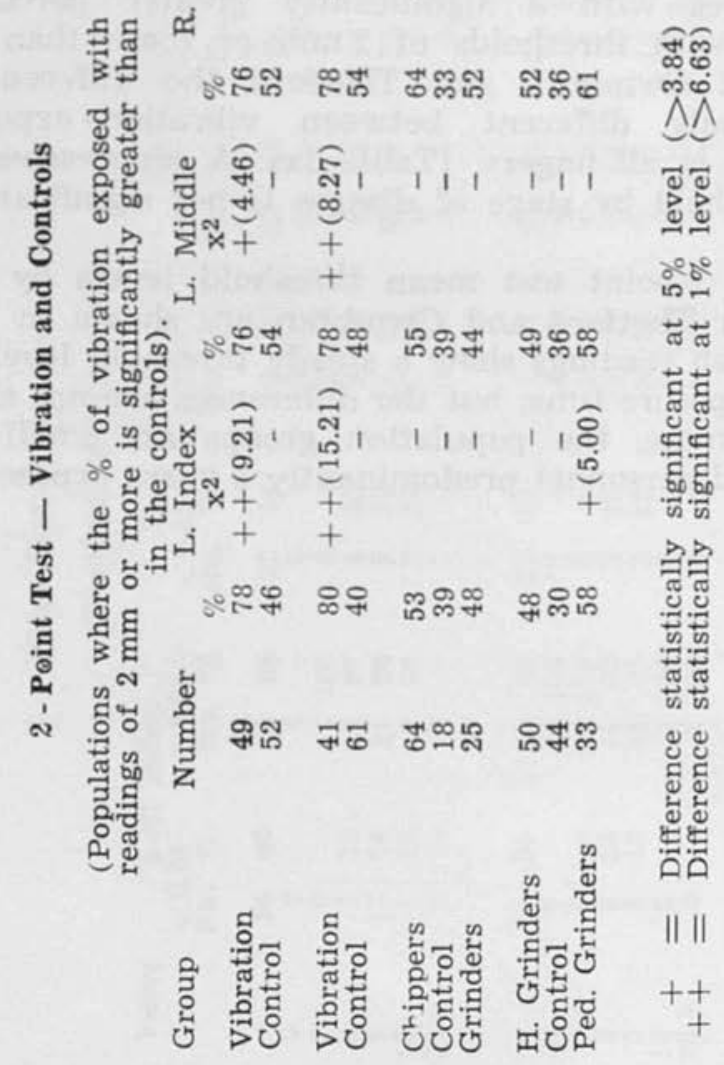

लึ




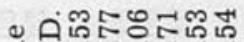

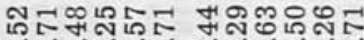

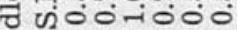
胥

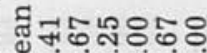
00000 000000 000000 000000

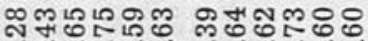

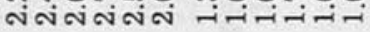

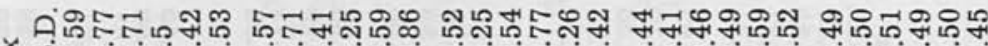
(ำ ב

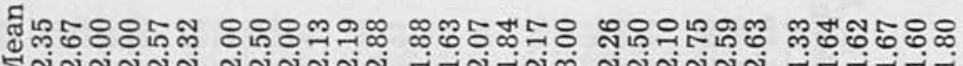
艄 vio0000 $00000000000-00000000000$

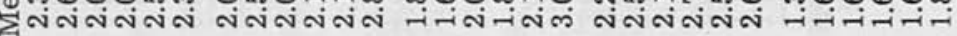

है

๑ ด

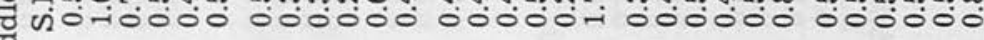

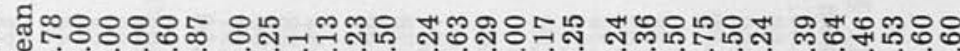

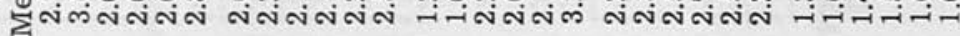

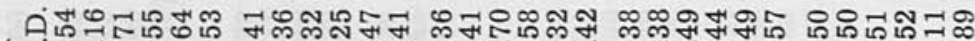

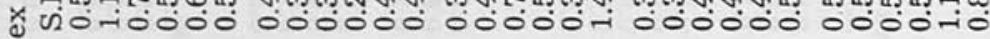
$\therefore$

สีโ능ำำ

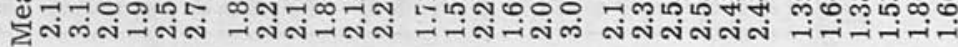

๑ี

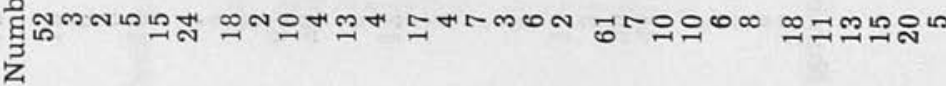

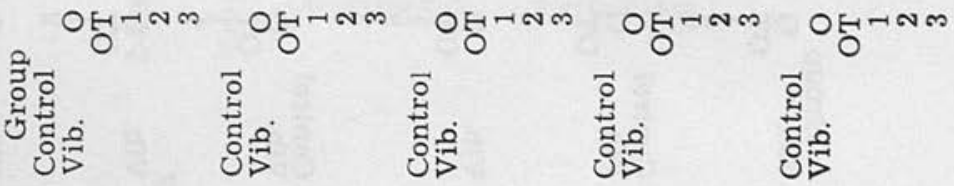

兽

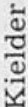

है

है

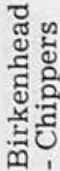




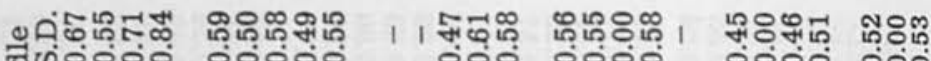

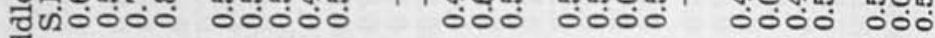
究 ำ ్ㅐㅇํํํำำ

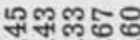

8,

땅ㅇㅇㅇ

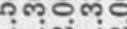

เค요유 당요 -ififi-i rifi-i riciñ

구윰ำ

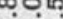
-1ก-

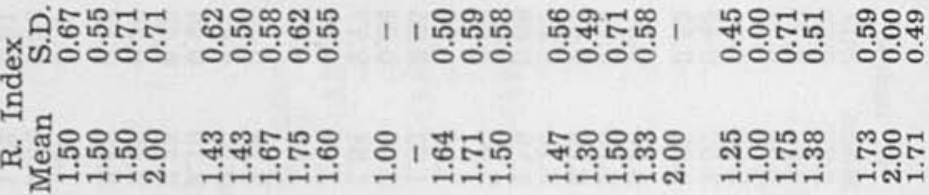

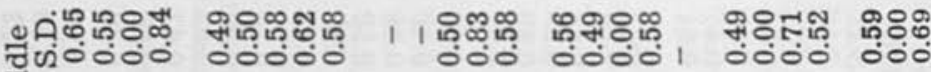
究

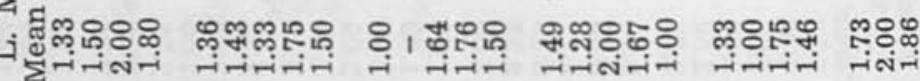

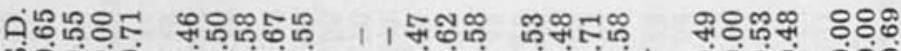

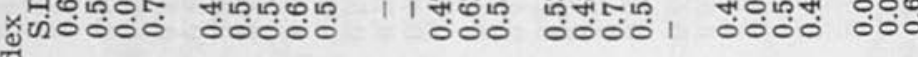
ชับ

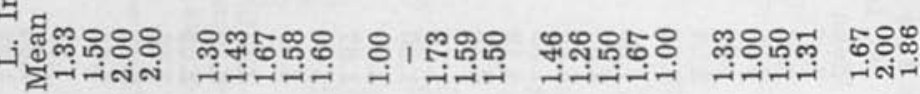

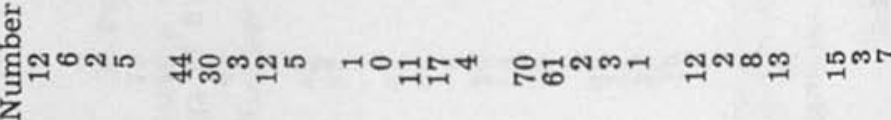

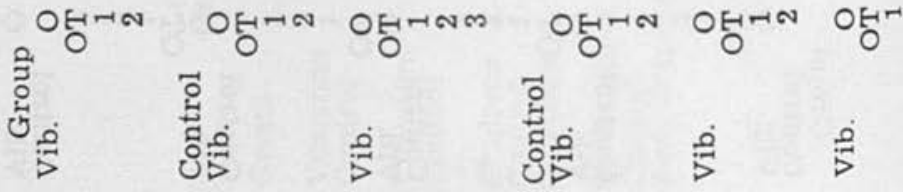
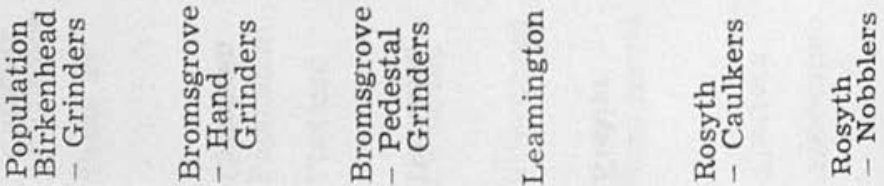


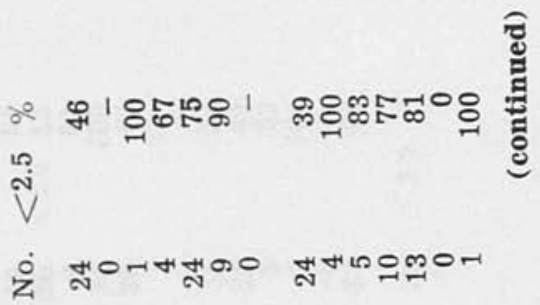

हี

్ㅐ

गी เัต

กิ

¿

를

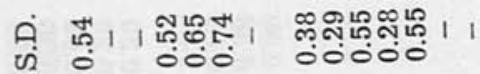

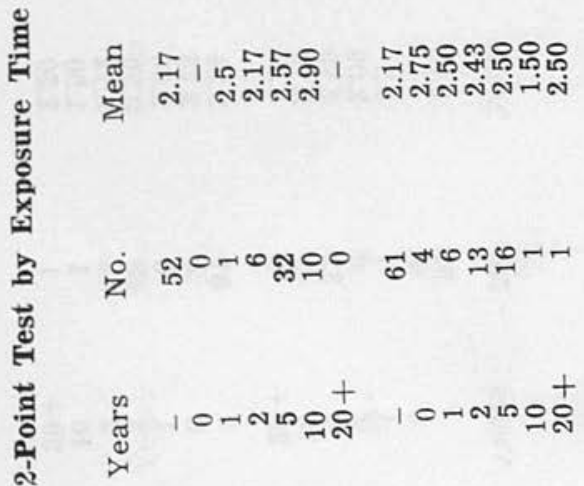

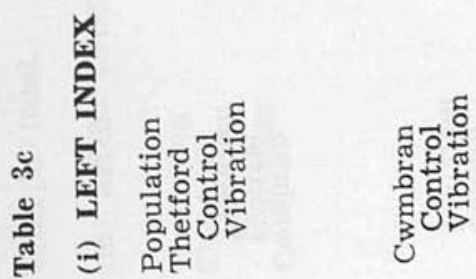


P. L. PELMEAR, W. TAYLOR AND J. C. G. PEARSON

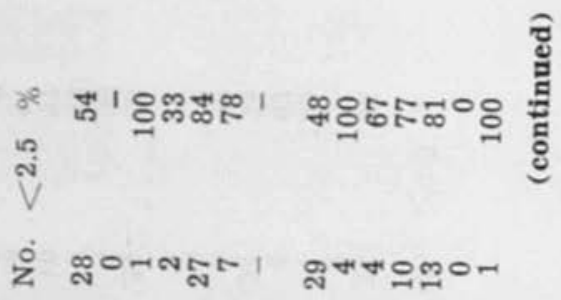

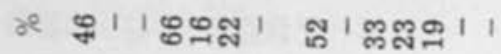

กุ

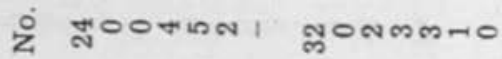

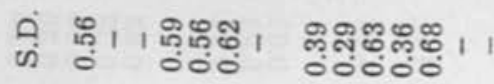

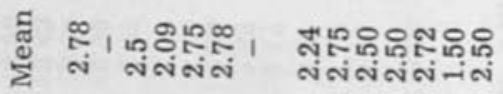

ฉं กิ०

㫕 10 -

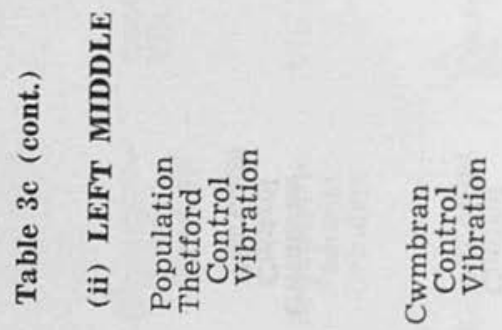


6. CLINICAL OBJECTIVE tests

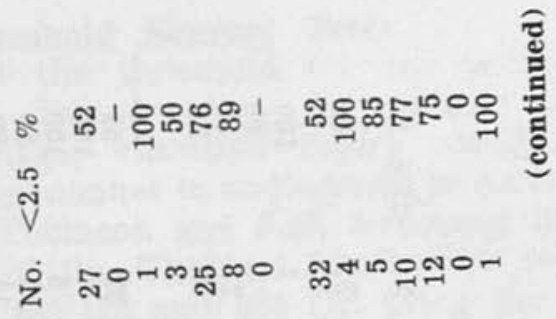

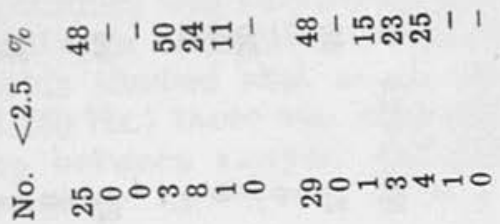

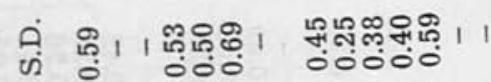

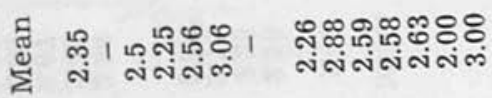

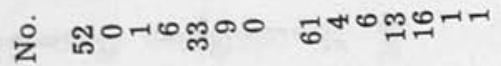

๙

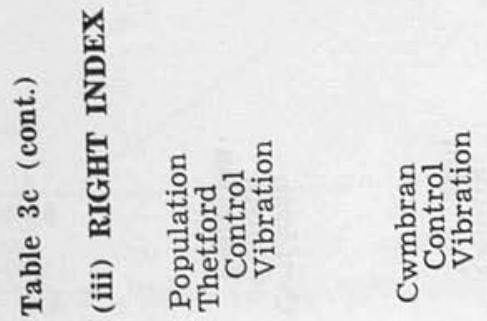



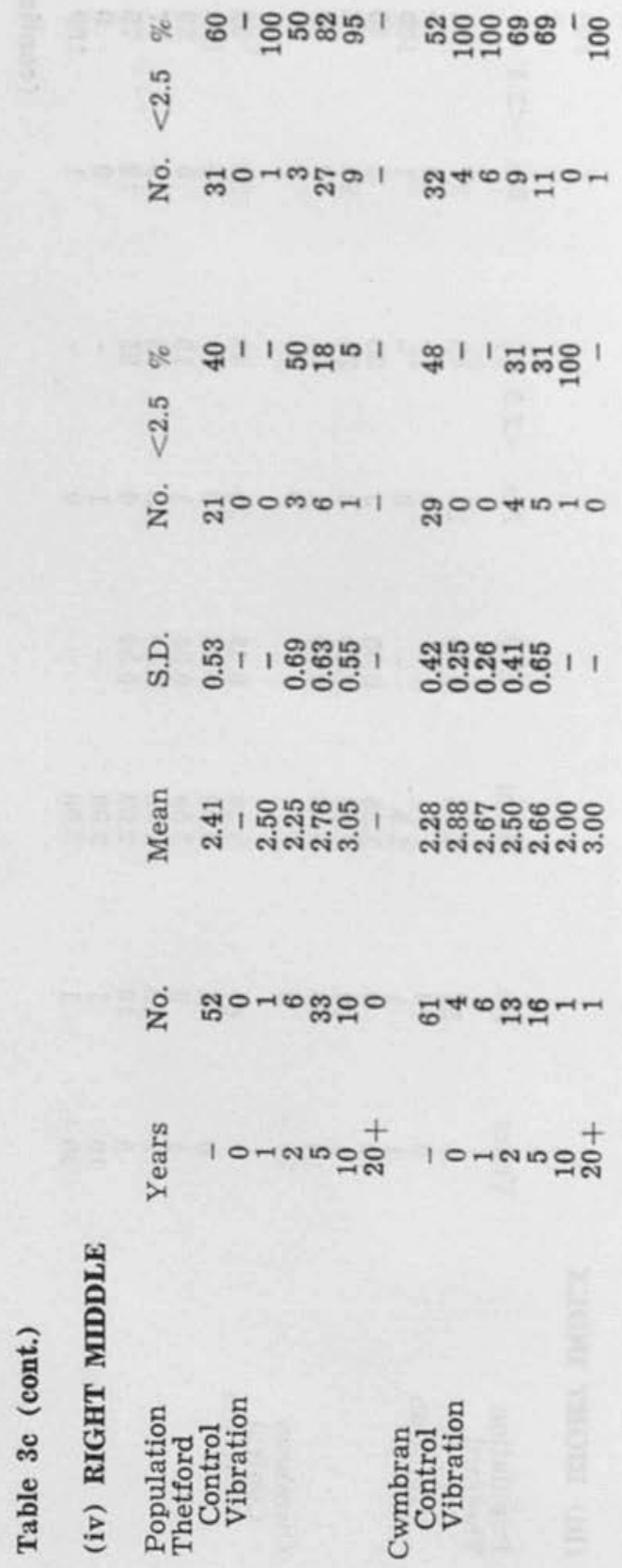


\section{Vibro-Tactile Threshold Sensory Tests}

Assuming that the threshold for the perception of vibration is higher (less sensitive) for subjects with peripheral nerve damage, vibration injury could then be assessed in a similar manner to audiograms in noise-induced deafness. In 1969 Thomson and Kell measured the vibrotactile thresholds of the Thetford Chain Saw population at frequencies $31,63,125$ and $250 \mathrm{~Hz}$. using the vibrator assembly shown in Figure 1. The finger platform was $6 \mathrm{~mm}$ in diameter and by means of a balance mechanism an upward force of 8 grammes was exerted on the finger. The subject was provided with ear muffs. Examination of the vibro-tactile thresholds showed that at all four frequencies $(31,63,125$ and $250 \mathrm{~Hz}$.) there was wide variation with considerable overlap between sawyers and controls. Frequency polygons are shown in Figures 2 and 3.

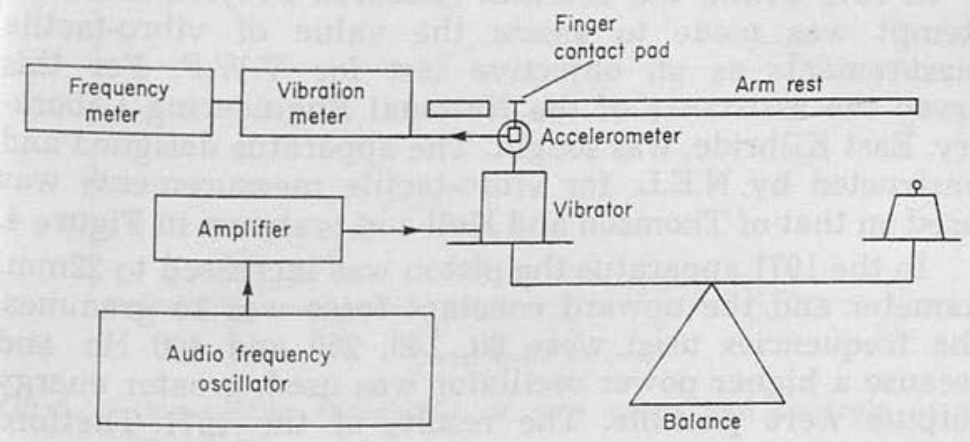

Fig. 1. Apparatus for finger tip vibration threshold

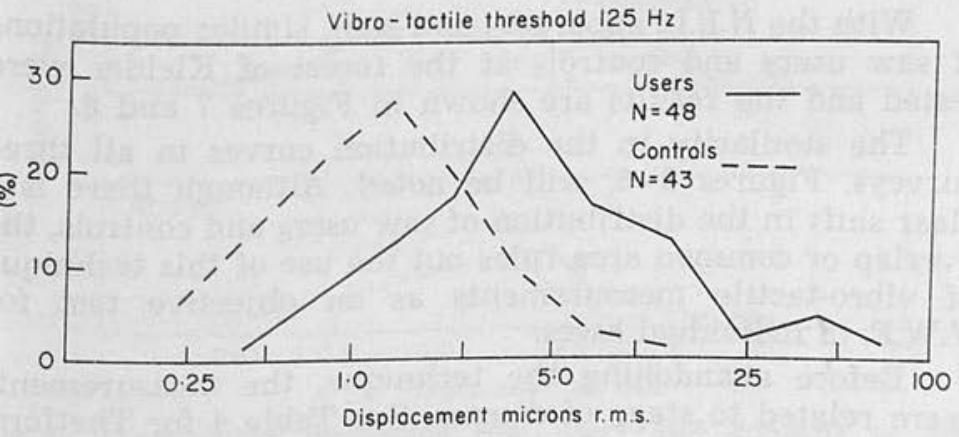

Fig. 2. Vibro-tactile thresholds at $125 \mathrm{~Hz}$. 
Vibro-tactile threshold $250 \mathrm{~Hz}$.

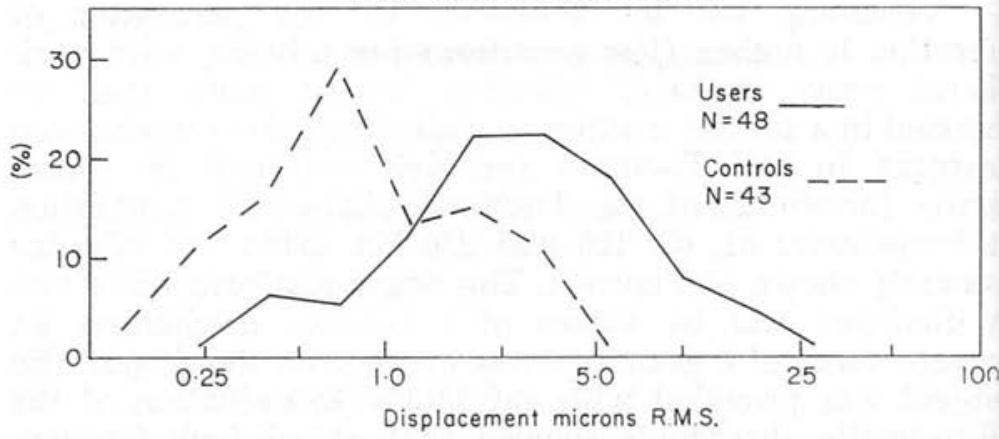

Fig. 3. Vibro-tactile thresholds at $250 \mathrm{~Hz}$.

In 1971 within the D.H.S.S. Research Project, a seconc attempt was made to assess the value of vibro-tactile measurements as an objective test for V.W.F. For this survey the assistance of the National Engineering Labora tory, East Kilbride, was sought. The apparatus designed anc constructed by N.E.L. for vibro-tactile measurements wa: based on that of Thomson and Kell and is shown in Figure 4

In the 1971 apparatus the piston was increased to $22 \mathrm{~mm}$ diameter and the upward constant force was 15 grammes The frequencies used were $80,140,250$ and $400 \mathrm{~Hz}$. anc because a higher power oscillator was used, greater energy outputs were possible. The results of the 1971 Thetforc survey are shown in Figure 5 and Figure 6, the distribu tions being the average of the results of the first two fingers of each hand.

With the N.E.L. apparatus and staff, similar population: of saw users and controls at the forest of Kielder were tested and the results are shown in Figures 7 and 8.

The similarity in the distribution curves in all three surveys, Figures 2-8, will be noted. Although there is clear shift in the distribution of saw users and controls, the overlap or common area rules out the use of this technique of vibro-tactile measurements as an objective test for V.W.F. in individual cases.

Before abandoning the technique, the measurement: were related to stage of disease. See Table 4 for Thetford Table 5 for Kielder, and Table 6 for Cwmbran. 


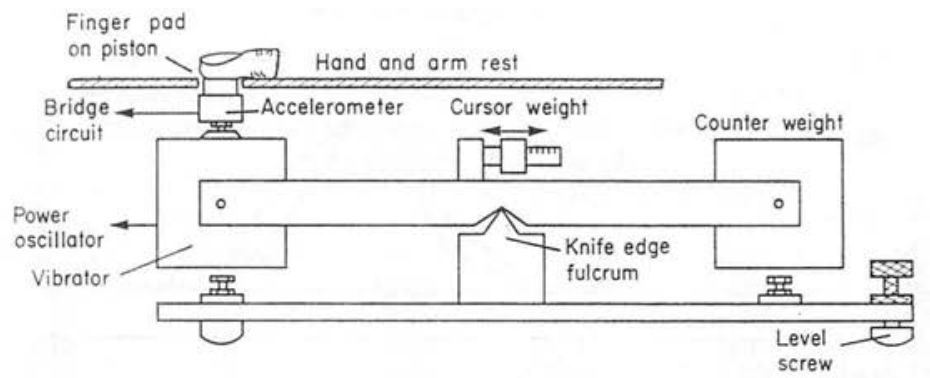

Fig. 4. Vibro-tactile threshold measurement appartus designed by the National Engineering Laboratory, East Kilbride

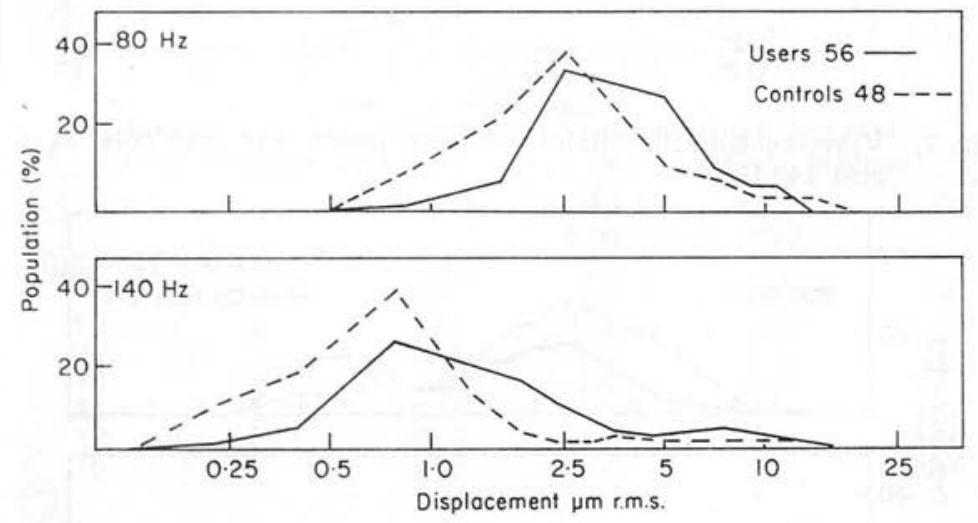

Fig. 5. Vibro-tactile thresholds of saw users and controls at 80 and $140 \mathrm{~Hz}$.

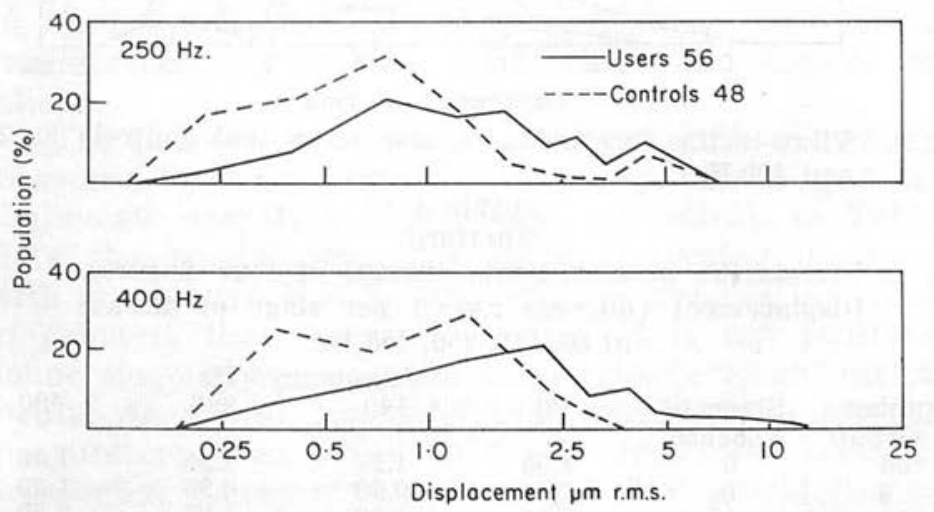

Fig. 6. Vibro-tactile thresholds saw users and controls at 250 and $400 \mathrm{~Hz}$. 


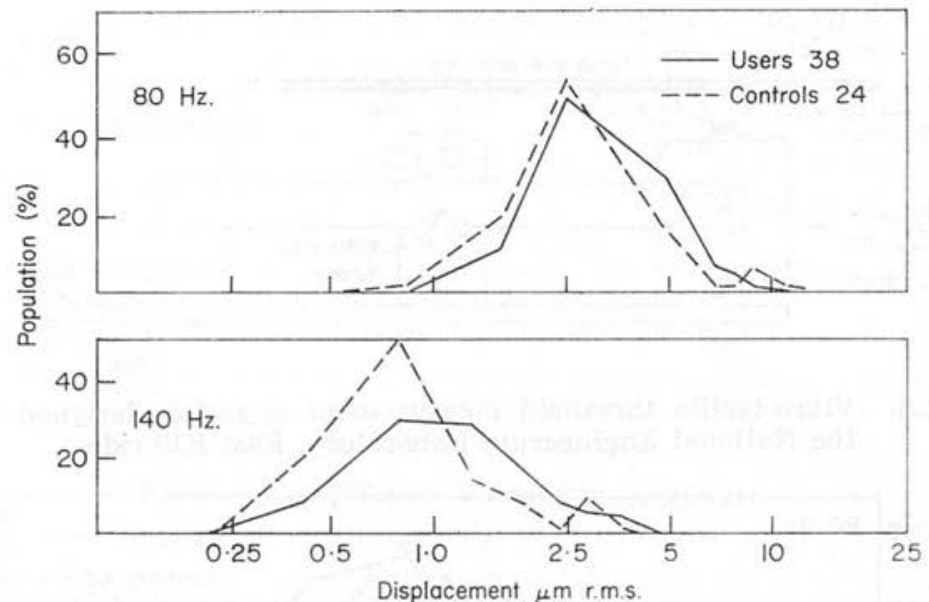

Fig. 7. Vibro-tactile thresholds of saw users and controls at and $140 \mathrm{~Hz}$.

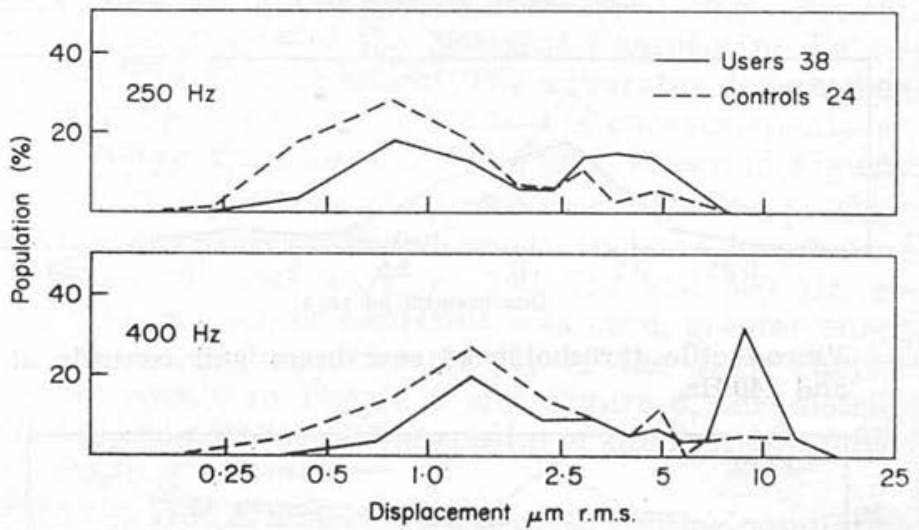

Fig. 8. Vibro-tactile thresholds of saw users and controls at 25 and $400 \mathrm{~Hz}$.

\section{Table 4}

Thetford

Vibrotactile measurements (means of four fingers). Displacement (microns r.m.s.) per stage of disease at 80, 140, 250, $400 \mathrm{~Hz}$.

$\begin{array}{cccccc}\begin{array}{c}\text { Number } \\ \text { in Group }\end{array} & \begin{array}{c}\text { Stage of } \\ \text { Disease }\end{array} & 80 & \begin{array}{c}\text { Freguency } \\ 140\end{array} & \begin{array}{c}\mathrm{Hz}) \\ 250\end{array} & 400 \\ 63 & 0 & 3.65 & 1.17 & 1.28 & \\ 3 & 0_{T} & 2.68 & 0.90 & 0.90 & 1.56 \\ 11 & 1 & 5.06 & 1.82 & 1.98 & 2.50 \\ 22 & 2 & 4.84 & 1.75 & 2.33 & 3.68 \\ 29 & 3 & 7.18 & 2.33 & 2.81 & 3.57\end{array}$


Table 5

Kielder

Vibrotactile measurements (means of four fingers). Displacement (microns r.m.s.) per stage of disease at $80,140,250,400 \mathrm{~Hz}$.

\begin{tabular}{cccccc}
$\begin{array}{c}\text { Number } \\
\text { in Group }\end{array}$ & $\begin{array}{c}\text { Stage of } \\
\text { Disease }\end{array}$ & \multicolumn{4}{c}{ Frequency $(\mathrm{Hz})$} \\
25 & 0 & 3.56 & 140 & 250 & 400 \\
13 & $0_{T}$ & 3.50 & 1.09 & 1.83 & 3.33 \\
10 & 1 & 3.66 & 1.73 & 1.63 & 2.85 \\
14 & 2 & 4.52 & 2.44 & 3.47 & 3.58 \\
6 & 3 & 4.24 & 2.18 & 4.99 & 7.71
\end{tabular}

Table 6

Cwmbran

Vibrotactile measurements (means of four fingers). Displacement (microns r.m.s.) per stage of disease at $80,140,250,400 \mathrm{~Hz}$.

\begin{tabular}{cccccc}
$\begin{array}{c}\text { Number } \\
\text { in Group }\end{array}$ & $\begin{array}{c}\text { Stage of } \\
\text { Disease }\end{array}$ & \multicolumn{4}{c}{ Frequency $(\mathrm{Hz})$} \\
79 & 0 & 4.76 & 140 & 250 & 400 \\
11 & $0_{\mathrm{T}}$ & 5.84 & 1.52 & 1.58 & 2.03 \\
18 & 1 & 8.88 & 3.87 & 1.96 & 2.58 \\
11 & 2 & 5.76 & 2.07 & 4.54 & 5.34 \\
12 & 3 & 12.32 & 5.23 & 4.74 & 3.29 \\
6 & 4 & 9.76 & 9.07 & 4.63 & 4.68 \\
& & & & &
\end{tabular}

In summary from Tables 4 and 5 will be seen that progressive V.W.F., as assessed clinically by stage of disease $\left(0,0_{\mathrm{T}}, 1,2\right.$ and 3$)$ causes increasing impairment of vibrotactile sensitivity in both the Thetford and Kielder populations.

The pedestal grinders at Cwmbran were subsequently measured by N.E.L. using the same appartus as used in the chain saw operators. The results are shown in Table 6 . Here the results show the same increasing impairment with progressive V.W.F. although the trend is less obvious in grinders than in saw workers. It is not possible to define stage of disease from known displacement measurements. As a test for individual sensitivity, vibro-tactile measurement has failed in the retrospective method. A prospective survey with increasing V.W.F. would give more evidence as to the value of this test in the V.W.F. assessment. 


\section{Skin Temperature Tests}

Vascular tests previously used to confirm the presence of Raynaud's phenomenon have proved disappointing. There are many instances in the literature where cooling fails to provoke visible evidence of V.W.F. in patients who are known to suffer from attacks of V.W.F. induced by exposure to reduced temperature either in the home or in the factory.

It was decided, despite the negative results so far obtained, to repeat the provoked cooling and heating tests with more sophisticated electronic instrumentation (thermocouples in intimate contact with the skin; cold junctions; 16 point temperature recorder). It was not possible, however, to control central body temperature in the field in the absence of a constant temperature room.

No significant differences could be found between known V.W.F. cases and age-sex matched controls when measuring temperature changes following hot water immersions ( 3 minutes at $45^{\circ}$ C.), and after cooling (cold water immersion -3 minutes at $15^{\circ}$ C.). After cold immersion the general trend was that V.W.F. cases gave lower readings for a longer time (delayed heating or return to normal) but there was again a large area of overlap between vibration exposed and controls. In all the experiments, thumb temperatures cooled more slowly and warmed faster than digits indicating an increased blood supply when compared to the digits of the same hand.

\section{Skin Temperature Thermography}

The Department of Medical Biophysics, University of Dundee had had research experience estimating skin temperatures by means of an infra-red camera technique. It was claimed that by means of thermography, skin temperature differences of $\pm 0.2^{\circ} \mathrm{C}$. could be detected and recorded on film. To evaluate this technique, the camera equipment was transported to Thetford and Cwmbran to survey chain saw workers and pedestal grinders. The object was to compare this photographic skin temperature method with the standard thermocouples, cold junctions and temperature recorders. The subjects' oral temperatures were first recorded using a standard clinical thermometer, then the temperatures of the tips of the fingers, middle phalanx, proximal phalanx and back of hand using a probe thermo- 
meter. Three polaroid photographs of the thermographic display were then taken. (1) following the initial screening for body and skin temperature. (2) after cooling at $7^{\circ}-8^{\circ} \mathrm{C}$ for 4 minutes then hands withdrawn for 5 minutes. (3) after heating - hot water dip $55^{\circ}-60^{\circ} \mathrm{C}$ for three minutes with slow hand movement within the bath. Finally the temperatures of index finger and back of hand were checked by probe thermometer.

In summary the results obtained by thermography were disappointing. Interpretation of the films proved to be difficult and did not distinguish either (a) vibration exposed from controls, or (b) degrees of severity of V.W.F. As a clinical objective test, thermography, in our hands experimenting on a severely V.W.F. affected population, failed.

\section{Bone Density}

To measure bone density, any method devised must be accurate and non-destructive thus ruling out microscopic methods. Of the microscopic methods available, radiographic densitometry and morphological indices are the most commonly used. The most promising method depends on measurements made of the transmission of radiation of a single photon energy or two different photon energies, the sources of these being appropriate radio nuclides. Accordingly the Department of Medical Biophysics, University of Dundee, was approached with a request to join the D.H.S.S. Research team working on the Vibration Syndrome. The object was to use a double isotope method for serial bone mineral measurements in a population of vibration exposed personnel and an age- and sex-matched control population. Preliminary work and evidence from the literature had indicated that vibration caused osteoporosis in the metacarpals due to the reduced blood supply.

The apparatus, designed, tested and in use in geriatric populations, depends on the measurement of the transmission through the tissues of the $\mathrm{X}$-rays from two radioactive isotope sources whose emissions are of substantially different energies. These sources, embodied in a machine for scanning the metacarpals, consisted of Americium 241 and Caesium 137. These radiation sources each with a strength of $100 \mathrm{~m}$ Curies $(\mathrm{mCi})$ were mounted in separate disc shaped planchets which by means of a simple manual remote control device could be moved in and out of posi- 
tion behind a $2 \mathrm{~mm}$. brass collimator. The patient's hand le was placed on a perspex platform which was motor driven a at a uniform speed through the fixed collimated beam of $d$. photons from the double source, thereby scanning the metacarpals. The count rate was recorded continuously as the metacarpals were scanned and the integrated counts over 10 secs. recorded graphically and on punch tape for subsequent computer analysis.

The radiation doses were small, in the worst case, beta emission (from Caesium 137) gave a dose of about $10 \mathrm{mR}$ across the scanned region. Serial hand examinations therefore on a single individual presented no problems of radiation exposure. The apparatus, having passed the experimental stage, was used first on post-mortem material and subsequently on live patients in a geriatric ward in a Dundee Hospital. The apparatus with its radioactive sources was then transferred first to Thetford forest, Santon Downham, Norfolk, for a survey of the Thetford chain saw operators (January, 1971) and then to Cwmbran to survey the pedestal grinders (February, 1971). On the 11th February, 1971, the research fellow operating the bone scanning apparatus was recalled to Dundee by the Head of the Department of Medical Biophysics, following the discovery of radiation contamination in the laboratory, University of Dundee. Radiation leaks were then discovered at the Dundee Hospital, at the District Commissoner's office, Santon Downham, where the Thetford chain saw operators were examined and at the Cwmbran works surgery where the pedestal grinders were examined. After monitoring of all areas likely to have been contaminated and examinational of all personnel who may have been exposed, the body burdens of the D.H.S.S. Research Team and the research fellow responsible for the bone scanning equipment were measured. The possibility of further contamination or complications was ruled out by monitoring all possible risk areas including the industrial locations.

Following this radiation leak all experimental work on the measurement of bone density of vibration exposed workers was stopped. Unfortunately the results from the two completed vibration surveys namely Thetford and Cwmbran (350 individuals bone scanned) were declared null and void due to the stray radiation arising from a defect in the bone scanning apparatus. This chain of events 
leading to abandonment of the experiment is regretted and it is hoped to repeat the bone density work at a later date.

\section{CONCLUSIONS - CLINICAL OBJECTIVE TESTS}

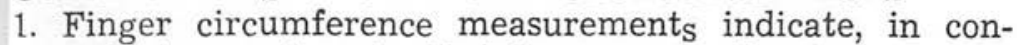
trolled experiments, that in general vibration exposed subjects have larger fingers than non-vibration exposed populations.

2. Depending on the energy input to the hands, there is an initial increase in size but there is no further progression by clinical determination, i.e. with stage of disease, or with increasing vibration exposure time.

3. In certain operations the finger in direct contact with a high vibrational energy source (chisel in pneumatic chippers) shows the greatest increase in size.

4. Of the neurological tests, the depth sense aesthesiometer gave statistically the greatest difference between vibration and exposed populations. The ridge test also gave progressive increases in threshold by stage of disease in chain saw operators and pedestal grinders.

5. Statistical differences may be shown between vibration and control populations in vibro-tactile sensory measurements of the finger pulps but as a test for individual sensitivity, it has failed on the data shown in this report.

6. Cooling and heating tests whether using thermocouples or thermography techniques failed as objective tests for the assessment of V.W.F. severity.

7. Bone density experiments using a bone scanning radiation method were abandoned after two surveys due to technical failure in the equipment. 


\section{The Results of Long-term Vibration Exposure with a Review of Special Cases of Vibration White Finger}

P. L. PELMEAR and W. TAYLOR

\section{INTRODUCTION}

For many years the diagnosis of Raynaud's Disease has been made in patients with signs of ischaemia in the fingers. Clinicians, however, have been puzzled when the digits in such patients, after showing the usual attacks of intermittent pallor, have progressed to permanent cyanosis. Some patients even developed areas of necrosis affecting the finger pulps. In Raynaud's original work in 1862, he clearly defined his signs and symptoms. He did not adhere to his definitions and we now know that he had included in his series of cases other causes of reduced circulation, e.g. arteriosclerosis, hemiplegia and scleroderma.

Raynaud and others attributed the pallor of the digits to vasospasm of the digital arteries. It is evident, however, that to produce ex-sanguinated fingers there must also be spasm of the venules secondary to spasm of the arteries and arterioles (Naide and Sayen, 1946). Vibration stimuli introduced into the hands and fingers from handheld vibratory tools produces in the first instance intermittent attacks of white finger. It is generally accepted that the blanching, in the early stages, is due to vasospasm but why the vessels react in this manner is still obscure. With long term exposure to vibration, the characteristics of which we are now able to define within broad limits, narrowing of the bore of the arteries and arterioles takes 
place. As the vibration damage increases, the pathological changes within the vessel walls prevents normal contraction and dilatation. Intermittent attacks of white finger are no longer observed and give way to a permanent cyanotic appearance of the digits with stasis of the blood in the arterioles and venules. It must also be noted that from an arteriographic and histological study, Laws et al (1967) confirmed the findings of Lewis (1938) that digital arteries of normal subjects usually showed some narrowing due to increased intimal thickening with age. A severe degree of narrowing or complete occlusion, however, is uncommon. Beyond the age of 50-60 years narrowing occurs mainly in men and this ageing process is difficult in the majority of cases to dissociate from secondary disease such as peripheral vascular lesions associated with rheumatoid arthritis, periarteritis nodosa or scleroderma.

In 1945 Gurdjian and Walker obtained fingertip biopsies from five women with Raynaud's phenomenon of occupational origin. On histological examination no abnormalities of the capillaries or larger vessels were found. On the other hand, Ashe et al (1962) biopsied the fingers of two users of Jackleg drills. In Patient 1 where the signs and symptoms of V.W.F. were not severe, and came on only after the introduction of a new drill, the muscular walls showed medial muscular hypertrophy and some sub-intimal fibrosis. In Patient 2 where white finger attacks had given way to a permanent cyanosis of the digits, the muscular wall of the artery showed advanced intimal hypertrophy together with marked sub-intimal fibrosis. Ashe and his colleagues interpreted the arteries of Patient 2 as showing such advanced pathological changes that a cold stimulus was no longer able to cause spasm of the vessel. Where physiologically induced vasospasm can take place, there is blanching of the skin and/or tissues but where the hypertrophy and resulting fibrosis is advanced only limited blood flow, unaffected by an external stimulus, is possible leading to cyanosis of the digits of the stagnation type. Ashe et al considered that the most logical overall explanation of the V.W.F. phenomenon on the basis of the observed histology was that the process is biphasic

(a) functional over-reaction on the part of the arteries innervated by the sympathetic nervous system, and 
(b) subsequent hypertrophy and fibrosis of the vessel wall after continuous exposure to vibration in the majority of employees exposed to vibration extending over a period 10-15 years. The fundamental physiological processes are not known.

Two further variables which are operating are (i) skin and digital blood flow and (ii) proliferation of sub-cutaneous tissue or the so-called "callus" formation observed in the digits of vibration exposed cases.

\section{Skin and Digital Blood Flow}

In digital skin, thermoregulation is provided by a widely variable blood flow ranging from $0.5 \mathrm{ml} /$ minute, through each $100 \mathrm{ml}$. of tissue during intense vasoconstriction to more than $50 \mathrm{ml}$. with the vessels fully dilated (Fox, 1968). The oxygen requirements of digital skin have been calculated to be provided by $0.8 \mathrm{ml}$. of blood through each $100 \mathrm{ml}$. of tissue (Burton, 1961). Therefore in the normal person vasoconstriction control is powerful enough to reduce the blood supply almost to the point of anoxia. The control of blood flow through the skin depends partly on central control through sympathetic vasomotor nerves and partly on a direct local effect of temperature. Over the greater part of the body surface, cutaneous control is mediated by both vasoconstrictor nerves and a vasodilator mechanism, whereas in the extremities only vasoconstrictor control is present. (Fox and Edholm, 1963; Abramson, 1967). Certain psychogenic stimuli are also known to produce a strong vasoconstriction.

Sympathectomy of a normal limb produces an immediate and large increase in blood flow. This, however, is shortlived, subsiding rapidly after two to three days following surgery and then more slowly in the succeeding weeks until the flow is barely above the normal base line preoperatively (Barcroft and Walker, 1949). The mechanism of this return of vessel "tone" is not known but it is a major factor in contributing to the disappointing and unpredictable late results of sympathectomy for the relief of both Raynaud's disease and Raynaud's phenomenon (Buchanan et al, 1952; Johnston et al, 1965). Moreover the initial blanching and pallor induced by cold, may still be elicited following sympathectomy indicating that vessel 
nerve enervation is not the only mechanism involved in the blanching process.

\section{Callus formation in vibration exposed personnel}

In a survey carried out by Stewart and Goda (1970) at the request of the Industrial Injuries Advisory Council, the hypothesis was advanced that V.W.F. resulted from deposition of callus or job callosities on the finger pads. This toughened sub-cutaneous tissue results in a fall in the volume of blood which can be held in the capillaries and "makes it difficult for the local capillaries to react quickly". This theory assumes that arterial spasm is an essential part of the process rather than vibration-induced damage to nerve endings. Nevertheless the theory claims that callus formation is an essential element in the V.W.F. process. In the majority of cases measured (See Paper 6), there is an increase in sub-cutaneous tissue, particularly in digits subjected to maximum pressures such as the index finger in pedestal grinders. We do not know what is the nature of the tissue increase (i.e. cellular or liquid elements) but it has been shown that when the vibration stimulus is withdrawn there is usually a reduction in finger size. There is not, however, a related decrease in V.W.F. in the majority of cases, especially if they are as advanced as Stages 2 and 3. Furthermore, as pointed out by McCallum (1971) there are many manual operators producing job callosities with no signs and symptoms of V.W.F. Again this survey has shown V.W.F. to be present in fingers of normal size. There is no evidence in either the 1970 Report of Stewart and Goda or in our findings that proliferation of tissue per se will result in arterial spasm. We would agree with the view expressed by McCallum (1971) that the callus theory, although a completely new approach to the aetiology of V.W.F., is difficult to accept. We have frequently noted in severe V.W.F. cases with marked dorsal pads and sub-cutaneous tissue swelling that when withdrawn from vibration exposure, the digital swelling subsides but the attacks of V.W.F. persist.

In summary, the evidence suggests that the probable phases in V.W.F. are:

(1) Ischaemia of the tissues as the digital arteries and veins shut down. 
(2) A reactive hyperaemia as the circulation is fully restored.

(3) In the more severe vibration cases resulting from prolonged vibration exposure there is a permanent reduction in blood flow, and cyanosis with venous stagnation is more evident than blanching. The venous blood becomes deprived of oxygen and stagnates before the venous return comes fully into operation.

(4) Permanent occlusion of the digital arteries, at first at the extremities of the digits and with further vibration exposure extending to the roots, has been demonstrated by arteriography. The lumen narrowing is due either to vessel wall pathology and/or thrombosis.

(5) Progressive occlusive changes in the digital arteries and attempts to improve blood flow by the development of collaterai blood vessels disturb the former balance of blood pressure and flow resistance, so that a chronic state of congestive ischaemia is observed.

(6) In some of the long term cases described in this paper the persistent cyanosis, at first present only in the winter months, extends gradually throughout the summer. The clinical picture is independent of the early low temperature stimulus.

(7) The end picture of progressive narrowing of the digital arteries is tissue anoxia and ultimately necrosis of the finger pulps.

(8) Arteriography has shown wide variation in digital artery size in different subjects. This initial difference in digital artery bore diameter will allow large variation in latent intervals (i.e. time taken to reach Stage 1), those with the most efficient circulation taking longer to present with V.W.F. signs and symptoms. This variable will also extend throughout Stages 1 to 4 and is one of the main factors accounting for the variation in the mean vibration exposure time at the various stages of disease.

\section{CASE HISTORIES - SEVERE EXAMIPLES OF V.W.F. ENCOUNTERED DURING THE D.H.S.S. RESEARCH PROJECT}

\section{R.P. aged 52. Occupation, School Janitor}

No previous history of circulation complaints in hands, feet or ears. No chilblains. No trauma or lacerations affect- 
ing fingers, wrists, elbows or shoulders. Previous employment, after war service 1939-46, was with the Earl of Rosebery as a gamekeeper for four years. It entailed trapping over the entire winter months during which time he never noted cold hands or feet. At age 43 years he joined a Foundry Company in Bathgate as a "dresser" of heavy castings up to 13 tons weight using a variety of pneumatic tools and varying lengths of chisels from a few inches up to 6-8 feet in length. These chisels were held in his left hand and the greatest force was exerted on the 4th finger of this hand. If the chisels in this tool are not held firmly, they leave the body of the tool. The metal on which he worked was S.G. iron and stainless steel and the operation consisted of cleaning long welds and chipping off "necks," "feeders" or "risers." $\mathrm{He}$ also used a powerdriven buff which was associated with excessive vibration. One year following the commencement of pneumatic tool dressing R.P. noticed the tip of his left 4th finger turning white and stiff with swelling of all the fingers on his left hand. This blanching gradually extended from the tip to the root of his 4th finger and after 2-3 years pneumatic drill work all fingers of his left hand were involved. At the end of 5 years pneumatic tool dressing he was compelled to change his occupation because his "white finger" had progressed so rapidly with time that his General Practitioner recommended that he leave the foundry. $\mathrm{He}$ then registered as a Disabled Person and entered the Granton Rehabilitation Centre. On completion of the course he tried unsuccessfully to obtain suitable employment and finally, in desperation, accepted a tractor driving job. The firm discontinued operations after 3 months which was fortunate since he was having difficulty with his fingers blanching, especially in the early mornings. He then was successful in gaining employment as a school janitor and has been free from vibration for $3 \frac{1}{2}$ years since leaving the foundry. His complaints are now -

(Examination 12/4/72)

1. Pins and needles and cramps during the night, and interference with sleep.

2. White fingers on both hands on rising and always worse in the morning. His thumbs have never been involved but he has seen the blanching extend approximately 1" beyond the roots of the fingers on both hands. A bad 
attack on a cold damp morning, in winter will whiten all fingers (to the roots) of both hands. There is pain on return of circulation.

3. There is interference with social activities. The hobby which occupied most of his free time was fishing but he has now had to abandon this activity because of white fingers (touching the cold rod) and because his fingers are "clumsy." $\mathrm{He}$ no longer attends football matches. The inactivity in the winter months immediately produces white finger. He still gardens (and this is part of his school duties) but white finger occurs on contact with the cold ground. He cannot change his clothes in a cold room and when fresh sheets are put on his bed he is in difficulty with his fingers during the night and in the early morning. He has had to give up cycling and does not drive a car or motorcycle.

4. His restlessness at night and his cold hands cause complaints from his wife.

Examination by W. Taylor, 12-4-72

On visiting R.P. at his school (Armadale) without prior arrangement, I found his hands cold with cyanosed digits, the left more so than the right. On cooling his hands in cold water his left 4th finger immediately blanched and a photograph was taken of this. His blood pressure was R. $\operatorname{arm} 145 / 95$ and L. arm $148 / 98 \mathrm{~mm}$.Hg. Skin sensitivity tests of the pulps of the index and middle fingers are shown below. Both tests showed markedly raised thresholds.

\begin{tabular}{lcccc} 
& \multicolumn{2}{r}{ Index } & finger & \multicolumn{2}{c}{ Middle } & finger \\
& $\mathrm{R}$ & $\mathrm{L}$ & $\mathrm{R}$ & $\mathrm{L}$ \\
Ridge Test & .75 & .75 & .80 & .75 \\
2-Point Test & 7.5 & 8.5 & 8.0 & 9.0
\end{tabular}

Conclusion

This patient is a Stage 4 (Change of Employment) V.W.F. Case. His condition has remained stationary after 3 years free from vibration. The latent interval of $1-1 \frac{1}{2}$ years indicates that initially the vibration energy input to the hands was high. R.P. did not raise the question of compensation. $\mathrm{He}$ is, however, anxious that future employees are not subjected to vibration which will cause Vibration White Finger. Since this case is a classical one 
in the sense that the patient progressed through all Stages of V.W.F. (to Stage 4) and that his signs, symptoms and hobby interference are typical, it is of interest to report in full a consultant's report previously obtained on this case $6 / 5 / 69$.

\section{Consultant's Report}

(dated 6th May, 1969).

"I interviewed and examined R.P. at the Western Infirmary on the 6th of May, 1969. The medical history is as follows:

His principal complaint is of recurrent attacks of white discolouration, numbness, and pain in the fingers and thumbs of both hands. In almost every attack both hands are involved, but the severity appears to be slightly greater in the right than on the left. The symptoms first appeared approximately in 1966, and have slightly increased in severity since that time. The attacks are regularly precipitated by exposure of the hands, or even of other parts of the body to cold. The degree of cold which is required to precipitate the attacks appears to vary, and even a reasonably cool day is enough to bring on attacks whenever he goes out in the open. He does not have the symptoms while in a warm environment, and in fact warming the hands either near a fire or in warm water usually brings an attack fairly rapidly to an end. During the attacks of white discolouration and pain and numbness, his hands act in a clumsy fashion, and he is not able to feel things normally. He notices difficulty when out in the cold in performing tasks involving any reasonable manipulation of the fingers, such as fastening his clothes, fixing buttons, or perhaps more distressing, attending to his own toilet requirements. Occasionally he has noticed attacks of the usual sequence of changes in his finger on a reasonably warm day when he is carrying heavy loads, but this is not a frequent occurrence. Occasionally also he has been wakened from his sleep at night with pain and tingling and numbness in the fingers. This has possibly been brought on by his hands becoming exposed outside the bedclothes.

Apart from the presenting symptoms he has been in reasonable health, apart from occasional headaches, and in addition he states that his feet get perhaps a little more cold 
than they should in the colder weather. He smokes about $1_{2}^{1}$ oz. tobacco per week and has occasional cigarettes in addition. His weight has been steady in recent years, he has had no chest pain or abdominal symptoms, and he remains generally pretty active.

His work history is quite varied. After leaving school at the age of 14 he worked for a while with the Forestry Commission doing outdoor work in a tree nursery. From 1937 to 1939 he was in the Territorial Army, and this took him out to the Far East. He had no trouble with his hands during these years. After the World War II he had a short spell in a local factory doing general jobs, and in 1947 became an Under Keeper. Thereafter he worked with the Scottish Gas Board doing general labouring and latterly weighbridge work. This work closed down approximately about 1960 , and thereafter he worked with a Parks Department but moved to a steel foundry in Armadale in 1962 or 3, since the pay was better in the foundry. He worked at the foundry until leaving in October, 1968, and the reason he left his work he tells me is that he was no longer able to do it on account of the trouble with his hands.

I gather that the work which he did at the steel foundry involved using a pneumatic hammer, and in addition a power driven buff. This latter tool is, I understand, associated with a considerable amount of vibration. It appears from his history that it is only after working with this sort of machinery about 2-3 years that he began to have the trouble with his fingers.

A thorough clinical examination of R.P. revealed no abnormality in the heart, in the chest, in the abdomen, or in the neck. The upper limbs appeared quite normal in contour and in muscle power. There was no clinical sign of abnormality in the bones of the upper part of the chest, and an X-ray showed that there was no congenital abnormality such as the cervical rib. His blood pressure appeared to be normal for his build and age at 155/95 $\mathrm{mm}$.Hg. The legs and feet showed no abnormality and the circulation appeared quite normal.

Turning to his hands, these had the typical appearances of Raynaud's phenomenon, with slight tapering of the pulps of mainly the first and second fingers in each hand, but also to a lesser extent on the other fingers. The 
colour of the palmar skin was unduly pink while they were exposed to the warm environment of the consulting room, but after 3-4 minutes of being immersed in running cold water and then being exposed to the air, typical quite marked blanching of all the fingers and thumbs was noted. The proximal edge of the discolouration was just about the metacarpo-phalangeal joints in each of the fingers. With gentle re-warming the fingers gradually changed from a white appearance to a blotchy cyanosed colour. This in turn was replaced by an exaggerated redness, and after 10 to 15 minutes the colour gradually returned to its previously normal state. There was no abnormality in the pulses or other aspects of the circulation to the upper limbs.

In summary, therefore, I have no doubt that R.P. has typical Raynaud's phenomenon, and the colour changes in his fingers appear to be particularly easily induced by cold. It would seem therefore that he has quite a marked degree of the Raynaud's changes. I was unable to detect any other abnormality on physical examination. The history presented would suggest that there may be a relationship between his working with vibrating machinery in recent years, and the disorder in his fingers."

\section{A.H. aged 61. Occupation, Wagon Repairer, 1929-63.}

No previous history of white fingers, never had chilblains. No history of trauma or lacerations. He has used a large pneumatic tool for ten years (1953-63) to screw and unscrew bolts, and to fasten and chisel off fixed, rusted bolts. His work rate was high, 53 hours $/ 5 \frac{1}{2}$ days per week. There was no previous history of exposure to vibration. Approximately 5 years after working with his compressed air tool he first noticed white fingers. The attacks were provoked by immersing his hands in cold water; when gardening in cold weather; and while watching football matches. At first the attacks occurred in Winter but then extended to the Summer. He particularly noticed around 1960 that his fingers, on using the tool, became swollen with a bluish-white discolouration of the digits on both hands. The tips of the fingers at first were painful following attacks but then the pain persisted throughout the day. He also noted changes in the skin near the finger tips where small ulcers appeared. 
He consulted his General Practitioner and was referred to Bromsgrove General Hospital in October 1961. On examination at that time his left had was worse than the right, the tissues were puffy and the fingers were bluish and rather livid in appearance. He had normal pulses at the wrists and no cervical ribs could be felt. No obliteration of the pulse occurred with traction on the arm. X-ray of the chest was clear and no cervical ribs could be seen. The blood was normal - haemoglobin 12.7 gms. \%, white cell count 6,800 .

As he did not respond to treatment with Priscol and Ronicol it was decided to do a left transaxillary cervical sympathectomy and this was performed on 29th November, 1961 - the second, third, fourth and fifth thoracic ganglia being removed with the intervening chain. There were no post-operative complications. The effect of the operation was dramatic. The hand and fingers became pink and warm and the patient was very pleased. The texture of the skin improved and the callosities at the ends of the fingers disappeared. The beneficial effects however, only lasted for about four months and then he had a recurrence of the condition. A right cervical sympathectomy had been considered but was not undertaken when it became apparent that the left one had not been a success.

In August 1962, he was seen by consultants at the Birmingham General Hospital. They were of the opinion that the condition was due to the vibrating tools. In August, 1966 he was referred to a dermatologist at the Bromsgrove General Hospital, who reported as follows:

"The patient's skin showed the features of peripheral vascular disease, with patchy purple discolouration, and areas of necrosis about the fingertips. There was no clinical evidence of scleroderma and a normal barium meal excluded any radiological evidence of scleroderma affecting the lower oesophagus."

\section{Examination by P. L. Pelmear, $1 / 2 / 73$.}

The fingers are still cool and swollen with a blotchy blue and white discolouration - especially when cold. Trophic changes appear intermittently at the tips of all his fingers. The palms are moist and the skin of the dorsum of the hands thin but normal for his age. His blood pressure is $155 / 70$ and the radial pulses can both be felt. 
Allen's test is negative. Although taking Hexopal daily the hand circulation is still very poor. Sensation as tested by 2 -point and ridge tests is normal. $\mathrm{He}$ is still a moderate smoker - 15 cigarettes daily. The patient being severely incapacitated has been a Registered Disabled Person since 1967.

\section{W.P. aged 59 years. (Died 25/1/69). Occupation, Pneumatic} Road Drill Operator.

Investigation by P. L. Pelmear.

This patient was a pneumatic road drill operator for 27 years with the City of Birmingham Public Works Department. In August 1967 W.P. was transferred to become a yard man at his own request and thus removed from further exposure to vibration. In retrospect the probable reason for this transfer was dissatisfaction with the organisation of his work - he was constantly being recalled to the depot to take his compressor and drill to another site.

\section{History}

The patient was a bachelor and lived alone for many years. He had good, friendly neighbours. They stated that he had been a keen gardener and fisherman but had discontinued both about two years before his death. He appeared to have lost interest. As far as they were aware he had always enjoyed good health and his hands always appeared normal, but during the year prior to his death he was seen to be wearing gloves whenever they met him. During the latter half of 1968 his fingers began to trouble him. His workmates did not see him with white fingers but during the lunch break he was seen frequently to rub his hands, presumably to warm them up and improve the circulation. During his latter years he was seen to apply rags to the handles of his pneumatic road drill to reduce the blast of cold air. When gangrene of his fingers developed about three months before his death, the first-aider at the depot and his workmates helped bandage his fingers. They advised him to consult his doctor and he assured them that he had done so, but in fact did not. On 8th January, 1969, when his neighbours discovered the state of his hands they took him to the Casualty Department of Selly Oak Hospital, Birmingham. On admission his 
hands were so swollen and painful that he could not write or use a knife and fork. There was necrosis to the bone of the right index and middle fingers, and necrosis of the left index and ring fingers, with scarring of the middle finger. His general condition was poor and he looked much older than 58 years.

\section{Investigations and Treatment}

His blood pressure was $140 / 90$ with radial pulses palpable and normal. Haemoglobin 4.5 gms. \%; white cell count 9,800 (82\% Polymorphs); ESR 114 mm.; L.E. cell test negative; R.A. latex test negative; Serum Proteins $6.8 \mathrm{~g} / 100 \mathrm{ml}$; Cryoglobulins may well have been present in the specimen although it is not certain. If they were present, they were in much smaller amounts than in the majority of positive sera. Lee and White clotting time 7 minutes. The left brachial artery was punctured in the antecubital fossa and an injection of $8 \mathrm{cc}$ of contrast media made. The left radial and ulnar arteries were tortuous but patent with an even lumen. Both superficial and deep palmar arteries were patent. Patchy obliteration and marked generalised narrowing of the lumina of nearly all digital arteries was observed. There was inadequate blood supply to the fingers distal to the proximal interphalangeal joints. The appearance suggested widespread arteritis of digital arteries, presumably traumatic rather than multiple emboli. An attempted puncture of the right brachial artery was unsuccessful. The patient was initially treated with anticoagulant drugs and then on 24th January, a right cervical sympathectomy was satisfactorily carried out. During the operation on the left side the patient collapsed and became pulseless. External cardiac message restored the circulation but an ECG tracing indicated that the patient had sustained a myocardial infarction. The operation on the left side was discontinued. The patient did not regain consciousness and died some twenty hours later on 25th January, 1969. Cause of death was certified as being due to congestive cardiac failure and pulmonary oedema following cardiac arrest during bilateral sympathectomy for gangrene of fingers. Contributory factors cardiac hypertrophy and benign essential hypertension. Post-operatively, blood pressure of 190/80 and 200/70 had been recorded, but the post-mortem did not reveal any 
gross abnormality of the cardiovascular system other than that in the arteries of the hands. There was no evidence of blood clots having been carried to the fingers from other parts of the body.

\section{Pathologist's Report}

"The heart weighed 485 gms. The enlargement of the heart was due mainly to marked hypertrophy of the myocardium of the left ventricle. On section into this ventricle the muscle was very firm and showed fine diffuse fibrosis, but no evidence of acute infarction or gross fibrous scarring. The cardiac valves were normal. The coronary arteries were markedly dilated and patent. There was a moderate degree of atheroma of the aorta. The pulmonary artery and branches were normal. Examination of the great vessels did not show untoward involvement by atherosclerosis. Examination of the sub-clavian, brachial and radial arteries showed no evidence of atherosclerosis nor of any obliterative lesion. No evidence was found anywhere in the body suggestive of a generalised connective tissue disease. Sections were taken at various levels through the left index finger and the right middle finger. These showed considerable keratinization of the epidermis and patchy areas or hyaline degeneration of the dermal collagen. While the main trunks of the digital nerves and Meissner's corpuscles were normal, degeneration and perineural infiltration by small round cells was seen affecting the nerves of the superficial cutaneous plexus and the branches extending into the dermal papillae. The digital bones showed generalised osteoporosis and the terminal phalanges showed necrosis and infiltration of the marrow by chronic inflammatory granulation tissue. The main digital artery was almost completely occluded, at all the levels examined in each finger, by marked intimal proliferation and sub-intimal hyaline change. The media showed diffuse fibrosis. There was evidence of (mainly) platelet thrombi in veins and venules. There was no evidence of atheromatous change and frozen sections stained for lipid showed no evidence of lipid infiltration. On the other hand, sections examined by the technique of immunofluorescence showed the presence of residual fibrin or fibrinogen. These appearances suggest an obliterative endarteritis due to organisation of previous thrombosis, 
rather than an embolic process. They are consistent with the traumatic vasospastic syndrome associated with the use of vibrating tools."

This case was known prior to the publication of the 1970 Interim Report and was not accepted as evidence because the findings suggested that the case was not a pure vibration-exposed one, but had medical complications. The authors of this paper do not agree with this verdict. Walton (1974) is of the same opinion.

\section{A.W. aged 32 years. Occupation, Pedestal Grinder (now Inspector of Forgings)}

Investigation by P. L. Pelmear.

No previous white finger, circulation difficulties or trauma to hands or fingers.

Medical Examination

Blood pressure, 125/75. No previous vibration exposure until he joined the malleable foundry on $12 / 2 / 65$ as a pedestal grinder. He worked with zirconia wheels until $2 / 11 / 71$ - a period of $6 \frac{1}{2}$ years, until he was declared unfit for further vibration exposure by the works medical officer. There was an unusually long latent period of 4 years. On $20 / 11 / 69$ he reported numbness of the fingers of both hands with blanching especially when handling cold tools, washing hands in cold water and driving. These symptoms were more troublesome in Winter. A medical certificate signed by his general practitioner dated 12/11/69 stated, "This man shows Raynaud's phenomenon related to his job as a grinder. He should be taken off the job working vibrating tools." Hexopal tablets were prescribed and taken with no beneficial effect. The patient, seen again 15/1/70 was anxious to continue as a grinder and was permitted to do so in spite of the general practitioner's opinion as the published medical evidence then available did not indicate that removal from the job was necessary. He was graded Stage 2 but deteriorating since examination of skin sensitivity revealed impairment. He was seen again $11 / 2 / 71$ when he was graded Stage 3 with social impairment - gardening, car washing, driving and maintenance all curtailed due to increasing V.W.F. attacks. On 21/12/71 with continued impaired sensation and blanching of all fingers to the metacarpo-phalangeal 
joints the patient was graded Stage 4, and was transferre to inspection work in November 1971 on the recommend tion of the works medical officer - declared unfit fo further employment as a grinder and removed fros further exposure to vibration $(2 / 11 / 71)$. He was see again on $6 / 10 / 72$ and $28 / 6 / 73$ when his V.W.F. conditio had remained unchanged. There has been no improvemer since he was removed from further vibration exposur

\section{R.E.E aged 27 years. Occupation, Pedestal Grinder (no' Contractors' Labourer)}

Investigation by P. L. Pelmear.

There was no history of previous vibration, no traum or lacerations, and no signs or symptoms of Raynaud Disease. $\mathrm{He}$ was employed in the malleable foundry as pedestal grinder from 15/1/65 but was declared redundar in November 1966. He was re-engaged for periods February to September 1968, and November 1968 December 1970. In May 1969 he reported pain in all h: fingers with intermittent blanching since 1967. Worse o cold mornings. He was graded Stage 2 deteriorating, cor firmed on examination at $2 / 9 / 70$. He ceased working as grinder in December 1970 and although working outdoor on cold nights (as a labourer) and handling cold object: no longer notices any blanching - reported on examina tion $14 / 8 / 72$. His grading has been reduced from Stage to Stage 0 and his ridge and two point tests have returne to normal.

Ridge Test

\begin{tabular}{clclc} 
& \multicolumn{2}{l}{ Index } & Finger & \multicolumn{2}{c}{ Middle Finger } \\
Date & $\mathrm{R}$ & $\mathrm{L}$ & $\mathrm{R}$ & $\mathrm{L}$ \\
2.9 .70 & .5 & .5 & .5 & .75 \\
14.8 .72 & .2 & .25 & .25 & .2
\end{tabular}

2-Point Test

\begin{tabular}{ccccc} 
& \multicolumn{2}{c}{ Index } & Finger & \multicolumn{2}{c}{ Middle } & Finger \\
Date & $\mathrm{R}$ & $\mathrm{L}$ & $\mathrm{R}$ & $\mathrm{L}$ \\
2.9 .70 & 3 & 3.5 & 3.5 & 3.5 \\
-14.8 .72 & 1 & 1 & 1 & 1
\end{tabular}

This patient, after removal from vibration exposure has spontaneously recovered. Two factors may be respon- 
sible for this improvement (a) age (27 years) and (b) the early stage of disease, Stage 2.

\section{A.J. aged 30. Occupation, Pedestal Grinder.}

Investigation by P. L. Pelmear.

No previous history of Raynaud's Disease or other vibration exposure. No trauma or lacerations. Normal medical history. Blood pressure $115 / 60$. This patient entered employment as a pedestal grinder at Cwmbran $2 / 3 / 70$ and has continued in this work since this date. On $7 / 7 / 70$ he was examined and was Stage 0 ; on $15 / 12 / 70$ Stage 1 ; on $21 / 12 / 71$ Stage 2 and beginning to complain of social interference with gardening, swimming and watching sport, and páraesthesia and aching of his fingers at night; on $11 / 9 / 72$ Grade 3 and still deteriorating. When offered alternative work he declined. $\mathrm{He}$ was seen again on $12 / 1 / 73$ and on $28 / 6 / 73$ - Grade 3 deteriorating but he is continuing to work against the advice of the works medical officer since he is not prepared to accept alternative work with a reduction of income of $£ 11$ per week.

\section{W.L. aged 33 years. Occupation, Pedestal Grinder.}

Investigation by $P$. L. Pelmear.

No previous history of Raynaud's Disease or other vibration exposure. Medical history normal with blood pressure $110 / 70 \mathrm{~mm}$. Hg. He became a Pedestal Grinder in May 1970 and has continued in this occupation since. His latent interval was 5-6 months and by $15 / 12 / 70$ he was Stage 1, well established with V.W.F. attacks occurring early mornings coming to work. A year later, $21 / 12 / 71$, he was in Stage 2 and deteriorating. The works medical officer advised alternative work. On 11/9/72 he was Stage 3 with the tips of both thumbs now blanching in cold weather. The patient still declined the offer of alternative work. By $12 / 1 / 73$ the thumbs were being increasingly affected - the right to the base and the left to the interphalangial joint. The fingers were cold to touch (not in an attack of V.W.F.) and the skin was blotchy white and of a dusky hue. Skin sensitivity has been progressively impaired. When seen again on $28 / 6 / 73$ this employee continues to work as a pedestal grinder against medical advice. He was not prepared to accept alternative emplcyment with a reduction of income of $£ 11$ to $£ 34$ per week. 
$\mathrm{He}$ is at this date graded Stage 3 deteriorating. The finge circumference measurements and the results from the Ridge and 2-Point tests are given below.

Finger Circumference (Proximal Phalanx)

\section{Date}

21.12.71

11.9.72

28.6.73
Index Finger

$\mathrm{R}$

62

60

63
L

60

58

58
Middle Finger

$\mathrm{R}$

60

59

59
L

58

56

57

Ridge Test

$\begin{array}{ccr}\text { Date } & \mathrm{R} & \mathrm{L} \\ 7.7 .70 & <.25 & <.25 \\ 15.12 .70 & <.5 & <.5 \\ 21.12 .71 & <.5 & <.5 \\ 11.9 .72 & .3 & .3 \\ 12.1 .73 & .5 & .5 \\ 28.6 .73 & .75 & 1.0 \\ \text { Test } & & \\ & & \\ \text { Date } & \text { Index } & \text { Finger } \\ 7.7 .70 & \mathrm{R} & \mathrm{L} \\ 15.12 .70 & 2 & 2 \\ 21.12 .71 & 3 & 2 \\ 28.6 .73 & 2 & <2 \\ & 7 & 8\end{array}$

Index Finger

L

$<.25$

$<.5$

$<.5$

.5

1.0
Middle Finger $\mathrm{R}$

$<.25<.25$

$<.5<.5$

$<.5 \quad<.5$

$\begin{array}{ll}.3 & .3\end{array}$

.5

.75

1.0

2-Point 'Test

Middle Finger

$\begin{array}{rr}\mathrm{R} & \mathrm{L} \\ 2 & 2 \\ 3 & 2 \\ 2 & <2 \\ 8 & 9\end{array}$

\section{REVIEW OF STAGE 4 CASES.}

In Stage 3 V.W.F., digits on both hands are involved in the blanching process both Summer and Winter. There is, in addition, interference with social and leisure activities and curtailment of hobbies. If the vibrationexposed subject receives more vibration energy and continues slowly to deteriorate, as indicated by a decreasing circulation in the fingers, the subject either leaves his job or asks management for a transfer to another department within the works where further exposure to vibration ceases. When this point in the gradually deteriorating V.W.F. syndrome is reached he becomes a Stage 4 Case.

There are many reasons for changing occupation. It is difficult to establish the true motives and to know from the subject's own history whether one or more reasons are valid and particularly where the employee leaves his job 
and his firm. Under the Industrial Injuries Scheme a worker in receipt of disablement benefit, who is unable to follow his regular occupation or to undertake employment of an equivalent standard, is entitled to an additional payment known as 'Special Hardship Allowance'. An attempt was made in this D.H.S. Survey to find out retrospectively by questionnaire from V.W.F. cases the reason for change of occupation:-

\section{CHANGE OF JOB (Part of Questionnaire completed for}

\section{Stage 4 Cases)}

Please tick and also number in order of importance which of the following reasons caused you to leave your job. Add any other factors at the foot of the list, and make any comments which you feel could explain the reason further.

To earn more

'To get better working conditions

Family reasons

Redundancy

On medical advice. Why?

Numbness and blanching of fingers:

Interference with work.

Interference with leisure.

Fear of further trouble.

Other health problems. Which?

To get lighter work.

Desire for change - (fed up with job)

Are you financially better or worse now than you were in your former job or jobs?

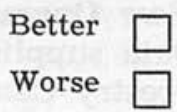

The attempt was abandoned because of (a) poor response rate (less than 20\%) and (b) change of addresses in all parts of the U.K. resulting in re-addressing and consequently a very high postage outlay for little or no return.

Clearly the number of variables in 'change of job' surveys may be reduced where works' medical officers and works' nursing teams can be involved. It is then possible to have the previous V.W.F. history and clinical findings up to Stage 3. The industrial medical officer usually arranges the transfer to alternative employment or has seen the subject if a request is made to terminate employment 
because of the finger blanching, deterioration of which has led to this action. Again the subject may have reported his worsening white finger to his General Practitioner who advises removal from further vibration. In large factories with efficient occupational health schemes operating, it is possible through the Personnel Department to arrange for alternative employment and thus remove the subject from further vibration exposure. With more knowledge of the progression of V.W.F. with time and knowing the vibration characteristics and the exposure time, it is possible to rehabilitate Stage 3 V.W.F. cases before further deterioration takes place. In the Forestry Commission, however, where it is difficult and sometimes impossible to find other employment which does not expose the subject to low temperatures (e.g. general labour duties or planting or tractor driving), attempts were made to re-train Stage 3 cases for light engineering or electronics. It was soon found that loss of ability to carry out fine movements, a characteristic feature of the majority of Stage 3 cases, prevents rehabilitation into areas where dexterity and the ability to handle small objects are necessary.

The postal survey of all vibration exposed personnel who had left their employment, was abandoned, and it was decided to look at all Stage 4 cases interviewed in the 18 populations surveyed in the $1970-1973$ D.H.S.S. project. The Stage 4 cases were found in (a) chain Saw Operators, (b) Pedestal Grinders and (c) Swagers.

\section{Chain Saw Operators}

(Data supplied by Mr G. D. Keighley,

Forestry Commission)

There were 19 Stage 4 cases reported throughout the 1100 regular saw users in Britain (1.7\%). It is certain that this may be a low estimate in that at least three cases left Forestry Commission employment for reasons unknown but which may have been for V.W.F. On the other hand the exact figure is of no significance in that in 1970 antivibration saws were issued and with the known improvement in vibration characteristics it is hoped that Stages 3 and 4 cases will no longer be seen. But for the prompt action of the Forestry Commission and Mr Keighley's efforts to prevent further deterioration the figure of $1.5-2 \%$ might well have been exceeded. The mean age of the Stage 
cases was 43 years and the mean vibration exposure time .2 years.

After transfer or other employment outside Forestry Commission, there were five (28\%) subjectively claiming in improvement in the V.W.F., ten $(60 \%)$ reporting No Change and two (12\%) deteriorating. There were 11 of the 9 claiming reduced finger size on removal from vibration vith seven reporting. No Change in V.W.F. when the ingers returned to their normal size. (See Table 1).

Table 1

Stage 4 cases. Changed Occupation Because of V.W.F. Vibratory Tool - Chain Saw

$(\mathrm{N}=19)$

\begin{tabular}{|c|c|c|c|c|}
\hline Name & $\begin{array}{c}\text { Age } \\
\text { (Yrs.) }\end{array}$ & $\begin{array}{l}\text { Vibration } \\
\text { Exposure } \\
\text { Time (Yrs.) } \\
\text { Int. = } \\
\text { Intermittent }\end{array}$ & $\begin{array}{c}\text { State of } \\
\text { Fingers: } \\
\mathrm{D}=\text { Deterioration } \\
\mathrm{I}=\text { Improvement } \\
\mathrm{NC}=\text { No Change }\end{array}$ & $\begin{array}{c}\text { Reduction } \\
\text { in finger } \\
\text { size } \\
\text { Yes }=\mathrm{Y} \\
\text { No }=\mathrm{N}\end{array}$ \\
\hline $\mathrm{KK}$ & 53 & 7 & $\mathrm{NC}$ & $\mathrm{N}$ \\
\hline$A B$ & 34 & 6 & $\mathrm{NC}$ & $Y$ \\
\hline NR & 52 & 4 & I & $\mathrm{Y}$ \\
\hline DR & 32 & 7 & NC & $\mathrm{Y}$ \\
\hline GM & 51 & 8 & I & $\mathrm{Y}$ \\
\hline WG & 52 & 7 & - & - \\
\hline WK & 41 & 11 & $\mathrm{NC}$ & $\mathrm{Y}$ \\
\hline RC & 36 & 8 & NC & $\mathrm{Y}$ \\
\hline SW & 56 & 9 & NC & $\mathrm{Y}$ \\
\hline AS & 44 & 9 & - & $\overline{-}$ \\
\hline PM & 24 & $3 \frac{1}{2}$ & $\mathrm{NC}$ & $N$ \\
\hline JW & 34 & 5 & $\mathrm{NC}$ & $\mathrm{N}$ \\
\hline TS & 44 & $1 \frac{1}{2}$ & I & $\mathrm{Y}$ \\
\hline LM & 55 & Int. & I & $N$ \\
\hline AM & 41 & $5 \frac{1}{2}$ & I & Y \\
\hline JR & 37 & 12 & D & $\mathrm{N}$ \\
\hline JCS & 52 & 2 & NC & $\mathrm{Y}$ \\
\hline WGR & 43 & 13 & $\mathrm{NC}$ & $\mathrm{Y}$ \\
\hline JR & 37 & 12 & D & $\mathrm{N}$ \\
\hline
\end{tabular}

MEAN

43

7.2

\section{edestal Grinders}

(Data supplied by P. L. Pelmear)

From the survey data on 51 pedestal grinders from 970 to September 1973 , there were 15 cases of Stage 4 noted i.e. change of occupation due to V.W.F.). All 15 were 
rehabilitated within the firm by the works medical office The mean age was 37 and the mean vibration exposur time of the group was 6 years. Thus the data presente in Table 2 is valuable in that it represents one of th most rapid deteriorating clinical pictures found in of D.H.S.S. project. It also represents prospective data wit the opportunity of checking the subjects' previous clinic. history and his present clinical state. We also have for th population the vibration characteristics and the exposur time.

On change of occupation one grinder improved wit regard to his V.W.F. state, one deteriorated and 13 showe no change. Of the 13 no change group, all reported reductic in finger size in particular the index fingers of both hand on cessation of grinding but there was no change in th number of blanching attacks or interference in the leisure and hobby activities. The percentage of pedest. grinders $(N=51)$ reaching Stage 4 was $29 \%$ compare with $1.7 \%$ found in the chain saw operators.

\section{Table 2}

Stage 4 Cases. Changed Occupation Because of V.W.F. Vibratory Tool - Pedestal Grinder

\begin{tabular}{|c|c|c|c|}
\hline Name & $\begin{array}{c}\text { Age } \\
\text { (Yrs.) }\end{array}$ & $\begin{array}{c}\text { Vibration } \\
\text { Exposure } \\
\text { Time } \\
\text { (Yrs.) }\end{array}$ & $\begin{array}{l}\text { State of } \mathrm{Fi} \\
\mathrm{I}=\text { Improv } \\
\mathrm{D}=\text { Deteri } \\
\mathrm{NC}=\text { No }\end{array}$ \\
\hline $\mathrm{PC}$ & 39 & 6 & I \\
\hline $\mathrm{KF}$ & 38 & 7 & $\mathrm{NC}$ \\
\hline VD & 32 & 6 & $\mathrm{NC}$ \\
\hline $\mathrm{AH}$ & 27 & 5 & $\mathrm{NC}$ \\
\hline WJ & 38 & 6 & $\mathrm{NC}$ \\
\hline AL & 43 & 9 & $\mathrm{NC}$ \\
\hline MM & 29 & 5 & $\mathrm{NC}$ \\
\hline RM & 33 & 7 & $\mathrm{NC}$ \\
\hline AP & 31 & 6 & $\mathrm{NC}$ \\
\hline PS & 27 & 3 & $\mathrm{NC}$ \\
\hline VS & 51 & 7 & D \\
\hline AW & 29 & $6 \frac{1}{2}$ & $\mathrm{NC}$ \\
\hline HW & 43 & 7 & $\mathrm{NC}$ \\
\hline GW & 39 & 5 & $\mathrm{NC}$ \\
\hline JP & 58 & 5 & $\mathrm{NC}$ \\
\hline MEAN & 37 & 6.0 & \\
\hline
\end{tabular}

A reduction in finger size in all cases. 


\section{Swagers}

There were six swagers in Stage 4 of the original 20 vibration exposed. These six had been transferred to other departments within the works having passed through Stage 3 and finding it impossible to carry on with the deteriorating clinical state of their V.W.F. Their mean age was 47 years. Two of the six showed improvement on removal from vibration, four showed no further deterioration and remained in the Stage 3 state and none deteriorated further. The energy input to the hands is known to be high (latent period 0.6 years) and therefore this population arrives at Stage 4 in the short vibration exposure time of 4.4 years. (See Table 3 ).

\section{Table 3}

Stage 4 Cases. Changed Occupation Because of V.W.F. Vibratory Processs - Swaging

$(\mathrm{N}=6)$

$\begin{array}{ccccc}\text { Name } & \begin{array}{c}\text { Age } \\ \text { (Yrs.) }\end{array} & \begin{array}{c}\text { Vibration } \\ \text { Exposure } \\ \text { Time } \\ \text { (Yrs.) }\end{array} & \begin{array}{c}\text { Effect on } \\ \text { Earnings } \\ \text { + Gain } \\ \text { - Loss }\end{array} & \begin{array}{c}\text { State of Fingers: } \\ \text { I= Improvement } \\ \text { D= Deterioration } \\ \text { NC = No Change }\end{array} \\ \text { FK } & 49 & 4 & 0 & \text { NC } \\ \text { AA } & 42 & 5 & -2 & \text { NC } \\ \text { JM } & 57 & 1 \frac{1}{3} & -4 & \text { NC } \\ \text { HS } & 39 & 5 \frac{1}{2} & -4 & \text { I } \\ \text { JH } & 43 & 5 & +3 & \text { NC } \\ \text { OH } & 50 & 5 \frac{1}{2} & +4 & \text { I } \\ \text { MEAN } & 47 & 4.4 & -00.50 & \end{array}$

A reduction in finger size in all cases.

\section{CHANGE OF EARNINGS IN STAGE 4 CASES.}

An analysis of gain or loss of earnings by Stage 4 cases has been made in one population in the survey. The question has been raised by the Council whether, when V.W.F. has reached Stage 4 (change of occupation) does the subject, when offered alternative employment, maintain his earnings? Again there are other factors involved such as age, work rate, opportunity for overtime and bonus schemes. It was decided in view of these variables to obtain the wages data from one factory - in this case the pedestal grinders at Cwmbran (See Table 4). Twelve of the 15 Stage 4 grinders on trasfer 


(5)

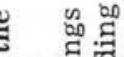

르를

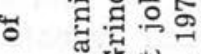

-

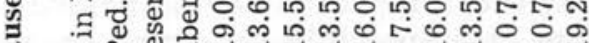

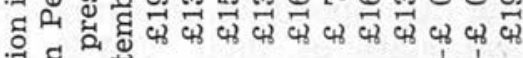

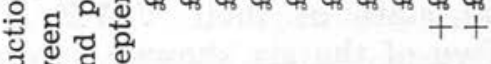

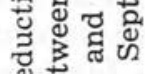

క

: ल

ठृ่

竎 究

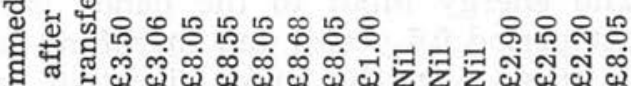

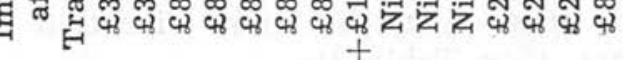

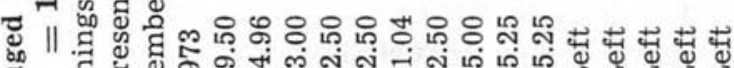

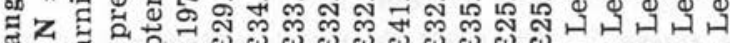
ल्ड ड़ ध

ن $\dot{0}$

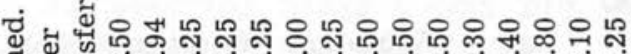
द

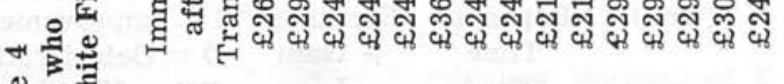
ค О Оิ Оิ 농

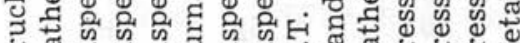

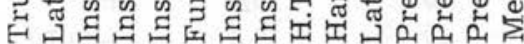

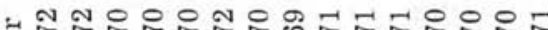

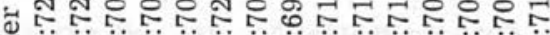

of $D *$

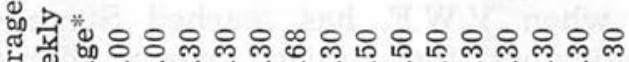

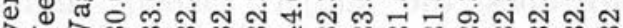

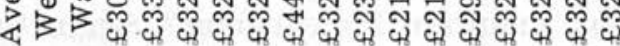


went on to reduced earnings, three maintained the same rate.

(1) Average weekly wage of 15 pedestal grinders before transfer to other employment

(2) Average weekly wage of the same 15 pedestal grinders immediately after transfer ... $£ 26.65$

Therefore average weekly reduction in earnings immediately on transfer ............

(3) Reduction in weekly earnings between present job (rate at September 1973) and pedestal grinding (rate at September 1973) $£ 12.07$

Note: Weekly rate for Pedestal Grinding (September 1973) is $£ 48.56$ whilst present earnings for Inspectors, Lathe operators, etc. is $£ 32-£ 35$.

(4) On transfer from pedestal grinding to other employment reduction in earnings per year

In the population of 19 Stage 4 chain saw operators, 12 had loss of earnings, 4 remained the same and 3 had an increase. The average weekly reduction in earnings for the whole group was $£ 4.60$ (annual reduction in earnings capacity of around £240).

\section{SUMMARY AND CONCLUSIONS}

1. The basic physiological process producing blanching of the digits in the early stages, and cyanosis in the late stages, is not known. It is likely that in Raynaud's phenomenon the process is biphasic with (a) functional overactivity on the part of the digital arteries enervated by the sympathetic nervous system, and with further exposure to vibration (b) subsequent hypertrophy and fibrosis of the digital arteries. In the past too much attention has been paid attempting to elucidate the 
complex physiology and pathology and too little attention to measurement of the stimulus.

2. Seven cases of advanced V.W.F. (i.e. Stages 3 and 4) have been examined in detail by two of the research team (W.T. and P.L.P.). The number of pure V.W.F. cases reaching tissue necrosis of the digits, is, as far as we are aware, very small and certainly in single figures. This finding, however, does not influence the view that this number will depend on the cumulative vibration dosage and the rate at which the vibration is fed into the hands. The main factors leading to serious disability are high energy vibration, long exposure time, the tightness of the grip and the susceptibility of the subject. There is no doubt that in the high energy situation in the pedestal grinding population, there has been found a process with disabling long term effects. Knowing the end result, it has been our object to first measure the stimulus and then to reduce the vibration to a safe level. We agree with one of the conclusions of the Industrial Injuries Advisory Council Interim Report (1970), that in the majority of cases the disablement is trivial. This conclusion will apply to the majority of hand-held vibratory tool populations, where the vibration is at or below the proposed vibration standard (Paper 10). It does not apply to three populations examined in this report (pedestal grinders, saw operators on old type saws, and swagers) where, if the vibration exposure had been continued for upward of 12-15 years, progressive arterial damage would have occurred resulting, in our view, in irreversible necrotic skin changes in the extremities of the digits. There would also have been increasing social, leisure and hobby interference. There will, even in the high energy work situations, be resistant or non-susceptible cases. It is thought that one of the factors determining susceptibility is variation in digital artery size, the larger the internal diameter, the longer the latent period and the more resistant the subject.

3. Of the 1,100 regular chain saw operators in the Forestry Commission (Britain), 19 (or 1.7\%) changed their jobs within the period 1970-1973 because of V.W.F. In the population of pedestal grinders, 15 (or 
$29 \%$ ) changed occupation. In the pedestal grinding population $(\mathrm{N}=51)$, there is available an accurate history of deterioration with regard to V.W.F. The vibration characteristics have also been studied in depth and there is no doubt that the high percentage ( $29 \%$ ) of Stage 3 progressing to Stage 4 is due to the intensity of the stimulus shown both by measurement and from the short vibration exposure time (mean exposure time -6 years). In the swagers, six (or $33 \%$ ) of the original 20 were transferred to other departments. The mean exposure time was again short (mean - 4.4 years).

The Stage 4 cases examined changed their occupation (a) at their own request with increasing V.W.F. signs and symptoms, (b) on the advice of the General Practitioner, or (c) the works medical officer advised rehabilitation for deteriorating Stage 3 cases.

It is not possible to put a percentage figure for Stage 3 - Stage 4 transfer as requested by I.I.A.C. The number for occupation transfer in any given works situation will depend on the vibration transfer to the hands and the exposure time with other less important variables also contributing.

It has been found that where the vibration characteristics are low and within the proposed standard, there are no Stage 4 cases (e.g. Leamington). At the other end of the scale is the Cwmbran situation where Stage 3 to Stage 4 may be as high as $30 \%$.

In the 827 vibration exposed subjects examined in this survey, there were 40 Stage 4 cases - (change of employment due to V.W.F.) $-4.8 \%$. When the 40 were questioned re V.W.F. on being withdrawn from vibration, 8 (or $21 \%$ ) had improved, 27 (or $71 \%$ ) showed no change and 3 (or $8 \%$ ) had deteriorated. A reliable answer could not be obtained from 2 subjects. Because of the small numbers of Stage 4 cases, the figures do no more than indicate a trend, but it is interesting to note that the 'cure rate' (i.e. the improved V.W.F. cases in the ex-vibration subjects) in the Stewart and Goda (1968) I.I.A.C. Report was $26 \%$ and this compares favourably with the $21 \%$ found here.

There is a clinical impression that the early Stages 1 and 2 of V.W.F. may show improvement on with- 
drawal from vibration but that in advanced Stage 3 cases and the majority of Stage 4 cases, the V.W.F. process is irreversible (see figure of $71 \%$ above). The question of reversibility is being pursued prospectively in the chain saw population at Thetford.

5. Stage 4 cases from the pedestal grinding population and the chain saw operators were examined, after occupation transfer, with regard to gain or loss of earnings. There was an average weekly reduction in earnings immediately on transfer of $£ 4.17$ (reduction applied to 14 out of a total of 15). Because a wage differential between pedestal grinding and other occupations within the factory has arisen, the reduction in weekly earnings between the present occupation (rate September, 1973) and pedestal grinding (rate September, 1973) is now $£ 12.07$ or approximately $£ 628$ per annum.

In the case of chain saw operators with a total of 19 Stage 4 cases, 12 had decreased earnings, 4 remained the same and 3 had increased earnings. The average weekly reduction in earnings of the 12 was $£ 4.60$ or $£ 240$ per annum.

An attempt was made to follow up by postal questionnaire Stage 4 cases who, it was reported to management, had left employment because of V.W.F. This exercise was abandoned due to a low response rate and the increasing cost of postal charges. Furthermore we were dealing with selected cases where motives other than V.W.F. may have been the reason for leaving the job. 


\section{Correlation of \\ Epidemiological Data and the Measured Vibration}

\section{W. TAYLOR, P. L. PELMEAR, T. I. HEMPSTOCK, D. E. O'CONNOR and R. KITCHENER}

\section{INTRODUCTION}

The published work on vascular disturbances of the fingers of occupational origin clearly demonstrates that vibration is a factor common to all outbreaks. The hardness of the materials has also been mentioned (Seyring, 1930). The strength of the men's grip has been considered (Hamilton, 1918; Bridge and Middleton, 1925). The length of the working day or the exposure time is a relevant factor (Taylor et al, 1971). At first the physical characteristics of the stimulus attracted little attention but Leake (1918) estimated the primary vibrations from limestone cutting tools at $50-60 \mathrm{~Hz}$. with harmonics $110-180 \mathrm{~Hz}$. Gerbis (1931) found tools in the shoe trade with vibrating frequencies of $280-600 \mathrm{~Hz}$. producing Raynaud's Phenomenon rapidly. Hunt (1936) found riveting hammers working at $40 \mathrm{~Hz}$. and weighing $13 \mathrm{lbs}$. Cummins (1940) quoted figures around $40-50 \mathrm{~Hz}$. and asserted that tool speeds beyond 40 $\mathrm{Hz}$. were hazardous. Hunter (1945) studied populations using tools of different speeds and concluded that frequencies of $30-50 \mathrm{~Hz}$. would be best avoided.

As well as a frequency parameter, earlier authors recognised the necessity to measure amplitude and to accept that hand vibratory tools transmit through the handles or barrels complex wave forms. These consist of a fundamental frequency of fairly large amplitude, upon which are superimposed harmonics of progressively rising multiples and 
decreasing amplitudes. Agate and Druett (1946 and 1947) examined the vibration characteristics of a representative collection of tools working under normal conditions (rock drills, road rippers, riveting, chipping and scaling hammers, polishing and grinding rotating tools) and attempted to correlate the findings with the clinical lesions produced in the subjects. They concluded that vibrations of large amplitude between the frequencies of $40-125 \mathrm{~Hz}$. are responsible for Raynaud's Phenomenon with frequencies over $600 \mathrm{~Hz}$. being unlikely to be harmful. Axelsson (1968) extrapolating from chain saw vibration data, proposed a safe limit of 80 microns within the frequency range 50 to $500 \mathrm{~Hz}$. These threshold curves were "U" shaped with higher amplitude levels for injury risk compared with the thresholds

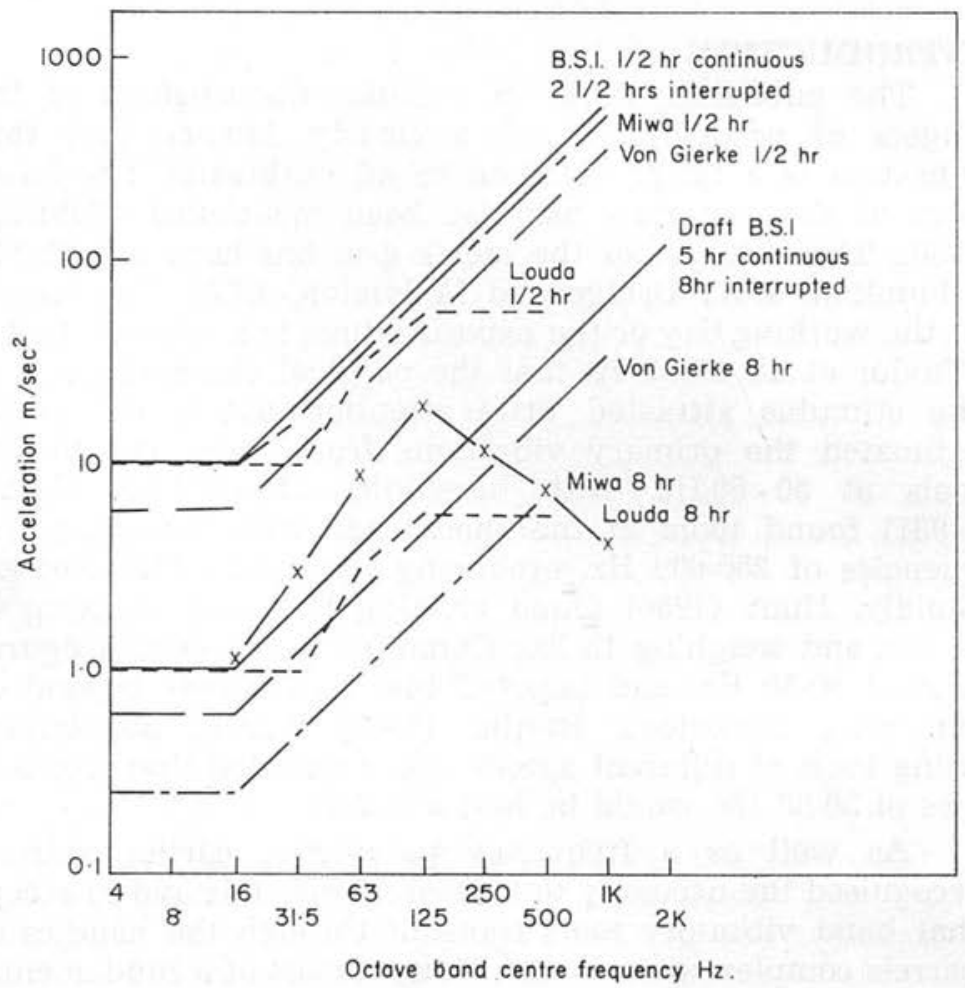

Fig. 1. Proposed standards for hand-arm vibration 
for fingers in a non-vibration exposed population. In 1969 a Czechoslovakian vibration standard was adopted in Europe, the shape of the curve being relatively flat and the maximum permissible values of vibration exposure to the hands for a period of eight hours being (all acceleration values r.m.s m/sec. ${ }^{2}$ ) 1.0 at $8 \mathrm{~Hz} ., 5.63$ at $250 \mathrm{~Hz}$. and 5.63 at $500 \mathrm{~Hz}$. In 1971 Von Gierke combined criteria proposed by the U.S.S.R., Czechoslovakia and Japan for an I.S.O. Working Group. (Fig. 1).

It will be noted that from $4 \mathrm{~Hz}$. to $16 \mathrm{~Hz}$. (octave band centre frequencies) the curve is flat, and from $31.5 \mathrm{~Hz}$. to $2 \mathrm{kHz}$. the slope is approximately $45^{\circ}$. This indicates a decreasing risk of V.W.F. with increasing frequency. The low frequency component (i.e. from 8 to $63 \mathrm{~Hz}$.) appears to be more hazardous than the range $125 \mathrm{~Hz}$. to $2 \mathrm{kHz}$.

The object of this paper is to attempt to correlate the epidemiological data from seven populations with the measured vibration characteristics of the tools used by each population.

\section{VIBRATION MEASUREMENT}

\section{Chain Saws}

In Paper 2 it was shown that with the introduction of anti-vibration modifications, the increasing prevalence of V.W.F. observed with the old types of saws had been halted and there was evidence from two forests that the V.W.F. position was improving. A prospective study is now in progress on subjects exposed only to $A / V$ saws. When we compare the vibration characteristics of the old and the new $A / V$ saws there is a marked and significant improvement with a clear reduction in vibration levels above 100 $\mathrm{Hz}$. The vibration data for two saws is seen in Fig. 4, Paper 8 and in Fig. 2 below are shown data for 2 old type saws and $2 \mathrm{~A} / \mathrm{V}$ models. (Data supplied by Mr Keighley of Forestry Commission).

It should be noted that there are variations in vibration levels between different makes of saws particularly at frequencies above $100 \mathrm{~Hz}$. Furthermore if we superimpose the B.S.I. Draft vibration standard on the same graph (Fig. 1 ), then the new $\mathrm{A} / \mathrm{V}$ saws lie between the $270-400$ minutes vibration per day from $200 \mathrm{~Hz}$. upwards. The average exposure time per man shift is in the area 300-350 minutes. 


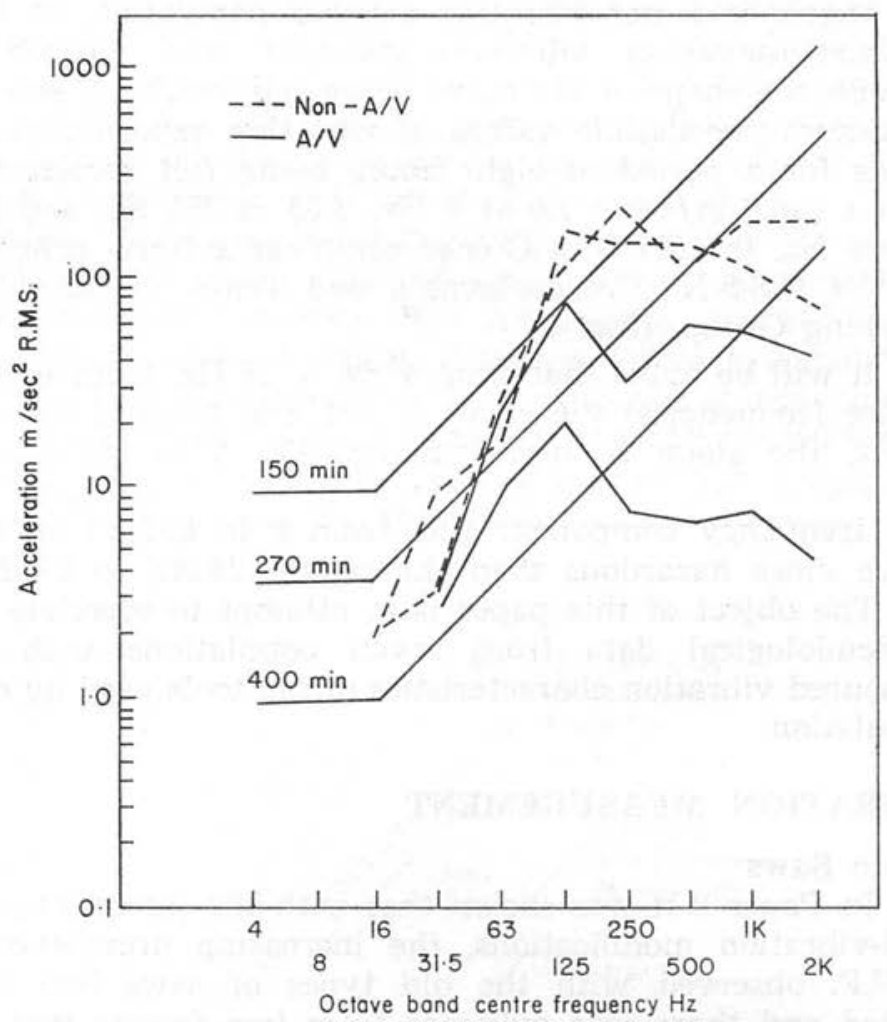

Fig. 2. Vibration data for non- $\mathrm{A} / \mathrm{V}$ and $\mathrm{A} / \mathrm{V}$ chain saws

\section{Pedestal Grinding}

Obtaining reliable vibration spectra from castings during hand-grinding has proved to be difficult and the characteristics more complex than at first thought. Four research teams have surveyed and measured this process. The fundamental vibration problem at issue is whether there are spectra differences between the soft "black" wheel in the grey iron foundry and the zirconia wheels in use in the malleable foundry.

University of Southampton (November 1969) "In general the results show that the vibration levels produced by 'soft' wheels, whether being used at 9500 surface f.p.m. on the old machines or at 16,000 surface f.p.m. on the new high speed 
Rowlands machine, are less hazardous than the levels produced by the 'hard' wheels."

National Engineering Laboratory, East Kilbride. (May, 1972).

"From these results it is possible to draw the following general conclusions. It does appear that the vibration levels in ' $g$ ' values for the 'black' wheel tend to be greater than those for the 'zirconia' wheel. There is no distinct difference in the spectral patterns for the 'black' and 'zirconia' wheels, nor were there any particular frequencies which could be related to either wheel. The predominant frequencies tended to be of 'high' orders with no components of any significance occurring in the 'vibration sensitive' region. When comparing the velocity values for the 'high' and 'low' order frequencies the actual values are of comparable magnitudes; whereas the relative displacements are higher at the 'lower' frequencies. It should be noted that similar amplitudes and frequencies exist for both wheels. The results do not, therefore, indicate the dramatic differences which were expected in view of the statements relating to the incidence of damage before and after the introduction of the current type of grinding wheel. This leaves a very problematic situation where either the theories or deductions regarding the incidences were incorrect or not fully investigated, or that some other factors are affecting the operators. This now leaves the problem of ascertaining if any of the predominant frequencies are significant in relation to the damage."

G.K.N. Group Technological Centre. (Nov., 1972)

Report from Mr R. Kitchener.

"While the levels of acceleration are subject to considerable variation from casting to casting and between one operator and another, two broad trends can be seen in the results -

(a) The smaller the wheel eccentricity, the lower the vibrations particularly at the low frequency end where they are most harmful. 
(b) The softer the abrasive bond, the lower the vibration."

University of Salford. (1972, 1973).

Report from T. I. Hempstock and D. E. O'Connor,

(a) A $200 \mathrm{~m} . \mathrm{m}$. die casting on a 'hard' zirconia wheel gave higher accelerations than the same casting on a 'soft' wheel. (Paper 8, Fig. 5).

(b) The 'harder' wheels are more likely to become non-circular and produce larger low frequency vibration.

(c) The vibration levels with large castings (400 m.m.) are lower than on the same wheel with smaller castings (200 m.m.). (Paper 8, Fig. 6).

During the course of the above vibration measurements, the methodology and techniques have been improved

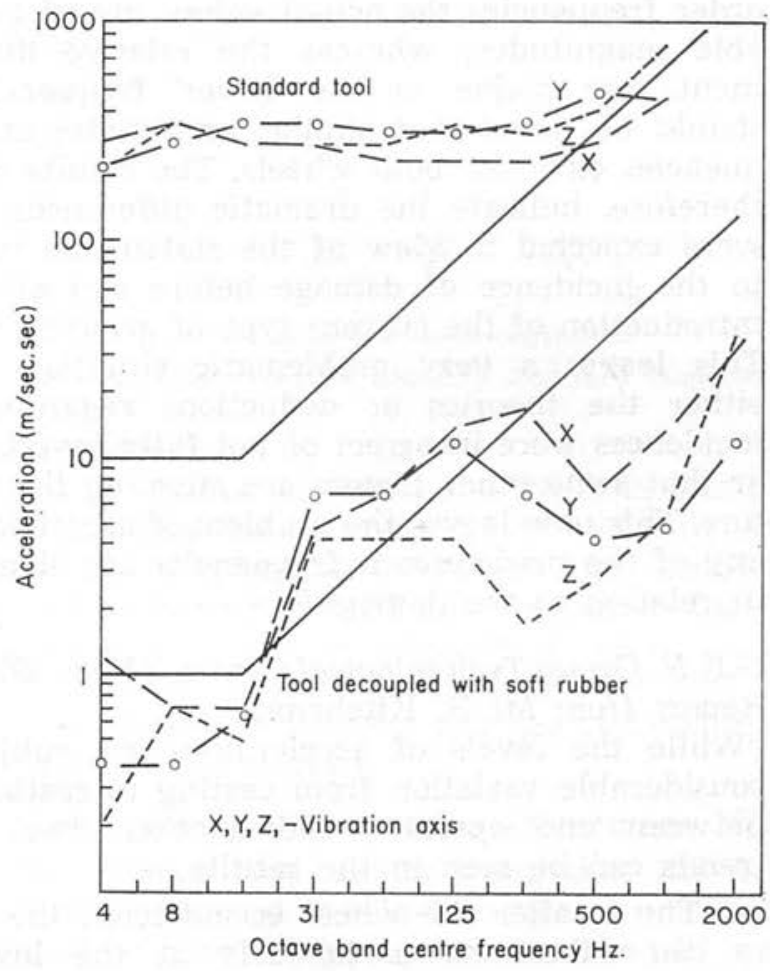

Fig. 3. Vibration data for wheel trimming operations 
and developed. This is probably one of the factors to explain the different conclusions of the N.E.L. team compared with the other three groups. The first team (Southampton) used accelerometers with a sound level meter and octave band analyser. The second team (N.E.L.) used accelerometers with a U.V.L. recorder. The third and fourth teams (G.K.N. and Salford) used accelerometers, a sound level meter with a digital event recorder in order to process short duration signals (approx. 10 secs.) and this technique was particularly useful for evaluating low frequency components. All measurements revealed very high vibration levels for the wheel trimming operation (Fig. 3) with values around $100-200 \mathrm{~m} / \mathrm{sec}^{2}$. It was also noted that the grinders in the grey iron foundry (soft, black wheels) trimmed with the trimming tool anchored to a base plate whereas in the malleable foundry (zirconia wheels) the grinders held the

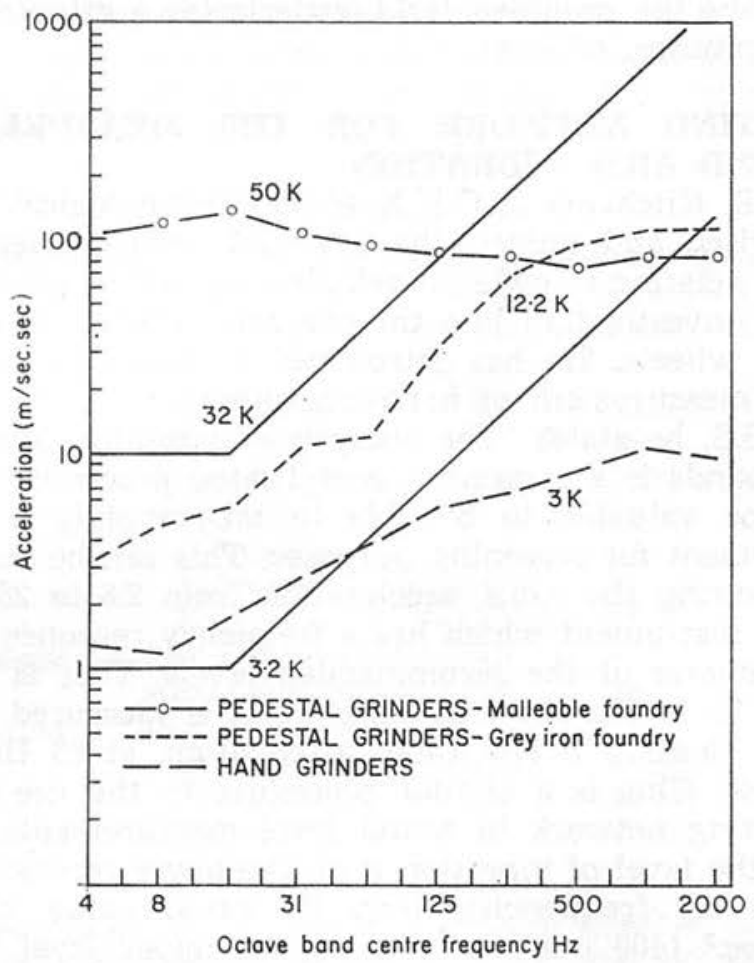

Fig. 4. Vibration data for pedestal and hand grinding operations 
wheel trimmer free. The former fixed trimming technique markedly reduces the wheel eccentricities.

In summary there is sufficient data to support the view that the vibration levels were higher in the malleable foundry due to a combination of factors:

(a) the firmer bonding medium of the grind wheels,

(b) the size of the castings - smaller and more force required in malleable,

(c) the trimming operations which failed to remove eccentricities,

(d) the harder metal in the malleable foundry,

(e) the work load.

If the measured vibration levels are now set against the B.S.I. Draft Standard for Hand-arm Vibration, it is seen that the differences are more marked over the lower frequency range and that the malleable foundry zirconia wheels are well above the proposed B.S.I. criteria for a grinding time of 301 minutes. (Fig. 4).

\section{WEIGHTING NETWORK FOR THE MEASUREMENT OF HAND-ARII VIBRATION}

Mr R. Kitchener of G.K.N. Group Technological Centre has advised and guided the vibration measurement programme relating to pedestal grinding, as well as conducting his own investigation into the characteristics of black and zirconia wheels. He has introduced a weighting network for the measurement of hand-arm vibration. In his report to D.H.S.S. he states "The analysis of vibration into these octave bands is a somewhat complicated procedure and it would be valuable to be able to take rapidly a single measurement for screening purposes. This can be achieved by measuring the r.m.s. acceleration from 2.8 to $2800 \mathrm{~Hz}$. with an instrument which has a frequency response which is the inverse of the recommended levels. That is to say that up to $16 \mathrm{~Hz}$. the true r.m.s. level is measured but at $31.5 \mathrm{~Hz}$. there is a two times attenuation, at $63 \mathrm{~Hz}$. four times, etc. This is a similar procedure to the use of the A-weighting network in sound level measurements.

"If the level of vibration is on the lower recommended level at all frequencies, then its r.m.s. value will be $3.2 \mathrm{~m} / \mathrm{sec}^{2}$ (400 minutes) and on the upper level it will be $32 \mathrm{~m} / \mathrm{sec}^{2}$. (150 minutes). (See Fig 4). However, if the 
vibration is concentrated into a smaller frequency range these values of acceleration will be given by vibrations which exceed the recommended levels. This error, however, will not be significant unless the frequency range is very small - an unlikely situation in practice - and in any case a similar situation is accepted with A-weighted sound measurements." To distinguish this weighted unit for vibration from the ' $A$ ' weighting used in noise, the vibration unit will henceforth be referred to as the ' $\mathrm{K}$ ' weighting (in metres per sec. ${ }^{2}$ ).

\section{CORRELATION OF VIBRATION MEASUREMENTS AND LATENT INTERVAL BY OCCUPATIONAL GROUPS}

As an indication of the risk of V.W.F. and a measure of the rate of cumulative vibration dosage, the latent interval has been used. This indication is then compared with both the linear vibration and the one figure $\mathrm{K}$ weighting. The results are shown in Table 1 for two populations of chain saw operators, three populations of grinders, a population of nobblers and finally, the copper tube swagers.

\section{Table 1}

Latent Interval and Linear ( + K-weighted) Vibration Measurements

Population

Thetford

Dumfries

Cwmbran

Bromsgrove

Leamington

Rosyth* Liverpool
Process

Latent Interval (in yrs.)

Non $\mathrm{A} / \mathrm{V}$ Saw

A/V Saw

Non A/V Saw

A/V Saw

Ped. Grinders

Soft Wheel

Zirconia

Ped. Grinders

Hand Grinders

Ped. Grinders

Soft Wheel

Zirconia

Nobblers

Swagers
2.8

- 15-25

3.0

$\begin{array}{cc}\text { Not known } & 100 \\ 1.8 & 125 \\ 4.5 & - \\ 13.7 & 20\end{array}$

14.0

$-$

16.5

0.6
150-350

35-50

Vibration $\left(\mathrm{m} / \mathrm{sec}^{2}\right)$

Linear K-weighted

$150-350 \quad 10.0-25.0$

2.5-3.5

$10.0-25.0$

4.0-6.5

*This population had a discontinuous work schedule, namely one week nobbling followed by one week painting, etc. One week's vibration exposure in two weeks. 
The comparison of latent interval and the single unit $\mathrm{K}$-weighted vibration is shown in Table 2 and Fig. 5.

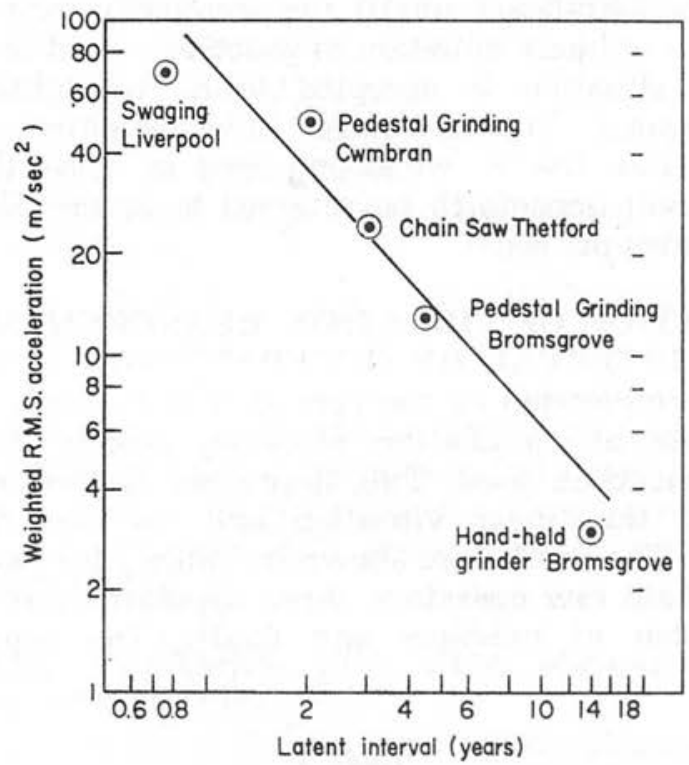

Fig. 5. Correlation of vibration data and latent interval

Table 2

Latent Interval (years) and K-weighting by Occupation Groups Population

1. Swaging

Latent Interval K-weighting (Years) $\mathrm{m} / \mathrm{sec}^{2}$

2. Pedestal Grinding (Cwmbran)

0.6 70

3. Chain Saw

$1.8 \quad 50$

4. Pedestal Grinding (Broms-

2.8

25 grove).

5. Hand Grinders (Bromsgrove)

4.5

12.2

13.7

3

\section{CONCLUSIONS}

1. There is a negative association between the latent interval (in years) and the linear and $\mathrm{K}$-weighting vibration measurements.

2. It is recommended that H.M. Factory Inspectorate (Engineering Division) become conversant with the B.S.I. Proposed Draft Standard for Hand-arm Vibratory Tools. 
It is further suggested that a Code of Practice for Vibration be drawn up for the guidance of tool designers and management.

3. There is a need for further research to correlate vibration measurements and latent intervals so that more clinical evidence may be obtained to quantify damage risk vibration criteria. 


\section{Hand-arm Vibration- British Standards Institution Draft for Development}

G. D. KEIGHLEY

A Draft for Development is nearly ready for publication by British Standards Institution. Published February, 1975. Guide to the evaluation of exposure of the human hand-arm system to vibration. British Standards Institution, London. Draft for Development DD 43:1975. The target date is early in 1975. It can be summarised as follows:

1. A uniform method of measuring is proposed and should be adopted by industry, inspectorates and research establishments. Working conditions, weight of machine, etc., will be recorded.

2. The vibration will be recorded at each hand in three mutually perpendicular directions by octave band centre frequencies from 4 to $2000 \mathrm{~Hz}$ for acceleration in metres per second per second.

3. The actual exposure time per day will be assessed for each industrial work situation where either hand is subject to vibration.

4. The highest vibration level for each octave band and exposure time will be compared with the vibration/ exposure graph (Figure 1).

(a) Levels between the 150 and 400 minute exposure lines which are approximately in proportion to the exposure time are not likely to cause vibrationinduced white fingers (V.W.F.). Vibration below the 400 minute line for exposure less than 400 minutes will not cause V.W.F. 
(b) Levels close to the 150 minute line with exposure times greater than 150 minutes are likely to cause V.W.F.

(c) Levels above the 150 minute line with exposure of more than twenty minutes continuously per day or more than sixty minutes spread over the day are also likely to cause V.W.F.

5. Medical checks are recommended wherever vibration exposure is found to be at V.W.F. danger levels (4(b) and (c) above).

6. B.S.I. will provide a focal point for all information on hand vibration findings for industrial, engineering and medical aspects and the Draft for Development lists all the factors which should be noted when reporting these findings. The Draft will be reviewed and revised in the light of experience at two-year intervals until it is precise enough to become a Standard.

7. The B.S.I. Panel who prepared the Draft and who will continue to serve on the Monitoring Panel include $\mathrm{Mr}$ Keighley as chairman and Messrs Kitchener, O'Connor and Professor Taylor (Dr James) as members.

8. $\mathrm{Mr}$ Keighley is also a member of the International Standards Organisation Working Group which has prepared a "Guide for the Evaluation of Human Exposure to Hand-transmitted Vibration" (ISO/TC108/ SC4/WG3) for submission to its Sub-Committee (TC108/SC4). The Guide is expected to be circulated to member countries for approval during 1974 and to be published in 1975. It is similar to the B.S.I. draft.

9. Comment. The Factory Inspectorate have the measuring equipment and could obtain the expertise to enable them to check all work situations where hand vibration is occurring. Any operators using machines which are above the recommended safe vibration levels could be referred to the Employment Medical Advisory Service so that V.W.F. cases could be identified. Exposure time per day could be reduced for V.W.F. cases and/or their machines could be modified to reduce vibration levels so that these would be less than the exposure/vibration safe limits in Figure 1.

10. An Example. Chain Saws used in the Forestry Commission (Fig. 1 Chain Saws). The 1100 regular chain 


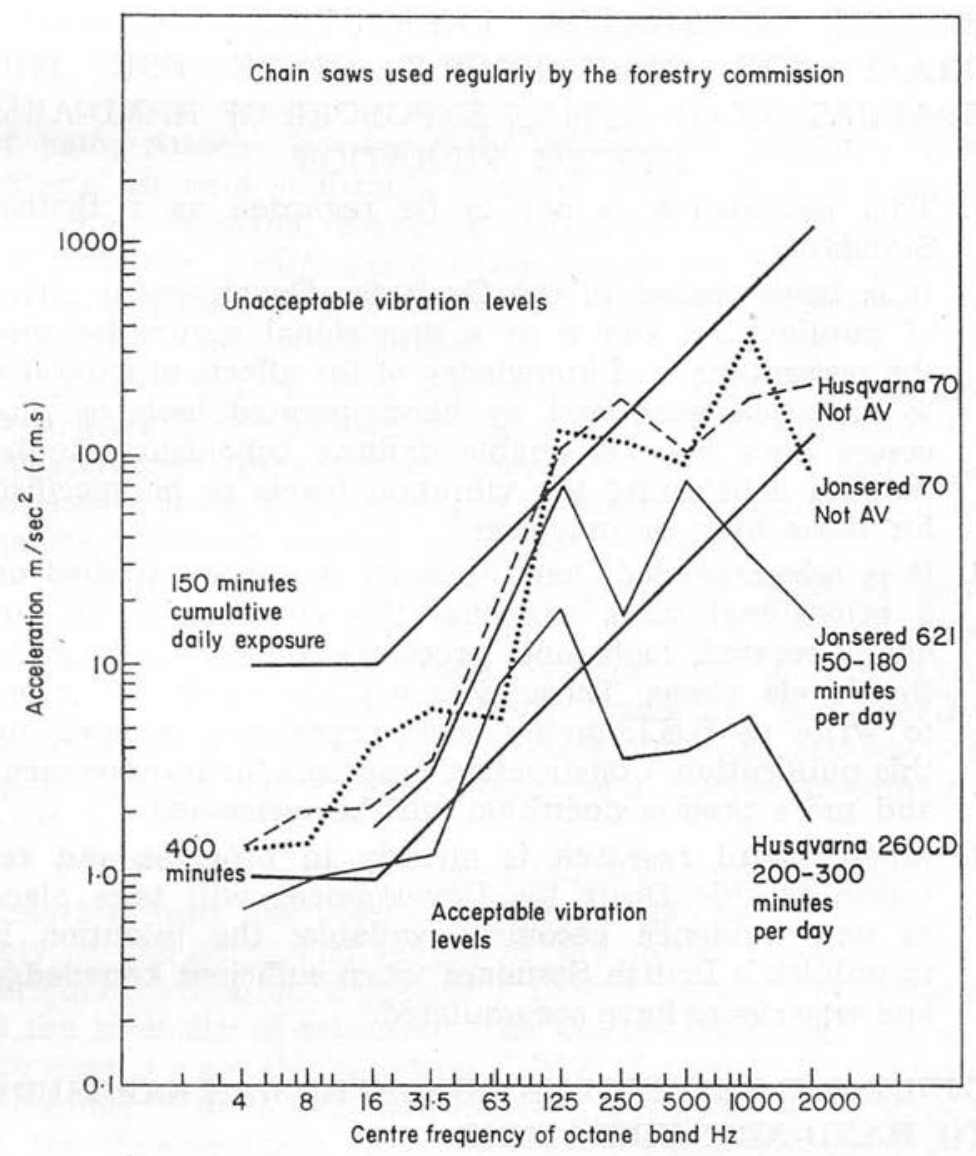

Fig. 1. Recommended hand-arm vibration exposure limits for regular users (the saw graphs are taken from the highest reading on either handle for each octave band)

saw operators were issued with vibration damped saws in 1970; these saws are within the 150 to 300 minute levels of vibration and it has not proved necessary to change the working system: V.W.F. damage caused by earlier types of chain saw has been halted and improvement is occurring. The earlier types of saws which caused V.W.F. are above the vibration limits (Figure 1) for 150 minutes and it is significant how critical the 150 minute line is up to $250 \mathrm{~Hz}$. 
BRITISH STANDARDS INSTITUTION PROPOSED DRAFT FOR DEVELOPMENT GUIDE FOR THE EVALUATION OF HUMAN EXPOSURE OF HAND-ARM SYSTEM VIBRATION

1. This publication is not to be regarded as a British Standard.

2. It is being issued in the Draft for Development series of publications and is of a provisional nature because the present state of knowledge of the effects of exposure to vibration generated by hand-operated tools or processes does not yet enable definite conclusions to be reached concerning the vibration levels to be specified for those tools or processes.

3. It is recommended that the draft should be applied on a provisional basis and that the vibration levels for hand-operated tools and processes should conform to the levels given. Those who use the draft are urged to write to B.S.I. giving their experience in applying this publication. Constructive proposals for improvement and more precise definition will be welcomed.

4. Much useful research is already in progress and revision of this Draft for Development will take place as new evidence becomes available; the intention is to publish a British Standard when sufficient knowledge and experience have accumulated.

\section{GUIDE FOR THE EVALUATION OF HUMAN EXPOSURE TO HAND-ARIM VIBRATION}

\section{Introduction}

\section{General}

If the hand is subjected to vibration, either when holding a power tool or when holding material which is vibrating, after a period the fingers become liable to attacks of blanching. The descriptive term "Vibration-induced White Finger (V.W.F.)" used by the Industrial Injuries Advisory Council in the recent Interim Report on Vibration Syndrome*, has been adopted for this draft.

*"Vibration Syndrome" (1970). Interim Report by the Industrial Injuries Advisory Council. Department of Health and Social Security. Cmnd. 4430, H.M.S.O., London. 
During attacks of V.W.F., which may last up to an hour, there is a loss of sensation in the affected fingers. The recovery phase is characterised by varying degrees of pain. Attacks are typically induced by handling cold objects on cold mornings and are rarely seen during a period of vibration exposure unless the work is in cold surroundings. Symptoms develop first in the tips of fingers applying pressure to the tool or material, extending in time to the whole of the finger.

Approximately $10 \%$ of the aduit male population experience minor infrequent episodes of White Finger without significant exposure to vibration; in a very small proportion of these the occurrence of White Finger is the first manifestation of serious progressive disease.

Exposure to vibration in industry may produce prevalence rates of V.W.F. as high as $100 \%$, most cases resulting in social disablement rather than a restriction of the ability to work. However, cases are occasionally encountered where there is considerable impairment of hand function which may necessitate a change of employment.

V.W.F. does not result from the casual use of vibrating tools but from the regular prolonged use normally found only in industry. The length of the initial symptom-free period of vibration exposure ("Latent period") is related to the intensity of vibration. The shorter the latent period, the more severe the resulting V.W.F. if vibration exposure continues. Present evidence suggests that in the early stages of the disease some recovery occurs when vibration exposure ceases. However, in the severe forms, the condition either remains static or gradually deteriorates.

Despite considerable research, little is known about how the attacks are caused but evidence is accumulating that in the severest forms of the complaint there are changes in the arteries and nerves of the fingers. The association of vibration exposure with other disorders, e.g. of bones and joints, is not proven and further research is in progress.

\section{Basis of the Guide}

Although it is not yet possible to determine precisely the vibration factors which are most significant in regard 
to this disease, it is nevertheless necessary to give guidance to designers and manufacturers so that they may be aware of the extent to which they should try to reduce vibration levels without either making tools too heavy or bulky to operate efficiently or giving rise to excessive increase in costs.

This guide has accordingly been prepared but it should be emphasised that the data on which the recommended limits are based are taken from determinations of vibration sensation levels supplemented by the results of industrial experience in this country and of considerable information from abroad. The vibration "dose" to which a man has been subject has proved difficult to assess with changing tools and work patterns and varying grip and vibration levels over a work cycle and is thus difficult to relate reliably to the objective response of symptoms of disease (the "dose-response" relationship). In spite of this, there is reason to believe that adherence to the vibration levels given in this document will result in a considerable decrease in the incidence of V.W.F. although it is not proven that adherence to these limits will prevent vibration diseases over the working lifetime of a regular user.

It is also important for employers, operators of the tools and medical experts to be able to understand the level of reduction in vibration and the working methods which are required to minimise the effect of the residual vibration.

It is hoped that this guide will help to clarify the situation for those concerned with the problem and encourage monitoring so that, if the onset of V.W.F. is observed, operators may be transferred to other work before the condition becomes irreversible. This would be of particular value in the case of the few operators who may be especially susceptible to injurious effects from vibration even though it is well within the limits recommended in this guide. (See the third paragraph of the preamble to the guide).

\section{Scope}

This Draft for Development gives recommended maximum values for vibration transmitted to the hands during an eight-hour working day (see clause 3 ). The levels on which these values are based are stated and recommended 
methods of measurement are described. Appendices cover the information which it is thought should be recorded by those carrying out research in this field and measures which can be taken to reduce the incidence of vibration injury to workers exposed to it.

Note 1. Those responsible for formulating this Draft for Development have given full consideration to work being carried out under the auspices of an I.S.O. Committee to which experts from Czechoslovakia, Japan, Sweden, the U.S.A. and other countries have contributed.

Note 2. There may be risks in applying the recommended levels to impulsive vibration but users are urged to measure and record it wherever practicable in order to provide information which may enable guidance to be given in the future.

\section{Recommended Limits of Vibration}

Factors of primary importance in determining the risk of V.W.F. include intensity (acceleration), frequency, duration of exposure to vibration and the susceptibility of the individual.

\section{Acceleration}

Acceleration is recorded as the root mean square value in metres per second per second ( $\mathrm{rms}$ in $\left.\mathrm{ms}^{2}\right)$.

\section{Frequency Range}

The frequency range concerned is divided into octave bands with the following centre frequencies, $4,8,16,31.5$, $63,125,250,500,1000$ and $2000 \mathrm{~Hz}$.

\section{Duration of Exposure}

Duration of exposure is the measured or estimated time when the operator is exposed to vibration during a normal working day of a five-day week in a normal year. In practice, given the normal breaks through the day, the cumulative exposure is unlikely to exceed 400 minutes. In many operations there will be longer interruptions to the vibration exposure and the measurement of the actual exposure time will become increasingly important. It is expected that a regular user in industry will be subject to at least 150 minutes cumulative exposure per day. 
Susceptibility

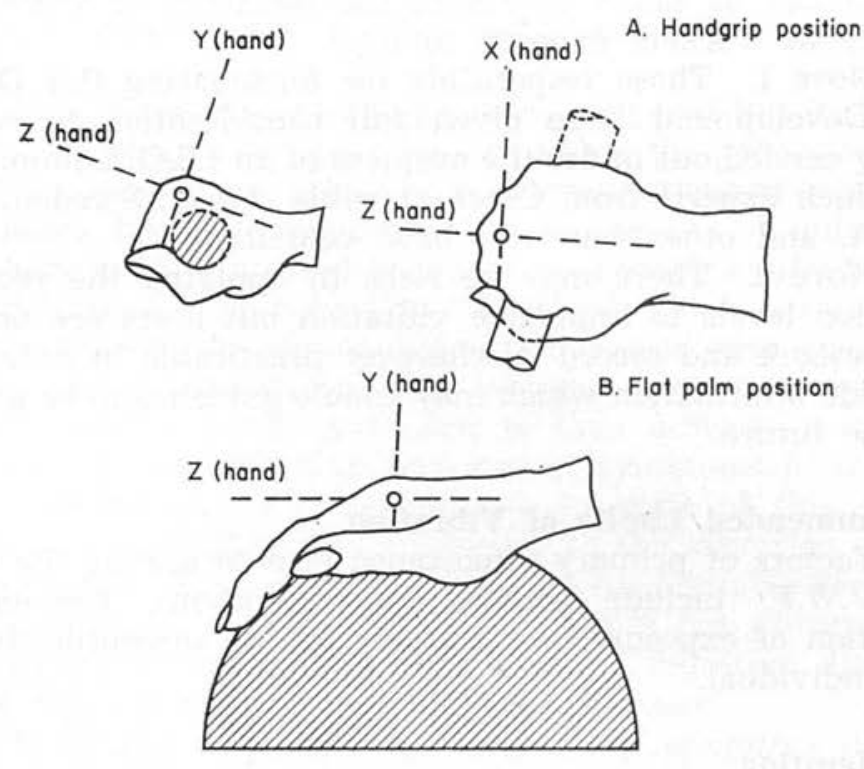

Fig. 2. Co-ordinate system for the hand. A. In the "handgrip" position (standardised grip on a cylindrical bar of radius $1 \mathrm{~cm}$ ). B. In the "flat palm" position (hand pressed onto bar of radius $5 \mathrm{~cm}$ ). The origin of the system is deemed by the longitudinal axis of that bone

See last paragraph of 1.2 and 3.5 .

Recommended Vibration Exposure Limits

Recommended vibration limits are given in Table 1 and apply to any of the three directions of a chosen rectangular co-ordinate system independently measured as near as possible to the hand (see Fig. 2).

\section{Recommended Method of Measuring Vibration}

This clause describes the recommended method of measurement. Details of a screening method which may be used when more elaborate facilities are not available are given in clause 5 . 


\section{Table 1}

\section{Recommended Vibration Exposure Limits} 1

Octave centre frequency

$\mathrm{Hz}$

4
8
16
31.5
63
125
250
500
1000
2000

$$
2
$$

Maximum permissible rms values

$$
\text { of acceleration }\left(\mathrm{ms}^{2}\right)
$$

400 minutes in an Cumulative total of eight-hour day 150 minutes in an eight-hour day
10
10
10
20
40
80

160

320

640

1280

NOTE: The values in column 3 should not be exceeded by regular users.

Mounting of Accelerometers

(1). The vibration should be measured using an accelerometer mounted rigidly to the vibrating surface as close to the hand as possible. If there is a resilient material between the hand and the vibrating surface (e.g. a glove or rubber handle) the transmission characteristics of this material must be determined and the vibration level at the hand calculated.

(2). Alternative Merhod. The accelerometer may be mounted on a suitably formed thin sheet placed in contact with the hand so that it is between the hand and the vibrating surface.

\section{Analysis of Vibrating Signals}

(1). Preferred Method. The signal from the accelerometer should be amplified and then recorded on a suitable tape recorder. The frequency response of the system should be flat to within $+2 \mathrm{~dB}$ in the frequency range $2 \mathrm{~Hz}$ to $3000 \mathrm{~Hz}$.

The recorded signal should be analysed into octave band levels (for the ten octave band centre frequencies from $4 \mathrm{~Hz}$ to $2000 \mathrm{~Hz}$ ). The measurement of the signal 
level within each octave should be achieved by the use of a device that has a long integration period and indicates the 'true rms' value of the signal (e.g. a true rms meter with "slow" damping).

If the duration of the vibration is short (less than 30 seconds) then a tape loop should be formed. Alternatively, true integration of the complete signal may be used to obtain the mean square level.

(2). Alternative Method. The amplified signal from the accelerometer may be fed directly into the octave band filter with an rms meter set to at least "slow" damping. The levels in the octave bands are then determined sequentially.

\section{Calibration of Vibration Measurement Systems}

A known level of vibration at a frequency between $4 \mathrm{~Hz}$ and $2000 \mathrm{~Hz}$ should be fed through the systems and recorded on the tape recorder before beginning the series of measurements. When using the alternative direct measurement method the known level should be fed to the amplifier and meter.

\section{SCREENING METHODS USING A SOUND LEVEL METER}

These methods can be used when more elaborate facilities are not available. No special equipment is necessary and the technique requires only items which are readily available commercially.

Ideally it is necessary to use a sound level meter which has a frequency response extending down to $2 \mathrm{~Hz}$ : limited information is possible from an instrument whose response does not go below $20 \mathrm{~Hz}$. In either case an octave band analysis in the bands from $3.15 \mathrm{~Hz}$ to $20 \mathrm{kHz}$ is necessary.

An accelerometer is mounted rigidly to the vibrating surface and connected via the appropriate cable and coupling to the input stage of the sound level meter. The instrument is set in its "slow" mode and the level in each of the octave bands is determined in the usual way. The sound level meter is calibrated with a known sound source and the reading can be converted to acceleration.

If the levels found by this method are all below the 
recommended limits, on present knowledge, fuller analysis is only required if any case of V.W.F. has occurred.

An alternative approach now being developed is to make use of a sound level meter with a frequency range from 2 to $2000 \mathrm{~Hz}$ and a weighting network whose response is the inverse of the recommended limits. This will enable the magnitude of the vibration to be specified in terms of a single figure. However, the level measured will be underestimated if the vibration is concentrated into three octave bands.

\section{INFORMATION TO BE RECORDED IN RESEARCH REPORTS}

Various factors affect the incidence and severity of the condition of Vibration-induced White Finger and it is recommended that at least the following particulars should be recorded for every study of the subject:

(a) The vibration levels and frequency content of the vibration. These should be measured in octave bands with centre frequencies from $4 \mathrm{~Hz}$ to $2000 \mathrm{~Hz}$, covering the range from $2.8 \mathrm{~Hz}$ to $2800 \mathrm{~Hz}$. Vibration levels or a range of levels in $\mathrm{ms}^{2}$ rms should be specified in each octave band for each of the three mutually perpendicular directions (see clause 3 and Fig. 2) for each hand.

(b) The complete work pattern should be specified, based upon work study principles, i.e. vibration levels/ frequency content should be given for each part of the timed work cycle, together with durations and frequency of rest spells. The proportion of time that a tool is held idling in the hand should also be given. This pattern should be quantified for a typical daily exposure and extended to give the normal weekly and annual exposure for each man.

(c) The type of vibrating machine, hand tool or process should be stated; in the case of a hand tool, the weight should be given.

(d) The posture of hand, arm and body during exposure (angle of wrist, elbow and shoulder joints) should be indicated and it should be stated whether the exposure relates to one or both hands.

(e) Details should be given of any precautions taken by 
the employer or operator which alter the effect of vibration, e.g., use of gloves, anti-vibration pads or handles.

(f) Smoking history.

(g) Details should be given of the climatic environment in which the operator is working, e.g. open air, in a mine or quarry, inside open sided or closed buildings. Temperature, humidity and air movements should be specified where appropriate and it should be stated whether the operator is subject to working in wet processes or in rain.

(h) Wherever possible, measurements should be given for the grip of the hand as this determines the force of vibration on the hand/arm system.

\section{MEASURES WHICH MAY HELP TO REDUCE THE INCIDENCE OF VIBRATION INJURY}

\section{The Operator and His Working Environment}

(a) Before an operator is engaged for employment entailing exposure of the hands to vibration, he should be asked if he has ever suffered from "dead fingers" or fingers that easily go white or blue on exposure to cold.

(b) Because cold hands are more susceptible to vibration damage than warm hands, warmth should be achieved before work starts by good central body warmth which results in good blood circulation to the hands. Do not use the work as a means of warming up.

(c) The indoor working temperature should be high enough to maintain the whole body and hand warmth in relation to the physical effort required for the operation. Where strenuous physical activity is necessary, the working temperature will be relatively low and suitable gloves should therefore be provided to maintain adequate warmth for the hands.

(d) For outdoor work, adequate central body temperature and warm hands are essential. Wind resistant clothing and gloves are necessary, with other clothing as required in relation to the physical effort involved. Additional gloves should be supplied to replace wet gloves after each meal break. 
(e) The reduction of smoking to a minimum is strongly recommended especially during working hours because of the effect on blood circulation.

\section{Working Techniques}

(a) The weight supported by the operator's hand should be as low as possible with the tool resting on the workpiece or on a support as much as possible.

(b) Tools should be held as lightly as possible consistent with proper control.

\section{Working Method}

(a) The working system should be designed to provide as many breaks as possible for work not involving vibration.

(b) It may be practicable to alternate the use of the tool with two or more operators during the working day.

(c) Certain tools must be run at working speeds unless they are in contact with the material.

\section{The Machine}

Vibration levels usually increase if attention is not paid to proper maintenance of the machinery, e.g.

(a) Good maintenance of all working parts of the machine and replacement before wear is excessive.

(b) Correct sharpening of cutters.

(c) Correct tuning of two-stroke engines (where applicable).

(d) Renewal of vibration isolators. 


\title{
Extract from THE VIBRATION SYNDROME
}

edited by W. Taylor

British Acoustical Society Special Volume No. 2, 1974 Academic Press, London.

\section{Raynaud's Phenomenon in Forestry Chain Saw Operators}

\author{
W. TAYLOR, P.L. PELMEAR and J. PEARSON
}

\author{
Department of Social and Occupational Medicine, \\ University of Dundee, Dundee, Scotland \\ and University of Birmingham, Birmingham, England
}

\section{INTRODUCTION}

Since the first description of white fingers in pneumatic tool workers by Loriga in Italy in 1911, there have been many accounts of Raynaud's Phenomenon in industry - from foundries in the $1930 \mathrm{~s}$, hand-grinding shops in the $1940 \mathrm{~s}$ and rock mines in the $1950 \mathrm{~s}$.

Throughout the 1960s in Britain and elsewhere evidence was accumulating that a new tool, now used universally in timber operations - the power-driven chain saw - was giving rise to Raynaud's Phenomenon.

This was first reported by Grounds in 1964 who studied 22 'timberfellers' using chain saws in Tasmania. In this small series, 20 men $(91 \%)$ showed signs of white finger but none felt it necessary to give up his job. As the use of chain saws spread, reports from other countries, e.g. Japan (Miura et al., 1966), Sweden (Kylin et al., 1968) and Australia (Barnes et al., 1969), described essentially the same condition, that after $2-4$ years saw operation, a proportion of the sawyers began to develop a condition in which first tingling and numbness were noted followed by the blanching of a finger tip. After 8-10 years constant use of the chain saws (usually 6-7 hr per day, 5 days per week), all fingers on both hands were involved.

The use of chain saws in Forestry in Britain, initially confined to felling and cross-cutting, was increased with the introduction of chain saw snedding (de-branching) in 1967. The saw usage time thus showed a steady increase from $1 \frac{1}{2}$ to $2 \mathrm{hr}$ per day (late $1950 \mathrm{~s}$ and early in the $1960 \mathrm{~s}$ ) to $5 \frac{1}{2}-6 \frac{1}{1} / 2 \mathrm{hr}$ in $1968-70$ (Axelsson, 1968). 
In 1969 an investigation of the prevalence of Raynaud's Phenomenon in Forestry Commission employees was carried out by a questionnaire given to a random sample of the employees (Taylor et al., 1971). Following this investigation which showed that the prevalence was highest in those areas where chain saws had been in use for the longest periods, the Forestry Commission offered facilities for medical examination of saw users at one of their largest felling centres, Thetford Chase, Norfolk. This population, which includes some of the men with the longest exposure to chain saw vibration in the United Kingdom, has now been examined four times at yearly intervals. This paper presents the results of these investigations.

\section{Clinical Criteria}

It is essential that Primary Raynaud's (Raynaud's Disease) be distinguished from Secondary Raynaud's, the latter including vascular changes in the arterioles of the fingers due to other causes such as trauma, vibration stimuli, occlusive vascular disorders (atherosclerosis), neurogenic and collagen diseases, and toxins such as ergot and nicotine. In considering Raynaud's Phenomenon of Occupational Origin due to hand-held vibrating tools, Primary Raynaud's Disease must first be eliminated. Thereafter the other medical conditions affecting finger blood-flow including simple fractures and lacerations, must also be excluded. The initial manifestations common to Raynaud's Phenomenon of Occupational Origin may, at first pass unnoticed by the workman. The usual occupational history is an attack of white finger confined to a finger-tip and subsequently, with further vibration exposure, extending to the base, accompanied by numbness. The most important provocative agent is exposure to cold but there are certainly other factors involved, e.g. body temperature, emotional state and metabolic rate. The length of attack is variable, between 15-60 min normally, but in advanced cases may extend to 1-2 $\mathrm{hr}$. The recovery phase is signalled by the appearance of a red flush - a reactive hyperaemia - which is seen usually in the palm and advances from the finger base. Due to the repeated attacks of ischaemia, peripheral nerve damage and nutritional changes may eventually occur. The finger extremities may become tapered with curved ridged nails, provided there is no finger pressure from holding tools or castings, and ultimately small areas of skin necrosis may appear at the finger-tips.

Following the prelimary investigation in 1969. (Taylor et al., 1971) of the prevalence of Raynaud's Phenomenon in a random sample of 
Forestry Commission (Britain) employees, an attempt was made to grade the severity of Raynaud's Phenomenon. This classification by Stages is seen in Table I.

TABLE I

Stages of Raynaud's Phenomenon

\begin{tabular}{cc}
\hline Stage & Wondition of Digits \\
Interference
\end{tabular}

$0 \quad$ No blanching of digits

No complaints

${ }^{0} \mathrm{~T} \quad$ Intermittent tingling

No interference with activities

$0_{\mathrm{N}} \quad$ Intermittent numbness

1 Blanching of one or more

No interference with activities fingertips with or without

tingling and numbness

2 Blanching of one or more complete fingers with numbness usually confined to Winter

Slight interference with home and social activities. No interference at work

$3 \quad$ Extensive blanching Definite interference at work, usually all fingers bilateral. at home and with social activites. Frequent episodes Restriction of hobbies

Summer as well as Winter

4 Extensive blanching. All fingers; frequent episodes Summer and Winter
Occupation changed to avoid further vibration exposure because of severity of signs and symptoms

\section{POPULATION FOR STUDY}

In the original study in December 1969, all of the 50 sawyers who were approached agreed to take part in the study. They were agematched with men in the same environment who had never been 
exposed to vibration, either from chain saws or from hand-held vibratory tools. This control group, however, was subsequently re-examined and those men whose occupational history indicated exposure to any form of vibration, e.g. drivers of excavators, heavy tractors and peeling machines, were rejected. This left only 48 in the control group. In January 1971 a similar study with 56 sawyers and controls was undertaken as part of a wider survey covering several industries where vibration induced white finger (VWF) was known to be present. Two subsequent surveys in January 1972 and January 1973 dealt solely with sawyers who had been examined in the earlier surveys. In 1972, 52 sawyers and in 1973, 46 sawyers were examined. The age distribution of those 46 men seen in 1973 is shown in Table II and their mean saw usage time per stage in Table III.

\section{TABLE II}

Age Distribution of 46 Chain Saw Operators Seen on 4th Survey, 1973

\begin{tabular}{l|c|c|c|c|c}
\hline Age & $20-29$ & $30-39$ & $40-49$ & $50-59$ & $60+$ \\
\hline Number & 2 & 14 & 11 & 15 & 4 \\
\hline
\end{tabular}

TABLE III

Mean Vibration Exposure for 46 Chain Saw Operators Seen for the Fourth Time in 1973 Related to Stage of Disease

\begin{tabular}{l|c|c|c|c}
\hline Stage of disease & $0+0_{\mathrm{T}}$ & 1 & 2 & 3 \\
\hline Mean exposure time & $7 \cdot 7$ & $8 \cdot 3$ & $9 \cdot 6$ & $10 \cdot 7$ \\
\hline
\end{tabular}

\section{Change in Vibration Characteristics}

From 1961 to June 1970 (See Appendix), the Thetford chain saw operators were handling saws with high acceleration values on both the front and rear handles $\left(200-400 \mathrm{~m} / \mathrm{sec}^{2}\right)$. Prior to June 1970 , the saws had no vibration damping.

Antivibration (AV) saws, conforming to limits laid down by the Forestry Commission (less than $60 \mathrm{~m} / \mathrm{sec}^{2}$ on either handle) were 
then gradually introduced throughout the year from June to December when by the end of 1970 , all sawyers were on antivibration saws. Thus by the January 1972 survey, the sawyers had at least one year on AV saws and by the fourth survey in January 1973, the AV saw usage was at least 2 years.

\section{Method}

In the December 1969 and January 1971 surveys, the men were seen by three examiners. The first (W. Taylor) took a full occupational history and graded the signs and symptoms according to the criteria in Table I. A second examiner (C. Thomson in 1969 and P. Pelmear in 1971) measured finger temperatures, and, if normal, made two sensory tests used by neurologists (Renfrew, 1969) with instruments shown in Fig. 1.

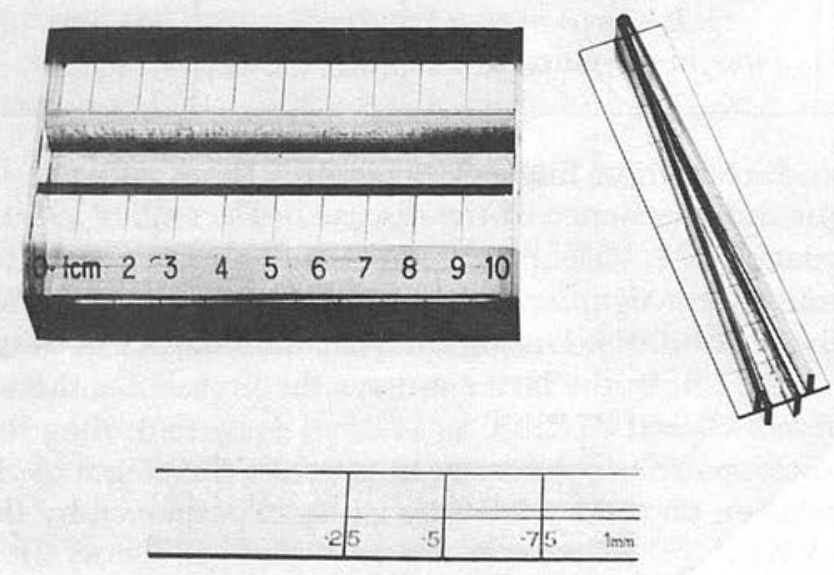

FIG. 1. The two-point discrimination and the depth-sense aesthesiometers.

In addition, in 1971, the circumference of the fingers was measured. A third examiner (R. Kell in 1969, a team from the National Engineering Laboratory at East Kilbride in 1971) ascertained finger pulp vibro-tactile thresholds.

In the 1972 and 1973 studies the vibration threshold tests were omitted, the other tests being repeated by the same examiners as in 1971.

\section{Prevalence of Vibration Induced White Finger}

The distribution of the sawyers by stage of the disease for the four surveys is shown in Table IV. 
TABLE IV

Prevalence (\%) of VWF per Stage of Thetford

Chain Saw Operators in Four Surveys at 12 -

monthly Intervals from December to January,

1969-1973

\begin{tabular}{|c|c|c|c|c|}
\hline Stage & $\begin{array}{c}1 . \\
\text { Dec. } 1969\end{array}$ & $\begin{array}{c}2 . \\
\text { Jan. } 1971\end{array}$ & $\begin{array}{c}3 . \\
\text { Jan. } 1972\end{array}$ & $\begin{array}{c}4 . \\
\text { Jan. } 1973\end{array}$ \\
\hline $\begin{array}{l}0 \\
1 \\
2 \\
3 \\
4\end{array}$ & $\left.\begin{array}{r}10 \\
12 \\
30 \\
40 \\
8\end{array}\right\} 90$ & $\left.\begin{array}{r}5 \\
14 \\
29 \\
52 \\
-\end{array}\right\} 95$ & $\left.\begin{array}{c}6 \\
15 \\
31 \\
46 \\
2\end{array}\right\} 94$ & $\left.\begin{array}{l}13 \\
20 \\
33 \\
35 \\
-\end{array}\right\} 87$ \\
\hline $\begin{array}{l}\text { Number } \\
\text { of } \\
\text { sawyers }\end{array}$ & 50 & 56 & 52 & 46 \\
\hline
\end{tabular}

vibration induced white finger is present in those subjects in Stages 1 to 4 . Thus the prevalence of the disease in December 1969 was $90 \%$ and in January $1971,95 \%$. At those times the prevalence rates in the control groups were significantly lower, being $6.0 \%$ and $6 \cdot 6 \%$ respectively $(\mathrm{P}<0.001)$. During the year the number of Stage 3 cases rose from 20 to 29 . In the latter surveys the prevalence rates in the sawyers were $94 \%$ and $87 \%$.

The questionnaire which was used to assess the stages of the disease gave information on the areas of difficulty experienced by the subjects with VWF.

As the saw usage time increased, attacks of white finger not only occurred at work, when the hands were exposed to cold, but were noticed to be triggered off by cooling of the hands whilst engaged in home duties or hobbies. Reported conditions giving rise to attacks were gardening, fishing, bathing, car washing, holding cold glasses of ale and woodworking in a non-heated home workshop. Changing clothes in a cold bedroom would precipitate an attack. Periods of inactivity such as rest periods in unheated shelters in the forests or standing at football matches on a winter's day would provoke attacks of white finger. Chain saw operators were particularly susceptible to attacks immediately on rising and during early morning. Touching cold objects in the house or the cold steering wheels of motor cars would initiate attacks, more commonly in winter than summer but also occurring in warm weather in advanced cases. Symptoms of 
sensory loss were also reported, not only during white finger attacks, but between attacks there was difficulty in undertaking fine work such as picking up and recognizing small coins, and doing and undoing items of personal clothing (buttons). Fingers were reported to be clumsy and becoming stiff with increasing vibration exposure. Four men $(8 \%)$ of the 56 workers examined at Thetford in 1969 were known to have given up their chain saw work because of the interference of VWF with their home, social and hobby activities.

\section{Longitudinal Study of VWF Prevalence}

In the four annual surveys, 46 sawyers have been seen on all four surveys. On each occasion the stage of the disease and the results were graded as:

Improved (I)

No change (NC)

Deteriorated (D) if subject was in lower stage

if subject was in same stage

if subject was in higher stage.

During the first year, between December 1969 and January 1971, when some AV saws were in use, 3 sawyers improved, 32 showed no change, and 11 deteriorated. However this may not represent a significant overall deterioration for the group $(\mathrm{P}<0.05)$.

At the 1972 examination, after at least one year of AV saw use, 11 sawyers improved, 23 showed no change and only 12 deteriorated, compared with their stage in 1971 at the beginning of the antivibration period. This again does not represent a significant departure from an overall 'no change' situation, $(P>0.05)$ but it is a reversal of the trend in the previous year.

By 1973, after at least 2 years of AV saw use, 19 sawyers showed improvement compared to their 1971 stage, 23 showed no change in stage and only 4 showed deterioration. This represents a significant overall improvement $(P<0.001)$. Indeed during the second year of $\mathrm{AV}$ saw use no sawyers showed deterioration in stage (Tables $\mathrm{V}$ and VII. Within Stage 3, however, and judging improvement or deterioration from social signs and symptoms, four sawyers had deteriorated. Of the four, two were considered to have deteriorated to such an extent that removal from further vibration exposure was advised.

Nine ex-vibration former chain saw operators were also examined. All had improved (1973 survey) since stopping chain saw usage with a vibration free interval ranging from 1-5 years. Of the 9 , one had changed his occupation because of the severity of VWF (Table VI). 


\begin{tabular}{|c|c|c|}
\hline \multirow{12}{*}{ 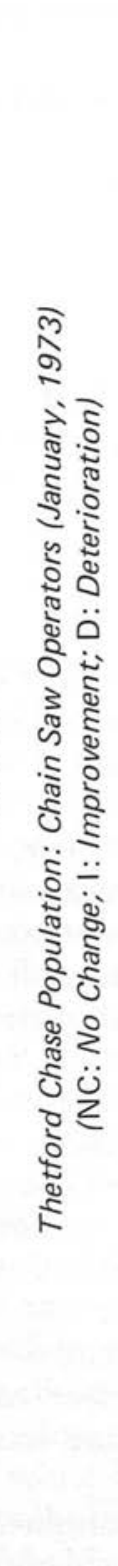 } & & \\
\hline & $n_{3} \sum_{2}^{\infty}$ & 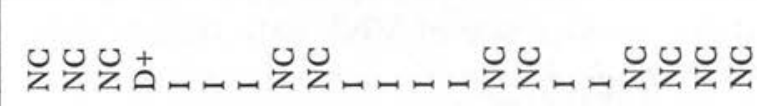 \\
\hline & 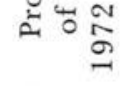 & 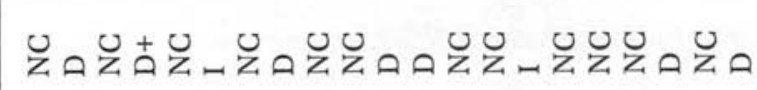 \\
\hline & & 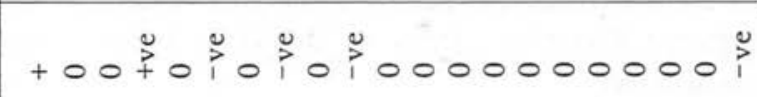 \\
\hline & 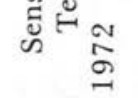 & 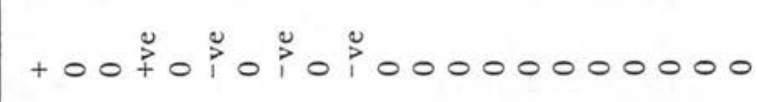 \\
\hline & & NT NNTH T W N N N \\
\hline & $\sum \stackrel{5}{5}$ & 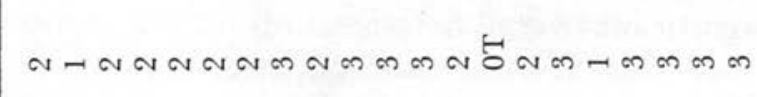 \\
\hline & & NONANman Nannat \\
\hline & 只 & 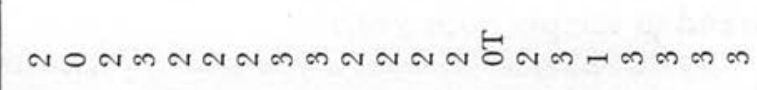 \\
\hline & 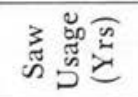 & 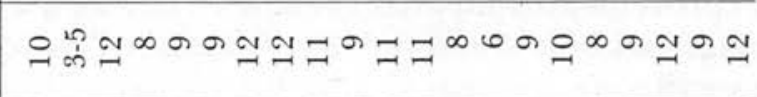 \\
\hline & $\underset{\substack{n \\
\hdashline}}{<}$ & 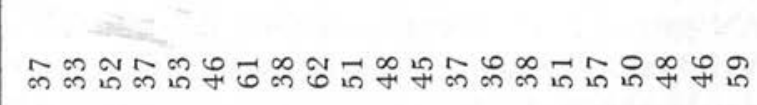 \\
\hline & 芩 & 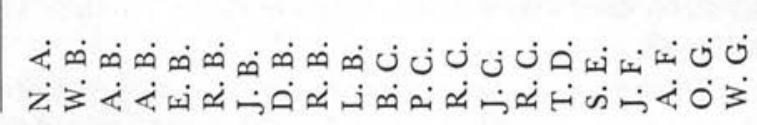 \\
\hline
\end{tabular}




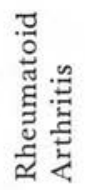

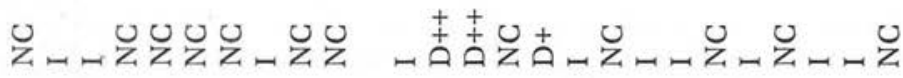

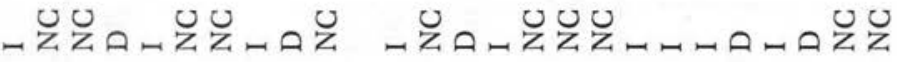

$00000 \stackrel{1}{1} 00000++00000000000+$

$00000000000++00000000000+$

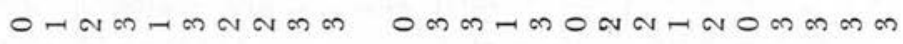

ONNm-MNmm Onm

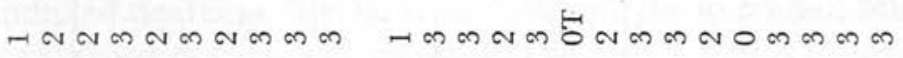

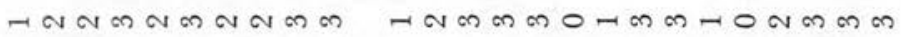

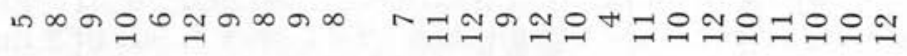

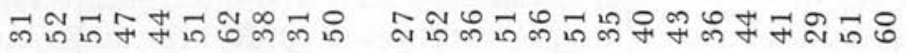

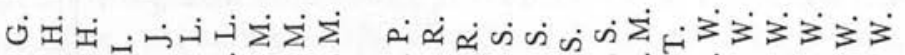

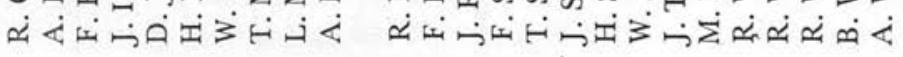




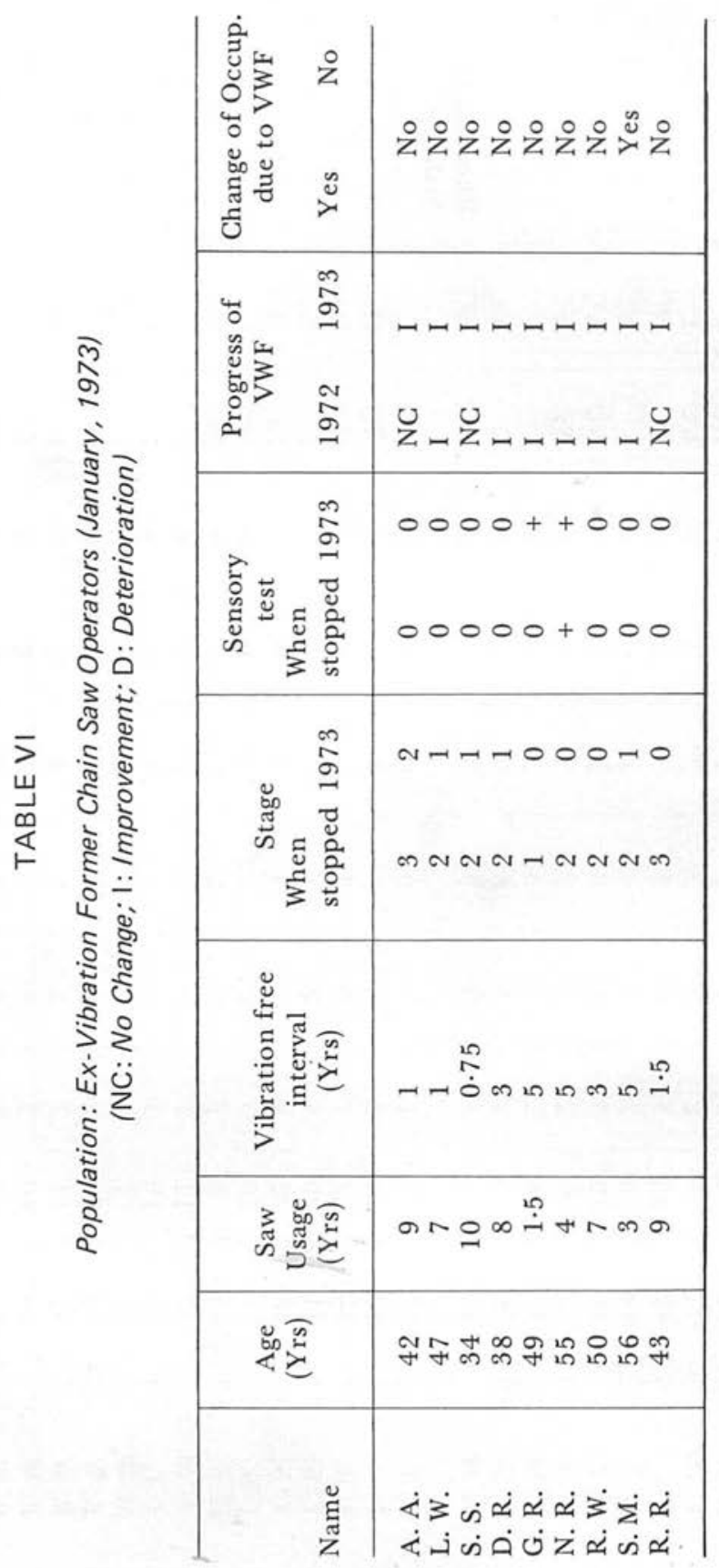


TABLE VII

Assessment of VWF from Work and Social History. The Same Population of 46 Chain Saw Operators Examined January 1972 and January 1973. (On AV Saws)

\begin{tabular}{rccc}
\hline Year & $\begin{array}{c}\text { No change } \\
(\mathrm{NC})\end{array}$ & $\begin{array}{c}\text { Improvement } \\
(\mathrm{I})\end{array}$ & $\begin{array}{c}\text { Deterioration } \\
(\mathrm{D})\end{array}$ \\
\hline $\begin{array}{r}\text { January } \\
1972\end{array}$ & $23(50 \%)$ & $11(23 \cdot 9 \%)$ & $12(26 \cdot 1 \%)$ \\
\hline $\begin{array}{r}\text { January } \\
1973\end{array}$ & $23(50 \%)$ & $19(41.3 \%)$ & $4(8 \cdot 7 \%)$ \\
\hline
\end{tabular}

\section{VIBRO-TACTILE THRESHOLD SENSORY TESTS}

In Japan, Miura (1966) reported the incidence and progress of Raynaud's Phenomenon in rock drillers, limestone quarries and chain saw users. As an objective test of impairment, Miura used the ability to perceive vibration in the finger pulps of the distal phalanxes. Assuming that the threshold for the perception of vibration is higher (less sensitive) for subjects with peripheral nerve damage, vibration injury could then be assessed in a similar manner to audiograms in noise-induced deafness. Bjerke et al. (1970) have extended Miura's test by exposing normal and vibration-exposed subjects to intense sinusoidal vibration and measuring the 'temporary threshold vibration shift' before and after provocation.

In December, 1969, Thomson and Kell measured the vibro-tactile thresholds of the Thetford chain saw population at frequencies 31, 63, 125 and $250 \mathrm{~Hz}$. A Peters AP5 audiometer was used to drive a Linq Altec vibrator on which was mounted a vertical piston with a flat top, diameter $6 \mathrm{~mm}$. To maintain a constant contact between the finger and the piston, the vibrator assembly (Fig. 2) was mounted on the pan of a balance weighted to give an upward force of $8 \mathrm{~g}$. A Bruel and Kjaer accelerometer was mounted on the vibrator and connected through an integrator to a sound level meter and an octave band analyser. The frequency of the vibration was measured by a Racal digital frequency meter, whilst the intensity was monitored by the sound level meter which was itself calibrated against a pistonphone constant source of noise, $124 \mathrm{~dB}$ at $250 \mathrm{~Hz}$. The subject was provided with ear muffs. 


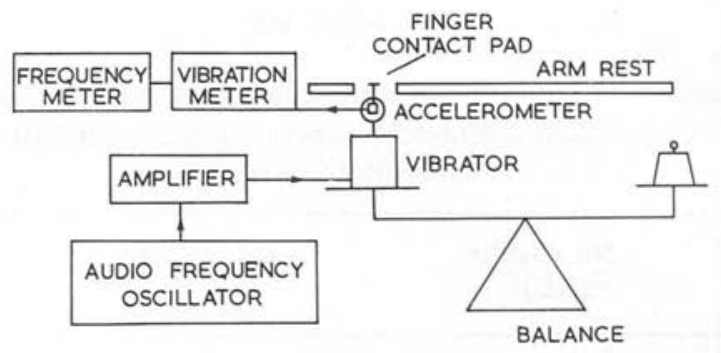

FIG. 2. Apparatus for finger-tip vibration threshold (Dundee).

Examination of the vibro-tactile thresholds showed that at all for frequencies $(31,63,125$ and $250 \mathrm{~Hz})$ there was wide variation with considerable overlap between sawyers and controls. Frequency polygons at 125 and $250 \mathrm{~Hz}$ are shown in Figs. 3 and 4.

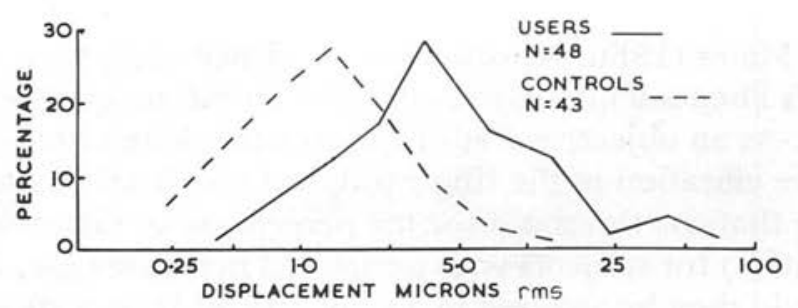

FIG. 3. Vibro-tactile thresholds of sawyers and controls at $125 \mathrm{~Hz}$ (Thetford).

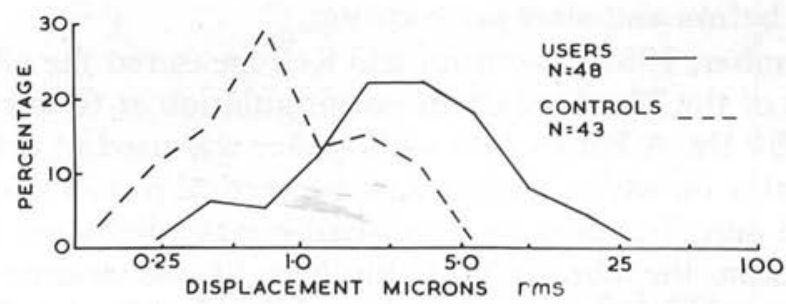

FIG. 4. Vibro-tactile thresholds of sawyers and controls at $250 \mathrm{~Hz}$ (Thetford).

In 1971 a second attempt was made to assess vibro-tactile measur ments as an objective test for VWF. For this survey the assistance o the National Engineering Laboratory, East Kilbride, was sought. Th apparatus designed and constructed by them (shown in Fig. 5), was 
based on that used by Thomson and Kell in 1969. In essence it is a beam balance loaded by means of a cursor weight to produce a constant upward force. The vibrator mounted on the beam produces a sinusoidal force about the constant force, the resultant being applied via the piston to the finger pad. An unbonded strain gauge accelerometer mounted on the piston senses the applied force. In the 1971

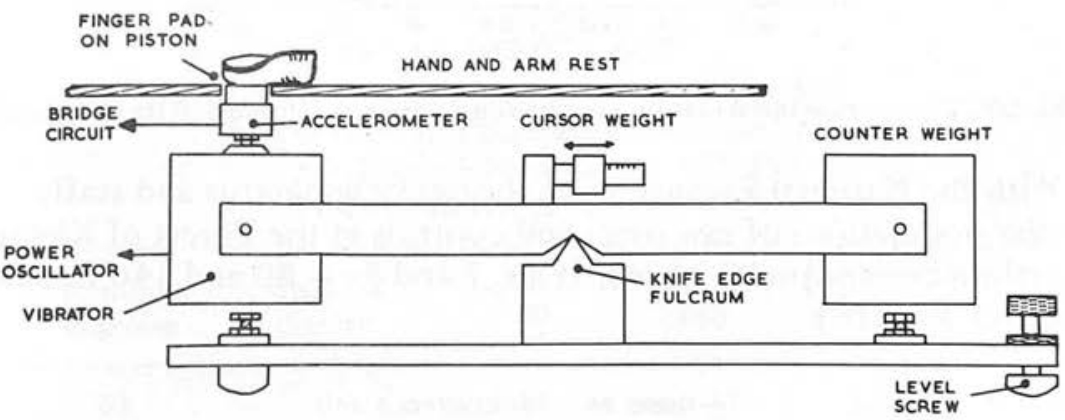

FIG. 5. Apparatus for finger-tip vibration threshold. (National Engineering Laboratory, East Kilbride.)

machine the piston was $22 \mathrm{~mm}$ diameter with a flat top and upward constant force of $15 \mathrm{~g}$. The frequencies used were $80,140,250$ and $400 \mathrm{~Hz}$ and because a higher power oscillator was used, greater energy outputs were possible. The results of the 1971 Thetford survey are shown in Fig. $6 \mathrm{a}(80$ and $140 \mathrm{~Hz})$ and Fig. $6 \mathrm{~b}(250$ and $400 \mathrm{~Hz})$. The distributions are the average of the results of the first two fingers of each hand.

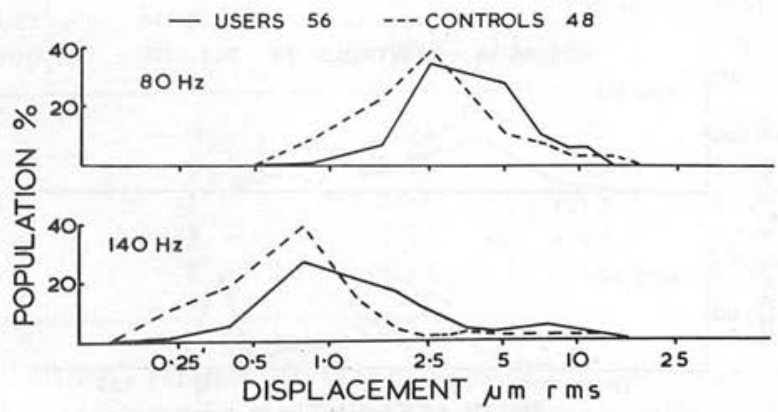

FIG. 6(a). Vibro-tactile thresholds for sawyers and controls at 80 and $140 \mathrm{~Hz}$ (Thetford). 


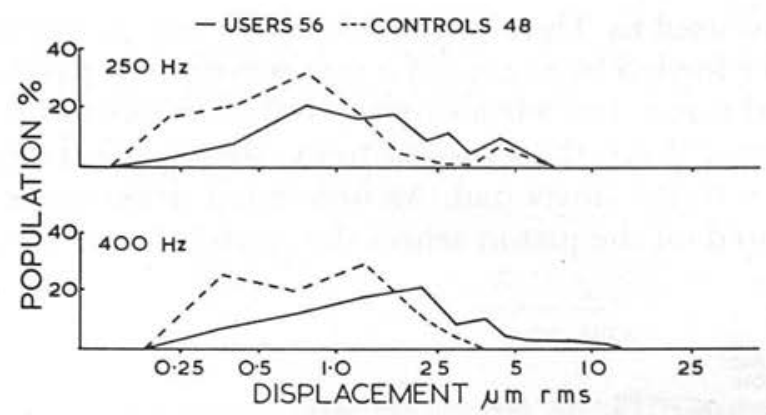

FIG. 6(b). Vibro-tactile thresholds for sawyers and controls at 250 and $400 \mathrm{~Hz}$ (Thetford)

With the National Engineering Laboratory apparatus and staff, similar populations of saw users and controls at the Forest of Kielde (Northumberland) were tested. (Figs. 7 and $7 \mathrm{a}-80$ and $140 \mathrm{~Hz}$, an 250 and $400 \mathrm{~Hz}$.)

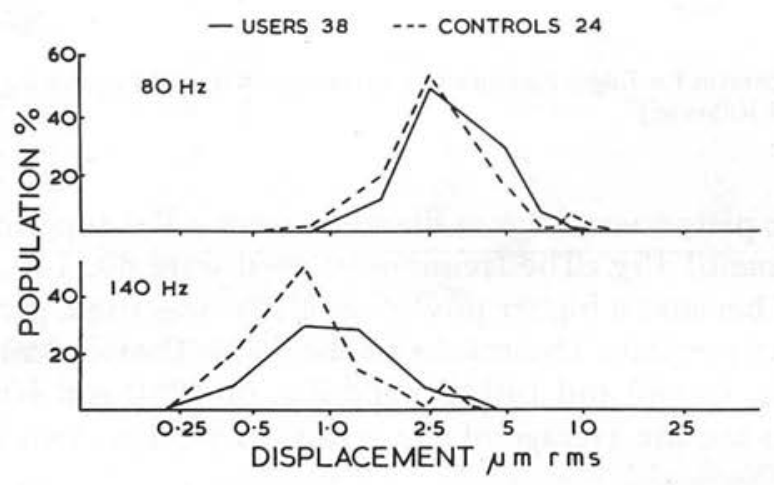

FIG. 7(a). Vibro-tactile thresholds for sawyers and controls at 80 and $140 \mathrm{~Hz}$ (Kielder).

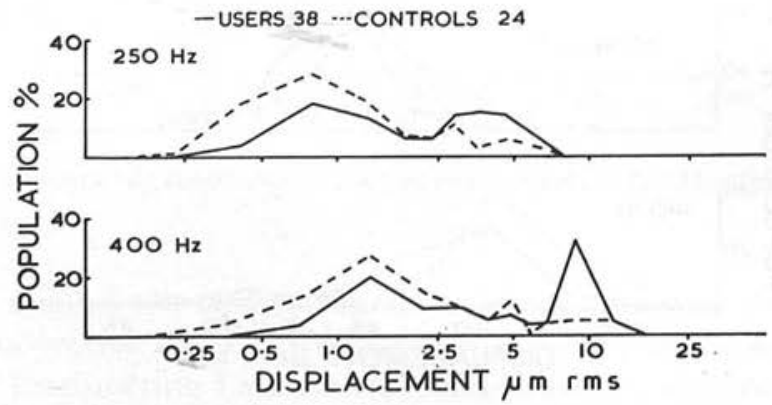

FIG. 7(b).Vibro-tactile thresholds for sawyers and controls at 250 and $400 \mathrm{~Hz}$ (Kielder). 
The similarity in the distribution curves in the three surveys, Figs. $3-7$, will be noted. There is a clear shift in the distribution of saw users and controls but the overlap between the groups rules out the use of this technique as an objective test for VWF in individual cases.

Before abandoning the technique, however, the measurements were related to Stage of disease shown in Table VIII for Thetford sawyers and Table IX for Kielder.

\section{TABLE VIII}

Vibro-tactile Measurements (means of four fingers). Displacement (microns rms) per Stage of Disease at $80,140,250$, $400 \mathrm{~Hz}$ (Thetford)

\begin{tabular}{|c|c|c|c|c|c|}
\hline \multirow{2}{*}{$\begin{array}{l}\text { Number } \\
\text { in group }\end{array}$} & \multirow{2}{*}{$\begin{array}{l}\text { Stage of } \\
\text { disease }\end{array}$} & \multicolumn{4}{|c|}{ Frequency $(\mathrm{Hz})$} \\
\hline & & 80 & 140 & 250 & 400 \\
\hline 63 & 0 & 3.65 & 1.17 & 1.28 & 1.58 \\
\hline 3 & ${ }^{0} \mathrm{~T}$ & 2.68 & 0.90 & 0.90 & $1 \cdot 39$ \\
\hline 11 & 1 & 5.06 & 1.82 & 1.98 & $2 \cdot 50$ \\
\hline 22 & 2 & 4.84 & 1.75 & 2.33 & 3.68 \\
\hline 29 & 3 & 7.18 & 2.33 & 2.81 & 3.57 \\
\hline
\end{tabular}

TABLE IX

Vibro-tactile Measurements (means of four fingers). Displacement (microns rms) per Stage of Disease at $80,140,250$ $400 \mathrm{~Hz}$ (Kielder).

\begin{tabular}{cccccc}
\hline \multirow{2}{*}{$\begin{array}{c}\text { Number } \\
\text { in group }\end{array}$} & \multirow{2}{*}{$\begin{array}{c}\text { Stage of } \\
\text { disease }\end{array}$} & \multicolumn{4}{c}{ Frequency $(\mathrm{Hz})$} \\
\cline { 3 - 5 } & & 80 & 140 & 250 & 400 \\
\hline 25 & 0 & 3.56 & 1.09 & 1.83 & $3 \cdot 33$ \\
13 & $0 \mathrm{~T}$ & 3.50 & 0.96 & 1.63 & $2 \cdot 85$ \\
10 & 1 & 3.66 & 1.73 & 2.47 & $3 \cdot 58$ \\
14 & 3 & 4.52 & 2.44 & 3.80 & $5 \cdot 71$ \\
6 & 3 & 4.24 & 2.18 & 4.99 & $7 \cdot 8$ \\
\hline
\end{tabular}

From Tables VIII and IX it is seen that in general progressing disease causes increasing impairment of vibro-tactile sensitivity in both Thetford and Kielder populations. 


\section{SUMMARY AND CONCLUSIONS}

1. A population of 56 chain saw operators from the Forest of Thetford, Norfolk, England, working 51/2-61/2 hr per day, 5 days week for from 5 to 14 years, has been studied. Of this populati the same 46 sawyers were seen at yearly intervals for 4 years. T prevalence of vibration induced white finger (VWF) was $90 \%$ when first seen (December 1969) and 95\% in January 1971. Th prevalence rates for a control group (age and sex matched in th same environment but without vibration) were $6.0 \%$ and $6.6 \%$ $(\mathrm{P}>0.001)$.

2. The degree or severity of VWF has been graded according to th following classification. Grade 0 - normal, Grade $0 \mathrm{~T}$ - tingling Grade $0 \mathrm{~N}$ - numbness, Grade 1 - blanching of one fingertip, Grade 2 - blanching of one or more complete fingers usually confined to the winter months, Grade 3 - extensive blanching of all fingers summer as well as winter and interference with home and social activities, Grade 4 - extensive blanching and restriction of social and hobby activities to such an extent that occupation has been changed.

3. In the four annual surveys, the same 46 sawyers were seen, the VWF assessed by Stage and by degrees within each Stage. From 1961 to June 1970 , all sawyers were handling saws with high acceleration values on both handles $\left(200-400 \mathrm{~m} / \mathrm{sec}^{2}\right)$. From 1971 onwards, all saws used were equipped with AV handles, the vibration on which conformed to limits laid down by the Forestry Commission (less than $60 \mathrm{~m} / \mathrm{sec}^{2}$ on either handle). Thus in the first two surveys, the population of sawyers had had all their saw usage time on vibration saws whereas in the remaining two surveys (1972 and 1973), the populations had used AV saws for at least 2 years.

4. Comparing the first and second surveys (on vibration saws), 3 sawyers improved, 32 showed no change and 11 had deteriorated. The VWF appeared to be deteriorating but the change is not significant. ( $P>0 \cdot 05)$. After one year of AV saw usage, 11 sawyers improved, 23 showed no change and only 12 had deteriorated. After two years of AV saws, 19 sawyers improved 23 showed no change and only 4 showed deterioration. This represents a significant overall improvement $(\mathrm{P}<0.001)$.

5. Judging improvement or deterioration within stages, then within Stage 3, four sawyers had deteriorated and of the four, although still working (and therefore in Stage 3), two were 
considered to have deteriorated to such an extent that removal from further vibration exposure was advised (i.e. Stage 3 to Stage 4).

6. The vibro-tactile threshold vibration tests, developed in Japan and Sweden, and used to measure finger pulp vibration thresholds in populations of sawyers at Thetford (twice) and at Kielder (once), showed that at four frequencies (31, 63, 125 and $250 \mathrm{~Hz}$ ) there was wide variation between sawyers and controls. There was a clear shift in the distribution curves of saw users and controls but the overlap between the groups rules out the use of this technique as an objective test for VWF in individual cases.

7. When the vibro-tactile measurements of sawyers and controls are compared by Stage of VWF, progressing disease causes increasing impairment of vibro-tactile sensitivity in both the Thetford and Kielder populations.

\section{APPENDIX}

The chain saws used by the sawyers in the populations surveyed in this paper for the years 1961 to 1973 are shown in Table X. The vibration characteristics (in terms of acceleration in $\mathrm{m} / \mathrm{sec}^{2}$ ) for each type of saw are shown at the principal frequency (columns 3 and 6) for the front and rear handles (columns 4 and 7).

The estimated safe limits of acceleration (columns 5 and 8) were applied to saws purchased by the Forestry Commission from February, 1970. From 1961 to 1970 the vibration characteristics of all saws exceeded the safe limits by a factor of 2 to 5 , in particular the saws used in the period 1961 to 1966 . The majority of the sawyers in the Thetford surveys were exposed to these high vibration levels at the beginning of their chain saw experience.

All saws exceed the vibration limits until the $180 \mathrm{~S}$ and $160 \mathrm{~S}$ and the $55 \mathrm{AV}$ became available in the period $1970-1973$.

A second factor possibly affecting VWF is the weight of the saw which, from the use of saws for snedding (from 1967) necessitated a reduction in weight from approximately $25-32 \mathrm{lb}$ to less than $20 \mathrm{lb}$.

\section{ACKNOWLEDGMENTS}

We are indebted to Drs C.B. Thomson and R.L. Kell for vibro-tactile measurements carried out in 1969 and 1970. Throughout this work within the Forestry Commission, Mr G.D. Keighley, of the Depart- 


\begin{tabular}{|c|c|c|c|c|c|c|c|c|c|c|c|}
\hline \multirow{8}{*}{ 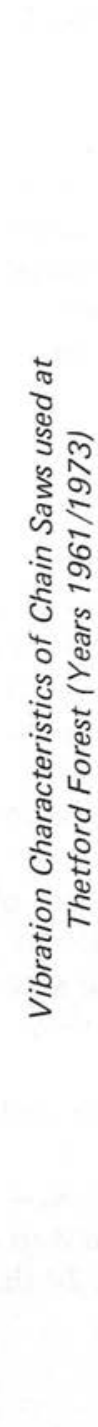 } & \multirow{3}{*}{ 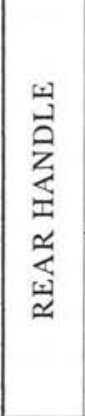 } & \multicolumn{3}{|c|}{ 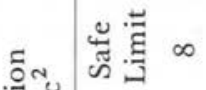 } & $\infty$ & 8 & 8 & 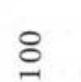 & 8 & ๓ి & ిొ \\
\hline & & 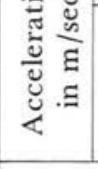 & 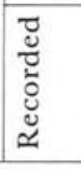 & $n$ & مै & ळి & $\stackrel{\text { }}{\stackrel{N}{N}}$ & ஓ̊ & कి & $\stackrel{12}{\alpha}$ & $\sigma$ \\
\hline & & 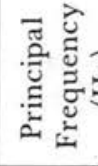 & & 6 & $\stackrel{\mathscr{2}}{\underset{N}{*}}$ & $\stackrel{2}{\simeq}$ & $\stackrel{f}{f}$ & $\stackrel{8}{\circ}$ & $\stackrel{10}{\cong}$ & $\therefore$ & 8 \\
\hline & & 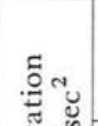 & 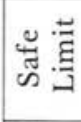 & in & $\infty_{\infty}$ & 8 & 8 & 8 & 8 & ติ & 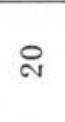 \\
\hline & 我 & 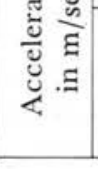 & 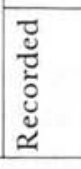 & + & ญิ & $\stackrel{\circ}{\rightarrow}$ & ฌั & ㅇ & ిొ & $\stackrel{12}{\rightarrow}$ & 0 \\
\hline & 曾 & 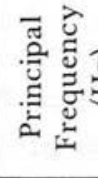 & & m & 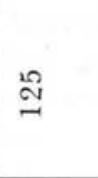 & $\stackrel{2}{\stackrel{2}{二}}$ & I & 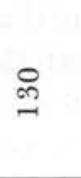 & $\stackrel{\circ}{\stackrel{2}{2}}$ & $\stackrel{R}{R}$ & $\mathscr{7}$ \\
\hline & & है & & N & 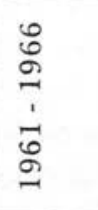 & $\begin{array}{l}\mathscr{0} \\
\stackrel{\circ}{7} \\
\stackrel{1}{0} \\
\stackrel{0}{2}\end{array}$ & 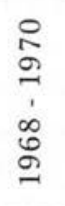 & 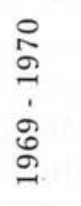 & 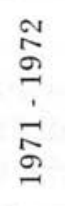 & 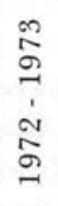 & \\
\hline & & 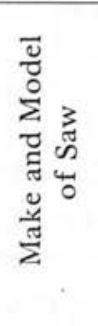 & & - & 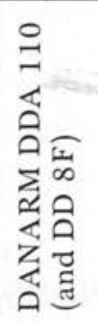 & 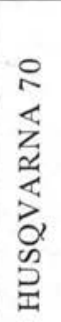 & 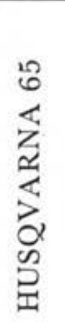 & 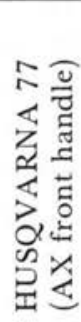 & 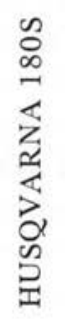 & 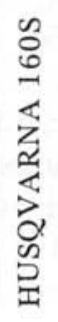 & 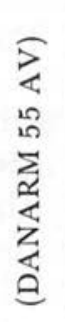 \\
\hline
\end{tabular}


ment of Health and Social Security Research Project team, has been the main organizer. Mr H.L. Wunch and Mr J.D. Tweedie of the National Engineering Laboratory, East Kilbride, designed the vibrotactile apparatus and carried out the measurements. Our thanks are due to Professor Alex. Mair, Head of the Department of Social and Occupational Medicine, University of Dundee for continued help and encouragement, to Mrs Catherine Murray for statistical analyses and to $\mathrm{Mr} \mathrm{J}$. Yates for analyses of the vibro-tactile data.

Over the four-year survey period, the authors gratefully acknowledge the assistance and co-operation of the Civil Service Departments Medical Adviser (Dr R.M. Oliver) and the award of a generous grant from the Department of Health and Social Security to the Vibration Research Team (W. Taylor, P.L. Pelmear, G.D. Keighley and P.B. James).

\section{REFERENCES}

Axelsson, S.A. (1968). Analysis of Vibration in Power Saws. No. 59, Skogshogskolan, Royal College of Forestry Monograph, Stockholm.

Barnes, R., Longley, E.O., Smith, A.R.B. and Allen, J.G. (1969). Vibration disease. Med. J. Aust. 1, 901-905.

Bjerke, N., Kylin, B. and Lidstrom, I.-M. (1970). Changes in the vibratory sensation threshold after exposure to powerful vibration. WorkEnvironment-Health 7, 1, 3, 7.

Grounds, M.D. (1964). Raynaud's Phenomenon in users of chain saws. Med. J. Aust. 1, 270-272.

Kylin, B., Gerhardsson, G., Hansson, J., Litstrom, S., Ligenberg, B., Swensson, A. and Astrand, I. (1968). Halso-Och Miljoundersokning Bland Skogsorb Etare Al-Rapportz.

Loriga, G. (1911). Il labora coi martelli pneumatici Boll. ispett, Lavero, 2, 35 and 6, 524 (1913).

Muira, T., Kimura, K., Tominaga, Y., and Kimotsuki, K. (1966). On Raynaud's Phenomenon of Occupational Origin due to vibrating tools - its incidence in Japan. Report of the Institute for Science of Labour, Tokyo, Japan. No. 65, $1-11$.

Renfrew, S. (1969). Fingertip sensation. A routine neurological test. Lancet, Feb. 22. 396-397.

Taylor, W., Pearson, J., Kell, R.L. and Keighley, G.D. (1971). Vibration syndrome in Forestry Commission chain saw operators. Brit. J. industr. Med. 28, 83-90. 


\title{
Raynaud's Phenomenon in Pedestal Grinders
}

\author{
P.L. PELMEAR, W. TAYLOR and J. PEARSON \\ University of Birmingham, Birmingham, England, and \\ University of Dundee, Dundee, Scotland
}

Although this paper discusses Raynaud's Phenomenon in pedestal grinders, other grinding situations - hand grinding or polishing and fettling - may cause the condition, but the hazard appears to be less.

Compressed air tools were introduced into the French mines in 1839 but Raynaud's Phenomenon resulting from the handling of them was not recognized until 1911, when Loriga described the peripheral vascular manifestations frequently associated with the use of these tools. He recommended as a measure of protection against such effects, the introduction of an elastic substance between the tool and the hand.

In 1918 Cottingham, Hamilton and other physicians reported their findings of a survey of stonecutters using pneumatic hammers in the Indiana limestone quarries. The survey was undertaken at the request of the Journeymen Stonecutters Association but the results were reported to the US Bureau of Labour Statistics. All physicians gave a clear description of their observations.

Dr Cottingham, who examined seven cases, declared that if other stonecutters are affected clinically to the same extent as those he examined, the work permanently and irreparably affects the nerves of their hands and in some instances their general health. He gave the symptoms as swelling, vasomotor change and loss of sensibility in the hands, pain, loss of sleep and general nervousness. In his opinion none of the cases he saw could become normal.

Dr Hamilton stated

'the men using the air hammer commonly suffer from a disturbance in the circulation of the hands, consisting of spasmodic contraction of the blood vessels of certain fingers, making them blanched, shrunken and numb. These attacks come on under the influence of cold, and are most marked, not while 
the man is at work with the hammer, but usually early in the morning or after work. The fingers affected are numb and clumsy while the vascular spasm persists. As it passes over, there may be decided discomfort and even pain, but the hands soon become normal in appearance and as a usual thing the men do not complain of discomfort between the attacks. There seems to be no serious secondary effects following these attacks. Few of the men complained of loss of sensation in the fingers great enough to hamper them, except when the fingers were actually numb. The majority noticed no change at all in the intervals between attacks of numbness. The condition is undoubtedly caused by the use of the air hammer; it is most marked in those branches of stonework where the air hammer is most continuously used and it is absent only where the air hammer is used little or not at all. Stonecutters who do not use the air hammer do not have this condition of the fingers'.

Since then the historical facts have been described by many autho Junghanns (1937) reported the phenomenon in a fettler who had used a compressed air hammer for eleven years. In addition he had nutritional deficiencies of his finger-tips and skin section revealed an end-arteritis obliterans. Mills (1942) reported the occurrence of occlusive vascular disease in the foot of a patient who operated a Jack hammer primarily with his foot. Hunt (1936) gave a nice revieu of the symptoms and signs in workmen with Raynaud's Phenomenor to the Royal Society of Medicine. The first paragraph of his lecture is as follows:

'Pneumatic instruments are now used for many purposes; in mining and quarrying, in road making, in locomotive and other workshops, in shipbuilding and in the construction of all metal aeroplanes, etc. Raynaud's Phenomenon is liable to develop in the hands of men using them and it is of the utmost importance to both workmen and employers alike that its occurrence be prevented as far as possible, and that should it develop it be recognised at once. This paper is merely a preliminary communication, but the work is unfinished and the problem not yet altogether solved'.

Thirty-six years later we have not advanced very much, if at all.

Gurdjan and Walker (1945) reported the phenomenon in six wom war workers using pneumatic riveters in aeroplane construction. Dart (1946) revealed the condition in other workers using vibrating tools the aircraft industry. Hunter et al. (1945) revealed a high incidence ir riveters, caulkers and fettlers. Agate and others (1946) reported Raynaud's Phenomenon in grinders of small metal castings in a foundry, and Agate (1949) published the results of an investigation an outbreak of Raynaud's Phenomenon in an engineering works amongst persons employed polishing and grinding metal castings. Seventy per-cent were affected with a latent period of 23 months. Jepson (1954) investigated 41 patients with Raynaud's Phenomenon who were working with vibratory tools.

My interest in the syndrome was stimulated when I became responsible for the Guest, Keen and Nettlefold foundry in Cwmbran 
in 1970. The iron foundry there had been in existence since 1800 , but in 1960 a malleable foundry was established adjacent to it. The medical centres were efficiently staffed, with a general practitioner attending weekly, but management was unaware of any vibration problems until 1969. It then became apparent that most if not all the malleable foundry pedestal grinders were suffering from the phenomenon and had done so for some time.

Dr Taylor examined the grinders in January 1970 and we have been monitoring them regularly since. Enquiries revealed that in April 1965 the silicon carbide wheels were replaced by zirconia ones with a stiffer bonding material. Prior to this event only a few of the grinders had noticed the phenomenon but subsequently all, given the necessary latent period, developed symptoms.

Within weeks of exposure the fingers become thickened and swollen. Subsequently tingling in the fingers is noticed intermittently, and after a latent period of about six months blanching of a finger or fingers is noticed. White fingers are noticed on going out of the house on a cold morning; washing in cold water; cleaning the car, gardening, swimming or playing rugby. The attacks become more frequent, unless avoiding action is taken, and all the fingers may become affected. The thumbs rarely so. During an attack the cold fingers are very numb and burns can be sustained quite easily. Sensory impairment may persist between attacks and cause considerable disability. Dart playing is affected and a cigarette or a glass of beer may be difficult to hold. Very rarely trophic changes may appear at the finger-tips.

During our survey of population groups for the Department of Health and Social Security, Dr Taylor and I have attempted to demonstrate the difference between vibration-exposed and controls in respect of finger-size and sensation. The instruments used were a It finger circumference measure; a depth sense aesthesiometer (the wedge test); and a two point discriminator. These instruments have been described by Renfrew (1969).

In this paper we refer only to the Cwmbran and Thetford populations and the results are as follows:

\begin{tabular}{ccccc} 
Number of subjects examined: & \multicolumn{2}{c}{ Cwmbran } & & Thetford \\
Vibration exposed & - & 51 & & 56 \\
Controls & - & 70 &
\end{tabular}

\section{Finger Circumference}

The mean circumference of the proximal phalanx at the mid-shaft an position shows that in both groups the figures for the right hand are 
greater than the left; the index fingers are larger than the middle; and the vibration exposed have bigger fingers than the controls. The differences between vibration exposed and controls is greater with the Cwmbran group.
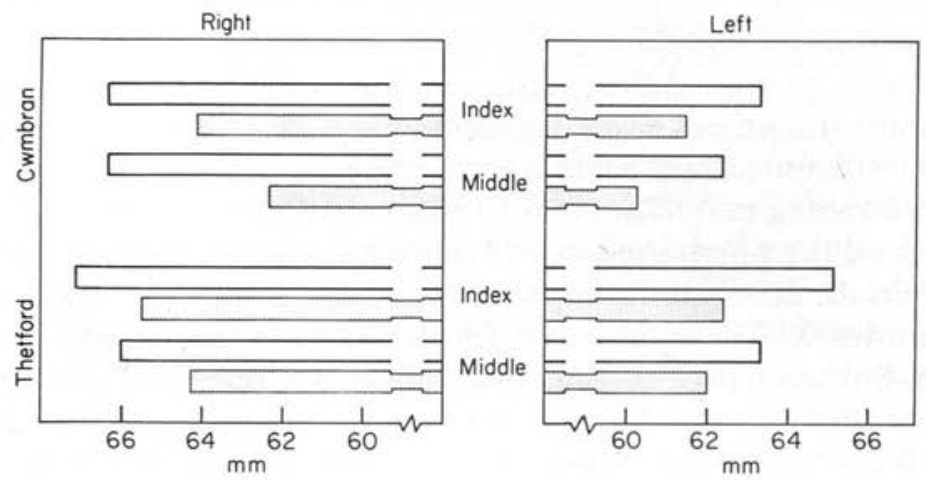

FIG. 1. Finger circumference. Open box: vibration; closed box: control.

\section{Finger Circumference by Stage of Disease}

In both vibration-exposed groups the circumference figures for the hand are greater than for the left and there is progression through stages 0 to 4 .
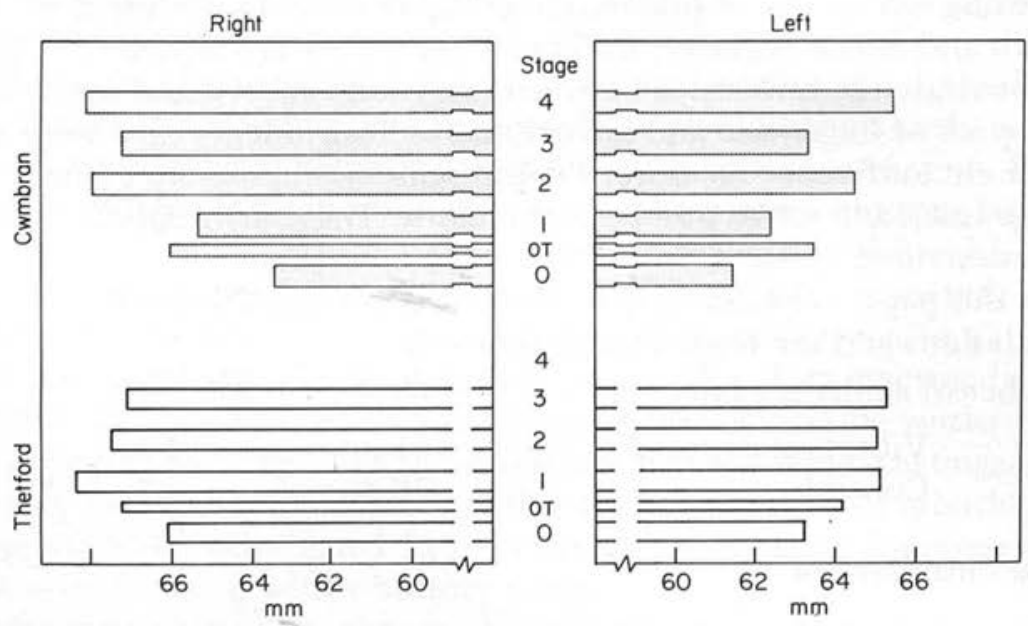

FIG. 2. Circumference of index finger 
Ridge Test

The vibration exposed subjects have less skin sensitivity at the fingertips than the controls in both groups, but the difference is greater at Cwmbran.
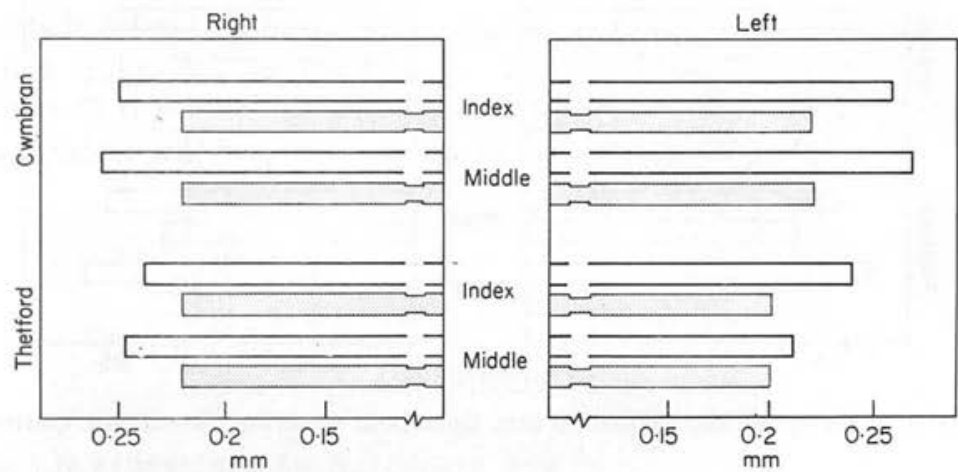

FIG. 3. Ridge test. Open box: vibration, closed box: control.

Ridge Test by Stage of Disease

This shows progression in loss of sensitivity through the stages 0 - 4 in both vibration-exposed groups, but only at Cwmbran is it significant.
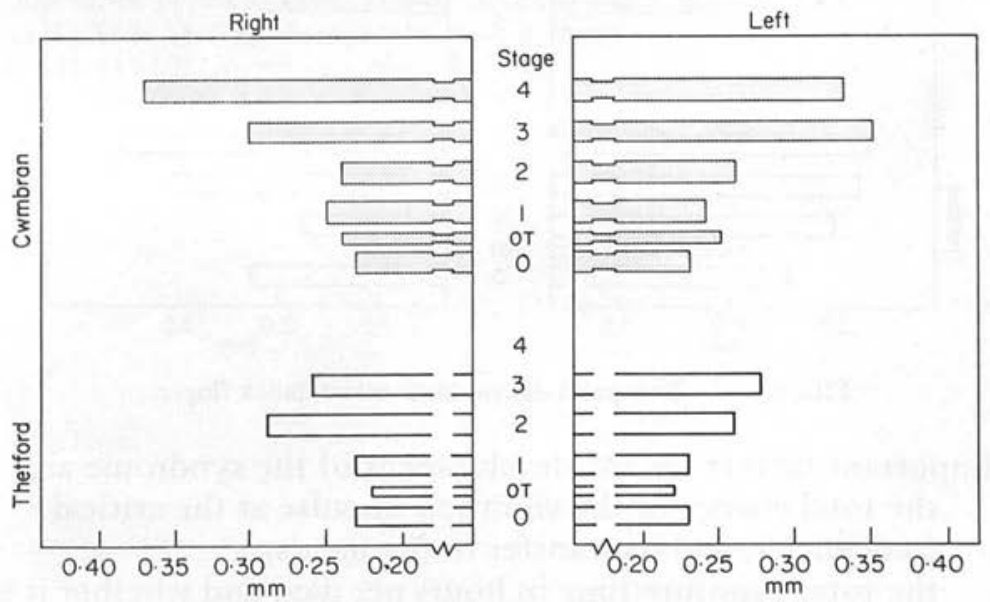

FIG. 4. Ridge test; index finger. 


\section{Two Point Test}

The vibration exposed subjects have less skin sensitivity at the fingertips than the controls.
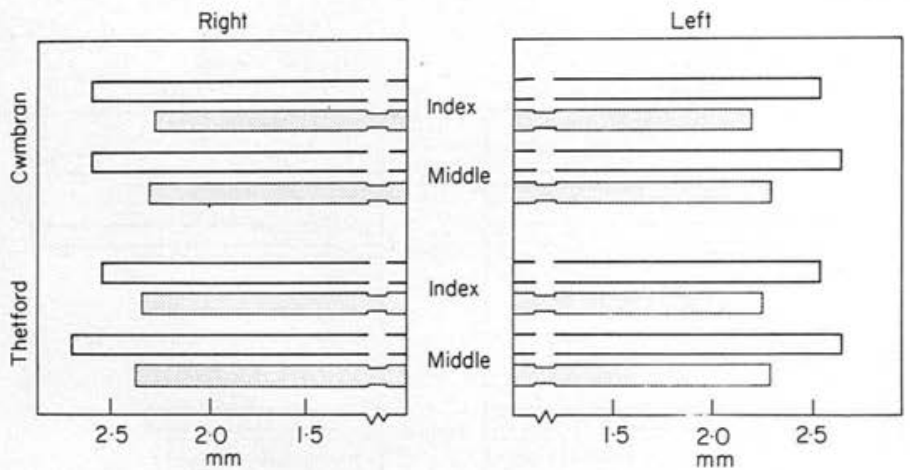

FIG. 5. Two-point discrimination test. Open box: vibration; closed box: control.

\section{Two Point Test by Stage of Disease}

The progression through stages $0-4$ is not significant.
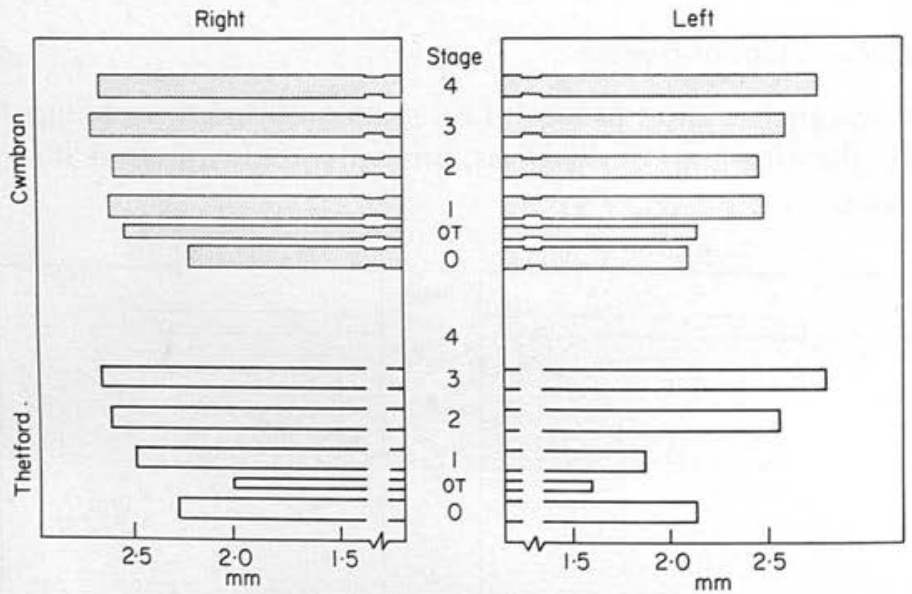

FIG. 6. Two-point discrimination test; index finger.

The important factors for the development of the syndrome are:

1. the total energy of the vibration impulse at the critical frequencies, and its transfer to the hands;

2. the total exposure time in hours per day, and whether it is continuous or interrupted;

3. individual susceptibility. 
As yet, no modification of the pedestal grinding machines at Cwmbran has taken place because the vibration measurements to date have not indicated any marked difference between the two wheels silicon carbide and zirconia. Although milling machines (lathes) have been introduced to deal effectively with the surplus flash metal on some castings, pedestal grinding at Cwmbran and in many other factories remains intolerably dangerous, and the company is most anxious to identify and eliminate the hazard. All our resources and efforts have been directed to this end and we sincerely hope that the results of the present investigation will help us and others to achieve this aim.

\section{REFERENCES}

Agate, J.N. (1949). Brit.J.indust.Med. 6, 144

Agate, J.N., Druett, H.A. and Tombleson, J.B.L. (1946). Brit.J.indust.Med. 3,167

Cottingham, C.E. (1918). U.S. Bureau of Labor Stat. 286, 19, 25

Dart, E.E. (1946). Occupat.Med. 1, 513

Gurdjan, E.S. and Walker, L.W. (1945). J.Am.med.Assoc. 129, 668

Hamilton, A. (1918). U.S. Bureau of Labor Stat. 236, 19, 25.

Hunt, J.H. (1936). Proc. R. Soc. Med. 30, 171

Hunter, D. McLaughlin, A.I.E. and Perry, K.M.A. (1945). Brit.J.indust.Med. 2,10

Jepson, R.P. (1954). Brit.J.indust.Med. 11, 180

Junghanns, H. (1937). Arch. Klin. Chir. 188, 466

Loriga, G. (1911). Bull. Inspett. Lavoro, 2, 35.

Mills, J.H. (1942). Northwest Med. 41, 282

Renfrew, S. (1969). Lancet, 1, 396 
edited by $W$. Taylor

British Acoustical Society

Special Volume No. 2, 1974

Academic Press, London.

\title{
The Vibration Syndrome: Introduction.
}

\author{
W. TAYLOR \\ Department of Social and Occupational Medicine, \\ University of Dundee, Dundee, Scotland
}

\section{RAYNAUD'S DISEASE}

n 1862 Dr Maurice Raynaud wrote an M.D. Thesis 'De L'Asphyxie ocale et de la Gangrène Symétrique des Extrémitiés'. In this thesis he escribed

'in its simplest form a condition, perfectly compatible with health, a local syncopy where persons, who are ordinarily females, see under the least stimulus, sometimes without appreciable cause, one or many fingers becoming pale and cold all at once. It is the phenomenon known under the name of the "dead finger". The attack is indolent, the duration varying from a few minutes to many hours. The determining cause is often the impression of cold. The skin of the affected parts assumes a dead white colour; it appears completely ex-sanguine. The cutaneous sensibility becomes blunted, then annihilated.'

his clinical entity affecting the fingers (and sometimes the toes) of oung women is a relatively common constitutional condition, and as now passed into the terminology of clinical medicine as primary Raynaud's Disease'. These intermittent blanching attacks of the ingers are symmetrical in distribution and, whilst relatively trivial in he early stages of the disease, a small proportion may become evere and in time lead to blue, cyanotic fingers, the skin of which ecomes atrophic and ulcerated, finally becoming gangrenous. The ause of these changes was assumed to be intermittent spasm of the rterioles of the fingers.

For many years Raynaud's Disease was used as a label for the allor, cyanosis, pain and ulcerative skin changes observed on hands nd, more rarely, in toes, nose or ears. Although Raynaud clearly lefined his symptomatology, he erroneously included many cases in is thesis of arteriosclerosis, scleroderma, rheumatoid disease and uberculosis. (See Table I). 
TABLE I

Classification of Raynaud's Phenomenon

PRIMARY: Without known associated and contributing conditions or disease
(1) Raynaud's Disease
Constitutional white finger

SECONDARY: With known associated and contributing conditions of disease
(1) Trauma
(a) Following injury, fracture or operation
(b) Of occupational origin (vibration)
(2) Occlusive Vascular Disease
(a) Thrombo-angiitis obliterans
(b) Arteriosclerosis obliterans
(c) Embolism
(d) Thrombosis
(3) Neurogenic Lesions
(a) Shoulder girdle compression syndrome (Cervical rib, scalenus anterior syndrome, costoclavicular and hyperabduction syndromes)
(b) Diseases of the nervous system (poliomyelitis, syringomyelia, hemiplegia)
(4) Intoxication
(a) Ergot
(b) Acroosteolysis
(c) Nicotine
(5) Miscellaneous
(a) Scleroderma
(b) Cold haemoglutination syndrome
(c) Cryoglobulinaemia
(d) Frostbite

Hunt (1936) admirably described Raynaud's Disease as 'Intermittent pallor or cyanosis of the extremities, precipitated by exposure to cold without clinical evidence of blockage of the large peripheral vessels, with or without nutritional lesions, these being limited to the skin'. Raynaud's Disease or Constitutional Cold Finger in the Community is estimated at 0.5 to $1 \%$ and of these $90 \%$ are female. The disease usually begins in the early decades of life predominantly in the first and second. The onset in $60 \%$ of cases is under 30 years and in $80 \%$ under 40 years. A heredity factor is usually present. In the majority of cases, exposure to cold is the main precipitating factor, (Allen et al., 1962). There is an emotional or psychosomatic factor present in 
the syndrome, the number and severity of attacks increasing during emotional stress and at menstruation (Winsor and Hyman, 1965).

\section{RAYNAUD'S PHENOMENON OF OCCUPATIONAL ORIGIN}

By the end of the nineteenth century, other conditions giving rise to Raynaud's Disease were recognized; in particular the association of intermittent attacks of cold-induced pallor with hand-held vibratory tools used in a wide range of industrial processes. Pneumatic tools were first used in French mines as early as 1839. Loriga (1911) first described 'vascular spasm' or white finger in the hands of pneumatic tool miners. Hamilton (1918) and Rothstein (1918) studied miners using drills in the limestone quarries of Indiana and described 'spastic anaemia' of the hands. This classical study contains the evidence of employees, employers, unions and doctors. During the next 20 years the historical facts have been described by several authors notably Maria Seyring (1930) who studied 189 fettlers in an iron foundry, Hunt (1936) who made a detailed study of seven riveters using pneumatic guns, Hunter et al. (1945) who studied 286 men using pneumatic tools and Telford et al. (1945) who described white finger in men working in a warm environment with electrically-driven highspeed rotating tools carrying cutting burrs. Here for the first time the effect of a cold external working environment was absent. Of 300 men questioned, 75 had symptoms of blanching of fingers. In 1946 and 1949 Agate examined 230 men who were grinding excess metal from small castings hand-held against large grinding wheels. Of this total $163(70 \%)$ gave a history of symptoms. Agate (1949) suggested the name 'Raynaud's Phenomenon of Occupational Origin' to distinguish the condition from primary 'Raynaud's Disease'. The colloquial terms such as 'dead hand', 'dead finger' or 'white finger' have thereafter been rejected by the Industrial Injuries Advisory Council (Interim Report, 1970) in favour of the descriptive term 'Vibration Induced White Finger' or VWF, and they have, in addition, named the complex of symptoms associated with vibrating tools 'The Vibration Syndrome'. These additional effects may include all or any of the following - neuritis, damage to bones, joints or muscles.

During this active British post-war period, the American literature, on the other hand, was remarkably free from reports of Raynaud's Phenomenon. Percora (1960) concluded as the result of a questionnaire sent to hospitals, industry and the Services, that Raynaud's Phenomenon of Occupational Origin did not occur among the 400,000 men estimated to be using vibratory tools at frequencies up to $1000 \mathrm{~Hz}$. His conclusion should be noted, 'that shorter hours, 
better tool design, and planned work breaks had removed a conditio: which had been well recognised in earlier years'. Despite these observations, however, two years later Ashe et al. (1962), Ashe and Williams (1964) reported on a small series of drillers from the hard rock mines of Saskatchewan who had symptoms, seven of whom were examined clinically in hospital and all were subject to arteriography and biopsy.

From 1964 onwards, the association appears between Raynaud's Phenomenon and chain saw usage. The first report was that of Grounds (1964). Of the 22 sawmen examined in Tasmania, 20 (91\%) had symptoms but none considered the disability to be sufficiently great to give up his job. From Japan (Miura et al., 1966) there followed a series of reports in which the incidence and progress of Raynaud's Phenomenon in drillers (26 men) limestone quarriers (70 men) and chain saw users $(17 \mathrm{men})$ were compared. The results of local and whole body cooling were investigated and changes in skin temperature and digital pulse pattern were recorded. It was in this study that the first objective measurements of the ability to perceive vibration through the finger pads were made and threshold vibration levels charted for controls and vibration exposed populations.

Of the Swedish work, the most comprehensive report is that of Kylin et al., (1968) who investigated a population of 453 forest workers and established strong correlation between the prevalence of white finger and the vibration exposure time (saw usage). Following Miura's work (1966) that the threshold for the perception of vibration is higher for persons with vibration injury than for control subjects, Bjerke et al., (1970) developed a method of determining the temporary change in the threshold of vibratory sensation resulting from a brief exposure to intense sinusoidal vibration. This is essentiall a provocative test where high vibration levels are fed into the fingers for a period of 5 minutes at varying frequencies $(50,100,200,400$ and $800 \mathrm{~Hz}$ ). The resultant shift in the threshold of vibratory sensaion resembles the temporary threshold shift found in audiograms esulting from exposure to high level noise. This interesting work is being continued in Sweden where it is hoped it will provide an objective test of the severity of VWF.

\section{THE VIBRATION SYNDROME - PRESCRIPTION OR NOT?}

\section{Raynaud's Phenomenon: 1954 Report}

In March 1950, the Minister of National Insurance referred to the Industrial Injuries Advisory Council for consideration and advice on 
io the question of whether Raynaud's Phenomenon should be prescribed under the National Insurance (Industrial Injuries) Act, 1946. The Council referred the matter to their Industrial Diseases Sub-

Committee, the report of whose five members was published in November 1954. By a majority of four to one the sub-committee advised against prescription. Of the 17 members of the Council, 12 advised against prescription (majority report) and 5 associated themselves with the sub-committee's minority report in favour of prescription. It is of interest to note that one member (the late Dr L.G. Norman) found himself unable to support, without qualification, either the majority or the minority report and advised 'that Raynaud's Phenomenon caused by the use of vibratory tools, should be a prescribed disease with the limitation that a claimant should not qualify for disablement benefit unless his loss of faculty exceeded ten per cent $(10 \%)^{\prime}$.

The 1954 Report, whilst considering prescription, recalled that in 1946 a Court of Appeal in the case of Fitzsimons $v$ Ford Motor Co. Ltd. (Aero Engines) had made an award under the Workmen's Compensation Acts on the basis that the vibration from an electrically operated rotating tool caused injury from the cumulative effect of a series of minute blows, each of which could be regarded as a separate accident. Subsequent cases in the House of Lords and Court of Appeal threw some doubt on this verdict and in 1949 in a case where injury benefit had been claimed under the Industrial Injuries Act for Raynaud's Phenomenon as an injury by accident, a tribunal decided that the Fitzsimons decision could not be regarded as valid and that the claimant's incapacity was the result, not of a single injury by accident, but of a continuous process and accordingly disallowed his claim. The Fitzsimons judgment could not subsequently be regarded as an authority in favour of VWF claims. Therefore the only alternative open to the Minister (and his request to Council) was to consider whether Raynaud's Phenomenon could be brought within the cover of the Act by the alternative method of being added to the list of prescribed diseases.

The 1954 Report emphasises the triviality of the disablement in the great majority of cases of Raynaud's Phenomenon - a majority not incapacitated in any way or at most for short intervals in cold weather. Very few workmen could, for example, qualify for injury benefit, payable only for complete days of incapacity. In the case of disablement benefit, payment depends on the extent of the claimant's loss of health and ability to enjoy a normal life. Furthermore the report added that difficulty would be experienced in distinguishing between occupational and non-occupational cases, although it was pointed out 
that the occupational-induced condition differed from the constitutional form, in that it tended to be limited to or affect more severely the fingers most exposed to the vibration. The Council thought that because of the difficulty of diagnosis and to exclude, as far as possible, cases of constitutional origin (Raynaud's Disease), 'it would be essential to have a thorough examination by a doctor with special knowledge of vascular diseases in general and of Raynaud's Phenomenon in particular; such specialists are few in number.' Further difficulties were anticipated in making the diagnosis on the claimant's own statement and in assessing his disability on his own history in the absence of objective tests of impairment or disability.

In the course of this enquiry for the 1954 Report, the Council arranged for a combined survey to be carried out by the Universities of Manchester and Birmingham. The survey confirmed that Raynaud'? Phenomenon could be produced by hand-held vibrating tools and that there are to be found a certain amount of clearly defined occupational cases involving a definite, although relatively minor, degree of disablement. The survey emphasized the triviality of the disablement, in the great majority of cases, and that this was the most important consideration whether to prescribe the condition or not.

Finally, in the 1954 Report it is of interest to examine Mr C.R. Dale's Minority Report. On the question whether Raynaud's Phenomenon could be diagnosed with reasonable certainty Dale quoted the Universities' Survey, 'In the fully co-operative patient the diagnosis can usually be made with reasonable accuracy on a history taken by a physician familiar with vascular disease supported by clinical examination to exclude certain other conditions with which Raynaud's Phenomenon might be confused.' The Majority Report in Dale's view laid too much stress on the difficulty of finding suitable specialist doctors for diagnosis and that the diagnosis of a number of prescribed diseases may have to be made in the light of the claimant's own account of his signs and symptoms. On the question of loss of faculty and assessment of disablement the majority report stated:

'We think it is a serious objection to prescribing a condition if this can only be done in such a way as to give rise to a large number of claims of which the great majority would have to be disallowed, often after considerable trouble to all those concerned with the case, either because the condition could not be accepted as occupational in origin or because the disablement was so trivial th neither injury benefit nor disablement benefit could be paid.' '

Dale's view on this section of the Majority Report was: 'Once it is established that cases of significant disablement occur, I am unable to accept that the incidence of other cases of trivial disablement is a justification for refusing prescription.' 
In summary the Industrial Injuries Advisory Council adopted the Sub-Committee's Majority Report not to prescribe Raynaud's Phenomenon on the understanding that an opportunity be given to reconsider the question in the full light of any future developments. The grounds for rejecting prescription were as follows: (a) the difficulty of distinguishing between occupational and non-occupational cases; (b) the difficulty of deciding and defining the occupational cover; (c) the problems of diagnosis and assessment; and (d) the triviality of disablement in the majority of cases.

\section{VIBRATION SYNDROME: INTERIM REPORT, 1970}

In 1967 the Minister of Social Security referred to the Industrial Injuries Advisory Council the question whether diseases of the bones, joints, muscles, blood vessels or nerves of the hand, arm or shoulder (including Raynaud's Phenomenon) caused by vibrating machines, should be prescribed under the National Insurance (Industrial Injuries) Act, 1965. The matter was referred to their Industrial Diseases SubCommittee for detailed investigation and their Interim Report was published in 1970. Further information was sought including a contribution from Reynard (1954) who described, as well as white fingers, damage to arteries, nerves, muscles, joints, bones and subcutaneous tissue of the upper limbs - this complex he termed 'the Vibration Syndrome.' Marshal et al., (1954) made a detailed neurological study of 39 clinchers and flangers using pneumatic hammers, $37(95 \%)$ of whom gave a history of Raynaud's Phenomenon. Using nylon bristles which bent under a known pressure for estimating tactile threshold and using weighted needles for testing pain threshold, persistent nerve damage characterized by motor weakness and sensory loss, was demonstrated. It was also held that the vasospasm causing the finger blanching was due to the traumatized nerve endings. It should be noted that no separate controls were used by these authors to establish normal thresholds. No other attempts had been made to measure nerve damage.

The 1970 Sub-Committee had before them a fact-finding survey commissioned by the Council and carried out by one of the Council members (Dr Alice Stewart) with the assistance of her colleagues in the Department of Social Medicine, University of Oxford. The survey by Stewart and Goda (1970) covered over one thousand vibratory tool users in 27 industries. In 542 men with VWF, the condition was not regarded as disabling to a significant extent. In some cases on a change of job (108 men with white fingers - improvement rate $27 \%$ ), the 
condition was found to be reversible. There was a limitation on tho hobbies which were pursued out of doors, particularly in cold weat The suggestion that all tissues of the upper limb are liable to be irretrievably damaged as a result of vibrations producing permanent and possibly progressive damage to nerve endings (Reynard, 1954; Marshal et al., 1954) was not accepted by Stewart and Goda; nor w it accepted that Raynaud's Phenomenon was the result of vibration. induced injury to nerve endings with resulting heightened sensitivity to cold of the finger arterioles. The Report of the Stewart-Goda survey also developed a theory that VWF was caused by the growth callus on those fingers affected by pressure (finger pads) and that th callus formation results in a fall in capillary blood volume with increased sensitivity to blood flow change with temperature. The development of callus is a response to the work situation and is a form of protection against further tool/component trauma. It was accepted by Stewart and Coda that finger blanching was due to vasospasm although the abnormal element in the situation was not traumatized nerve endings but callus formation under the palmar surfaces of fingers and thumbs.

The callus theory of Stewart and Goda is a new approach to the nc aetiology of VWF. It is difficult to accept since callosities occur in Jy many manual occupations without VWF and conversely-cases of VTPY are known where no obvious callus formation is present. The Counc ${ }^{2} \mathrm{x}$ in its 1970 Report, section 17, states

'we recognise that the callus theory awaits clinical confirmation and that the may be other factors contributing to VWF in which symptoms have been displayed before the onset of finger callus, but it does tend to confirm earlieh findings about the limitation of the possible disabling effects of VWF.'

It is difficult to accept the final clause of this conclusion.

As in the 1954 Industrial Injuries Advisory Council Report, the $1 \mathrm{cl}$ Sub-Committee concluded that further enquiries were necessary on aspects of the question referred to them. Two members of the Sub- 2 Committee were unable to sign the 1970 Interim Report and furnis ${ }^{\text {sic }}$ a Minority Report recommending, 'that while further research is required into other aspects, the condition Vibration Induced White ${ }^{1}$ Finger should be prescribed forthwith'. The Majority Report of the Sub-Committee recommended that further enquiries were necessary on all aspects of the question referred to them. The Council considered both the Majority and Minority Reports. Twelve members associated themselves with the Majority Report while four members $n$ wished to be associated with the Minority Report.

In summary, the Council's 1970 Interim Report left over

'whether Raynaud's phenomenon can be accepted as a disabling condition 
which would justify the payment of compensation under the Industrial Injuries Act. There is a considerable amount of research still being carried out for the Sub-Committee and which indicated that the syndrome was not seriously disabling. The other aspect of the syndrome is the possibility of permanent and disabling damage to nerves, bones and muscles of the upper limbs. Our fact-finding survey showed that the resulting muscle pains are simply what might be expected of such work and, therefore, inappropriate for consideration as an object of compensation. The possibility of damage to bones is still under investigation.'

\section{THE FUTURE}

Whether or not prescription is conceded, there has been little emphasis slaced to date on prevention of the clinical effects attributed to ibration. There is no mention in either the 1954 or the 1970 Reports of assessment or measurement of vibration stimuli which could be elated to the severity of the vibration syndrome in order, ultimately, o develop a guide for the evaluation of human exposure to hand-arm iystem vibration. Teisinger and Louda (1972) emphasized preventive neasures aiming at limiting the damaging effect of vibrations at source sy designing to vibration standards, by shortening the exposure time, Tpy controlling environmental temperature and by selection of workers exposed to vibration standards. Some progress has already been made $\mathrm{n}$ reducing the vibration characteristics of certain hand-held tools snown to produce prevalence rates of VWF in the region $80-90 \%$ e.g. chain saws). In so far as the vascular pathology is concerned and ie he basic physiology and aetiology of both Raynaud's Phenomenon of Jccupational Origin and Raynaud's Disease, little progress has been nade over the last fifty years and there has been little to add to the classical description made by Alice Hamilton in 1918.

McCallum (1971) has drawn an analogy between VWF and the effects of noise-induced deafness, particularly in relation to life outside working hours, on recreation, on hobbies and on social activities. In the past occupational hazards have been accepted by tradition as a badge of office and without protest, for example the deafness of e joilermakers and weavers. For the great majority of people both noise and vibration may indeed be considered trivial in the sense of loss of faculty or ability to carry out a normal day's work. Yet the case for prescription for noise-induced deafness has now been accepted $\mathrm{n}$ Britain, although not yet implemented. The fact that an objective est of disability for VWF has not yet been found is not fundamentally 1 reason for not recognizing hand vibration as a condition for prescripion if it can be shown that (a) white finger is progressive with 
increased vibration exposure time, (b) the greater the energy input the hands the shorter the latent interval before the onset of $\mathrm{VWF}$ ar ${ }^{\text {Lylin }}$ (c) the end result of continued exposure to high levels of vibration energy may be gangrene of the finger extremities.

Nevertheless a significant step has been made between the $1954_{\text {a }} 6$, the 1970 Reports namely that the Council accepted the University survey findings that only those fingers which are under pressure frof tors the vibratory tool are affected. Raynaud's Disease of constitutional tc origin affects fingers of each hand symmetrically. The 1970 Industriuin Injuries Interim Report concluded that,

'given a reliable occupational history, including a history of the particular tools in use, we are now reasonably satisfied that there should be no great difficulty in distinguishing occupational from non-occupational cases of vibration induced white finger.'

\section{REFERENCES}

Agate, J.N. (1949). An outbreak of cases of Raynaud's Disease of Occupational Origin. Brit. J. indust. Med. 6, 144-163.

Agate, J.N., and Druett, H.A., (1947). A study of portable vibrating tools in relation to the clinical effects which they produce. Brit. J. indust. Med. 4, 141-163.

Agate, J.N. and Tombleson, J.B.L. (1946). Raynaud's Phenomenon in grinders Ste of small metal castings. Brit. J. indust. Med. 3, 167.

Allen, E.V., Barker, N.W., and Hines, E.A. (1962). 'Peripheral Vascular DiseasesTei W.V. Saunders Co., Philadelphia and London.

Ashe, W.F., and Williams, N. (1964). Occupational Raynaud's. Arch. Environ. Health. 9, 425-433.

Ashe, W.F., Cook, W.T. and Old, J.W. (1962). Raynaud's Phenomenon of Occupational Origin. Arch. Environ. Health 5, 333-343.

Bjerke, N., Kylin, B., and Lidstrom, I.-M. (1970). Changes in the vibratory sensation threshold after exposure to powerful vibration. Work-Environment Health, $7,1,3,7$.

Grounds, M.D. (1964). Raynaud's Phenomenon in users of chain saws. Med. J. Aust. 1, 270-272.

Hamilton, A. (1918). A study of Spastic Anaemia in the hands of stone cutters. U.S. Department of Labor, Bureau of Labor Statistics, Bulletin 236 (Industri Accidents and Hygiene Series, No. 19), Washington, D.C.

Hunt, J.H. (1936). Raynaud's Phenomenon in workmen using vibratory instruments. Proc. R. Soc. Med. 30, 171-177.

Hunter, D., McLaughlin, A.I. and Perry, K.M.A. (1965). Clinical effects of the u of pneumatic tools. Brit. J. indust. Med. 2, 10-16.

Industral Injuries Advisory Council (1970). Interim Report on the Vibration Syndrome. National Insurance (Industrial Injuries) Act, 1965. H.M. London. Comnd. 4430.

Industrial Injuries Advisory Council (1954). Report on Raynaud's Phenomenon National Insurance (Industrial Injuries) Act, 1946. H.M. London. Comnd. 9347. 
lin, B., Gerhardsson, G., Hansson, J., Litstrom, S., Ligenberg, B., Swensson, A., and Astrand, I. (1968). Halso-Och Miljoundersokning Bland Skogsorb Etare Al-Rapportz.

riga, G. (1911). Il labora coi martelli pneumatici. Boll. ispett, lavoro 2, 35; and 6, 524, 1913 (also quoted Occupational Health Supplement, I.L.O., Geneva, Sept., 1938.

rshall, J., Poole, E.W., and Reynard, W.A. (1954). Raynaud's Phenomenon due to vibrating tools. Neurological observations, Lancet, 1, 1151-1156.

Callum, R.I., (1971). Vibration Syndrome. Brit. J. indust. Med. 28, 90-93. ura, T., Kimura, K., Tominaga, Y., and Kimotsuki, K. (1966) on Raynaud's Phenomenon of Occupational Origin due to vibrating tools - its incidence in Japan. Report of the Institute for Science of Labour, Tokyo, Japan. No. 65, $1-11$.

cora, L.J., Udel, M., and Christman, R.P. (1960). Survey of current status of Raynaud's Phenomenon of Occupational Origin. Amer. indust. Hyg. Ass. J., $21,80-83$.

ynaud, M. (1862). Local Asphyxia and Symmetrical Gangrene of the

Extremeties. M.D. Thesis, Paris.

ynard, W.A. (1954). Effects of vibrating machines. In 'British Encyclopaedia of Medical Practice.' Interim Supplement (February) pp. 11-14. Butterworth, London.

thestein, T. (1918). U.S. Department of Labor, Bureau of Labor Statistics. Bulletin 236, 67.

yring, Maria (1930). Maladies from work with compressed air drills. Arch. Gewerbehyg, (Berlin), 1, 359-75.

ewart, A.M., and Goda, D.F. (1970). Vibration Syndrome. Brit. J. indust. Med. $27,19-27$.

isinger, J., and Louda, L. (1972). Vascular Disease, disorders resulting from vibrating tools. J. Occup. Med. 14, 129-133.

Iford, E.D., McCann, M.B. and MacCormack, D.H. (1945). Dead hand in users of vibrating tools. Lancet 2, 359-361.

nsor, T. and Hyman, C. (1965). 'Peripheral Vascular Diseases.' Henry Kimpton, London. 


\section{Vibration syndrome in Forestry Commission chain saw operators}

W. TAYLOR, J. PEARSON, R. L. KELL, AND G. D. KEIGHLEY

Reprinted from British Journal of Industrial Medicine Volume 28, page 83,1971

Copyright (C) 1971

British Journal of Industrial Medicine

All rights of reproduction of this reprint are reserved

in all countries of the world 


\title{
Vibration syndrome in Forestry Commission chain saw operators
}

\author{
W. TAYLOR, J. PEARSON, R. L. KELL, and G. D. KEIGHLEY \\ The Department of Social and Occupational Medicine, University of Dundee, and the \\ Forestry Commission of Great Britain
}

\begin{abstract}
Taylor, W., Pearson, J., Kell, R. L., and Keighley, G. D. (1971). Brit. J. industr. Med., 28, 8389. Vibration syndrome in Forestry Commission chain saw operators. A preliminary investigation has been made into the prevalence of the vibration syndrome in the employees of the Forestry Commission (Britain). A questionnaire covered 20 randomly selected employees for each of 40 forests chosen at random, giving a total sample of 800 out of 9600 employees. Of the 756 employees still with the Forestry Commission, 732 responded $(97 \%)$. The analyses were confined to the 711 male employees, of whom 142 were chain saw operators. In this number, the prevalence of the vibration syndrome was $44 \%$ whereas in men who did not handle the chain saw the prevalence was significantly lower at $18 \%(0.005$ level of significance). A regional difference was found. South England showed the highest rate at $69 \%$ compared with North England at $31 \%$ and Scotland at $33 \%$. An increase in prevalence with years of chain saw usage was found, starting at around two years with a marked increase $(73 \%)$ at over eight years. In part, this effect explains the regional differences. Men with the syndrome were significantly more affected by chilling at work, during rest periods, and while sheltering from bad weather, with blanching of the fingers $(89 \%)$ most affected by the weather, followed by sensory loss $(84 \%)$.

During the survey vibration levels were measured on 18 chain saws. The major vibration component from each saw fell within the $125 \mathrm{~Hz}$ octave band and the vibration levels considerably exceeded the criterion of Axelsson (1968). In 16 of the saws the amplitudes were greater on the lower (trigger) handle.
\end{abstract}

Pneumatic vibrating tools were first used in French mines in 1839. In 1911, Loriga in Rome described vascular spasm of the blood vessels in the hands (Raynaud's phenomenon) attributable to the use of pneumatic tools. Hamilton (1918) studied miners using drills in the limestone quarries of Indiana and described 'spastic anaemia' of the hands. More than 20 years later, Raynaud's phenomenon in rotating tools, giving rise to vascular spasm, was recognized in America (Dart, 1946; Peters, 1946) and in Britain (Agate and Druett, 1947; Agate, 1949). However, 10 years later Pecora, Udel, and Christman (1960), in a survey in America, indicated that Raynaud's phenomenon of occupational origin had by the year 1960 become 'an uncommon occupational disease approaching extinction'.

\section{Prescription in Great Britain}

During the period 1950 to 1954 the Industrial Injuries Advisory Council of the Ministry of Pensions and National Insurance in Britain made a detailed examination of Raynaud's phenomenon with a view to prescribing this condition as an industrial disease for the purpose of benefit under the Industrial Injuries Act, 1946. The Advisory Council in December 1954 advised against prescription.

In April 1965, the Advisory Council was again asked to investigate the question of prescription and whether any new evidence was forthcoming on (a) the prevalence and severity of Raynaud's phenomenon in employees using vibrating tools, (b) the establishment of the vibration characteristics 
giving rise to Raynaud's phenomenon, and $(c)$ means of distinguishing occupational cases of Raynaud's phenomenon from non-occupational. In their investigation, the definition has been broadened to include diseases of bone, joints, muscles, blood vessels or nerves of the hand, arm or shoulder (including Raynaud's phenomenon) caused by vibrating machines. This complex has been designated the 'vibration syndrome'. In July 1970, the Industrial Injuries Advisory Council issued an Interim Report.

The results of this survey were submitted to their Industrial Diseases Sub-committee in 1969. The Sub-committee concluded that further research was necessary into the condition of vibration-induced white finger (Vibration Syndrome, 1970).

\section{Role of power chain saws}

Throughout the 1960s in Britain, as in other countries, evidence was accumulating that a new vibrating tool - the power-driven chain saw - was giving rise to subjective signs and symptoms of Raynaud's phenomenon. The chain saw was first introduced by timber fellers in Germany before the second world war and in Sweden in ever increasing numbers in the early $1950 \mathrm{~s}$. With the increasing mechanization of forest work in all timber-growing countries, the chain saw has undergone steady technical development and is now widely used for felling, cross-cutting, and limbing (or snedding). By 1965, 40000 power saws were sold in Sweden alone and the utilization time had increased from $1 \frac{1}{2}$ to 2 hours per day in 1950 to 4 to 6 hours in 1967-8 (Axelsson, 1968). The signs and symptoms arising from the use of power saws in forestry operations and reported from Japan, Sweden, and Australia (Miura, Kimura, Tominaga, and Kimotsuki, 1966; Axelsson, 1968; Kylin, Gerhardsson, Hansson, Litstrom, Ligenberg, Swensson, and Astrand, 1968; Barnes, Longley, Smith, and Allen, 1969) were (a) blanching of the fingers, $(b)$ sensory loss in fingers and palms of the hands, $(c)$ coarse tremor of the hands, $(d)$ pain on returning circulation, $(e)$ cyanosis of the fingers, $(f)$ osteoporosis of the phalanges, $(g)$ cystic changes in the carpal bones, and $(h)$ wrist, elbow, and shoulder joint pain. The 'white', cold, numb fingers occur at first only when triggered off by the stimulus of the saw vibration, i.e., at work. Once established, however, by repeated trauma, attacks may be readily induced by cold, initially at work, but later, after 1 to 2 years' saw usage, by hobbies such as sea bathing, fishing, and gardening. This response to lowered environmental temperature is widely reported and the evidence suggests a distinct geographical distribution with a higher prevalence of 'white finger' in the colder, northern forestry areas of Russia, Canada, Finland, and Sweden.
In 1968, the Forestry Commission of Britain and the Department of Social and Occupational Medicine, University of Dundee began an investigation of this problem. The first part of this study consists of (a) measurement of vibration in chain saws in use in two forests in Scotland, and (b) estimation of the prevalence of the syndrome in Great Britain, as indicated by the subjective symptoms of blanching, numbness, and pain in the fingers. The aim of the second part of this study will be to develop objective tests to measure disability or handicap arising as a result of chain saw usage.

\section{Vibration characteristics of chain saws}

Two investigations were made, the first on seven chain saws in use in two forests in Scotland, by the Department of Social and Occupational Medicine (Dundee), and the second on 11 new chain saws, four with anti-vibration handles, by the National Institute of Agricultural Engineering (NIAE). The results have been combined in Table 1.

Dundee method The vibration intensity and frequency characteristics of power saws, chosen at random, were recorded in the field and subsequently analysed in the laboratory. All measurements were made cross-cutting a horizontal $\log , 9$ in to $1 \mathrm{ft}(23$ to $30 \mathrm{~cm})$ in diameter. A calibrated Bruel and Kjaer accelerometer, type 4313, was attached to each saw handle in turn and in each of three mutually perpendicular directions. The accelerometer was mounted rigidly on the saw handle and connected via a B. \& K. ZR0020 integrator and a B. \& K. 2203 sound level meter to a Nagra IIIb tape recorder. Acoustic calibration signals from a B. \& K. pistonphone were used to define the recording level.

In the laboratory, loops from the tape recordings were analysed by a B. \& K. audiofrequency spectrometer and pen recorder. The true vibration level was obtained from the calibration signal.

Analysis records were made in octave bands centred at $31.5 \mathrm{~Hz}$ to $8 \mathrm{kHz}$ for each of the three directions. The vibration amplitudes were summed, as vectors for each octave band, and the total vibration level for a saw handle was determined from the addition of the vibration levels in all the octave bands. The vector values are given in microns (micrometres) as a measure of displacement from the at-rest position.

NIAE method The NIAE method is similar to that of Dundee. The output from the accelerometer (B. \& K. type 4329) mounted in three positions on each handle was connected through a cathode follower amplifier (B. \& K. type $1606 / 2107)$ to an ultraviolet light galvanometer recorder and FM tape recorder (Thermionics T400). The frequency response of this instrumentation is flat over the range 5 to $500 \mathrm{~Hz}$ and calibration signals were introduced by mounting the accelerometer on $\mathrm{a} \pm 10 \mathrm{~g}$ vibration generator. Measurements were made while cross-cutting, felling, and snedding, but only the cross-cutting results are given for comparison with the Dundee measurements.

Results of vibration analysis A summary of the overall vibration levels is given in Table 1, for the upper handle, 
TABLE 1

Chain Saw Vibration: Summary of Measurements

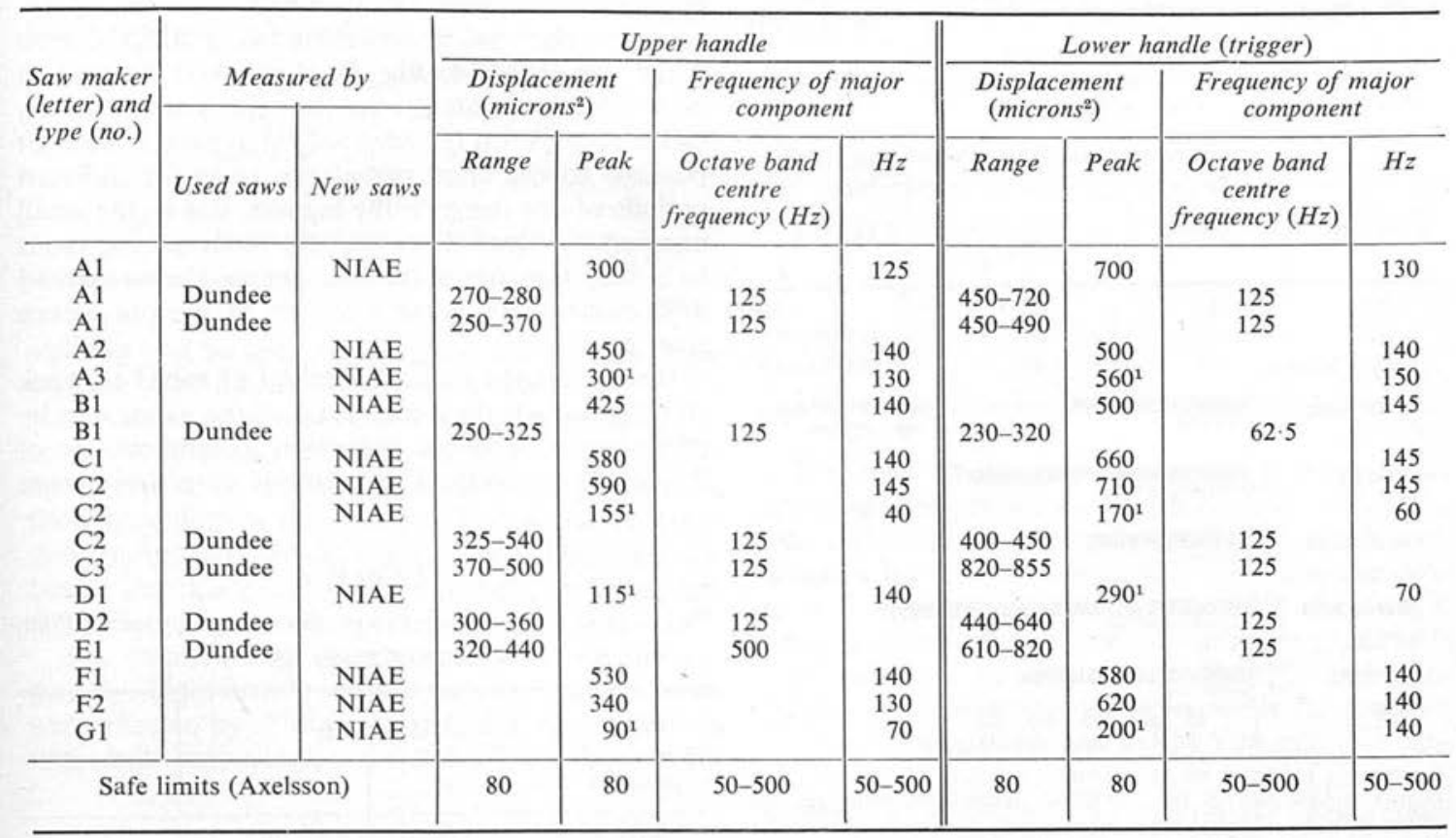

${ }^{1}$ Saws fitted with anti-vibration handles.

${ }^{2}$ Micrometres.

which is normally gripped by the left hand, and the lower handle, which incorporates the trigger-type throttle or accelerator and is normally gripped by the right hand.

The results from the two studies are, in general, similar. It would be expected that worn parts on the saws tested in Dundee would give rise to higher levels than were found in the new saws measured at NIAE. All measurements show levels considerably higher than the criterion of 80 microns (micrometres) amplitude in the range 50 to $500 \mathrm{~Hz}$, proposed by Axelsson (1968). The major component of the vibration is usually found in the $125 \mathrm{~Hz}$ octave band. The direction of this component varied on the upper handle but was vertical, i.e., normal to the direction of the chain bar, in 6 of the 7 saws tested in Dundee.

The use of anti-vibration mountings reduced the overall vibration level and lowered the frequency of the major component (see, in particular, saw C2).

\section{Estimation of prevalence of vibration syndrome}

Methods To estimate the prevalence of the vibration syndrome in forestry workers employed by the Forestry Commission, a survey was carried out on a sample of the employees covering England, Wales, and Scotland. A specially designed questionnaire was used, completed by the supervisor, in most cases the Forest District Officer. The questions concerning the vibration syndrome were included within a general health questionnaire, covering a number of health and safety aspects of forest work; this had the advantage that it avoided undue bias in the association between the syndrome and chain saws. Vibration syndrome was defined using the replies to the questions relating to blanching, numbness, and pain of the fingers, one or more 'yes' being taken as positive for the syndrome. Tremor of the hands was not accepted as positive when it occurred alone.

To ensure an adequate range of forest operations and adequate specialist work among employees in the sample, the survey was restricted to forests with more than 20 employees. Forty forests were chosen at random and 20 employees were selected from each, again by random sampling. The total sample was 800 out of 9600 . Of the employees selected, 44 had left the employment of the Commission, leaving 756 available for this study. To the first request, 679 persons $(90 \%)$ responded. By interviewing the sick on return to duty, by following movement within the Commission and by writing to first refusals requesting co-operation, an additional 53 replies were obtained, giving a total response of $732(97 \%)$. In this total were 21 females, leaving 711 males used for analysis.

\section{Results}

In the total sample of 711,142 men were chain saw operators and 569 were not. In the men using the chain saw the prevalence of the vibration syndrome was $44 \%$, while in men who did not handle the chain saw the prevalence was significantly lower at $18 \%$ $(0.005$ level of significance) (Table 2; Fig. 1). 


\section{TABLE 2}

Vibration Syndrome and Use of Chain SaW.

\begin{tabular}{c|c|c|c}
\hline \multirow{2}{*}{$\begin{array}{l}\text { Vibration } \\
\text { syndrome }\end{array}$} & \multicolumn{2}{|c|}{ Use of chain saw } & \multirow{2}{*}{ Total } \\
\cline { 2 - 3 } & Yes & No & \\
\hline+ & $63(44 \%)$ & $102(18 \%)$ & $165(23 \%)$ \\
\hline & 79 & 467 & 546 \\
\hline Total & 142 & 569 & 711 \\
\hline
\end{tabular}

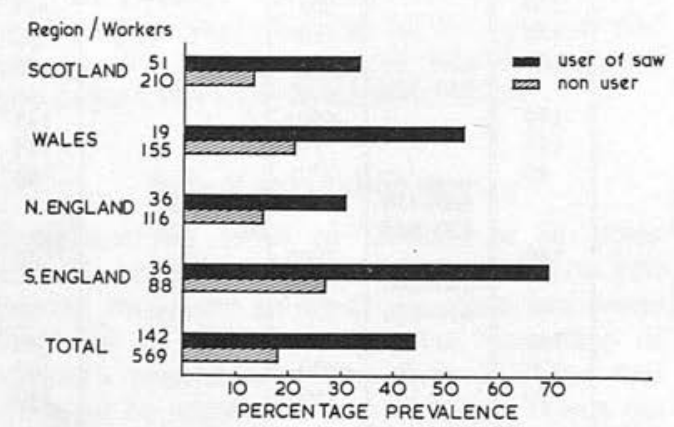

FIG. 1. Prevalence of vibration syndrome and use of chain saw in 711 forestry workers.

Among the chain saw users the prevalence was found to vary between the four regions studied. South England (south-west and south-east) showed the highest rate, $69 \%$, Wales had $53 \%$, and north England (north-west, north-east, and east conservancies) and Scotland had $31 \%$ and $33 \%$, respectively (Table 3; Fig. 1). These significant differences ( 0.005 level of significance) are in an unexpected direction, if climatic influences (e.g., low temperatures) are operating. In contrast, the small regional differences in prevalence seen among the men who did not use chain saws are not statistically significant $(\mathrm{P}>0.05)$.

\section{TABLE 3}

Regional Differences in Prevalence of Vibration SYNDROME AND USE OF CHAIN SAW

\begin{tabular}{l|c|c|c|c}
\hline \multirow{2}{*}{ Region } & \multicolumn{2}{|c|}{ User } & \multicolumn{2}{c}{ Non-user } \\
\cline { 2 - 5 } & Syndrome & $\begin{array}{c}\text { No } \\
\text { syndrome }\end{array}$ & Syndrome & $\begin{array}{c}\text { No } \\
\text { syndrome }\end{array}$ \\
\hline Scotland & $17(33 \%)$ & 34 & $28(13 \%)$ & 182 \\
Wales & $10(53 \%)$ & 9 & $33(21 \%)$ & 122 \\
N. England & $11(31 \%)$ & 25 & $17(15 \%)$ & 99 \\
S. England & $25(69 \%)$ & 11 & $24(27 \%)$ & 64 \\
\hline Total & $63(44 \%)$ & 79 & $102(18 \%)$ & 467 \\
\hline
\end{tabular}

A further factor investigated was the number of years the men worked as chain saw operators. Prevalence rates were calculated for each year of saw use up to eight years, non-users being taken as zero years' use (Table 4; Fig. 2). A marked increase in prevalence is apparent over the eight years. In part, this effect explains the regional differences. It was not possible to calculate prevalence rates for different periods of saw usage in the regions, due to the small numbers involved. However, the average time spent as a chain saw user in the four regions shows marked differences in the same direction as the prevalence rates (Table 5).

It was thought that the method of travel to work could influence the occurrence of the syndrome by producing a pre-work reduction in temperature of the hands or body. The methods considered were

\section{TABLE 4}

Prevalence of Vibration Syndrome and Time Using Chain SaW

\begin{tabular}{c|r|r|r}
\hline \multirow{2}{*}{$\begin{array}{c}\text { Time using } \\
\text { saw }(y r)\end{array}$} & \multicolumn{2}{|c|}{ Syndrome } & \multirow{2}{*}{ Total } \\
\cline { 2 - 3 } & + & - & \\
\hline 0 & $102(18 \%)$ & 467 & 569 \\
1 & $10(31 \%)$ & 22 & 32 \\
2 & $9(30 \%)$ & 21 & 30 \\
3 & $7(37 \%)$ & 12 & 19 \\
4 & $6(40 \%)$ & 9 & 15 \\
5 & $10(63 \%)$ & 6 & 16 \\
6 and 7 & $5(63 \%)$ & 3 & 8 \\
$8+$ & $16(73 \%)$ & 6 & 22 \\
\hline Total & 165 & 546 & 711 \\
\hline
\end{tabular}

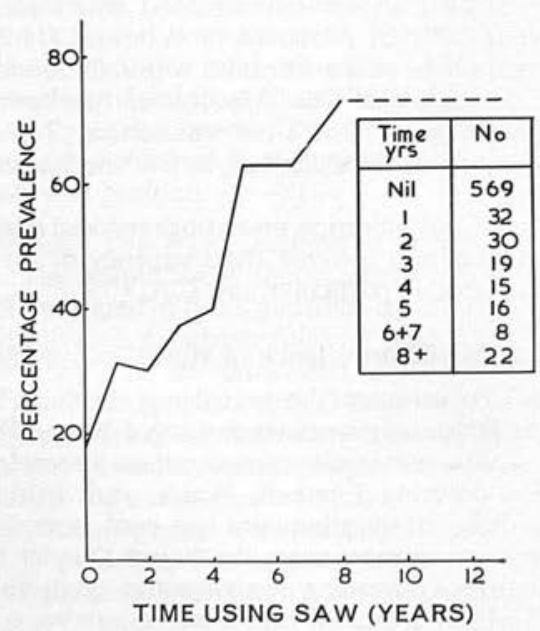

FIG. 2. Prevalence of vibration syndrome and time spent using chain saw in 711 forestry workers. 
TABLE 5

Average Time Using Chain Saw in the Four REgions STUdied

\begin{tabular}{l|c}
\multicolumn{1}{c|}{ Region } & $\begin{array}{c}\text { Mean time } \\
(y r)\end{array}$ \\
\hline Scotland & 3.67 \\
Wales & 7.42 \\
N. England & 3.58 \\
S. England & 6.72
\end{tabular}

walking and travelling by bicycle, motor cycle, bus, and car. The results are shown in Table 6. For all methods the saw users have higher rates than the controls. Among the users, those travelling by bicycle, motor cycle, and bus have higher rates than those travelling by other means. In the control group only motor cyclists show high rates. The rates are based on relatively small numbers and are not statistically significant.

The influence of climate was also investigated directly. Significantly more men with the syndrome were affected by chilling at work, during rest periods and whilst sheltering $(\mathrm{P}<0.005)$ (Table 7). Blanch-

\section{TABLE 6}

Prevalence of Vibration Syndrome and Method OF TRAVEL TO WORK

\begin{tabular}{l|r|r|r|r}
\hline \multirow{2}{*}{ Method $^{1}$} & \multicolumn{3}{|c|}{ User } & \multicolumn{2}{c}{ Non-user } \\
\cline { 2 - 5 } & Syndrome & $\begin{array}{c}\text { No } \\
\text { syndrome }\end{array}$ & Syndrome & $\begin{array}{c}\text { No } \\
\text { syndrome }\end{array}$ \\
\hline No travel.. & $8(36 \%)$ & 14 & $2(5 \%)$ & 42 \\
Walking .. & $10(42 \%)$ & 14 & $19(20 \%)$ & 77 \\
Bicycle .. & $13(65 \%)$ & 7 & $10(14 \%)$ & 64 \\
Motor cycle & $4(57 \%)$ & 3 & $9(28 \%)$ & 23 \\
Bus .. & $6(67 \%)$ & 3 & $6(13 \%)$ & 42 \\
Car .. & $23(43 \%)$ & 30 & $40(20 \%)$ & 159 \\
\hline
\end{tabular}

${ }^{1}$ Some men used more than one method.

TABLE 7

Chilling and Vibration Syndrome

\begin{tabular}{l|c|c}
\hline \multirow{2}{*}{ Questions } & \multicolumn{2}{|c}{ No. replying 'yes' } \\
\cline { 2 - 3 } & $\begin{array}{c}\text { With } \\
\text { syndrome } \\
(165 \mathrm{men})\end{array}$ & $\begin{array}{c}\text { Without } \\
\text { syndrome } \\
(546 \mathrm{men})\end{array}$ \\
\hline $\begin{array}{l}\text { Do you get chilled at work? } \\
\text { Do you get chilled during } \\
\text { rest periods? }\end{array}$ & $52(32 \%)$ & $103(19 \%)$ \\
$\begin{array}{c}\text { Do you get chilled while } \\
\text { sheltering? }\end{array}$ & $95(58 \%)$ & $233(43 \%)$ \\
\hline
\end{tabular}

ing of the fingers $(89 \%)$ was most affected by the weather, followed by sensory loss $(84 \%)$, both of which become noticeably worse with cold or damp (Table 8).

TABLE 8

SYMPTOMS AFFECTED BY WEATHER

\begin{tabular}{ll|c|c|c}
\hline \multicolumn{1}{c|}{ Symptom } & $\begin{array}{c}\text { No. with } \\
\text { symptoms }\end{array}$ & No. affected & Percentage \\
\hline Pain .. &.. & 53 & 31 & 58 \\
Numbness &. & 120 & 101 & 84 \\
Blanching &.. & 83 & 74 & 89 \\
\hline
\end{tabular}

The final factor examined in this survey was smoking. The prevalence of the vibration syndrome was estimated in smokers, ex-smokers, and nonsmokers for both the chain saw users and the controls. The results are shown in Table 9 and Figure 3. Among the chain saw users a significant gradient is seen (smokers $52 \%$, ex-smokers $42 \%$, and nonsmokers $25 \%$ ) whereas in the controls the gradient is absent $(18 \%, 20 \%$, and $17 \%)$. This gradient cannot be explained by differences in time of exposure, smokers, ex-smokers, and non-smokers having spent approximately the same length of time using the saw.

TABLE 9

Prevalence of Vibration Syndrome and SMOKING HISTORY

\begin{tabular}{|c|c|c|c|c|}
\hline \multirow{2}{*}{$\begin{array}{c}\text { Smoking } \\
\text { history }\end{array}$} & \multicolumn{2}{|c|}{ Saw users } & \multicolumn{2}{|c|}{ Non-users } \\
\hline & $\begin{array}{c}\text { With } \\
\text { syndrome }\end{array}$ & $\begin{array}{l}\text { Without } \\
\text { syndrome }\end{array}$ & $\begin{array}{c}\text { With } \\
\text { syndrome }\end{array}$ & $\begin{array}{l}\text { Without } \\
\text { syndrome }\end{array}$ \\
\hline Smoker & $42(52 \%)$ & 39 & $62(18 \%)$ & 290 \\
\hline Ex-smoker & $14(42 \%)$ & 19 & $24(20 \%)$ & 97 \\
\hline Non-smoker & $7(25 \%)$ & 21 & $16(17 \%)$ & 80 \\
\hline
\end{tabular}

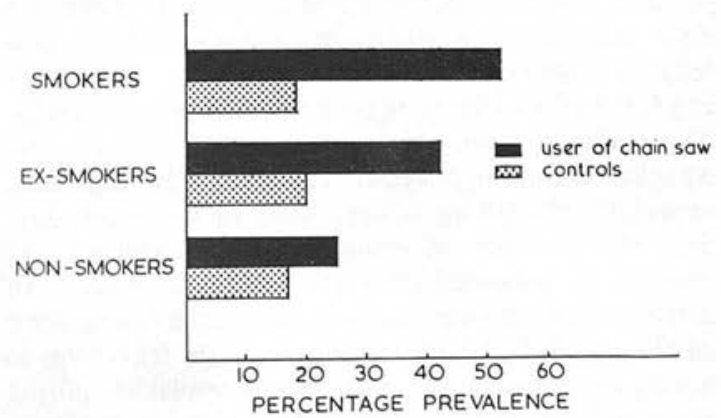

FIG. 3. Prevalence of vibration syndrome and smoking history. 


\section{Discussion and conclusions}

In this study the main interest centred on the role of chain saws in the production of the vibration syndrome in forestry work. The users of chain saws were compared with other Forestry Commission employees and they show a significantly higher rate of vibration syndrome. The prevalence in the "control' group is high (18\%). This 'control' group included employees exposed to vibration other than chain saws, e.g., pneumatic drill operators, tractor drivers, and drivers of tree-moving equipment. In addition, both groups will contain persons suffering from Raynaud's phenomenon of non-occupational origin and from constitutional cold fingers.

When reports of Raynaud's phenomenon of occupational origin are compared, the prevalences are markedly different. Figures vary from $25 \%$ (75 of 300 grinders; Telford, McCann, and MacCormack, 1945 ) through $48 \%$ (139 of 290 fellers; Kylin and his colleagues, 1968) to $93 \%$ (26 of 28 fettlers; Agate, Druett, and Tombleson, 1946). Examination of these results shows that the prevalence is related primarily to the length of exposure to vibration, and to a lesser extent to the physical characteristics of the vibration stimulus and the age of the operators. The regional differences found in this survey, when related to the average time spent as a chain saw user, support the view that a rising prevalence of the vibration syndrome is to be expected with increasing saw usage time (see Fig. 2). If this graph be extended it is likely that saw usage times of 10 to 12 years will result in a prevalence of white finger in the region of $90 \%$.

The survey indicated that a major factor precipitating attacks of white finger was a reduced environmental temperature once the condition was established. Attacks are more commonly found in winter (Hunter, McLaughlin, and Petty, 1945; Agate and his colleagues, 1946). The number of attacks is not related to the absolute temperature but to rapid falls in either the body or the hands. Hunt (1936) gave as examples of precipitating factors related to temperature, washing in cold water, picking up cold tools or utensils, and cycling to work on cold mornings. In Australia, Barnes and his colleagues (1969) quoted swimming, fishing, and watching football as leisure pursuits precipitating attacks. The evidence from this survey clearly showed that attacks commonly occur in the early morning, especially if chilling occurs early in the work day, and the number of attacks increases during rest periods in unheated shelters. As the prevalence of attacks rises with years of saw usage, the importance of the control of body temperature on travelling to work, or during rest periods, and whilst sheltering from inclement weather, becomes more important as a preventive measure.

Although this survey was mainly concerned with vibration white finger, the vibration characteristics of the tools, in this case chain saws, are reported for future reference. Previous work by Hunter and his colleagues (1945) had shown that there was a lower prevalence $(54 \%)$ among riveters working with guns vibrating at $35 \mathrm{~Hz}$ or below than among riveters working at between 35 and $50 \mathrm{~Hz}(74 \%)$ and fettlers working in the same 35 to $50 \mathrm{~Hz}$ range $(84 \%)$. It is essential, however, to know the amplitude range as well as the frequency in order to establish the traumatizing nature of the vibration. In forestry work there are wide variations in the physical stimulus received by the hand, evident by comparing the $86 \%$ prevalence in Tasmanian hardwood fellers with the $48 \%$ found in Swedish soft wood fellers (Grounds, 1964; Kylin and his colleagues, 1968). In the present study, the vibration characteristics of 18 chain saws are reported, seven of these actually taken from the forest before test and 11 new saws without any previous service life. All showed vibration amplitudes exceeding the safe limit of 80 microns (micrometres) (on either handle) advised by Axelsson. In some cases the measured amplitudes found exceeded the recommended safe limit of 80 microns (micrometres) by a factor of seven.

To reduce the rising prevalence of vibrationinduced white finger following the use of existing chain saws, immediate steps were taken by the Forestry Commission (a) to encourage all saw manufacturers to develop anti-vibration mountings (a safe limit of 80 microns (micrometres) amplitude and below), (b) to replace all older saws of the nonAV type with the new designs for all regular operators before the end of October 1970, and (c) to ensure that all regular chain saw operators are using the recommended working techniques and are following the recommendations based on the research findings (see Appendix, p. 89). Whilst these preventive measures are being carried out in the field, a second study essentially clinical in approach will be made on a population of chain saw operators with a saw usage time of five years or more.

The authors gratefully acknowledge the financial assistance and encouragement given by the Forestry Commission. Our thanks are due to the Statistical Branch of the Commission, the Civil Service Department's Medical Adviser, and the staff and employees of the Commission's forests for their willing co-operation.

We are specially indebted to Mr. John Matthews, Head of the Tractor and Ergonomics Department, National Institute of Agricultural Engineering, for the chain saw vibration analyses.

\section{References}

Agate, J. N. (1949). An outbreak of cases of Raynaud's phenomenon of occupational origin. Brit.J. industr. Med., 6, 144-163. 
-, and Druett, H. A. (1947). A study of portable vibrating tools in relation to the clinical effects which they produce. Brit. J. industr. Med., 4, 141-163.

- $-\longrightarrow$, and Tombleson, J. B. L. (1946). Raynaud's phenomenon in grinders of small metal castings. Brit. J. industr. Med., 3, 167.

elsson. Sven-Ake (1968). Analysis of Vibration in Power Saws. No. 59, Skogshogskolan. Royal College of Forestry Monograph, Stockholm.

mes, R., Longley, E. O., Smith, A. R. B., and Allen, J. G. (1969). Vibration disease. Med. J. Aust., 1, 901-905.

rt, E. E. (1946). Effects of high speed vibrating tools on operators engaged in the airplane industry. Occup. Med., $1,515-550$.

ounds, M. D. (1964). Raynaud's phenomenon in users of chain saws. Med. J. Aust., 1, 270-272.

milton, A. (1918). A Study of Spastic Anaemia in the Hands of Stone Cutters. U.S. Department of Labor, Bureau of Labor Statistics, Bulletin 236 (Industrial Accidents and Hygiene Series, No. 19). Washington, D.C.

int, J. H. (1936). Raynaud's phenomenon in workmen using vibrating instruments. Proc. roy. Soc. Med., 30, $171-178$.

inter, D., McLaughlin, A. I., and Petty, K. M. A. (1945). Clinical effects of the use of pneumatic tools. Brit. J. industr. Med., 2, 10-16.

lin, B., Gerhardsson, G., Hansson, J., Litstrom, S., Ligenberg, B., Swensson, A., and Astrand, I. (1968). Halso-Och Miljoundersokning Bland Skogsarb Etare AI-Rapportz.

riga, G. (1911). Il labora coi martelli pneumatici. Boll. ispett, Lavoro 2, 35 and 6, 524 (1913).

iura, T., Kimura, K., Tominaga, Y., and Kimotsuki, K. (1966). On the Raynaud's phenomenon of occupational origin due to vibrating tools - its incidence in Japan. Report of the Institute for Science of Labour, Tokyo, Japan, No. 65, 1-11.

cora, L. J., Udel, M., and Christman, R. P. (1960). Survey of current status of Raynaud's phenomenon of occupational origin. Amer. industr. Hyg. Ass. J., 21, $80-83$.

ters, F. M. (1946). A disease resulting from the use of pneumatic tools. Occup. Med., 2, 55-66.

Iford, E. D., McCann, M. B., and MacCormack, D. H. (1945). 'Dead hand' in users of vibrating tools. Lancet, 2, 359-360.

bration Syndrome (1970). Interim Report by the Industrial Injuries Advisory Council (Section 62 of National Insurance Industrial Injuries Act, 1965). Department of
Health and Social Security. Cmnd. 4430. H.M.S.O., London.

\section{Appendix}

Guidance given to chain saw operators by the Forestry Commission

There are a number of ways in which you can reduce the amount of vibration passing into your hands, when you are using any saw, and these points apply whether or not the saw has anti-vibration handles:

(1) Good techniques for felling, cross-cutting, and snedding with light-weight saws include resting the saw as much as possible on the tree (or occasionally on your thigh); this means that some of the vibration is absorbed by the tree or the large muscles of your thigh. Holding the saw as lightly as possible when it is at full throttle, without, of course, reducing effective control of the saw, will also reduce vibration absorbed into your hands.

(2) Wearing chain saw gloves spreads the grip over a larger area of your hands. (Often the first sign of white fingers is on one or two finger joints which have taken most of the vibration due to too tight a grip.)

(3) Good blood circulation to the arms and hands gives maximum protection to the flesh, nerves, and bones in the hands and this is achieved by warming up before starting the saw and wearing suitable clothing and gloves. Thus, it is better to be too warm than cold.

(4) Sprockets, guide bars, and chains should be well maintained, and chains should be correctly sharpened with the recommended clearance for the depth gauge. Poor maintenance increases vibration by as much as onethird of the normal level for the saw.

(5) The 'safe' limits are based on continuous use of the saw and every time the saw is idling or stopped gives your hands and arms a chance to recover from the effects of vibration. The more evenly breaks in saw usage can be spread throughout the day, the less the risk of any discomfort in your hands; try to organize the stops for fuel, sharpening, meals, piling of timber, or other work so that the saw is switched off for at least 10 minutes as often as possible during the day rather than a few longer stoppages.

Received for publication January 13, 1970. 


\section{PRIMARY AND SECONDARY RAYNAUD PHENOMENA}

A symposium devoted to the pathogenesis of vascular insufficiency of the upper extremities

organized by the Departments of Clinical Physiology and Surgery,

Central Hospital, Växjö, Sweden.

March 1975 in Växjö Sweden.

Editors: Jan Erik Gjöres and Olav Thulesius.

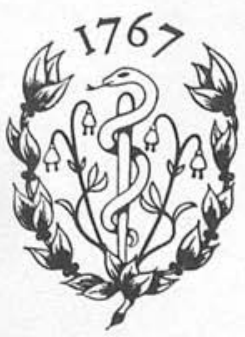




\section{Contents}

O. Thulesius: Primary and secondary Raynaud phenomena. $\ldots \ldots \ldots \ldots \ldots \ldots \ldots \ldots \ldots \ldots \ldots$

A. Bollinger, F. Mahler \& M. Anliker: Velocity of red blood cells in human nailfold capillaries. $\quad \ldots . .7$

H. Schmid-Schönbein: Critical closing pressure or yield shear stress as the cause

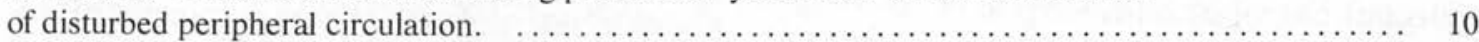

R. Sivertsson \& B. Ljung: Vibration-induced changes in vascular tone. $\ldots \ldots \ldots \ldots \ldots \ldots \ldots \ldots$

I. Pyykkö \& J. Hyvärinen: Vibration-induced changes of sympathetic vasomotor tone. $\ldots \ldots \ldots 23$

W. Taylor \& P.L. Pelmear: Raynaud's phenomenon of occupational origin.

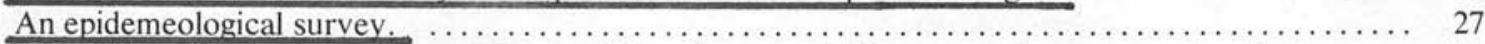

S.L. Nielsen: Raynaud's phenomenon in obliterative arterial disease on the upper extremity. $\ldots \ldots .33$

S. Zetterquist: Vasospastic symptoms in neurological disorders. $\ldots \ldots \ldots \ldots \ldots \ldots \ldots \ldots \ldots \ldots$

A. Bollinger \& M. Schlumpf: Finger blood flow in healthy subjects of different age and sex and in

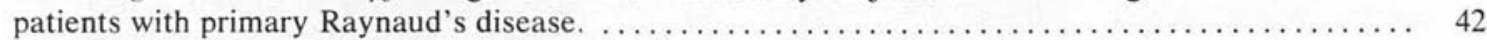

A.J. Zweifler: Detection of occlusive arterial disease in the hand in patients with Raynaud's

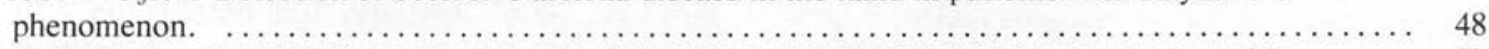

O. Thulesius: Methods for evaluation of peripheral vascular function of the upper extremities. $\quad \ldots \ldots \quad 53$

F. Borgnis, T. Dvorak: Application of time derivate curves in the evaluation of

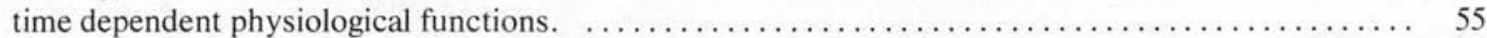

F. Lund: Fluorescin angiography especially of the upper extremities. $\ldots \ldots \ldots \ldots \ldots \ldots \ldots \ldots \ldots$

J.T. Holmberg, O. Thulesius \& J.E. Gjöres: Nicotine-induced changes of vascular tone. $\ldots \ldots \ldots \ldots 1$

B. Eklöf: Vascular compression syndromes of the upper extremity. $\ldots \ldots \ldots \ldots \ldots \ldots \ldots \ldots \ldots$

J.E. Gjöres, $C$-A. Svendler \& R. Todoreskov: Thrombosis of the subclavian vein - a feature

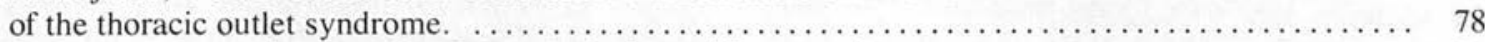

B. Hamrin: Stenosing arteritis of the subclavian-axillary arteries. $\ldots \ldots \ldots \ldots \ldots \ldots \ldots \ldots \ldots \ldots$

$P$. Thune \& $O$. Fyrand: Further observations on the therapy with a beta-stimulating agent in

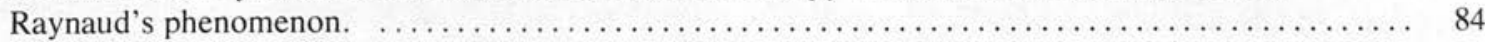

V. Hansteen: Medical treatment in Raynaud's disease. $\ldots \ldots \ldots \ldots \ldots \ldots \ldots \ldots \ldots \ldots \ldots \ldots \ldots \ldots$

A.M. Ehrly: Treatment of patients with secondary Raynaud's syndrome. $\quad \ldots \ldots \ldots \ldots \ldots \ldots \ldots . \ldots 2$

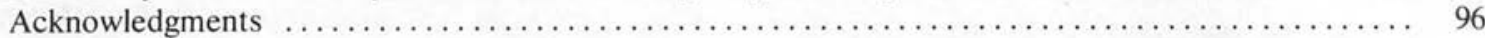




\title{
Raynaud's Phenomenon of Occupational Origin An Epidemiological Survey
}

\author{
by W. Taylor and P.L. Pelmear \\ From Dept of Social and Occupational Medicine, Univ. of Dundee, Scotland
}

\section{Introduction}

In Britain a worker who develops one of the 44 industrial diseases is entitled to industrial injuries benefit from the State. This list of prescribed diseases is extended from time to time as evidence accumulates to justify its inclusion. In 1954 (1) the question whether Raynaud's Phenomenon, vibration induced white finger (V.W.F.), should be prescribed under the National Insurance (Industrial Injuries) Act, 1946 was considered but rejected on the grounds that (a) the disablement was minimal, (b) that the incapacity lasted only for short intervals in cold weather, (c) the difficulty of distinguishing between occupational and non-occupational cases, and (d) the problem of assessing disability. From 1967 to 1970 , further investigations were undertaken on behalf of the Industrial Injuries Advisory Council, the effects of vibration being extended to bones, joints, muscles, blood vessels or nerves of the hand, arm or shoulder, (The Vibration Syndrome). Again the Council (2) left over whether Raynaud's phenomenon can be accepted as a disabling condition which would justify the payment of compensation under the Industrial Injuries Act. This paper summarises further research work undertaken on behalf of the Department of Health and Social Security on V.W.F. in Industry.

\section{Populations surveyed}

From 1969 to 1973,18 populations within the United Kingdom were examined where V.W.F. was known to be an occupational hazard. The total number surveyed was 1283 of which 722 were accepted in the vibration exposed group (hand-operated vibratory tools) and 307 controls, age matched with men from the same working environment who had never been exposed to vibration. A total of 254 were rejected of which $96(7.5 \%)$ had injuries to hand and fingers, 68 (5.3\%) had Primary Raynaud's Disease (or Constitutional Cold Finger), 66 (4.9\%) had a history of previous vibration and $12(1 \%)$ had medical reasons (raised blood pressure, diabetes, etc.). A summary of the populations is given in Table 1 .

Table 1. V.W.F. Survey: Population Groups: Response Rate

\begin{tabular}{|l|c|c|c|c|}
\hline Population & $\begin{array}{l}\text { Total } \\
\text { examined }\end{array}$ & $\begin{array}{l}\text { Vibration } \\
\text { exposed }\end{array}$ & Controls & $\begin{array}{l}\text { Response } \\
\text { rate }(\%)\end{array}$ \\
\hline Chain sawyers & 250 & 105 & 87 & 96 \\
Crinders & 799 & 466 & 189 & 98 \\
Chippers & 131 & 89 & 18 & 99 \\
Swagers & 33 & 2 & 13 & 95 \\
Caulkers \& & 70 & 60 & - & 99 \\
\hline Nobblers & 1283 & 722 & 307 & 97 \\
\hline Total & & & & \\
\hline
\end{tabular}




\section{History}

A full occupational history was taken from all subjects shown in Table 1 with particular reference to previous history of white finger, past and present vibration exposure, details of attacks of white finger and the digits involved and finally work, hobby or social disabilities arising from these attacks. The subjects were then classified according to their severity of signs and symptoms in the following Stages (Table 2.)

Table 2

\begin{tabular}{|l|l|l|}
\hline Stage & Conditions of digits & $\begin{array}{l}\text { Work and social } \\
\text { interference }\end{array}$ \\
\hline O & No blanching of digits & No complaints \\
\hline O T & $\begin{array}{l}\text { Intermittent Tingling } \\
\text { No interference } \\
\text { with activities }\end{array}$ \\
\hline 1 & $\begin{array}{l}\text { Blanching of one or } \\
\text { more fingertips with } \\
\text { or without tingling } \\
\text { and numbness }\end{array}$ & $\begin{array}{l}\text { No interference } \\
\text { wlanching of one or } \\
\text { more complete fingers } \\
\text { with numbness usually } \\
\text { confined to Winter. }\end{array}$ \\
\hline 2 & $\begin{array}{l}\text { Extensive blanching } \\
\text { usually all fingers } \\
\text { bilateral. Frequent } \\
\text { episodes Summer as } \\
\text { well as Winter }\end{array}$ & $\begin{array}{l}\text { Slight interference } \\
\text { with home and social } \\
\text { activites. No } \\
\text { interference at work }\end{array}$ \\
\hline 3 & $\begin{array}{l}\text { Definite interference } \\
\text { at work, at home and } \\
\text { with social } \\
\text { activities. } \\
\text { Restriction of } \\
\text { hobbies }\end{array}$ \\
\hline 4 & $\begin{array}{l}\text { Extensive blanching. } \\
\text { All fingers; frequent } \\
\text { episodes Summer and } \\
\text { Winter }\end{array}$ & $\begin{array}{l}\text { Occupation changed to } \\
\text { avoid further } \\
\text { vibration exposure } \\
\text { because of severity } \\
\text { of signs and } \\
\text { symptoms. }\end{array}$ \\
\hline
\end{tabular}

\section{Prevalence (\%) of V.W.F.}

At one forest (Thetford) the prevalence of V.W.F. was $90 \%$, whilst in another forest, using the same saws with a lower work load and half the total vibration exposure time, it was $40 \%$. Furthermore it is not possible to make statistical comparisons between forest sawyers or other population groups using prevalence rates since many vibration exposed subjects leave the occupation at various stages of vibration exposure. The wide variation found in prevalence rates is seen in Table 3 . For this reason prevalence rates, as a measure of degree or severity of V.W.F., have been abandoned. 
Table 3.

Prevalence $(\%)$ of White Finger in Vibration Exposed and Control Groups.

\begin{tabular}{|c|c|c|c|}
\hline Group & & $\begin{array}{l}\text { \% Prevalence V.W.F. } \\
\text { Vibration Group }\end{array}$ & $\begin{array}{l}\text { \% Prevalence V.W.F. } \\
\text { Control Group }\end{array}$ \\
\hline Sawyers & $\begin{array}{l}\text { Thetford } \\
\text { Kielder } \\
\text { Dumfries }\end{array}$ & $\begin{array}{l}90 \\
70 \\
40\end{array}$ & $\begin{array}{l}6 \\
8 \\
4\end{array}$ \\
\hline Grinders & $\begin{array}{l}\text { Pedestal \& } \\
\text { Hand }\end{array}$ & $8-96$ & $4-17$ \\
\hline Chippers & & $54-85$ & 19 \\
\hline $\begin{array}{l}\text { Caulking and } \\
\text { Nobbling }\end{array}$ & & $35-55$ & - \\
\hline Swagers & & 95 & 6 \\
\hline
\end{tabular}

\section{Latent interval}

atent interval is defined as the time between irst using a vibratory hand-held tool or grindng operation and the first appearance of a whie finger tip. Referring to Table 2, the time terval between commencement of employnent with vibratory tools (or other process there vibration is introduced into the hands) nd the first appearance of a blanched digit. he results for the latent interval measured in ears for the main processes are shown in able 4, and Fig. 1.

able 4.

atent Interval (in years) for 4 processes

\begin{tabular}{|ll|c|}
\hline Population and process & $\begin{array}{l}\text { Latent } \\
\text { interval } \\
\text { (in years) }\end{array}$ \\
\hline 1. Chain Sawyers Kielder & 2.8 \\
Dumfries & 3.6 \\
2. Grinding & Pedestal & 1.8 \\
& Hand & 8.7 \\
& Pedestal & 14.0 \\
3. Chipping \& & Birkenhead & 5.3 \\
Nobbling & Rosyth & 14.0 \\
& Rosyth & 16.5 \\
4. Swaging & Liverpool & 0.6 \\
\hline
\end{tabular}

Fig. 1

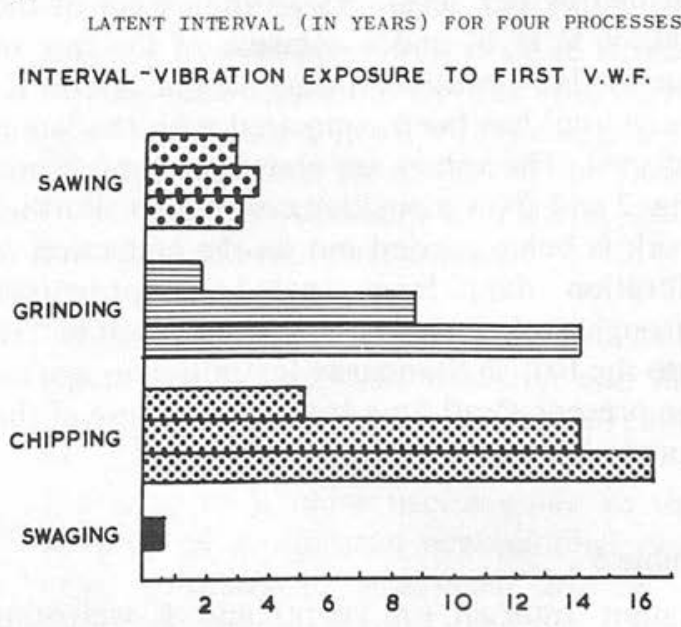

From Table 4, swaging represents the shortest latent interval - mean 6-8 months (with some cases around 6-8 weeks). The mean interval for pedestal grinding is 1-6 years (with some cases around 6-7 months), and Chain Saws (without anti-vibration treatment) from 2.8 years to 3.6 years. Chipping in this survey is from 5-9 years, caulking - 14 years, and nobbling -16.5 years. The latter processes represent discontinuous or interrupted work with one week in eyery two on vibratory tools. For any one process the latent interval has been found to be a more reliable guide to the energy input than the V.W.F. prevalence rate. There is further evidence for this when the vibration 
characteristics of each process is measured. Correlation of the vibration data from the processes in this survey with the V.W.F. data (including latent interval) will be the subject of a separate report (3) since measurement of short time high energy vibration energy presents many difficulties. Kitchener (4) has introduced a weighting network filter whereby the complicated procedure of analysing vibration into octave bands is replaced by a single measurement for screening purposes. This is achieved by measuring the r.m.s. acceleration from 2.8 to $2800 \mathrm{~Hz}$ with an instrument which has a frequency response which is the inverse of the proposed Draft British Standard (5) for hand-arm vibration. This is a similar procedure to the use of the A-weighting network in sound level measurements and to distinguish it from this weighting, the vibration unit will henceforth be referred to as the $\mathrm{K}$-weighting (in metres per $\sec ^{2}$ ). As an indication of the risk of V.W.F. and a measure of the rate of cumulative vibration dosage the one figure ' $\mathrm{K}$ weighting' has been compared with the latent interval. The values are shown in Table 5 and Fig. 2 and show a positive correlation. Further work is being carried out on the collection of vibration data from tools and processes throughout Britain. This data will then be fed into the British Standards Institution to update the present Draft Standard for exposure of the human hand-arm system to vibration.

\section{Table 5}

Latent Interval (in years) and $\mathrm{K}$-weighting (metres $\mathrm{m} / \mathrm{sec}^{2}$ )

\begin{tabular}{|l|c|c|}
\hline Population & $\begin{array}{c}\text { Latent } \\
\text { interval } \\
\text { yrs }\end{array}$ & $\begin{array}{c}\mathrm{K} \text { - } \\
\text { weighting } \\
\mathrm{m} / \mathrm{sec}^{2}\end{array}$ \\
\hline 1. Swaging & 0.6 & 70 \\
2. Pedestal Grinding & 1.8 & 50 \\
$\begin{array}{l}\text { 3. Chain Sawing } \\
\text { 4. Pedestal Grinding } \\
\text { (Bromsgrove) } \\
\begin{array}{c}\text { 5. Hand Grinding } \\
\text { (Bromsgrove) }\end{array}\end{array}$ & 2.8 & 25 \\
\hline
\end{tabular}

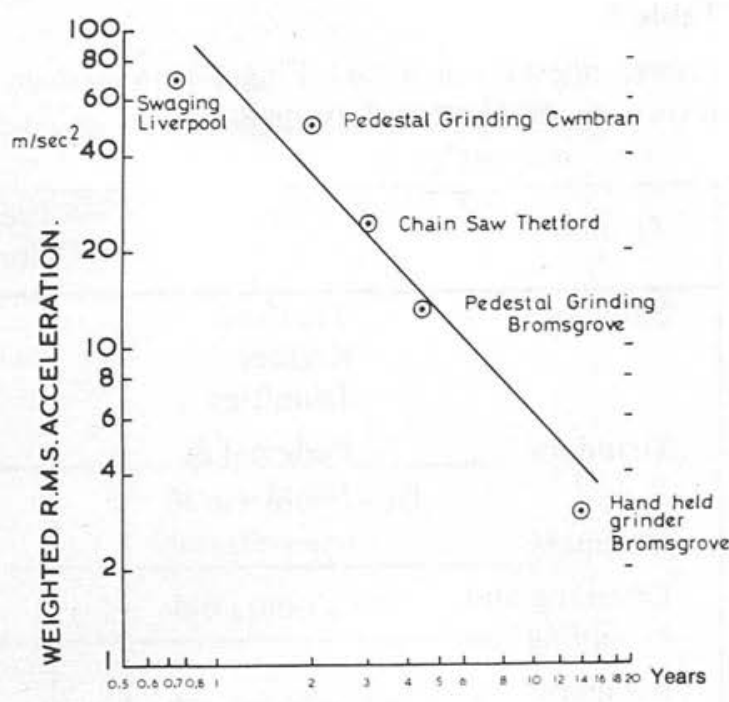

Fig. 2. Latent interval in years and weighted acceleration in meters per $\sec ^{2}$ by occupational groups.

\section{Clinical tests: Assessment of disability - prescription}

Subjects with Raynaud's Disease or Phenomenon are known to have reduced sensitivity in the finger pulps. Much time and effort has been spent attempting to find suitable clinical tests to assess the degree or severity of this condition. It is essential, as evident from the published literature, that surveys must be rigidly controlled and that a large population sample is required particularly in the age-sex matched controls. Furthermore it is not feasible to apply physiological tests in the field requiring controlled environmental conditions (e.g. constant temperature rooms). The emphasis in the past has been on acquiring retrospective data for expediency and avoiding the time-lag necessary for the collection of prospective data. In the present survey, the population groups in this survey (Table 1) were given the following tests in an attempt to develop an objective clinical test which could be used to assess the degree of disablement resulting from V.W.F. 


\section{Table 6}

Clinical Objective Tests for V.W.F.

\begin{tabular}{|c|c|}
\hline No. & Test \\
\hline 1 & Finger Circumference Measurement \\
\hline 2. & Depth Sense Aesthesiometer * \\
\hline 3. & Two Point Discrimination * \\
\hline 4. & Vibro-tactile threshold of digits \\
\hline 5. & $\begin{array}{l}\text { Response to hot and cold stimuli } \\
\text { (heating and cooling hands) }\end{array}$ \\
\hline 6. & Thermography \\
\hline 7. & $\begin{array}{l}\text { Determination of Bone Density } \\
\text { (osteoporosis of terminal phalanges) }\end{array}$ \\
\hline 8. & Presence of Bone Cysts in the hands \\
\hline
\end{tabular}

* Neurological Tests

The techniques, methods and results of the tests applied to the survey populations are reported in detail elsewhere (3). The neurological, temperature and vascular tests, whilst they differentiated between vibration exposed and control groups, failed on an individual basis. It is possible to detect a case deteriorating for example by the depth sense aesthesiometer and the two point discrimination tests, knowing the base line measurements. There was no significant difference in the total number of bone cysts between the vibration exposed and the control group. As a test for individual loss of sensitivity in the finger pulps, vibro-tactile measurements failed by this retrospective method. Finger circumference measurements indicated that vibration exposed subjects have larger fingers than controls but after 1-2 years vibration exposure there is no further progression. A digit in direct contact with a vibrating source also increases in size, e.g. a 4th finger in contact with the chisel of a pneumatic chipper. In the pedestal grinding situation at Cwmbran (latent interval 1.8 years) with a high proportion of stage 3 cases, brachial arteriography was carried out on 18 grinders (7). Results were obtained in 14 subjects and 68 digital arteries demonstrated. Of these 34 arteries showed definite evidence of occlusion and at least one occlusion was present in each grinder. Although this is positive evidence of digital artery damage directly attributable to vibration, arteriography cannot be used as a routine objective test in industry.

\section{Conclusions:}

(1) A survey has been carried out involving 18 populations with 722 vibration exposed subjects and 307 age-sex matched controls. There was a large variation in the prevalence or V.W.F. from 8 to $95 \%$, dependant on the vibration characteristics and the length of exposure time. In 15 of the 18 population groups examined, the vibration induced white finger (V.W.F.) could be described as trivial, seasonal and in the nuisance category. But in two populations - pedestal grinding and swaging the V.W.F. prevalence was above $90 \%$ and the majority of cases were in Stage 3 with blanching of all digits and interference with social, recreational and hobby pursuits. The condition - the Vibration Syndrome - has not been prescribed in Britain despite consideration by the Industrial Advisory Council in 1954 (1) and again in 1970 (2). A recent Report (8) by the Industrial Injuries Advisory Council in 1975 has again rejected Prescription.

(2) The latent interval (the time interval between first exposure to vibration and the first appearance of a white finger tip) rather than the prevalence rate has been found to be a more useful guide to the severity of a vibration occupational process (grinding or prolonged use of a hand-held vibratory tool). There is a positive association between the latent interval and the ' $\mathrm{K}$ ' weighting r.m.s. acceleration unit (metres/ $/ \mathrm{sec}^{2}$ ) developed to measure the vibration energy input of the hand.

(3) There was no evidence found in this survey of peripheral nerve damage or impairment beyond the pulps of the fingers. There was however damage to the digital arteries as shown by brachial arteriography in 14 subjects in Stage 2 or Stage 3 V.W.F. (7).

(4) From 1969 to 1973 attempts were made to find an objective test for the degree of severity of V.W.F. The neurological, tempe- 
rature, vascular, vibro-tactile and thermographic tests, whilst they statistically differentiated between vibration exposed and control groups, failed for individuals, since many subjects in the control groups (if a large enough sample was chosen) had more impaired values than some of Stage 3 vibration exposed individuals. There are as yet, in our opinion, no generally recognised clinical tests which can be used to assess objectively the degree of disablement resulting from V.W.F. The clinical tests outlined in this survey might prove, however, to be useful on a prospective basis where the base line is known prior to exposure to vibration. This area of research is being pursued in a population of chain saw operators (3) who have now been examined annually over the last 6 years. Meantime it is necessary to rely on the subjects' occupational and white finger history in arriving at an assessment of handicap in respect of V.W.F.

(5) Since the survey work was completed 1973 (and reported 1974) the Industrial Injuries Advisory Council in Britain has issued a further Report (8). The conclusion of this Report (Para 32) is, "'we have found the question referred to us a very difficult one to decide. Undoubtedly vibrating tools do lead to a condition in the fingers (V.W.F.) which affects several thousands of people. Normally it amounts to no more than temporary inconvenience but at worst it can lead to a change of job and a substantial loss of earnings. We have been made aware of the feelings amongst workers and their Trade Unions in the industry in which V.W.F. occurs most commonly, that the condition should be prescribed. These have been given long and careful consideration but, for the reasons given we have concluded that we cannot recommend the prescription of V.W.F. either for the whole field of workers exposed to vibration or for a more limited group.'

(6) Further basic physiology is urgently required to understand the mechanism of Primary Raynaud's Disease and Raynaud's Phenomenon of Occupational Origin. In the occupational field the diagnosis, the degree of blanching and the assessment of disability (Stage) at present depend on the subjective history, whilst the subjects description of his signs, symptoms and description of social and recreational activities cannot be accepted as legal evidence on which to base prescription and compensation.

(7) Further medical surveys are required to correlate the V.W.F. medical and vibration data to provide further evidence for the vibration criteria set in the Draft British Standard for Hand-arm Vibration specifying maximum vibration limits for a normal 8-hour working day. It is hoped by adopting these standards and other preventive measures to reduce or eliminate advanced cases of V.W.F. (Stages 2 and 3 ) from the working population.

\section{References}

1. Industrial Injuries Advisory Council Report: Raynaud's Phenomenon. H.M.S.O.. London. CMND. 9347. 1954.

2. Industrial Injuries Advisory Council Interim Report: Vibration Syndrome. H.M.S.O.. London. DMND. $4430,1970$.

3. Pelmear, P.L. Taylor, W. Edit., White Finger in Industry. The Academic Press, London \& New York (in press), 1975.

4. Kitchener, R. Correlation of Epidemiological data and the Measured Vibration. White Finger in Industry. Academic Press, London and New York, 1975.

5. Draft for development. Guide to the evaluation of exposure of the human hand-arm system to vibration. British Standards Institution. 2 Park Street. London.

6. Renfren: S. Fingertip Sensation, A Routine Neurological Test. Lancet.1, 396. 1969.

7. James, P.B. and Galloway, R.W. Brachial arteriography in vibration induced white finger. The vibration syndrome. Edit. W. Taylor. Academic Press. London and New York. 1974.

8. Vibration Syndrome, Report by the Industrial Injuries Advisory Concil. H.M.S.O., London CMND. 5965. 1975. 